\title{
Reconstrução de superfícies a partir de nuvens de pontos
}

\author{
João Paulo Gois
}





\title{
Reconstrução de superfícies a partir de nuvens de pontos
}

\author{
João Paulo Gois
}

Orientadora: Prof $^{\circ}$. Dr ${ }^{\mathrm{O}}$ Antonio Castelo Filho

Dissertação apresentada ao Instituto de Ciências Matemáticas e de Computação - ICMC-USP, como parte dos requisitos para obtenção do título de Mestre em Ciências de Computação e Matemática Computacional.

USP - São Carlos

Abril de 2004

${ }^{1}$ Este trabalho tem apoio financeiro da FAPESP processo $\mathrm{N}^{\mathrm{o}} \cdot 01 / 10678-7$ 

Dedico aos meus pais com muito carinho. 



\section{Agradecimentos}

Em primeiro lugar e acima de tudo, agradeço a Deus por estar presente em todos os momentos de minha vida.

Agradeço aos meus pais, José Ricardo e Gercira, pelo amor deles por mim e por me apoiarem com o possível e o impossível no que está ao alcance deles.

Minhas irmãs Mariane e Clariana e a minha avó Maria Aparecida que todas as vezes que eu voltava para a casa para descansar e matar a saudade, estiveram lá me dando atenção e carinho.

Aos meus amigos, quatro melhores amigos Endrigo, Gabriel, Renato e Rodrigo que estão cada um num canto do mundo mas nunca perdemos o contato e conforme o tempo passa nos tornamos mais amigos e junto aprendemos a viver e compartilhar momentos felizes e dificeis.

Ao casal de amigos Daniel e Eliane que me acompanham desde minha adolescência me aconselhando e ajudando com tudo que precisei.

As amigas Fer, Dani, Evê e Kika que sempre lembram de mim e me acolhem com muito carinho.

Aos meus companheiros de república, Cassio e Olivâine, que os conheci no primeiro ano de graduação e desde então passamos a ter muita afinidade e se tornaram grandes amigos. Junto aprendemos a dividir não apenas um espaço físico, mas também assuntos acadêmicos, divertidos e pessoais.

Agradeço a Gil e a Day por serem aqui em São Carlos minhas irmãs.

Aos outros amigos de graduação, Kémelli e Samuel que estão também vivendo em São Carlos e sempre pude contar com a amizade deles.

Aos meus amigos de laboratório, principalmente ao grupo de Computação Gráfica e Geração de Malhas que me ajudaram infinitamente com minhas dúvidas. Cada um deles sabe o quanto me ajudaram. Os principais são Igor, Helton, Alex e Eduardo.

Agradeço meus orientadores Castelo e Gustavo por tudo que aprendi com eles e por serem, para mim, exemplos de perseverança, dedicação e simplicidade.

Existem outras pessoas não citadas aqui, algumas por não existirem palavras para descrever o quão especiais elas são para mim!

Novamente agradeço a Deus por ter colocado todas estas pessoas fantásticas que fazem parte da minha vida, da minha história. E neste momento me recordo da canção da irmã Glenda que fala: "Encontrar um amigo é encontrar um tesouro".

Ficam aqui meus singelos agradecimentos João Paulo 



\section{Resumo}

Representações computacionais de formas podem ser criadas em ferramentas CAD ou geradas a partir de um objeto físico já existente. Esta última abordagem oferece como vantagens rapidez e fidelidade ao objeto original, que são os aspectos fundamentais em muitas aplicações, como Simulações Numéricas de Equações Diferenciais Parciais e Imagens Médicas.

A reconstrução (ou geração de malhas superficiais) a partir de pontos amostrados de uma superfície de um objeto é um problema clássico de representação de formas.

Nesta dissertação apresentamos um vasto levantamento bibliográfico deste tipo de reconstrução, classificando e descrevendo os principais trabalhos presentes na literatura. A partir do levantamento bibliográfico, selecionamos um conjunto de algoritmos sobre os quais foram realizadas comparações teóricas e empíricas cujos resultados são apresentados.

Para finalizar, apresentamos aplicações de nossas implementações em Simulação Numérica de Equações Diferenciais Parciais e Processamento de Imagens. 



\section{Abstract}

Computational representations of shapes can be developed using CAD applications or created from data acquired from a real physical object. This latter is advantageous with respect to time and fidelity to the original object which are essential to several applications, such as Numerical Simulation of Partial Differential Equations and Medical Imaging.

A classical shape representation problem is that of reconstruction (or superficial mesh generation) from points sampled over the surface of an object.

In this Master's thesis we describe a broad survey of these reconstruction methods. We focus in the classification and characterization of the main algorithms proposed in the literature. From this survey, we selected some algorithms and conducted some theoretical and practical comparisons.

We conclude this work describing applications of the algorithms implemented in Numerical Simulations of Differential Partial Equations and Image Processing. 



\section{Sumário}

1 Introdução 1

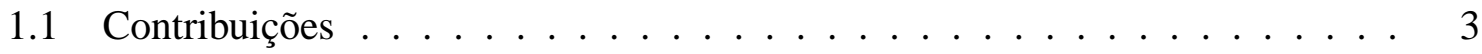

1.2 Organização do trabalho . . . . . . . . . . . . . . 6

2 Conceitos Básicos 9

2.1 Considerações iniciais . . . . . . . . . . . . . . . . . . 9 9

2.2 Fundamentos teóricos . . . . . . . . . . . . . . . . . . . 10

2.3 Considerações finais . . . . . . . . . . . . . . . . 24

3 Reconstrução de objetos tridimensionais a partir de nuvens de pontos 25

3.1 Considerações iniciais . . . . . . . . . . . . . . . . 25

3.2 Métodos baseados em esculpimento . . . . . . . . . . . . . . 27

3.3 Métodos baseados em função implícita . . . . . . . . . . . . . . . . . . 37

3.4 Métodos incrementais . . . . . . . . . . . . . . . . . . . . 39

3.5 Métodos baseados em modelos deformáveis . . . . . . . . . . . . . . . 43

3.6 Considerações finais . . . . . . . . . . . . . . . . . . . 44

4 A família Crust $\quad 45$

$4.1 \quad \beta$-skeleton . . . . . . . . . . . . . . . . . 46

4.2 Garantindo a reconstrução . . . . . . . . . . . . . . . . . . . . 47

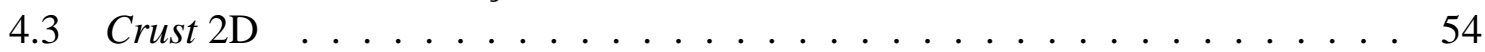

4.4 Comparações entre o crust e o $\beta$-skeleton . . . . . . . . . . . . . 58

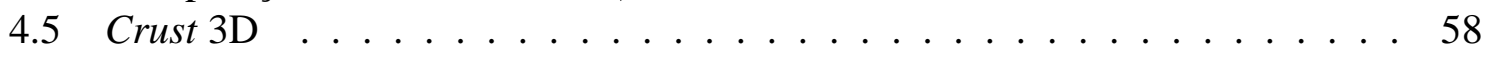

4.6 Power crust . . . . . . . . . . . . . . . . . . . 61 61

4.7 Cocone . . . . . . . . . . . . . . . . . . 67

4.8 Tight cocone . . . . . . . . . . . . . . . . . 69

4.9 Considerações finais . . . . . . . . . . . . . . 70

5 Implementações $\quad \mathbf{7 1}$

5.1 As triangulações . . . . . . . . . . . . . . . . . . 71

5.2 Entrada/Saída . . . . . . . . . . . . . . . . . . 73

5.3 Algoritmos bidimensionais . . . . . . . . . . . . . . . . 74

5.4 Raw crust . . . . . . . . . . . . . . . . . . 74

5.5 Power crust .......................... 75 
5.6 Ruídos . . . . . . . . . . . . . . . . . . . . . 85

5.7 Considerações finais . . . . . . . . . . . . . . . . . 87

6 Comparações e exemplos $\quad 89$

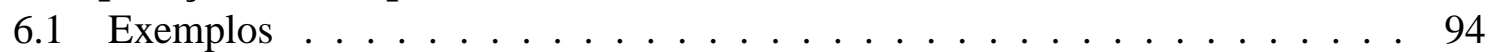

6.2 Considerações finais . . . . . . . . . . . . . . . . 97

7 Aplicações $\quad 103$

7.1 Simulação numérica de E.D.P.'s . . . . . . . . . . . . . . . . . . . . . . . . . . . . . . . .

7.2 Detecção de contornos via Geometria Computacional . . . . . . . . . . . . 105

7.3 Considerações finais . . . . . . . . . . . . . . . . 115

8 Conclusão $r$ 


\section{Lista de Figuras}

1.1 Reconstrução a partir de seções planares: a) conjunto de fatias de um dente, b) reconstrução do dente segundo a técnica descrita por Nonato (Nonato et al., 2001). . . . . . . . . . . . . . . . . . 2

1.2 Alguns exemplos de scanners 3D aplicados a objetos de diferentes tamanhos (retiradas do site http://www.cyberware.com/). . . . . . . . . . . . . . 3

1.3 Sequiência de tarefas básica para o conjunto de algoritmos de reconstrução a partir de nuvens de pontos: a) coleta de dados utilizando um scanner 3D, b) dados de entrada para algoritmos de reconstrução, c) reconstrução do modelo. 4

1.4 Exemplo de uma malha bidimensional em um espaço tridimensional. . . . . . 5

1.5 Malha volumétrica gerada a partir da fronteira definida por um algoritmo de reconstrução a partir de nuvens de pontos. . . . . . . . . . . . . . . . 5 5

2.1 Exemplo bidimensional do fecho convexo de um conjunto de pontos. . . . . . 10

2.2 Objetos topologicamente equivalentes. . . . . . . . . . . . . . . 11

2.3 Objetos que não são topologicamente equivalentes. Em a) duas regiões planas, uma contendo um buraco e em b) uma esfera e um cilindro sem suas tampas.

2.4 Exemplo de uma variedade de dimensão 2 imersa em $\mathbb{R}^{3}$. a) toma-se um aberto em intersecção com a variedade $M$ (região hachurada de $M$ ) difeomorfo a um aberto de $\mathbb{H}^{2}$, dado por b). . . . . . . . . . . . . . . . 12

2.5 Exemplos de variedade: a) variedade com bordo, b) variedade sem bordo. . . 13

2.6 Exemplos de não-variedade imersas em $\mathbb{R}^{3}$. . . . . . . . . . . . . . . 13

2.7 Em a) exemplos de curvas suaves, em b) curvas não suaves. . . . . . . . . . . . 14

2.8 a) 0-simplexo, b) 1-simplexo, c) 2-simplexo, d) 3-simplexo. . . . . . . . . . . 15

2.9 a) Exemplo de um complexo simplicial, b) não define um complexo simplicial. Note que existem intersecções que não definem uma face. . . . . . . . . . 16

2.10 a) 2-variedade, b) 2-variedade linear por partes. . . . . . . . . . . . . . . 18

2.11 As regiões hachuradas definem a) a estrela de uma aresta $e$ e b) a estrela de um vértice $v$. As arestas mais largas indicam seus respectivos links da aresta $e$ e do vértice $v \ldots \ldots \ldots \ldots \ldots \ldots \ldots$

2.12 Diagrama de Voronoi (dos pontos sem preenchimento) em linhas contínuas. Em linhas pontilhadas, seu dual, a triangulação de Delaunay (definição 29).

2.13 Exemplo de uma triangulação de Delaunay de um conjunto de 100 pontos no plano Euclidiano. . . . . . . . . . . . . . . . . . . 
2.14 Exemplo de uma triangulação de Delaunay com peso: Os círculos verdes são os pontos com peso. Em azul, a triangulação de Delaunay com peso e em vermelho o power diagrama. . . . . . . . . . . . . . . . 22

2.15 Exemplo do eixo medial de uma curva (linhas pontilhadas). . . . . . . . . . 23

2.16 Exemplo bidimensional do local feature size $\operatorname{LF} S(p)=\|p-m\|$. . . . . . . 23

2.17 Curvas que exemplificam quais regiões necessitam de maior número de pontos (regiões no interior dos círculos tracejados): a) em regiões de maior curvatura e b) em regiões de "estrangulamento". As linhas pontilhadas representam o eixo medial. . . . . . . . . . . . . . . . . . . . . . . 24

3.1 Exemplo bidimensional dos itens que um método de reconstrução tenta satisfazer: a) curvas não homeomorfas, mas próximas; b) curvas homeomorfas mas não próximas.

3.2 Exemplo bidimensional do mapeamento de um triângulo para um domínio anisotrópico. . . . . . . . . . . . . . . . . . . . . 29

3.3 Representação do ângulo $\delta$ para malhas normalizadas. . . . . . . . . . . . . . 31

3.4 Tetraedro sliver. . . . . . . . . . . . . . . . . . 31

3.5 Exemplos de valores de $\lambda$ para a aresta definida por $a$ e $b \ldots \ldots 33$

3.6 Contra-exemplos de guarda-chuva 3D (figura do trabalho de Adamy (Adamy et al., 2002))

3.7 Os pontos críticos são os pontos em que a derivada da função se anula. $M$ representa os máximos locais, $m$ os mínimos locais e $S$ o ponto de sela. . . . 35

3.8 Exemplo que caracteriza os pontos críticos definido pela função 3.2. . . . . . 36

3.9 Descrição do processo de estimativa das curvaturas da superfície e da malha proposta por Huang e Menq. . . . . . . . . . . . . . . . . . . . . . . 42

4.1 Regiões proibidas: a) $\beta=1$, b) $\beta>1 \ldots \ldots \ldots$. . . . . . . . 47

4.2 Interpretação geométrica do teorema 2. Em linhas contínuas temos a curva $C$, em tracejados, o eixo medial. A circunferência, em pontilhado, representa a interpretação do teorema. . . . . . . . . . . . . . . . . . . 48

4.3 O círculo, em pontilhado, representa um disco de Voronoi curvo. . . . . . . . 49

4.4 Descrição geométrica que caracteriza a observação $13 . \ldots$. . . . . . . . . . 50

4.5 Figura utilizada no teorema $7 \ldots \ldots \ldots \ldots$. . . . . . . . 51

4.6 Descrição geométrica da observação 15. . . . . . . . . . . . . . . . 52

4.7 Descrição geométrica do teorema $9 . \ldots \ldots \ldots$. . . . . . . . . . 53

4.8 A garantia da reconstrução da curva original se dá para valores na região hachurada. . . . . . . . . . . . . . . . 54

4.9 Construindo a contradição do teorema 13. . . . . . . . . . . . . . . 56

4.10 Representação geométrica da contradição do teorema 14. . . . . . . . . . . . 57

4.11 Nota-se que o ângulo $\theta$ é maior que seu correspondente ângulo do outro lado. 57

4.12 A célula de Voronoi para superfícies $r$-amostradas são finas e compridas (fonte: http://www.cs.utexas.edu/users/amenta/powercrust/). . . . . . . . . 61

4.13 (Fonte: http://www.cs.utexas.edu/users/amenta/powercrust/) Descrição do power crust em sua versão $2 \mathrm{D} . \ldots \ldots \ldots$. . . . . . . . . . . . . 
4.14 Ângulo $\alpha$ formado entre a intersecção de duas bolas polares. . . . . . . . . . . 64

4.15 Exemplos em que a união de bolas polares internas determinam aproximações dos objetos. . . . . . . . . . . . . . . . . .

4.16 Cocone (em azul) de ápice em $p$. $n$ é o vetor normal, $p^{+}$e $p^{-}$são os pólos de p. $V_{P}$ é a célula de Voronoi de $p \ldots \ldots \ldots \ldots$. . . . . . . . 68

4.17 a) e b) exemplos de superfícies water tight, c) e d) superfícies não water tight. 69

5.1 Tetraedros slivers presentes na superfície dos objetos (em vermelho). . . . . . 75

5.2 Ângulo entre as esferas: exemplo bidimensional. . . . . . . . . . . . . . . 77

5.3 Diagrama de Voronoi em vermelho, em linhas contínuas pretas, arestas de Delaunay. Nomeado a bola polar $p$, alteram-se as prioridades das bolas polares $q$, pelo valor do ângulo $\beta=\widehat{p s q}$. . . . . . . . . . . . . . . . .

5.4 Comparação entre o algoritmo de rotulação dos pólos teórico (algoritmo 8) e prático (algoritmo 9): Em a) b) e c) o conjunto de pontos, em d) e) e f) a saída do algoritmo quando aplicado o algoritmo teórico, em g) h) e i) quando aplicado o algoritmo prático. . . . . . . . . . . . . . . . .

5.5 Estratégia para redução dos cálculos necessários para determinação do ortocentro: a) situação inicial, b) nesta etapa realiza-se a translação do tetraedro para a origem do sistema de coordenadas e é feito o cálculo do ortocentro para o tetraedro transladado, c) translada-se novamente o tetraedro para sua posição inicial e conseqüentemente seu ortocentro. . . . . . . . . . . . . .

5.6 Representando variedade com bordo: a) exemplo de meio toro. Note que nos extremos do objeto as bolas polares internas estão entre o interior e o exterior, b) omitindo as faces do power diagrama destas esferas e c) versão original do power crust do objeto.

5.7 Exemplos de ângulos entre as faces: a) apenas duas arestas (negrito) sofrem grande variação entre as normais das faces que as compartilham, b) várias arestas sofrem variações entre as normais das faces. . . . . . . . . . . . 84

5.8 Aplicação do filtro laplaciano: a) objeto original, b) aplicação de 500 vezes o filtro laplaciano, c) aplicação de 10000 o filtro laplaciano. . . . . . . . . . . . .

5.9 Geração de uma malha triangular a partir de uma malha híbrida: a) malha triangular do objeto apresentado na figura 5.8-a), b) malha triangular com aplicação do filtro laplaciano com 1000 iterações, c) "zoom in" de a) e d) "zoom-in" de b) na mesma posição de c).

5.10 Exemplo do teste das células de Voronoi para detecção de ruídos: a) triangulação de Delaunay do conjunto de pontos (em vermelho as identificações de ruídos), b) reconstrução sem a remoção dos ruídos, c) reconstrução com a remoção dos ruídos. . . . . . . . . . . . . . . . . . . . . . .

6.1 Reconstrução de múltiplas componentes conexas: Em a) e b) observamos a reconstrução utilizando o power crust e em c) e d) reconstrução utilizando o tight cocone que ignorou completamente as componentes conexas internas. 
6.2 Resultados diferentes das implementações do power crust: Em a) temos a reconstrução da lebre (1000 pontos) com a versão original do power crust, em b) temos a nossa implementação. . . . . . . . . . . . . . . . . . 93

6.3 Reconstrução de curvas: a) triangulação de Delaunay do conjunto de pontos, b) $\beta$-skeleton, c) crust e d) power crust (a reconstrução não está próxima). . . 94

6.4 Reconstrução de curvas: a) triangulação de Delaunay do conjunto de pontos, b) $\beta$-skeleton, c) crust e d) power crust. . . . . . . . . . . . . . . . . . . . 94

6.5 Reconstrução de curvas: a) triangulação de Delaunay do conjunto de pontos, b) $\beta$-skeleton, c) crust e d) power crust. . . . . . . . . . . . . . . . . . . . 94

6.6 Reconstrução de curvas: a) triangulação de Delaunay do conjunto de pontos, b) $\beta$-skeleton, c) crust e d) power crust. . . . . . . . . . . . . . . . . 95

6.7 Reconstrução de curvas: a) triangulação de Delaunay do conjunto de pontos, b) $\beta$-skeleton, c) crust e d) power crust. . . . . . . . . . . . . . . . 95

6.8 Exemplos de $\alpha$-shape: Nestes exemplos buscamos os melhores valores de $\alpha$ para representação dos objetos. a) Buda (50000 pontos com $\alpha=40)$, b) lebre (1000 pontos com $\alpha=50)$, c) cacto (3500 pontos com $\alpha=18)$, d) salsichas (1700 pontos com $\alpha=17)$, e) lebre (30000 pontos com $\alpha=40)$, f) mão (36000 pontos com $\alpha=37$ ), g) e f) dragão com diferentes valores de $\alpha$ (10000 pontos com $\alpha=35$ e $\alpha=44$ respectivamentes) e h) toro (500 pontos com $\alpha=50$ ). Vale lembrar que o intervalo dos possíveis valores de alpha para esta implementação é [0,100], em que 0 é a nuvem de pontos e 100 é o fecho convexo. . . . . . . . . . . . . . . . . 96

6.9 Exemplos do raw crust: a) sela (1900 pontos), b) parabolóide (1400 pontos) c) peça mecânica (4100 pontos), d) "zoom-in" de c), e) feto (1000 pontos), f) Buda (50000 pontos), g) "zoom-in" de f), h) tênis (2000 pontos), i) sola do tênis de h).

6.10 Exemplos do cocone: a) dente (4000 pontos), b) espinha dorsal (22000 pontos), c) pés (120000 pontos), d) Beethovem (2600 pontos), e) "zoom-in" de d) (presença de buracos), f) vaca (3000 pontos), g) “zoom-in” de f) (presença de buracos), h) gato (10000 pontos), i) “zoom-in” de h) (presença de buracos). 99

6.11 Exemplos do tight cocone: a) feto (1000 pontos), b) tênis (2000 pontos) c) “zoom-in” de b) (presença de buracos), d) peça mecânica (4100 pontos), e) tricerátopes (2800 pontos), f) "zoom-in" de e), g) porche ( 6100 pontos), h) distribuidor (12700 pontos ), i) manequim (12700 pontos). . . . . . . . . . 100

6.12 Exemplos do power crust: a) peça mecânica (4100 pontos), b) mão (36000 pontos), c) bomba de óleo (31000 pontos), d) feto (1000 pontos), e) espinha dorsal (22000 pontos), f) dragão (1400 pontos), g) dragão (10000 pontos), h) Buda (10000 pontos), i) monstro (24800 pontos). . . . . . . . . . . . . 101

7.1 Exemplo da aplicação da equação do calor à metade de um tóro: a) condição inicial, b) 200 iterações, c) 600 iterações, d) 800 iterações, e) 1200 iterações, f) 1400 iterações, g) 1600 iterações, h) 2000 iterações. 
7.2 Exemplo da aplicação da equação do calor: a) condição inicial, b) 200 iterações, c) 600 iterações, d) 1000 iterações, e) 1200 iterações, f) 1600 iterações, g) 1700 iterações, h) 2000 iterações. . . . . . . . . . . . . . . . . . . . 107

7.3 Exemplo da aplicação da equação do calor: a) condição inicial, b) 200 iterações, c) 800 iterações, d) 1000 iterações, e) 1400 iterações, f) 2000 iterações. 108

7.4 Exemplo de triangulações de Delaunay com peso sobre uma imagem cujos pesos dos vértices são o valor da convolução no pixel: a) imagem original, b) peso obtido pelo Laplaciano, c) peso obtido pelo Sobel e d) peso obtido pelo Log. . . . . . . . . . . . . . . . . . . . . . . 110

7.5 Representação de uma aresta $e$ da triangulação de Delaunay com peso. . . . . 111

7.6 Aplicação da etapa de pós-processamento que analisa a variação das intensidades das cores nos triângulos: a) imagem sem o pós-processamento, b) imagem aplicada o pós-processamento. . . . . . . . . . . . . . . . . . . 112

7.7 Exemplo de resultados da detecção de contornos via triangulação de Delaunay com peso 7.4: a) imagem original, b) Laplaciano da imagem, c) triangulação de Delaunay com peso sobre a imagem cujos pesos dos pontos são $\alpha=0.1$ do laplaciano no ponto. . . . . . . . . . . . . . . . . 112

7.8 Exemplo de resultados detecção de contornos via a triangulação de Delaunay com peso da imagem 7.4: a) Laplaciano, b) detecção do contorno com pesos originados do Laplaciano, c) Sobel, d) detecção do contorno com pesos originados do Sobel, e) Laplaciano do Gaussiano, f) detecção do contorno com pesos originados do Laplaciano do Gaussiano. . . . . . . . . . . . . . . . . 113

7.9 Aplicando o threshold aos pesos durante o processo de triangulação não inserindo pontos com peso inferior a $\tau:$ a) Laplaciano, b) Sobel, c) Laplaciano do Gaussiano. . . . . . . . . . . . . . . . . . . . . . . . . . . . 114

7.10 Aplicação do método de remoção de ruídos proposto por Amenta (capítulo 5, seção 5.6) aliado aos algoritmos crust e power crust: a) crust sem remoção de ruídos, b) crust com remoção de ruídos, c) power crust, d) power crust com remoção de ruídos. . . . . . . . . . . . . . . . . . . . . . . . . . 116

7.11 Aplicação da técnica de detecção de contornos via triangulação de Delaunay com peso em uma imagem ruidosa: a) imagem original, b) laplaciano da imagem, c) detecção do contorno via triangulação de Delaunay com peso, d) detecção do contorno cuja triangulação não contém pontos cujo peso é menor que $\tau$ ( $\tau=1 / 10$ do maior valor de laplaciano da imagem), e) crust, f) power crust. 



\section{Lista de Tabelas}

5.1 Raw crust: Através desta tabela é possível verificar o número de tetraedros slivers e o número de faces presentes em alguns modelos. . . . . . . . . . . . 75

6.1 Informações teóricas dos algoritmos. A segunda coluna refere ao tipo de malha, a terceira coluna indica se o algoritmo apresenta garantias teóricas e a última coluna diz se, em geral, os algoritmos apresentam semelhanças geométricas. . . . . . . . . . . . . . . . . 91

6.2 Custo computacional. . . . . . . . . . . . . . . . . . . . . 91

6.3 Vantagens e desvantagens de cada método (*esta implementação é lenta, pois o algoritmo pré-calcula 100 valores de $\alpha$ ), (** pontos Steiner são os pontos utilizados por um algoritmo que não são parte da amostragem). . . . . . . . . . 92

6.4 Teste prático: Para quais modelos garantiu-se homeomorfismo (* número de

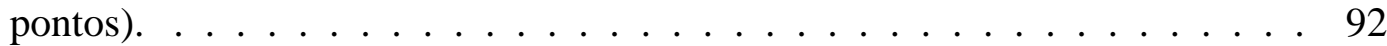

6.5 Tempo de execução em segundos (* número de pontos). . . . . . . . . . . . . . 92

6.6 Tempo de execução em segundos (* número de pontos): Comparação entre a implementação original do power crust (Hull e a nossa implementação (CGAL). 93

7.1 Matrizes de convolução utilizadas pelo método desenvolvido para detecção de contornos em imagens via Geometria Computacional. . . . . . . . . . . . 111 



\section{Lista de Algoritmos}

1 Heurística baseada em perímetro das faces . . . . . . . . . . . . 28

2 Heurística baseada nos EMST e EGH . . . . . . . . . . . . 32

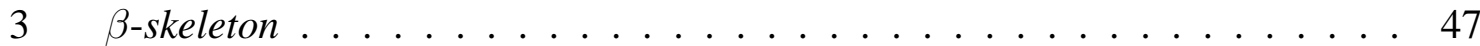

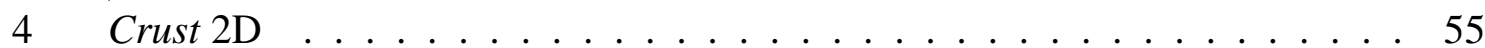

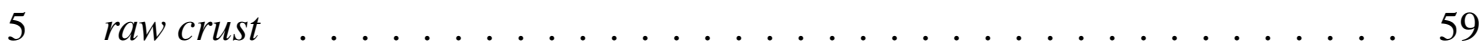

6 Cálculo de pólos para o raw crust . . . . . . . . . . . . 60

$7 \quad$ Power crust ...................... 65

8 Nomeia as bolas polares . . . . . . . . . . . . . . . . 66

9 Algoritmo prático de rotulação dos pólos . . . . . . . . . . . . . . 79

10 Lista: atualize . . . . . . . . . . . . . . . . . . . . . 79

11 Classifica arestas que representam o contorno da imagem . . . . . . . . . 110 



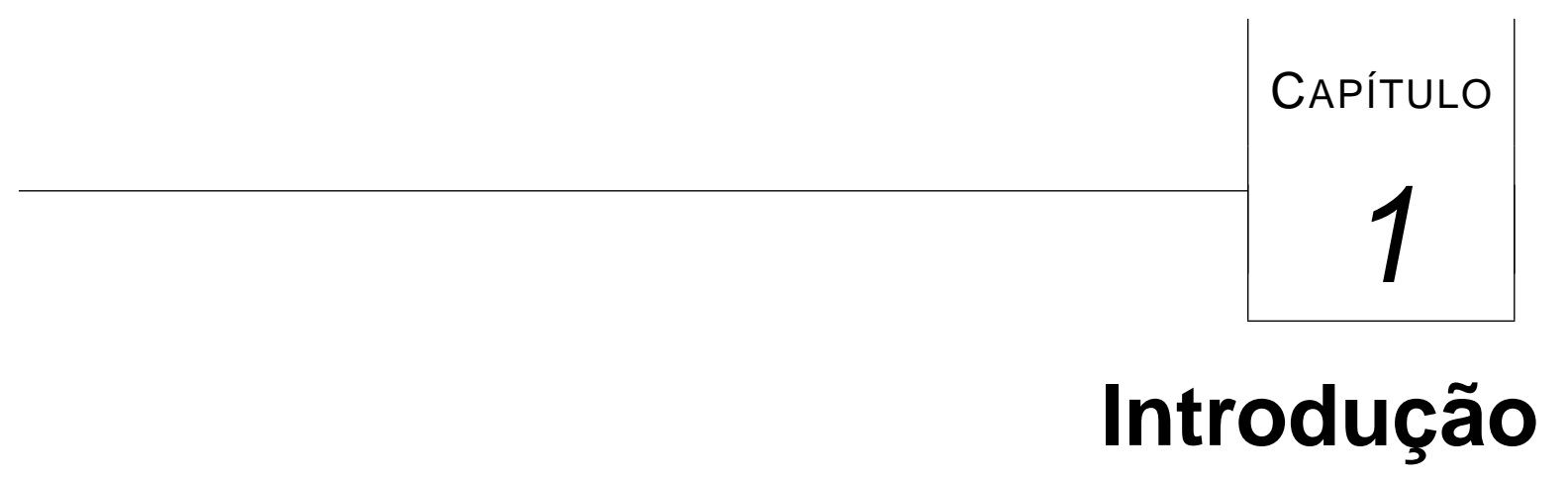

Nas últimas duas décadas foram propostos muitos algoritmos de Reconstrução de Superfícies, também denominada na literatura como Geração de Malhas Superficiais ou Modelagem Geométrica via Complexo Celular. Algoritmos de reconstrução estão presentes em diferentes campos de pesquisa, por exemplo em Simulação Numérica de Equações Diferenciais Parciais e em Imagens Médicas, dois exemplos de aplicações que têm motivado grupos de pesquisa de todo o mundo a desenvolver métodos de reconstrução melhores e mais eficientes.

O conjunto de algoritmos de reconstrução pode ser subdividido em duas classes, discutidas a seguir.

A primeira classe engloba os algoritmos de Reconstrução a partir de Seções Planares. $\mathrm{O}$ problema de reconstrução surgiu na área de Imagens Médicas, motivado por equipamentos de aquisição como aparelhos de Ressonância Magnética e de Tomografia Computadorizada, que capturam sequiências de imagens bidimensionais de um objeto tridimensional. Essas imagens são entradas para um processo que gera uma representação tridimensional do objeto em estudo.

Os procedimentos básicos para definir tal representação tridimensional a partir das seções bidimensionais são:

- Detectar os contornos de cada imagem;

- Gerar os pontos sobre estes contornos;

- Conectar os contornos de modo a definir uma representação tridimensional. 
A figura 1.1 apresenta uma seqüência de contornos e a reconstrução final obtida por um algoritmo de reconstrução proposto por Nonato (Nonato et al., 2001). Outros algoritmos de reconstrução a partir de seções planares foram propostos, por exemplo por Boissonnat (Boissonnat, 1988) e Vargas (Vargas et al., 2002).

a)

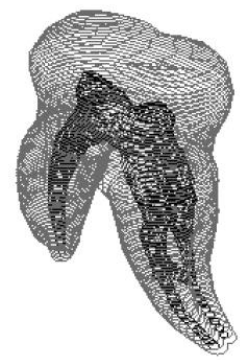

b)

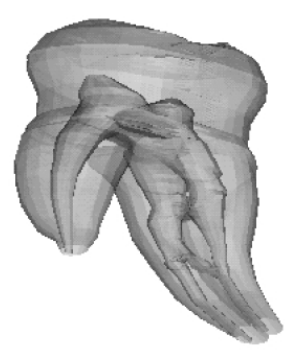

Figura 1.1: Reconstrução a partir de seções planares: a) conjunto de fatias de um dente, b) reconstrução do dente segundo a técnica descrita por Nonato (Nonato et al., 2001).

A segunda classe de algoritmos de reconstrução é mais recente e engloba algoritmos de Reconstrução a partir de Nuvens de Pontos. Para esta classe, os pontos não são amostrados a partir de seções planares, e não existem, a princípio, relações entre os pontos (por exemplo pontos distribuídos sobre um mesmo plano). Tais amostragens de pontos são fornecidas por radares, sondas sísmicas, pontos amostrados em superfícies implícitas e principalmente por scanners 3D. A figura 1.2 apresenta alguns modelos de scanners 3D aplicados a objetos de diferentes tamanhos.

Na figura 1.3 é apresentado um esquema típico de reconstrução a partir de nuvens de pontos. A figura 1.3-a) exibe um scanner 3D para captura dos dados que definem uma amostragem de pontos em $\mathbb{R}^{3}$, a qual é ilustrada na figura 1.3-b). Estes dados são utilizados por algoritmos que retornam uma superfície que define o objeto (figura 1.3-c) ). No capítulo 3 apresentamos uma definição formal do problema de Reconstrução a partir de Nuvens de Pontos, sendo que o foco desta dissertação é o estudo de algoritmos desta classe.

Além da aplicação em reconstrução de imagens médicas, os métodos de reconstrução também se aplicam à Geração de Malhas para Simulação Numérica de Equações Diferenciais Parciais (E.D.P.'s) (Babuska, 1995). Modelos gerados por algoritmos de reconstrução de superfície em $\mathbb{R}^{3}$ são utilizados de duas maneiras distintas para simulação numérica de E.D.P.'s: A primeira usa os modelos gerados diretamente, isto é, para simulação sobre um domínio originalmente bidimensional (figura 1.4). A segunda utiliza os modelos gerados como fronteira de um domínio em que é gerada uma malha volumétrica (figura 1.5). 
a)

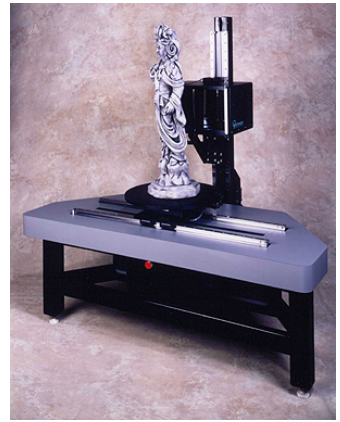

b)

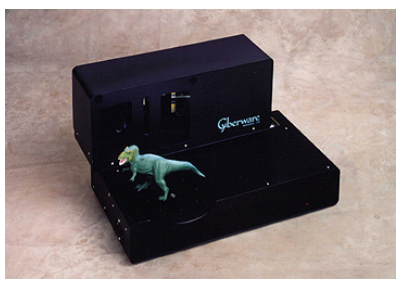

c)

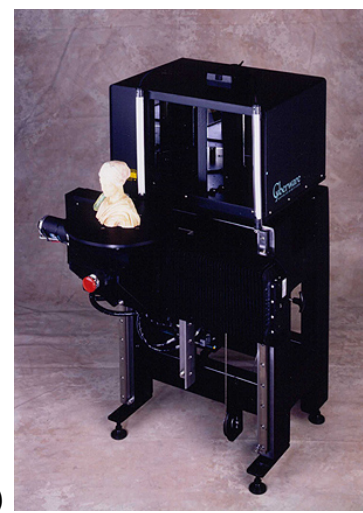

d)

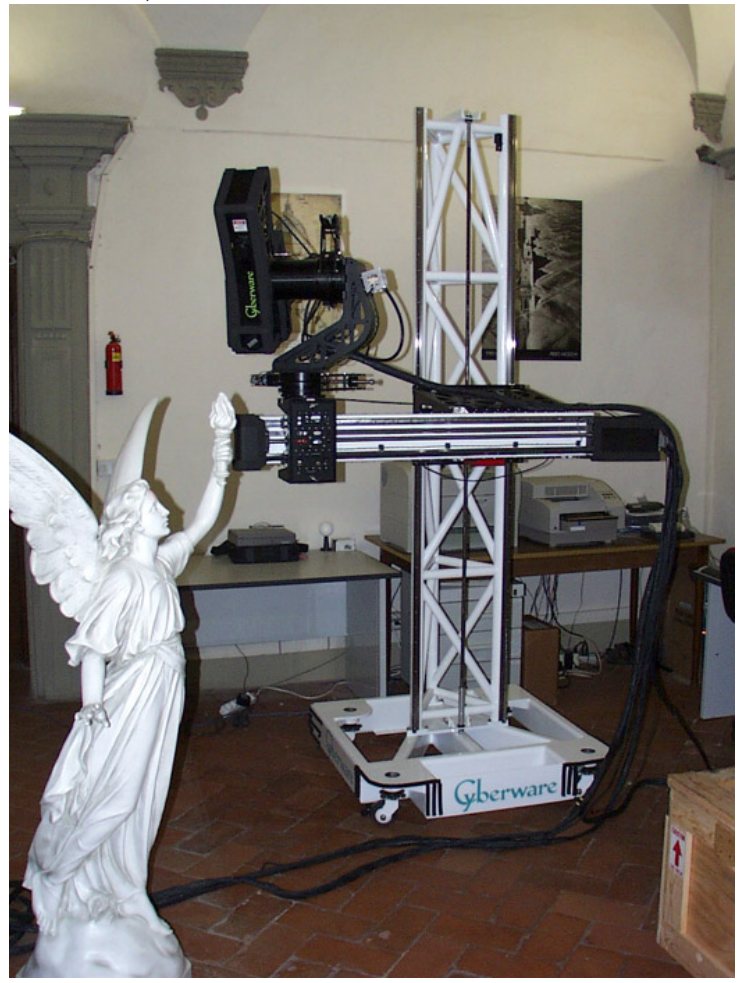

Figura 1.2: Alguns exemplos de scanners 3D aplicados a objetos de diferentes tamanhos (retiradas do site http://www.cyberware.com/).

\subsection{Contribuições}

Destacamos como principais contribuições desta dissertação:

Levantamento bibliográfico. Existem muitos trabalhos na área de geração de malhas superficiais a partir de nuvens de pontos. Neste trabalho buscamos focalizar na classificação, compreensão e, principalmente na descrição de maneira sucinta e clara dos trabalhos propostos na literatura. 
a)

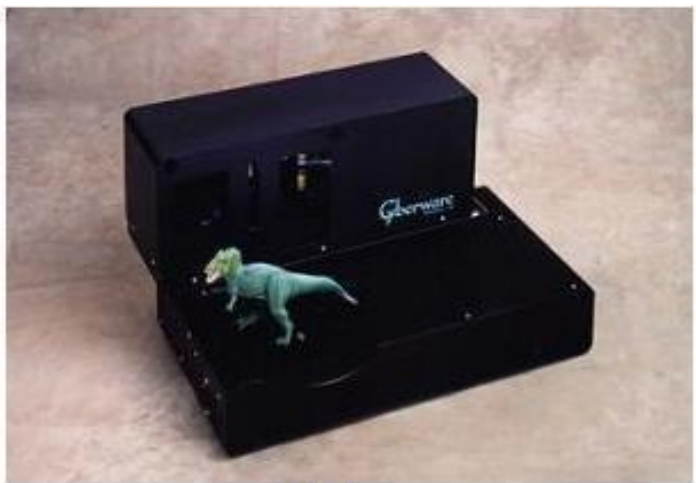

b)

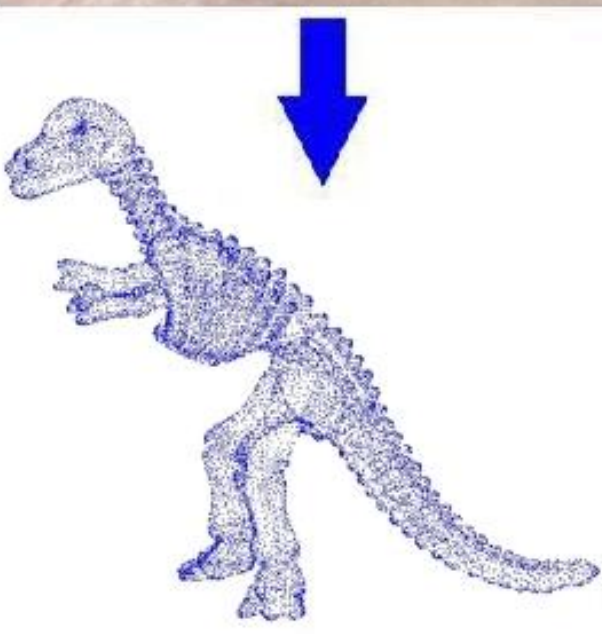

c)

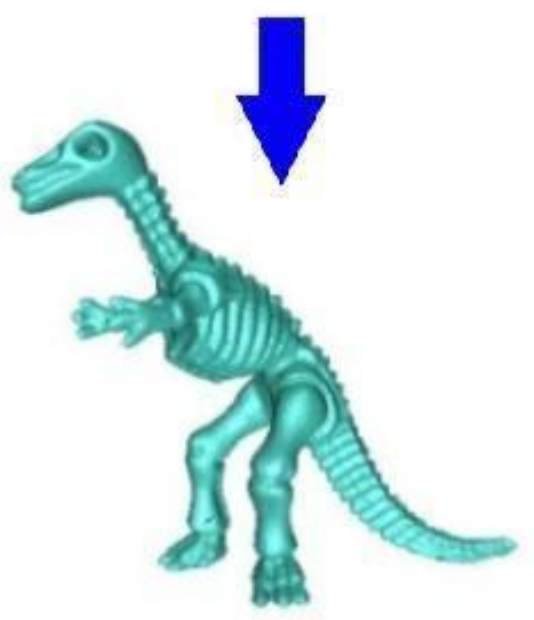

Figura 1.3: Sequiência de tarefas básica para o conjunto de algoritmos de reconstrução a partir de nuvens de pontos: a) coleta de dados utilizando um scanner $3 \mathrm{D}$, b) dados de entrada para algoritmos de reconstrução, c) reconstrução do modelo. 


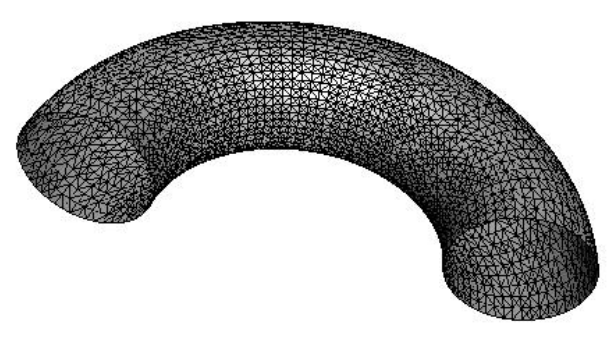

Figura 1.4: Exemplo de uma malha bidimensional em um espaço tridimensional.
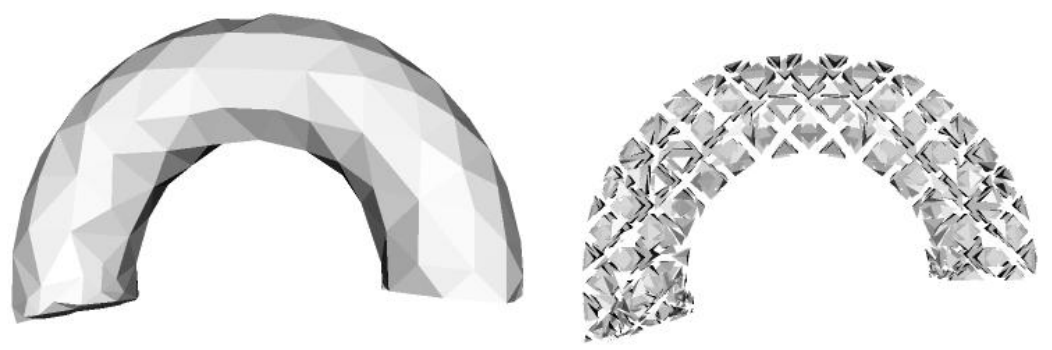

a)

b)

Figura 1.5: Malha volumétrica gerada a partir da fronteira definida por um algoritmo de reconstrução a partir de nuvens de pontos.

Comparação entre métodos. O levantamento bibliográfico realizado permitiu escolher técnicas recentes e interessantes para implementar e comparar com outras técnicas presentes na literatura (Gois et al., 2003). Poucos trabalhos encontrados na literatura realizam comparações teóricas e práticas, de forma simultânea, desses algoritmos. Apresentamos aqui comparações teóricas e as primeiras comparações práticas entre alguns algoritmos de reconstrução. Acreditamos que a realização de tais comparações é necessária para o amadurecimento da área, pois muitos trabalhos existentes na literatura deixam uma idéia muito vaga da eficiência dos algoritmos e apresentam poucos exemplos práticos de reconstrução.

Aplicações dos modelos gerados em simulações de E.D.P.'s. Os modelos gerados por nossas implementações de algoritmos clássicos da literatura deram origem a fronteiras de objetos tridimensionais nas quais foram geradas malhas volumétricas utilizadas como domínios 3D para simulações de E.D.P.'s pelo método de Volume Finitos (Maliska, 1995).

Aplicação em Processamento de Imagens. Aplicamos o arcabouço teórico de Geometria Computacional e de Reconstrução de Curvas em Processamento de Imagens, para a detecção de contornos de interesse em imagens. Nossa intenção nestas aplicações, consiste em 
substituir a análise do threshold em cada pixel por testes geométricos, como por exemplo o teste proposto por Amenta (Amenta et al., 2001a).

\subsection{Organização do trabalho}

Organizamos a dissertação da seguinte maneira:

- Capítulo 2 - Conceitos básicos: Inicialmente é apresentado um breve histórico das áreas de Geometria e Topologia Computacional. Em seguida, um conjunto de definições é apresentado para o enquadramento do leitor. Procuramos, para facilitar a compreensão dos conceitos, apresentar ilustrações e exemplos. Ainda para não tornar a leitura deste capítulo cansativa, buscamos esclarecer, quando julgamos necessário, em que momento do trabalho as definições serão necessárias.

- Capítulo 3 - Levantamento Bibliográfico: Neste capítulo é apresentado um vasto levantamento bibliográfico da área de reconstrução de superfícies a partir de nuvens de pontos. Nossas metas neste capítulo são: $i$ ) apresentar os trabalhos mais recentes e citados na literatura e enquadrá-los em cada sub-área de Reconstrução a partir de Nuvens de Pontos; $i$ ) focar as principais características de cada trabalho conforme a idéia central proposta pelos seus autores, isto é, os trabalhos são, em geral, caracterizados por três itens: fundamentação teórica, algoritmo e detalhes de implementação, sendo que geralmente cada autor direciona o trabalho a um desses três itens acima. Buscamos seguir a linha de raciocínio de cada autor para preservar a essência dos trabalhos. Provavelmente o leitor notará que as descrições dos trabalhos têm enfoques diferentes.

- Capítulo 4 - Família Crust: O levantamento bibliográfico deste capítulo trata de um conjunto especial de algoritmos, aqueles que foram os primeiros a apresentar garantias teóricas de reconstrução, isto é, que definem as condições de amostragem que garantem que a reconstrução é homeomorfa e próxima ao objeto original.

- Capítulo 5 - Implementações: Neste capítulo são descritas as implementações realizadas ao longo deste trabalho. Iniciamos com uma breve descrição da biblioteca CGAL Computational Geometry Algorithms Library (CGAL, 2004), com ênfase no pacote de triangulações (Boissonnat et al., 2002). Em seguida, focamos na descrição de nossas implementações. Adaptações e extensões realizadas nos algoritmos originais também 
são apresentadas. Implementamos três algoritmos bidimensionais $(\beta$-skeleton, crust $\mathrm{e}$ power crust) e dois tridimensionais (raw crust e power crust).

- Capítulo 6 - Comparações e exemplos: As comparações realizadas neste capítulo são uma das principais contribuições deste trabalho. Realizamos comparações teóricas e práticas do desempenho de algoritmos baseados em esculpimento que utilizam a biblioteca CGAL.

- Capítulo 7 - Aplicações: Apresentamos duas aplicações como resultados dos nossos estudos. A primeira consiste na simulação numérica de uma Equação Diferencial Parcial (E.D.P.) em que as fronteiras dos objetos dos domínios simulados foram obtidos por meio de reconstruções realizadas com os algoritmos implementados. Na segunda aplicação utilizamos resultados de Geometria Computacional e de reconstrução para os processos de detecção de contornos de imagens.

- Capítulo 8 - Conclusão: Concluímos este trabalho relatando os principais tópicos observados durante esta pesquisa e apresentando algumas sugestões de trabalhos futuros. 


\section{CAPÍtULO \\ 2 \\ Conceitos Básicos}

\subsection{Considerações iniciais}

Geometria Computacional tornou-se uma área muito produtiva nos últimos 20 anos com aplicações em muitos campos de pesquisa, tais como CAD, Robótica e Computação Gráfica. Geometria Computacional foca principalmente problemas discretos envolvendo conjunto de pontos, polígonos, poliedros e técnicas combinatórias para resolver problemas de ordem geométrica. Bern e Eppstein argumentam que existe a necessidade de extender a Geometria Computacional, com ênfase na eficiência e robustez, para domínios contínuos, superfícies curvas e altas dimensões (Bern e Eppstein, 1999).

Bern e Eppstein utilizam o nome Topologia Computacional para englobar tanto questões de desenvolvimento de algoritmos para solução de questões topológicas (por exemplo, reconhecimento de nós) quanto questões topológicas em algoritmos (por exemplo, em nossos estudos, quando uma reconstrução por nuvens de pontos preserva a topologia do objeto original).

Na próxima seção apresentamos definições e nomenclaturas pertinentes à Geometria e Topologia Computacional que serão utilizadas no decorrer deste trabalho. 


\subsection{Fundamentos teóricos}

Nesta seção apresentamos um conjunto de definições e nomenclaturas. No decorrer do trabalho apresentaremos outras definições conforme a necessidade de cada tema. Consideremos que o leitor tenha conhecimento das definições básicas de Cálculo Diferencial e Integral (por exemplo continuidade e diferenciabilidade), Espaços Métricos (conjunto limitado, conjunto fechado, combinação linear convexa, bola aberta) e Álgebra Linear (espaços e subespaços vetoriais).

Definição 1 (Espaço Euclidiano) Chamaremos de Espaço Euclidiano de dimensão n como sendo o espaço $\mathbb{R}^{n}$ dotado da métrica euclidiana usual, isto é, dado dois pontos $p=\left(p_{1}, \ldots, p_{n}\right)$, $q=\left(q_{1}, \ldots, q_{n}\right) \in \mathbb{R}^{n}$, medimos a distância entre $p$ e q por:

$$
\|p-q\|=\sqrt{\left(p_{1}-q_{1}\right)^{2}+\ldots+\left(p_{n}-q_{n}\right)^{2}}
$$

Definição 2 (Fecho Convexo) Dado um conjunto de pontos $P \subset \mathbb{R}^{n}$, o conjunto de todas as combinações lineares convexas, dado pela equação 2.1, exprime a definição de fecho convexo (figura 2.1).

$$
\operatorname{Conv}(P)=\sum_{i=1}^{n} \lambda_{i} p_{i}, \sum_{i=1}^{n} \lambda_{i}=1, \lambda_{i} \geq 0, \lambda_{i} \in \mathbb{R}, p_{i} \in P
$$

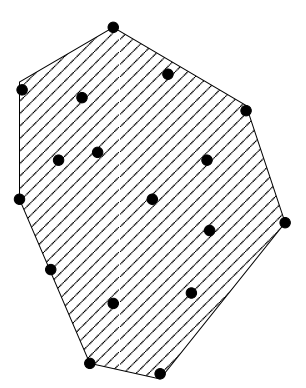

Figura 2.1: Exemplo bidimensional do fecho convexo de um conjunto de pontos.

O fecho convexo $\operatorname{Conv}(P)$ pode ser visto como o menor conjunto convexo que contém os pontos de $P$. O fecho convexo será utilizado para as definições de triangulação (definição 26) e triangulação de Delaunay (definição 29). 
Definição 3 (Homeomorfismo) Sejam os conjuntos $U \subset \mathbb{R}^{n}$ e $V \subset \mathbb{R}^{m}$. Dizemos que uma função $f: U \rightarrow V$ é um homeomorfismo se $f$ e $f^{-1}$ são contínuas. Neste caso $U$ e $V$ são ditos homeomorfos.

Definição 4 (Difeomorfismo) Dizemos que $f: U \rightarrow V$ é um difeomorfismo de classe $C^{r}$ se $f$ e $f^{-1}$ são diferenciáveis de classe $C^{r}$. Neste caso $U$ e $V$ são ditos difeomorfos.

Se um difeomorfismo $f$ é de classe $C^{0}$ dizemos que $f$ é um homeomorfismo.

Observação 1 Em geral, quando nos referimos a U e V como sendo homeomorfos, dizemos que $U$ e $V$ são topologicamente equivalentes. Por exemplo, o cubo, o tetraedro e a esfera são topologicamente equivalentes. Na figura 2.2 apresentamos conjuntos que são topologicamente equivalentes. Já na figura 2.3 apresentamos conjuntos que não são topologicamente equivalentes.

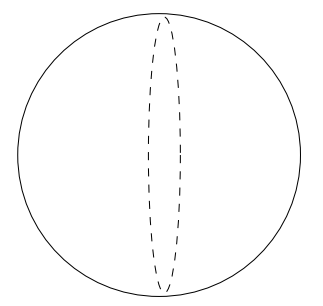

a)
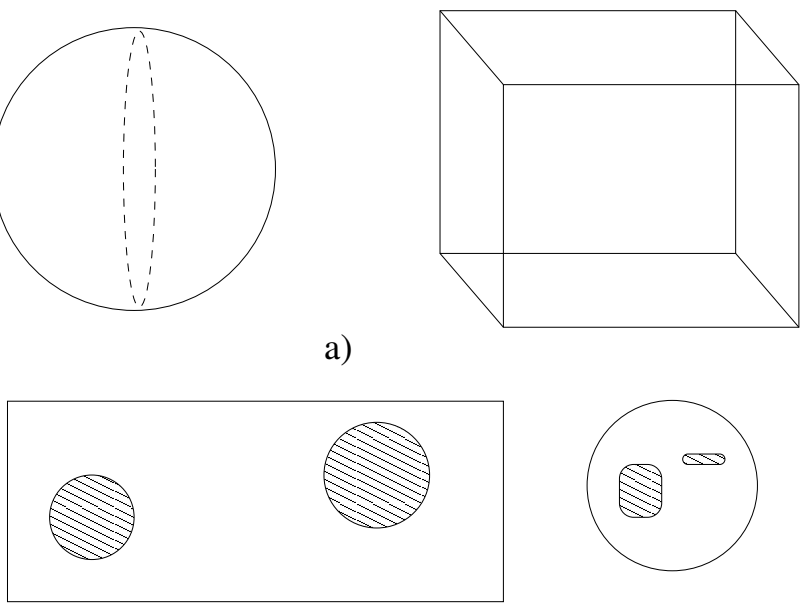

b)

Figura 2.2: Objetos topologicamente equivalentes.

Definimos semi-espaço para caracterizarmos variedade e conseqüentemente apresentarmos a definição de superfície.

Definição 5 (Semi-Espaço) Define-se por um semi-espaço de dimensão n o conjunto $\mathbb{H}^{n}=$ $\left\{\left(x_{1}, \ldots, x_{n}\right) \in \mathbb{R}^{n} \mid x_{1} \geq 0\right\}$. 

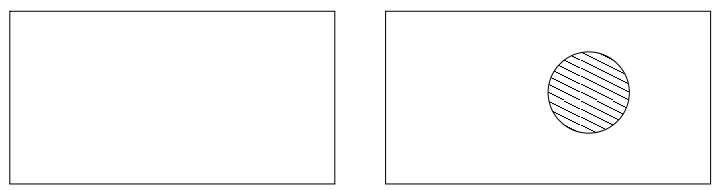

a)

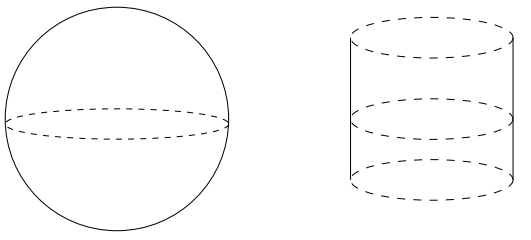

b)

Figura 2.3: Objetos que não são topologicamente equivalentes. Em a) duas regiões planas, uma contendo um buraco e em b) uma esfera e um cilindro sem suas tampas.

Definição 6 (Variedade) $O$ conjunto $M \subset \mathbb{R}^{k}$ é uma variedade de dimensão $n$ e classe $C^{r}$ se para todo $x \in M$ existem uma vizinhança aberta $U \ni x$, com $U \subset \mathbb{R}^{k}, V$ aberto de $\mathbb{H}^{n} e$ um difeomorfismo de classe $C^{r} \varphi: U \cap M \rightarrow V$ (figura 2.4).

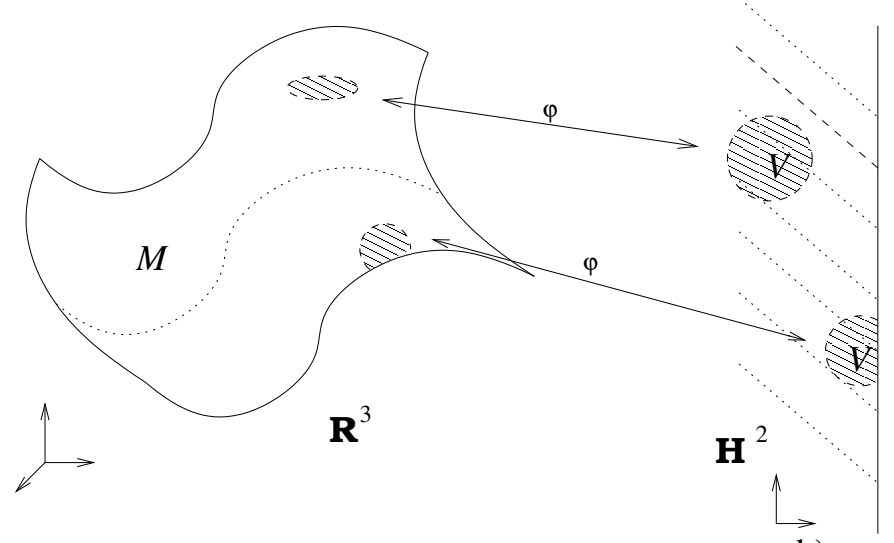

a)

b)

Figura 2.4: Exemplo de uma variedade de dimensão 2 imersa em $\mathbb{R}^{3}$. a) toma-se um aberto em intersecção com a variedade $M$ (região hachurada de $M$ ) difeomorfo a um aberto de $\mathbb{H}^{2}$, dado por b).

Observação 2 Se na definição 6 existir $e \in U \cap M \operatorname{com} \varphi(e)=\left(h_{1}, \ldots, h_{n}\right) \in \mathbb{H}^{n}$, com $h_{1}=0$, então dizemos que a variedade é com bordo. Caso contrário a variedade é dita sem bordo (figura 2.5). 


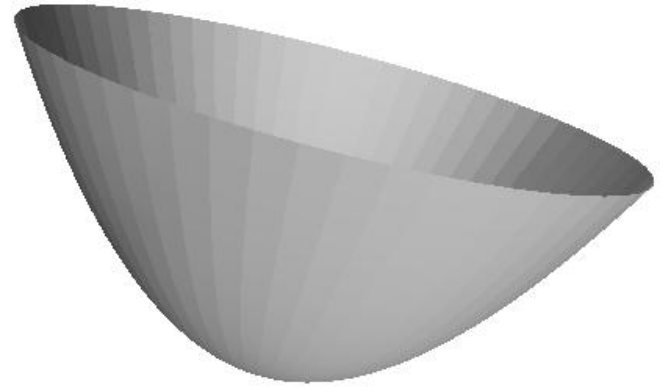

a)

Figura 2.5: Exemplos de variedade: a) variedade com bordo, b) variedade sem bordo.

Observação 3 Os pontos $x$ satisfazendo as condições de variedade são ditos pontos regulares. Se M não é uma variedade então os pontos que não satisfazem as condições de variedade são ditos pontos singulares.

A figura 2.6 apresenta exemplos de conjuntos que não são variedades.
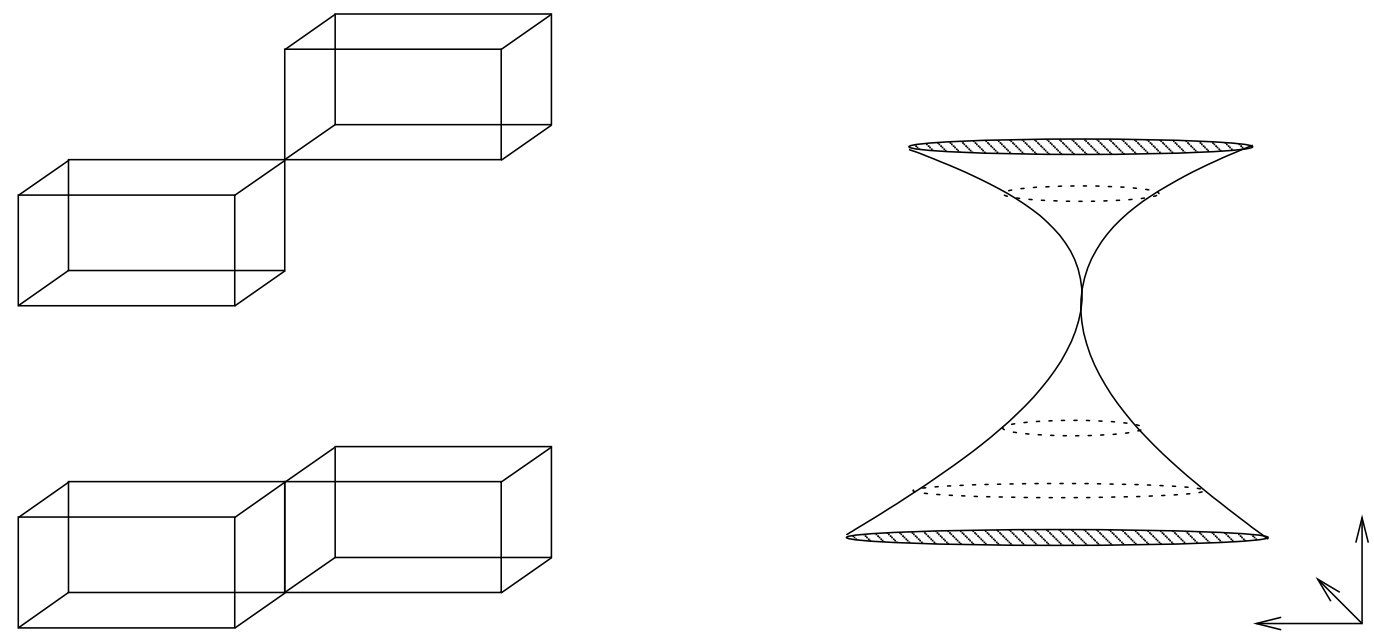

Figura 2.6: Exemplos de não-variedade imersas em $\mathbb{R}^{3}$.

Definição 7 (Superfície) Uma superfície $S \subset \mathbb{R}^{3}$ é uma 2-variedade imersa em $\mathbb{R}^{3}$. 
A seguinte definição é utilizada, em geral, como condição necessária para os algoritmos de reconstrução.

Observação 4 (Variedades suaves) Se $M$ é uma variedade, limitada e de classe $C^{k}, k \geq 2$, dizemos que a variedade é suave. Casos particulares ocorrem quando M é uma 1-variedade, que denominamos de curva suave (figura 2.7) e se $M$ for uma 2-variedade, denominamos de superfície suave.

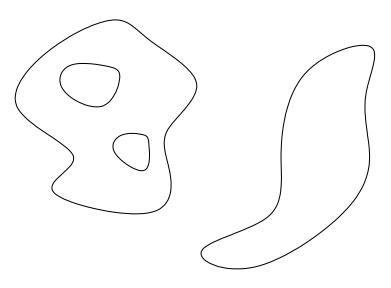

a)

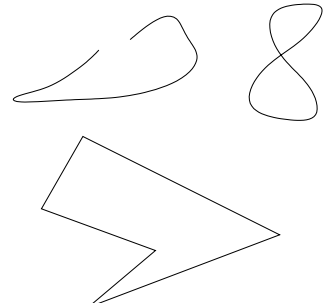

b)

Figura 2.7: Em a) exemplos de curvas suaves, em b) curvas não suaves.

Definição 8 (Amostragem) Uma amostragem de uma variedade $M$ é um conjunto finito de pontos de $M$.

Em geral os algoritmos de reconstrução a partir de nuvens de pontos assumem como entrada uma amostragem de uma variedade suave e tem como saída uma variedade linear por partes (definição 22).

De maneira intuitiva, podemos pensar no genus de um objeto como sendo o número de buracos nele contido. Os objetos da figura 2.2-a) tem genus 0 e os da figura 2.2-b) têm genus 2 (considerando as partes hachuradas como sendo os buracos das seções planares).

Apresentamos as seguintes definições para caracterizarmos os conceitos de triangulação, triangulação de Delaunay e seu dual, o diagrama de Voronoi.

Definição 9 (Esfera $S^{n}$ ) Uma esfera $S^{n}$ de centro em $c=\left(c_{0}, \ldots, c_{n}\right)$ e raio $r$ é o conjunto dos pontos $X=\left\{p \in \mathbb{R}^{n+1} / p=\left(x_{0}, x_{1}, \ldots, x_{n}\right)\right\}$ tal que:

$$
\sqrt{\left(x_{0}-c_{0}\right)^{2}+\left(x_{1}-c_{1}\right)^{2}+\ldots+\left(x_{n}-c_{n}\right)^{2}}=r
$$

Definição 10 (Subespaço Afim) Definimos um subespaço afim como sendo um subespaço vetorial transladado da origem. 
Definição 11 (Posição Geral) Dizemos que um conjunto de pontos $X \subset \mathbb{R}^{n}$ está em posição geral se:

1. Nenhum subespaço afim contém $X$;

2. Nenhuma esfera $S^{n-1}$ intercepta mais de $n+1$ pontos de $X$.

Definição 12 (Simplexo) $U m n$-simplexo $\sigma \subset \mathbb{R}^{n}$ é o fecho convexo de $n+1$ pontos em posição geral (figura 2.8).

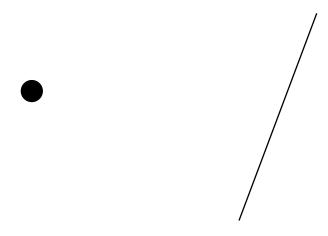

a) b)

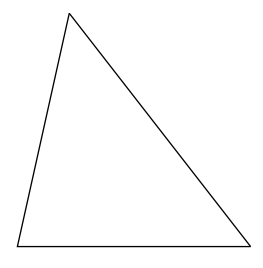

c)

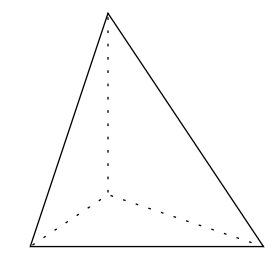

d)

Figura 2.8: a) 0-simplexo, b) 1-simplexo, c) 2-simplexo, d) 3-simplexo.

Definição 13 (Face) Se $\sigma$ é um n-simplexo formado pelos pontos $X=\left\{x_{0}, \ldots, x_{n}\right\}$, qualquer $l$-simplexo dado por um subconjunto de $l+1$ com $l<n$ elementos de $X$ é face de $\sigma$.

Definição 14 (Fronteira de um $n$-simplexo) $A$ fronteira de um $n$-simplexo $\sigma$, denotada por $\partial \sigma$, consiste de todos os $(n-k)$-simplexos contidos em $\sigma, 0<k \leq n$.

Cada simplexo na fronteira de $S$ é uma face de $S$. Um $k$-simplexo na fronteira é denominado $k$-face.

Pode ser mostrado (Munkres, 1984) que um $n$-simplexo contém exatamente $\left(\begin{array}{l}n+1 \\ k+1\end{array}\right) k$ simplexos como faces e mais:

$$
\sum_{k=-1}^{n}\left(\begin{array}{c}
\mathrm{n}+1 \\
\mathrm{k}+1
\end{array}\right)=2^{n+1}
$$


Definição 15 (Complexo Simplicial) $U m$ complexo simplicial $C$ é um conjunto finito de simplexos satisfazendo:

1. Se $\sigma$ é um simplexo em $C$ e $\sigma^{\prime}$ uma de suas faces, então $\sigma^{\prime}$ também pertence a $C$.

2. Se $\sigma_{1}$ e $\sigma_{2}$ são dois simplexos de $C$, então $\sigma_{1} \cap \sigma_{2}$ ou é face de ambos, ou é vazia (figura 2.9).

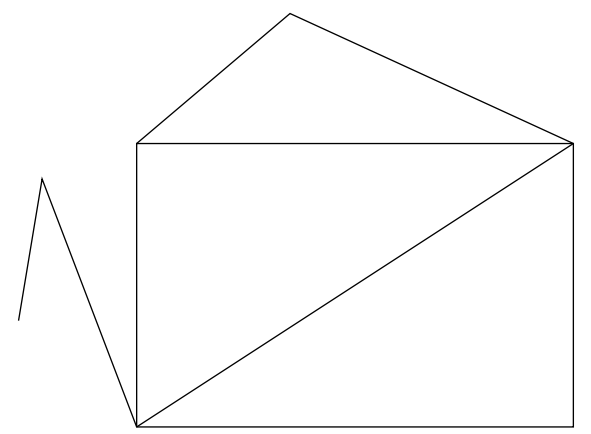

a)

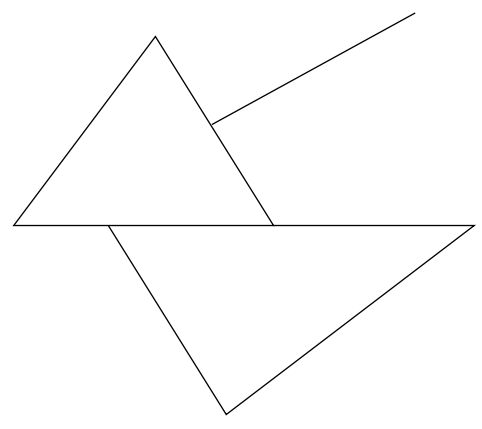

b)

Figura 2.9: a) Exemplo de um complexo simplicial, b) não define um complexo simplicial. Note que existem intersecções que não definem uma face.

Definição 16 (Dimensão de um Complexo Simplicial) $A$ dimensão de um complexo simplicial $C$ é definida pela dimensão máxima de seus simplexos.

Se $\sigma$ é um $n$-simplexo e $n>0$, então a fronteira $\partial \sigma$ é um complexo simplicial de dimensão $n-1$.

Definição 17 (Célula) $A$ célula $\varsigma$ (convexa) gerada pelos pontos $X=\left\{x_{0}, \ldots, x_{n}\right\}$ é dada pelo fecho convexo de $X$.

Definição 18 (Dimensão de uma Célula) Seja o conjunto de pontos $X=\left\{x_{0}, \ldots, x_{n}\right\}$. A dimensão de uma célula $\varsigma$ é o maior número de vetores linearmente independentes $\left\{x_{1}-\right.$ $\left.x_{0}, \ldots, x_{n}-x_{0}\right\}$.

Casos particulares são as células de dimensão 1, chamadas de arestas, e as células de dimensão 0 , denominadas vértices. 
Definição 19 (Bordo de uma Célula) $O$ bordo de uma célula $\varsigma$, denotado por $\partial(\varsigma)$, é o conjunto de células satisfazendo:

1. Se $\varsigma^{\prime} \in \partial(\varsigma)$, então $\varsigma^{\prime}$ é gerado por um subconjunto de vértices de $\varsigma$;

2. $\forall p \in \varsigma^{\prime}$, onde $\varsigma^{\prime} \in \partial(\varsigma)$, não existe uma bola inteiramente contida em $\varsigma^{\prime}$ de centro em $p$, raio r com dimensão de $\varsigma$;

3. $\varsigma_{1}^{\prime} \in \partial(\varsigma) e \varsigma_{2}^{\prime} \in \partial(\varsigma) \Rightarrow \varsigma_{1}^{\prime} \nsubseteq \varsigma_{2}^{\prime} e \varsigma_{2}^{\prime} \nsubseteq \varsigma_{1}^{\prime}$.

Definição 20 (Complexo Celular) Seja C uma coleção finita de células $\varsigma$ em $\mathbb{R}^{n}$. Dizemos que $C$ é um complexo celular de um conjunto $K \subset \mathbb{R}^{n}$ se forem satisfeitas:

1.

$$
K=\bigcup_{\varsigma \subset C} \varsigma
$$

2. Se $\varsigma_{1} e \varsigma_{2} \in C$, então $\varsigma_{1} \cap \varsigma_{2}=\emptyset$, ou $\varsigma_{1} \cap \varsigma_{2} \in C$ é uma face de $\varsigma_{1} e \varsigma_{2}$.

Os algoritmos de reconstrução que apresentamos neste trabalho geram saídas que são complexos celulares ou complexos simpliciais.

Definição 21 (Espaço Gerado) $O$ espaço gerado por um complexo celular $C$, denotado por $|C| \subset \mathbb{R}^{n}$ é a união de todos os pontos das células de $C$.

Definição 22 (Variedade Linear por Partes) Seja $M \subset \mathbb{R}^{n}$ uma n-variedade de classe $C^{0}$ e $M=|C|$, onde $C$ é um complexo celular, dizemos que $M$ é uma Variedade Linear por Partes de dimensão n (figura 2.10).

Definição 23 (Estrela) A estrela de uma célula $S$, denotada por $\operatorname{Star}(S)$, é o conjunto de células de $C$ que contém $S$ (figura 2.11).

Definição 24 (Link) O link de uma célula $S$, denotado por link $(S)$, é o conjunto $\partial(\operatorname{Star}(S))$ (figura 2.11). 
a)

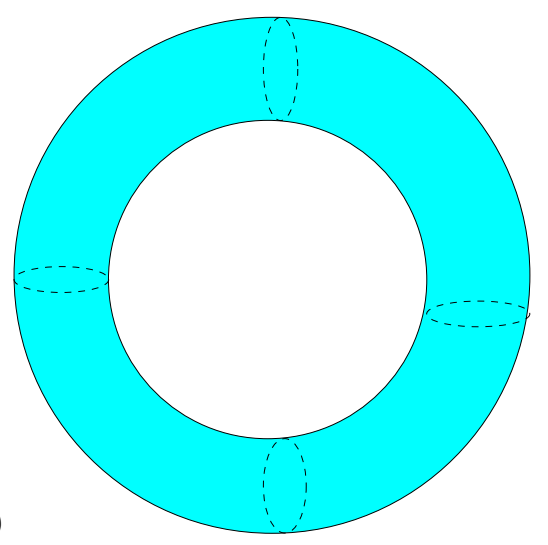

b)

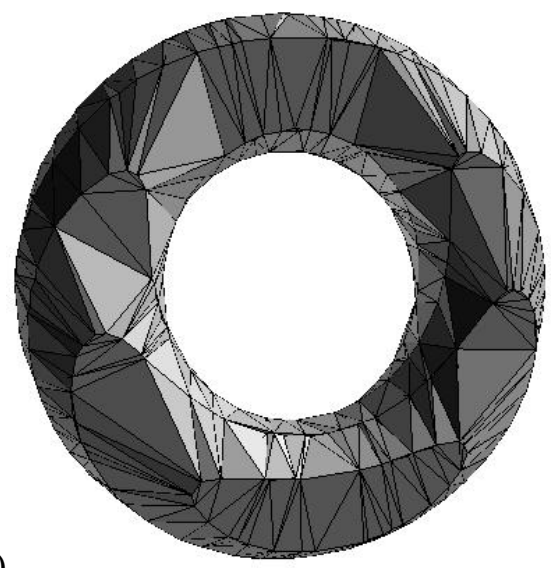

Figura 2.10: a) 2-variedade, b) 2-variedade linear por partes.

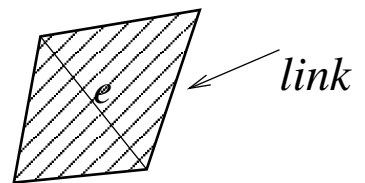

link

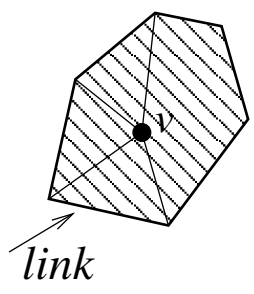

b)

Figura 2.11: As regiões hachuradas definem a) a estrela de uma aresta $e$ e b) a estrela de um vértice $v$. As arestas mais largas indicam seus respectivos links da aresta $e$ e do vértice $v$.

Definição 25 (Grafo) Um grafo $G(V, E)$ é definido como um conjunto finito de vértices $V \neq$ $\emptyset$ e um conjunto finito de arestas $E$, conectando os vértices de $V$.

Definição 26 (Triangulação) Seja $P \subset \mathbb{R}^{n}$ um conjunto de pontos. Uma triangulação de $P$ de dimensão $k \leq n$ é um complexo simplicial onde todo simplexo de dimensão $m<k$ está contido em algum simplexo de dimensão $k$ e os vértices da triangulação são pontos de $P$.

Observação 5 Uma triangulação é um exemplo de grafo.

Definição 27 (Diagrama de Voronoi) Seja $P \subset \mathbb{R}^{n}$ um conjunto de pontos. Para cada $p, q \in P$, seja $B(p, q)=\{x:\|x-q\|=\|x-p\|\}$ o bissetor de $p$ e $q$. Considere o semi-espaço $D(p, q)=\{x:\|x-p\| \leq\|x-q\|\}$ contendo $p$, e $D(q, p)$ é o semi-espaço que contém q. Define-se por $\operatorname{VR}(p, P)=\bigcap_{q \in P, q \neq p} D(p, q)$ a região de Voronoi ${ }^{1}$. $O$ diagrama de

\footnotetext{
${ }^{1}$ Conhecido também como célula de Voronoi.
} 
Voronoi de P é definido por:

$$
V(P)=\bigcup_{p, q \in P, p \neq q} V R(p, P) \bigcap V R(q, P)
$$

A figura 2.12 apresenta um exemplo de diagrama de Voronoi em $\mathbb{R}^{2}$.

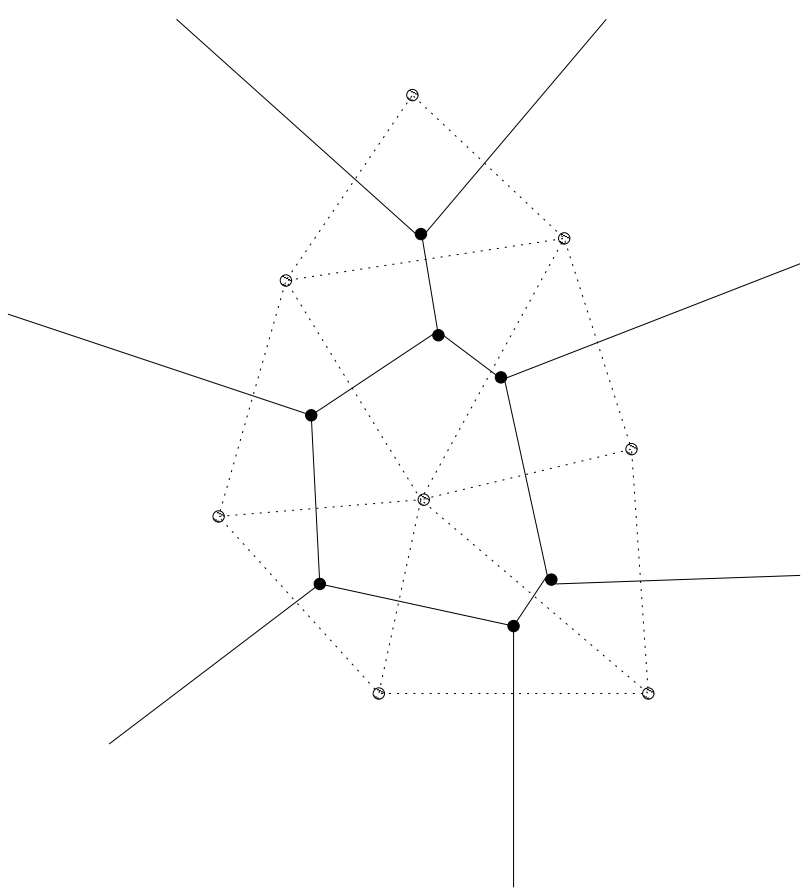

Figura 2.12: Diagrama de Voronoi (dos pontos sem preenchimento) em linhas contínuas. Em linhas pontilhadas, seu dual, a triangulação de Delaunay (definição 29).

Definição 28 (Circunsfera) Denominamos de circunsfera de um $n$-simplexo $\sigma$ a esfera $S^{n-1}$ que contém todos os vértices de $\sigma . E m \mathbb{R}^{2}$ denominamos de circuncírculo. O raio da circunsfera é denominado circunraio.

Definição 29 (Triangulação de Delaunay) Seja $X=\left\{x_{0}, \ldots, x_{k}\right\} \subset \mathbb{R}^{n}, n \leq k$, dizemos que uma triangulação de $X$ é de Delaunay se a circunsfera de todo n-simplexo não contém nenhum outro ponto de $X$ em seu interior (figura 2.13).

Entre as propriedades da triangulação de Delaunay podemos citar (Edelsbrunner, 2001; Shewchuk, 1997):

- O circuncírculo de cada triângulo não contém nenhum outro vértice da triangulação (é possível generalizar para $\mathbb{R}^{n}$ ). 
- Maximiza o ângulo mínimo de cada triângulo (válida somente em $\mathbb{R}^{2}$ );

- É dual do diagrama de Voronoi (Aurenhammer e Klein, 2000);

- É única para pontos em posição geral;

- Em $\mathbb{R}^{2}$ é possível obter a triangulação em $O(n \log n)$;

- Para pontos $(x, y) \in \mathbb{R}^{2}$, a triangulação é a projeção ortogonal da parte inferior do fecho convexo dos pontos $\left(x, y, x^{2}+y^{2}\right) \in \mathbb{R}^{3}$ (é possível generalizar esta relação para $\mathbb{R}^{n}$ ) (Edelsbrunner, 2001).

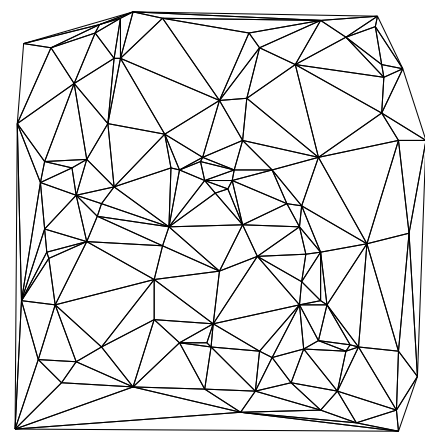

Figura 2.13: Exemplo de uma triangulação de Delaunay de um conjunto de 100 pontos no plano Euclidiano.

Alguns subconjuntos da triangulação de Delaunay, apresentados a seguir são utilizados como heurísticas para reconstrução de superfícies a partir de nuvens de pontos, descritas no capítulo 3.

Definição 30 (Grafo do Vizinho mais Próximo) $O$ grafo do vizinho mais próximo (Nearest Neighbour Graph, $\mathrm{NNG})$ de um conjunto de pontos $\mathrm{P}$ é o grafo $\mathrm{NNG}(\mathrm{P})=(\mathrm{P}, \mathrm{E})$ tal que $E \subseteq P \times P$ e $E=\left\{e_{k}=\left(p_{i}, p_{j}\right), k=1, \ldots, n: p_{j}\right.$ é o ponto de $P$ mais próximo de $\left.p_{i}\right\}$.

Definição 31 (Árvore Geradora Mínima Euclidiana) $A$ árvore geradora mínima Euclidiana (Euclidean Minimun Spanning Tree, EMST) é a árvore $\operatorname{EMST}(P, E)=(P, E)$, tal que $E \subseteq P \times P$ e $E=\left\{e_{k}=\left(p_{i}, p_{j}\right), k=1, \ldots, n: \sum\left\|p_{i}-p_{j}\right\|\right.$ é mínima $\}$.

Definição 32 (Grafo de Gabriel) $O$ grafo de Gabriel de P é o grafo $G G(P)=(P, E)$, definido por $E \subseteq P \times P$ e $E=\left\{e_{k}=\left(p_{i}, p_{j}\right), k=1, \ldots, n:\right.$ a menor esfera tocando $p_{i}$ e $p_{j}$ não contém qualquer outro ponto de $P\}$. 
A partir destas definições e denotando por $E D T(P)$ o conjunto das arestas da triangulação de Delaunay dos pontos pertencentes a $P$, tem-se a seguinte relação de inclusão:

$$
N N G(P) \subseteq E M S T(P) \subseteq G G(P) \subseteq E D T(P)
$$

Attene generaliza a definição de grafo de Gabriel para suportar triângulos, além de vértices e arestas (Attene e Spagnuolo, 2000).

Definição 33 (Hipergrafo de Gabriel Extendido (EGH)) Dado $P$ e dado o $G G(P)=\left(P, E_{G G}\right)$, o $E G H(P)=\left(P, E_{E G H}, T\right)$, onde $P, E$ e $T$ são, respectivamente o conjunto de vértices, de arestas e de triângulos do grafo. $O$ conjunto de arestas iniciais de EGH é o mesmo de GG. O conjunto de triângulos é construído da seguinte maneira:

- $\forall e_{1}, e_{2} \in E_{G G}, e_{1}=\left(v_{1}, v_{2}\right), e_{2}=\left(v_{2}, v_{3}\right)$, não colineares e se a menor esfera por $v_{1}, v_{2}$ e $v_{3}$ não contém quaisquer outros pontos de $P$, então $e_{3}=\left(v_{1}, v_{3}\right) \in E_{E G H}$;

- qualquer ciclo de três arestas em $E_{E G H}$ é um triângulo em $T$.

O EGH também é um subconjunto de uma triangulação de Delaunay, neste caso, para $\mathbb{R}^{3}$.

Mais detalhes sobre estas estruturas podem ser encontradas em (Stolfi, 1994; Attene e Spagnuolo, 2000).

As seguintes definições são utilizadas para a caracterização da triangulação de Delaunay com Peso.

Definição 34 (Ponto com Peso) Seja $\hat{p}=\left(p, w^{2}\right) \in \mathbb{R}^{n} \times \mathbb{R}_{+}$, dizemos ser um ponto com peso, onde $w^{2}$ é o peso associado ao ponto $\hat{p}$ e pé sua posição em $\mathbb{R}^{n}$.

Definição 35 (Distância com Peso) A distância com peso entre dois pontos com peso $\hat{p}=$ $\left(p, w_{1}^{2}\right)$ e $\hat{q}=\left(q, w_{2}^{2}\right)$ é dada por $\|\hat{p}-\hat{q}\|_{w}=\|p-q\|^{2}-w_{1}^{2}-w_{2}^{2}$.

Dizemos que dois pontos $\hat{p}$ e $\hat{q}$ são ortogonais se $\|\hat{p}-\hat{q}\|_{w}=0$.

Definição 36 (Ortocentro) Dado um conjunto de pontos com pesos $\hat{p}_{1}, \ldots, \hat{p}_{n+1} \in \mathbb{R}^{n}$ distintos dois a dois existe um único ponto com peso ô, que denominamos por ortocentro tal que $\left\|\hat{p}_{i}-\hat{o}\right\|_{w}=0$ para $1 \leq i \leq n+1$. 


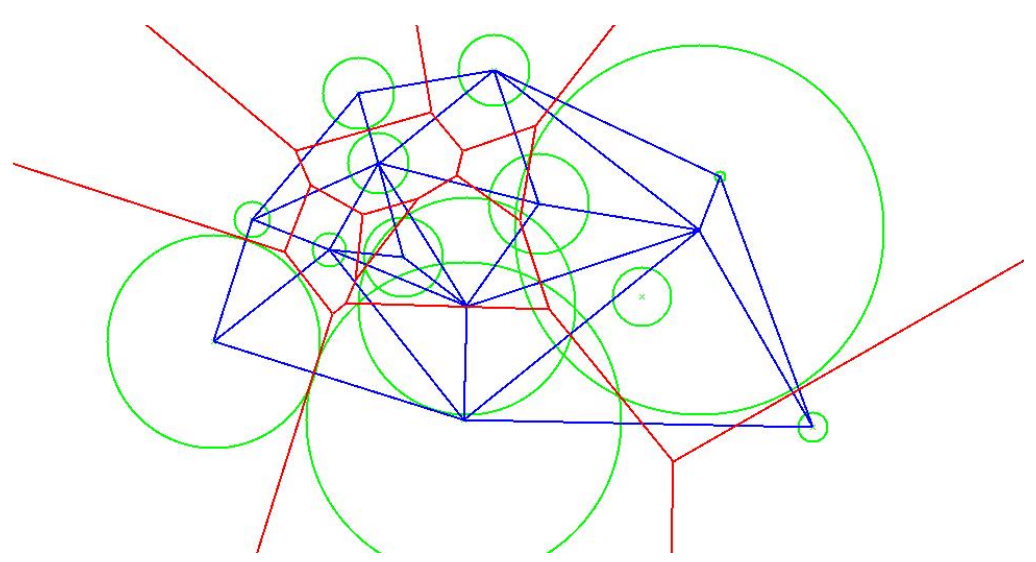

Figura 2.14: Exemplo de uma triangulação de Delaunay com peso: Os círculos verdes são os pontos com peso. Em azul, a triangulação de Delaunay com peso e em vermelho o power diagrama.

Um ponto com peso $\hat{p}=\left(p, w^{2}\right)$ pode ser interpretado geometricamente como uma esfera de centro em $p$ e raio $w$. A definição de distância com peso pode ser vista em termos de uma esfera ao invés de um ponto com peso (Edelsbrunner, 2001).

Definição 37 (Power Diagrama) $O$ power diagrama de um conjunto de pontos com peso é definido como o diagrama de Voronoi utilizando a distância com peso, ao invés da distância Euclidiana (figura 2.14).

Definição 38 (Triangulação de Delaunay com Peso) Define-se por triangulação de Delaunay com Peso ou Regular Triangulation o dual do power diagrama (figura 2.14).

Observação 6 O dual de cada n-simplexo de uma triangulação de Delaunay com peso em $\mathbb{R}^{n}$ é seu próprio ortocentro.

Existem alguns casos especiais de vértices da triangulação de Delaunay com peso. Um vértice da triangulação pode não estar dentro de sua célula do power diagrama ou até mesmo não existir tal célula (neste caso o vértice é denominado redundante). Edelsbrunner caracteriza em maiores detalhes a triangulação de Delaunay com peso (Edelsbrunner, 2001). Na figura 2.14 existem células do power diagrama sem vértices em seu interior e também vértices da triangulação sem arestas conectadas a ele (não existe sua célula dual).

As seguintes definições são empregadas nos capítulos 3 e 4 com o intuito de definirmos e apresentarmos os resultados que garantem a reconstrução das variedades. 
Definição 39 (Eixo Medial) Define-se como o eixo medial de uma n-variedade $M$ o conjunto dos pontos que definem os centros de esferas $S^{n}$ que tangenciam $M$ em ao menos dois pontos. (figura 2.15).

No caso bidimensional, se $P$ é uma amostra de pontos de uma curva $C$ então o diagrama de Voronoi é uma boa aproximação para o eixo medial. Consideremos $P$ um conjunto com $n$ pontos de $C$ e sejam $M$ o eixo medial de $C$ e $V_{v}$ o conjunto de vértices do diagrama de Voronoi de $P$. Então pode ser mostrado que (Brandt, 1994):

$$
n \rightarrow \infty, P \longrightarrow C \Rightarrow V_{v} \longrightarrow M
$$

Definição 40 (Transformação do Eixo Medial) (Amenta et al., 2001b) A Transformação do Eixo Medial define-se como a união das esferas que definem o eixo medial.

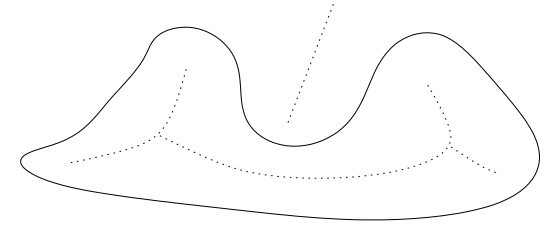

Figura 2.15: Exemplo do eixo medial de uma curva (linhas pontilhadas).

Definição 41 (Local Feature Size) (Amenta et al., 2001b) Seja um ponto $p \in P$. A distância Euclidiana de p ao eixo medial de $M$ é definida como o local feature size de p, denotado por LFS (p) (figura 2.16).

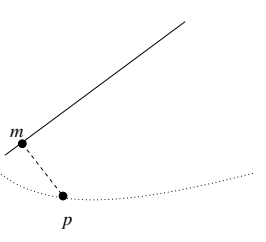

Figura 2.16: Exemplo bidimensional do local feature size LFS $(p)=\|p-m\|$.

Definição 42 ( $r$-amostragem) Dizemos que uma variedade $M$ é $r$-amostrada por um conjunto de pontos $P \subset M$ ou $P$ é uma $r$-amostragem de $M$ se: 


$$
\forall c \in M, \exists p \in P: \frac{\|p-c\|}{\operatorname{LFS}(c)} \leq r
$$

Intuitivamente o parâmetro $r$ determina a quantidade de pontos em determinadas regiões da variedade. Onde a variedade tem alto valor da curvatura (figura 2.17 a) ) e em regiões de estrangulamento (figura 2.17 b) ) necessita-se uma maior amostragem sobre a variedade para satisfazer a condição de $r$-amostragem. Notemos que em regiões de alta curvatura e de estrangulamento o eixo medial está próximo a variedade. Na figura 2.17 o eixo medial é dado em linhas pontilhadas.

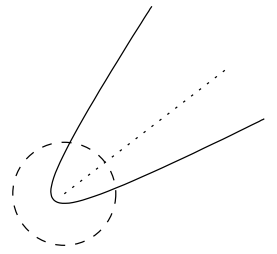

a)

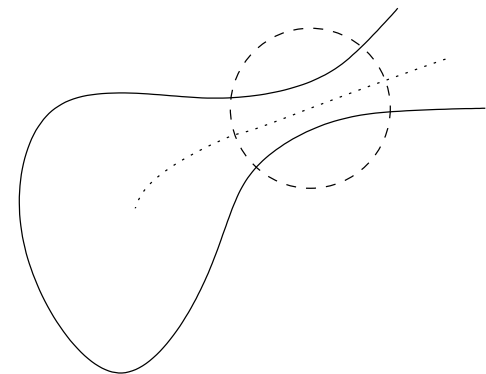

b)

Figura 2.17: Curvas que exemplificam quais regiões necessitam de maior número de pontos (regiões no interior dos círculos tracejados): a) em regiões de maior curvatura e b) em regiões de "estrangulamento". As linhas pontilhadas representam o eixo medial.

\subsection{Considerações finais}

Neste capítulo foram apresentadas definições gerais referentes à Geometria e Topologia Computacional que serão empregadas no decorrer deste trabalho.

No próximo capítulo apresentamos a primeira parte do levantamento bibliográfico referente à reconstrução de objetos tridimensionais a partir de nuvens de pontos. 


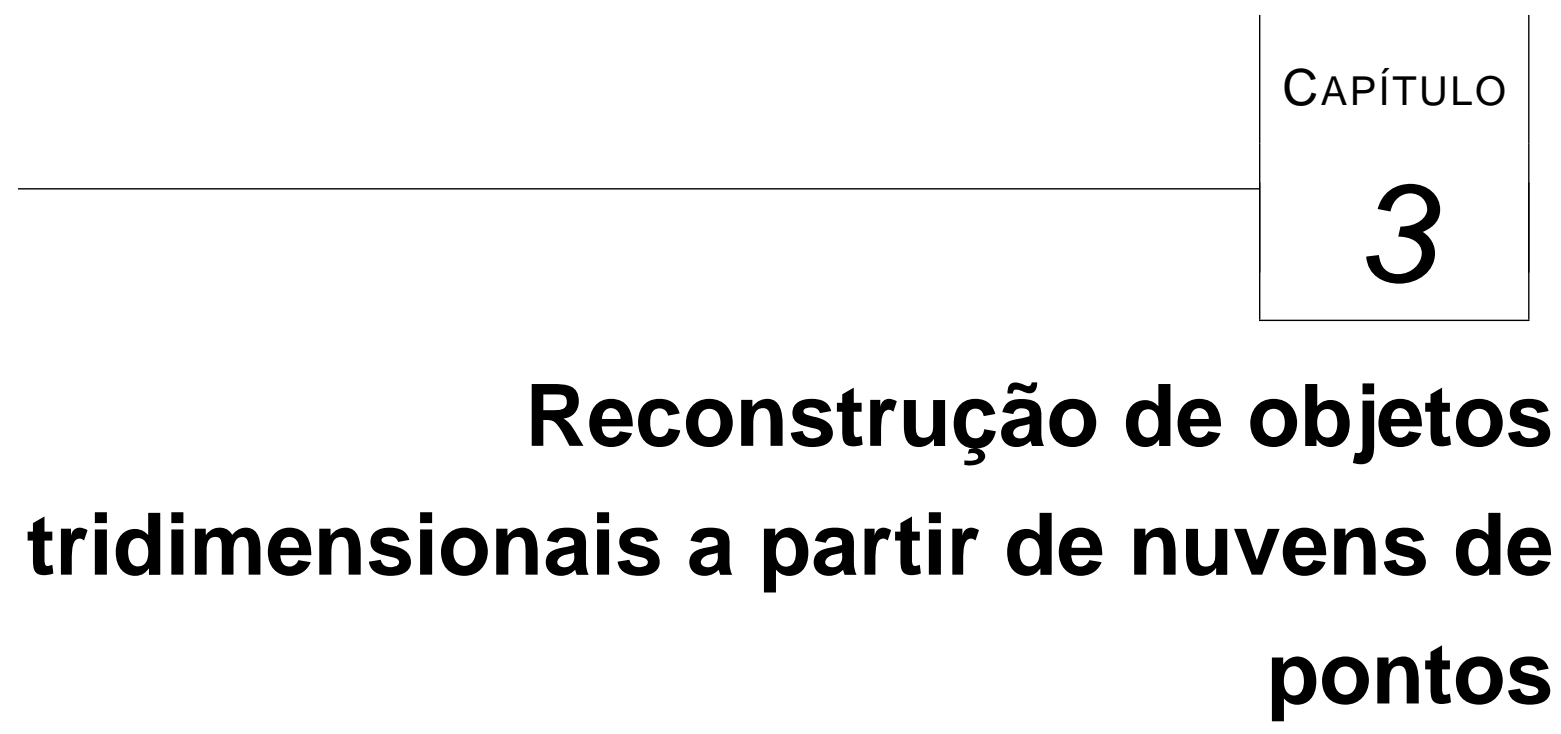

\subsection{Considerações iniciais}

Seja uma superfície $S \subset \mathbb{R}^{3}$ e uma amostragem de pontos $P \subset S$, que definimos como nuvem de pontos de $S$.

Uma reconstrução a partir de nuvens de pontos $P \subset S$ é, na quase totalidade dos trabalhos apresentados, uma aproximação linear por partes $S^{\prime}$ de $S$.

Os métodos de reconstrução buscam satisfazer os seguintes itens:

- $S^{\prime}$ deve manter a mesma topologia de $S$;

- Dado um ponto de $S^{\prime}$, sua distância à superfície $S$ deve ser suficientemente pequena (figura 3.1).

Questões críticas em reconstrução de superfícies são manipular superfícies de topologia arbitrária, utilizar conjunto de pontos não-uniformes e produzir superfícies que garantam uma boa representação da forma original do objeto. Os algoritmos de reconstrução, em geral, 


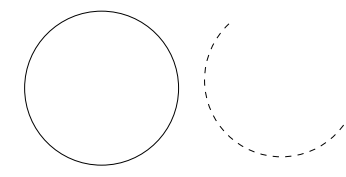

a)

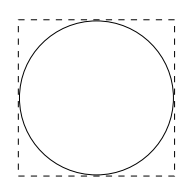

b)

Figura 3.1: Exemplo bidimensional dos itens que um método de reconstrução tenta satisfazer: a) curvas não homeomorfas, mas próximas; b) curvas homeomorfas mas não próximas.

além destas questões ainda buscam satisfazer requisitos como eficiência de tempo e espaço (estrutura de dados espaciais e topológicas eficientes).

A correta reconstrução de uma superfície é possível apenas se o conjunto $P$ for adequado. A definição de um conjunto adequado varia conforme os algoritmos. Em geral, ou exige-se uma maior densidade de pontos nas regiões em que a curvatura do objeto sofre maior variação (Gopi et al., 2000), ou superfícies $r$-amostradas (definição 42) (Amenta et al., 1998b), ou amostragem densa e uniforme (Edelsbrunner e Mücke, 1994).

Classificamos os métodos de reconstrução a partir de nuvens de pontos da seguinte maneira:

- Métodos baseados em esculpimento ou decomposição espacial;

- Métodos baseados em funções implícitas;

- Métodos incrementais;

- Métodos baseados em modelos deformáveis.

Outras formas de classificação menos gerais são encontradas na literatura. Huang classifica as categorias baseadas em superfície (equivalente aos métodos incrementais), volume (equivalente métodos de esculpimento) e implícitas (Huang e Menq, 2002). Zhao apenas classifica os trabalhos como paramétrico (baseados em esculpimento) e não paramétrico (superfícies implícitas) (Zhao et al., 2000).

Apresentamos nas seções 3.2 a 3.5 a descrição de trabalhos recentes na área de reconstrução de superfícies para cada uma das categorias acima. 


\subsection{Métodos baseados em esculpimento}

O princípio básico da abordagem de esculpimento consiste em obter primeiramente a triangulação de Delaunay do conjunto de pontos e, em seguida, por meio de heurísticas denominadas de esculpimento, remover um conjunto de simplexos com a finalidade de obter uma forma que melhor represente o objeto original. O conjunto de faces que representa a superfície será uma restrição da triangulação de Delaunay, de maneira semelhante a proposta por Chew (Chew, 1993).

Observação 7 (Triangulação de Delaunay sobre superfícies) Em 1993, Chew definiu uma triangulação de Delaunay de um conjunto finito de pontos $P$ sobre uma superfície $S \subset \mathbb{R}^{3}$ modificando o critério circunsfera vazia. Especificamente, o triângulo formado pelos pontos $q, q, r \in P$ pertence a triangulação de Delaunay da superfície se existe uma esfera $B$ com centro em $S$ e passando por $p$, q e r que é vazia de outros pontos de P (Chew, 1993). Em outras palavras, a superfície definida por Chew é um subconjunto de faces da triangulação de Delaunay dos pontos amostrados nas superfícies.

A observação 7 será utilizada na seção 4.2 no auxílio das demonstrações dos algoritmos de reconstrução de curvas no plano.

Rodriguez propõe uma heurística para esculpimento baseada no tamanho das faces triangulares dos tetraedros medida através do perímetro (Rodriguez et al., 1994). Existem outras medidas, tais como a área e o circunraio. A escolha do perímetro tem vantagens, primeiramente pelo fato de ser computacionalmente mais rápido que o cálculo de outras medidas. Além disso, dependendo da posição dos pontos, a triangulação de Delaunay gera elementos muito irregulares, com isso o circunraio e a área podem não ser boas formas de heuristica, pois, por exemplo, podem existir tanto triângulos grandes com área grande quanto triângulos grandes com áreas próximas de zero que mostra a possível ineficiência desta forma de medida. A heuristica baseada em perímetro é eficiente pois existem grandes chances de triângulos pequenos estarem presentes na superfície do objeto quando a superfície é bem amostrada.

O algoritmo 1 representa a heurística proposta por Rodriguez.

$\mathrm{O}$ autor argumenta que algumas vezes é conveniente multiplicar $v_{m}$ por um fator para evitar buracos na superfície. 


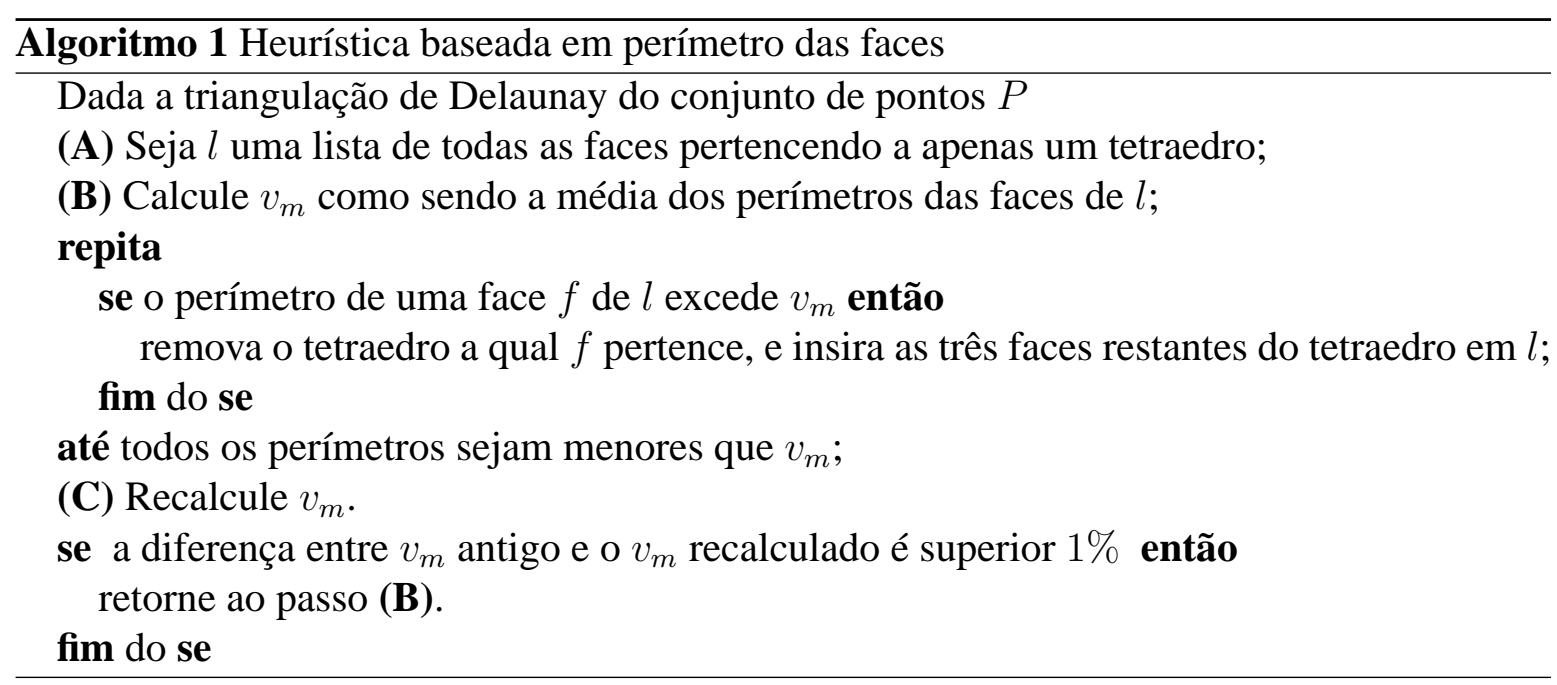

Edelsbrunner e Mücke (Edelsbrunner e Mücke, 1994) apresentam um algoritmo denominado $\alpha$-shape. Dada a triangulação de Delaunay, o parâmetro $\alpha$ controla o nível de detalhes do objeto (a definição formal de $\alpha$-shape entre outras definições relacionadas à técnica estão presentes no trabalho original (Edelsbrunner e Mücke, 1994)).

Uma visão intuitiva de $\alpha$-shape para complexo simplicial é obtida ao imaginar uma esfera com raio $\alpha$ cujo objetivo é "remover" todo o espaço que consegue atravessar, sem tocar nenhum dos pontos da triangulação. O objeto resultante é denominado $\alpha$-shape.

Dois extremos são o 0-shape, que se reduz à coleção de pontos original, e o $\infty$-shape, que coincide com a triangulação de Delaunay do conjunto de pontos.

Dado um complexo simplicial, existe um número finito de $\alpha$-shapes (Edelsbrunner e Mücke, 1994). $\alpha$-shape é adequado para pontos bem distribuídos, mas é freqüentemente problemático para a reconstrução de superfícies, porque o usuário deve definir o parâmetro $\alpha$ que é utilizado para todo o conjunto. É mais interessante utilizar vários valores de $\alpha$ para regiões específicas do domínio, no entanto, isso torna o processo ainda menos automático.

Em 1997, Bernardini e Bajaj apresentaram métodos práticos, para 1-variedades em $\mathbb{R}^{2}$, para selecionar automaticamente valores de $\alpha$ de forma que a reconstrução seja homeomorfa à curva original (Bernardini e Bajaj, 1997). No entanto este trabalho não foi extendido para $\mathbb{R}^{3}$. No capítulo 6 , na figura 6.8 apresentamos exemplos de $\alpha$-shapes para diferentes valores de $\alpha$.

Teichmann e Capps apresentam generalizações do $\alpha$-shape, denominado $\alpha$-shapes com densidade e anisotropia escalável (Teichmann e Capps, 1998). Este trabalho vem principalmente para contornar a deficiência do $\alpha$-shape de apresentar bons resultados apenas para 
amostragens regularmente espaçadas. Os autores propõem duas extensões para contornar as limitações sobre as amostragens para o $\alpha$-shapes para permitirem uma reconstrução de nuvens de pontos não regulares:

1. Escala anisotrópica: Permite substituir o teste da esfera por elipsóides que "atravessam" os simplexos ( $\alpha$-elipsóide). As normais estimadas em cada ponto da nuvem de pontos determina o eixo em que as esferas serão achatadas para se tornar o elipsóide do teste. Os autores argumentam que, ao invés de implementar o teste baseado em elipsóides, é mais conveniente realizar um mapeamento dos pontos dos triângulos para um domínio anisotrópico ${ }^{1}$ e realizar o teste do $\alpha$-shape convencional. Na figura 3.2 apresentamos um exemplo bidimensional do mapeamento de um triângulo para um domínio anisotrópico. A figura 3.2-a) o teste convencional do $\alpha$-shape (não remove o triângulo). A figura 3.2-b) a alteração do teste para elipsóide (remove o triângulo). A figura 3.2-c) o mapeamento do triângulo para um domínio anisotrópico e realização do teste tradicional do $\alpha$-shape. Note que os testes em b) e em c) são equivalentes.

2. Mapeamento de densidade: Permite variar o valor de $\alpha$ conforme a densidade (quantidade de pontos) local da superfície.

Os parâmetros da escala anisotrópica e do mapeamento de densidade são definidos pelos usuários.

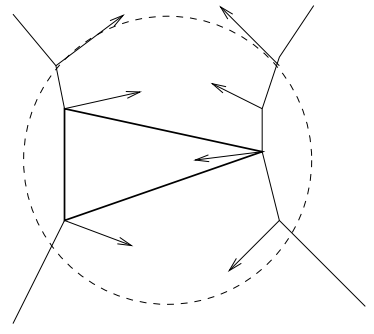

a)

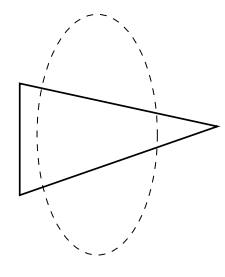

b)

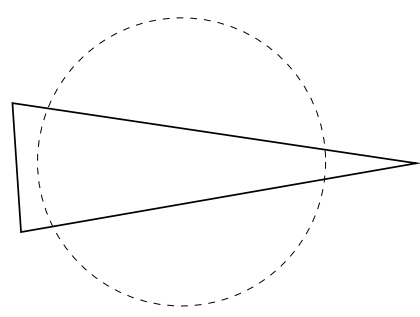

c)

Figura 3.2: Exemplo bidimensional do mapeamento de um triângulo para um domínio anisotrópico.

Attali (Attali, 1998) propôs um método cuja reconstrução é garantida para o caso bidimensional, no entanto a demonstração não pode ser extendida para o caso 3D. Attali apresenta

\footnotetext{
${ }^{1}$ Domínio anisotrópico pode ser visto como um domínio adaptado as características do problema em estudo.
} 
definições de malhas normalizadas, que são subconjuntos das arestas da triangulação de Delaunay e de r-regular shape no qual são estabelecidas as garantias de reconstrução, isto é, para determinados valores de $r$ tem-se a garantia da reconstrução correta de curvas no plano.

As definições e o problema bidimensional são caracterizados da seguinte maneira:

Definição 43 ( $r$-regular shape) Sejam $X \subset \mathbb{R}^{2}$ e $C$ a fronteira de $X . X$ é dito $r$-regular shape se o círculo passando por três pontos de $C$ tem raio maior que $r$.

Definição 44 (Malha normalizada) Malha normalizada é o grafo definido pelos simplexos cujos duais interceptam a curva $C$.

Definição 45 ( $\epsilon$-amostragem) Uma amostragem $P$ da fronteira $C$ de uma $r$-regular shape $e ́$ chamada de $\epsilon$-amostragem se $\forall x \in C, \exists p \in P:\|x-p\| \leq$ r. $\epsilon$.

Seja $\delta(p q)$ o ângulo definido pela interseção dos circuncírculos dos triângulos opostos pela aresta $p q$ (figura 3.3). Sobre certas condições de suavidade, é possível provar que a malha normalizada consiste exatamente de todas as arestas com pequeno valor de $\delta(p q)$. Os autores argumentam em selecionar as arestas com $\delta(p q)<\frac{\pi}{2}$.

O teorema a seguir junta os fatos e definições anteriores para apresentar a garantia de reconstrução:

Teorema 1 Seja $X$ uma $r$-regular shape, com uma amostragem de sua fronteira sendo $\epsilon$ amostragem e $\epsilon<r \cdot \operatorname{sen} \frac{\pi}{8}$. Então a malha normalizada representa a correta reconstrução da curva.

A definição de malha normalizada é extendida para $\mathbb{R}^{3}$, mas o algoritmo não é possível extender de maneira análoga ao bidimensional. O motivo é semelhante ao que ocorre para a generalização do crust 2D para o caso tridimensional (Amenta et al., 1998b) (que apresentamos no capítulo 4). As circunsferas dos tetraedros slivers não são "quase tangentes" à superfície. Um tetraedro sliver é caracterizado por possuir seus vértices próximos ao equador de sua circunsfera (a figura 3.4 apresenta um exemplo de tetraedro sliver). Attali apresenta heurísticas para contornar o problema de tetraedros slivers (Attali, 1998).

Obtida a triangulação de Delaunay de uma amostragem, Attene e Spagnuolo (Attene e Spagnuolo, 2000) propõem uma heurística baseada na árvore geradora mínima euclidiana EMST (definição 31) e no hipergrafo de Gabriel extendido - EGH (definição 33). 


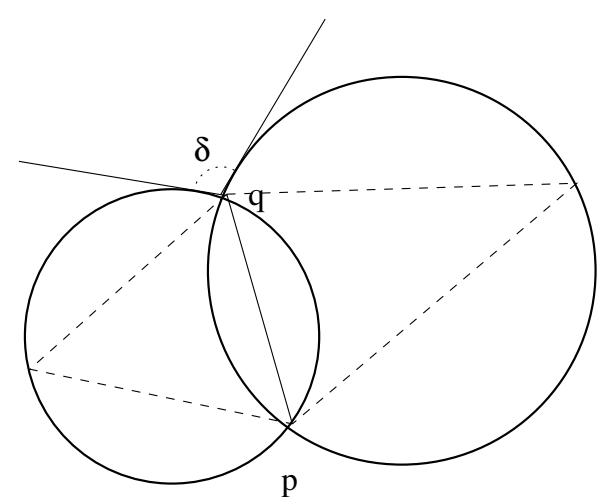

Figura 3.3: Representação do ângulo $\delta$ para malhas normalizadas.

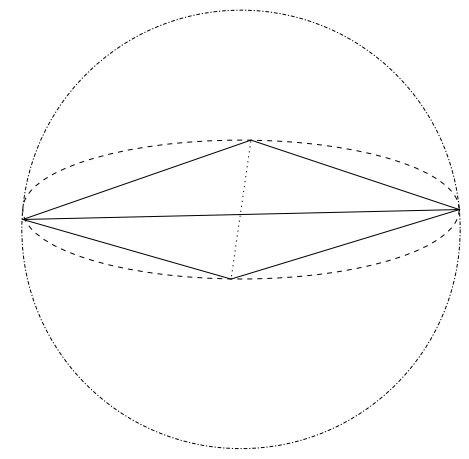

Figura 3.4: Tetraedro sliver.

O $E G H$ e o $E M S T$ são utilizados para localizar, na triangulação de Delaunay, aqueles triângulos que têm maior probabilidade de pertencer à superfície original. As seguintes condições (que chamaremos de condições de singularidade) são utilizadas em conjunto com o $E G H$ e o $E M S T$ no critério de esculpimento proposto por Attene e Spagnuolo.

1. Remover um tetraedro com três triângulos de fronteira desconectará um vértice da fronteira atual. Portanto, remover este tipo de tetraedro não é permitido;

2. Um tetraedro com apenas uma face na fronteira pode ser removido apenas se o vértice oposto à face não está na fronteira (caso contrário gera um ponto singular);

3. Um tetraedro com duas faces na fronteira que compartilham uma aresta em comum pode ser removido apenas se sua aresta oposta não está na fronteira (caso contrário gera uma aresta singular).

$\mathrm{O}$ algoritmo 2 sumariza esta técnica de esculpimento. 


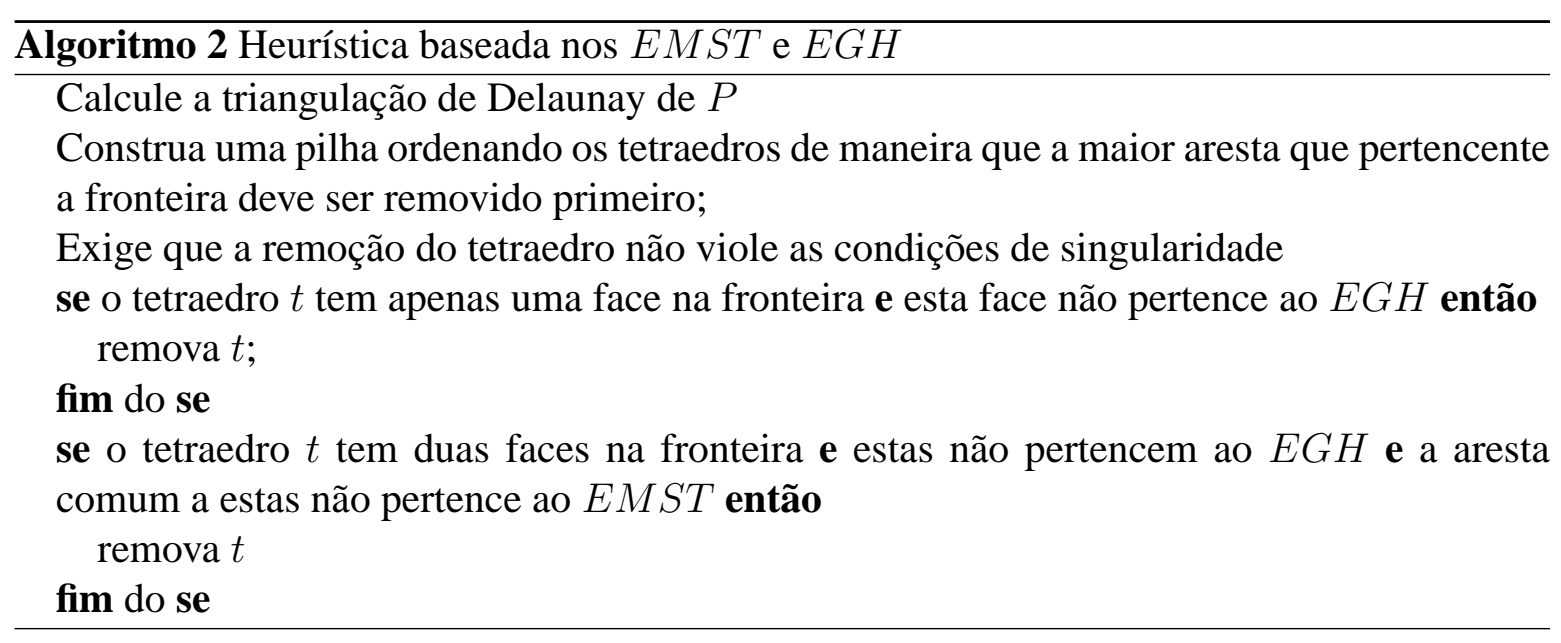

Adamy (Adamy et al., 2002) apresenta um algoritmo de esculpimento baseado no filtro guarda-chuva . Garantias de reconstrução homeomorfa e próxima à superfície original para o caso bidimensional são apresentadas. Para o caso 3D, para garantir reconstruções mais satisfatórias, o autor propõe um pós-processamento baseado em técnicas de programação linear.

As seguintes definições são empregadas no algoritmo proposto por Adamy:

Definição 46 ( $\lambda$-bola) Sejam $\lambda \in(0,1]$ e $\sigma$ um $(n-1)$-simplexo com vértices da amostragem, uma $\lambda$-bola $b_{\lambda}(\sigma)$ é uma bola aberta de dimensão n e diâmetro $\frac{\operatorname{diam}(\sigma)}{\lambda}$ cujos vértices estão em sua fronteira.

Definição 47 ( $\lambda$-intervalo) $O \lambda$-intervalo $I(\sigma)$ associado a um $(n-1)$-simplexo $\sigma$ com pontos da amostragem é:

$$
I(\sigma)=\left\{\lambda \in \mathbb{R} / b_{\lambda}(\sigma) \cap P=\emptyset\right\}
$$

e P é a amostragem.

A figura 3.5 apresenta alguns exemplos de $\lambda$-bola para o simplexo (aresta) definido por $a$ e $b$. O $\lambda$-intervalo da aresta é $I=[0.2,1]$.

Observação 8 Para $(n-1)$-simplexos de Delaunay, seus $\lambda$-intervalos $I(\sigma)$ são subintervalos de [0,1], enquanto que simplexos que não estão na triangulação de Delaunay tem $\lambda$-intervalos vazios. 


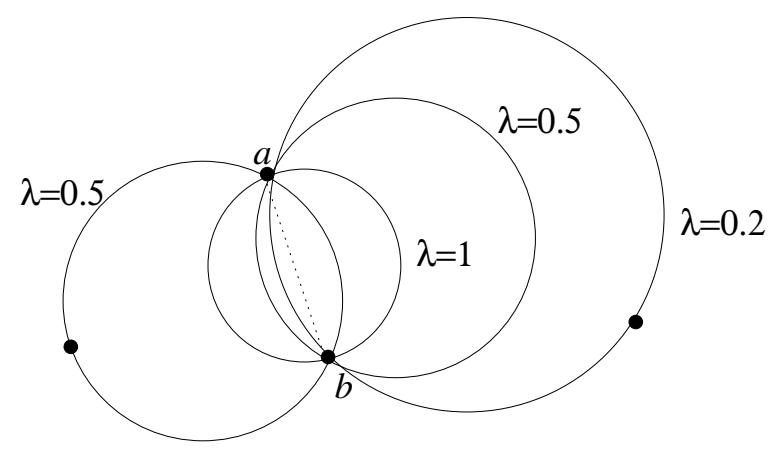

Figura 3.5: Exemplos de valores de $\lambda$ para a aresta definida por $a$ e $b$.

Observação 9 Se os $(n-1)$-simplexos de Delaunay possuem $\lambda$-intervalos degenerados $I(\sigma)=\{1\}$ temos o grafo de Gabriel (caso $2 D$ ) ou o hipergrafo de Gabriel extendido (caso $3 D)$.

Adamy argumenta que este trabalho tenta manter as boas características do $\alpha$-shape (Edelsbrunner e Mücke, 1994) e $\beta$-skeleton (Kirkpatric e Radke, 1985) e evitar as características indesejáveis. A saída deste algoritmo, que é denominada $\lambda$-complexo, não é tão restritiva quanto o $\beta$-skeleton e não é limitada a variações de densidade de amostragens assim como o $\alpha$-shape.

A seguir apresentamos a definição de guarda-chuva:

Definição 48 (Guarda-chuva) A vizinhança de um vértice $v$ de um complexo simplicial de dimensão n é a união dos interiores de todos os simplexos incidentes a v mais o vértice $v$. Se a vizinhança é homeomorfa a uma bola aberta n-dimensional então é dita guarda-chuva.

Para o caso bidimensional, duas arestas que compartilham um vértice $v$ e sem seus outros dois vértices definem um guarda-chuva. Note que esta configuração de arestas é homeomorfa a um intervalo aberto. Isto é, se existem três (ou mais) arestas incidentes a $v$, isto não é homeomorfo a um intervalo aberto e portanto não define um guarda-chuva. Um guardachuva em três dimensões é homeomorfo a uma região aberta $B \subset \mathbb{R}^{2}$. A figura 3.6 apresenta contra-exemplos de guarda-chuvas.

O critério de esculpimento para determinar o $\lambda$-complexo é definido da seguinte maneira:

Para cada ponto escolhe-se um guarda-chuva ótimo a partir do grafo de Gabriel utilizando o seguinte critério de otimização: Escolhe-se o guarda-chuva que minimize os limites inferiores dos $\lambda$-intervalos de todos os seus $(n-1)$-simplexos. Isto é, a idéia do critério de 


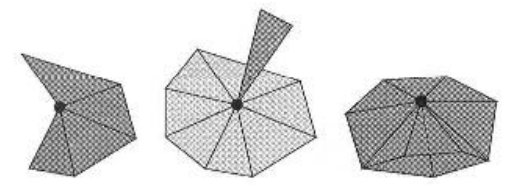

Figura 3.6: Contra-exemplos de guarda-chuva 3D (figura do trabalho de Adamy (Adamy et al., 2002)).

otimização, em duas dimensões, é escolher duas arestas incidentes a um vértice com limites superiores de seu $\lambda$-intervalo iguais a 1 e inferiores os menores possíveis.

Em três dimensões escolhe-se os triângulos incidentes a cada vértice com limite superior $\lambda=1$ e limites inferiores menores possíveis até definirem um guarda-chuva. Descarta-se os triângulos que não fazem parte do guarda-chuva.

Adamy mostra que os $\lambda$-intervalos podem ser eficientemente calculados a partir da triangulação de Delaunay.

Os dois trabalhos seguintes são significativamente diferentes dos demais devido aos conceitos matemáticos utilizados para definição das regras de esculpimento.

Edelsbrunner propôs um algoritmo em que utiliza-se um sofisticado conceito matemático, denominado Teoria de Morse (Edelsbrunner, 2002). Aqui omitiremos a descrição desta teoria e nos focaremos apenas na relação desta teoria e o critério de esculpimento proposto pelo autor. Para maiores informações sobre Teoria de Morse consulte o trabalho de Milnor (Milnor, 1963) .

Em linhas gerais, Edelsbrunner utiliza a Teoria de Morse para definir uma função, denominada função de Morse sobre a triangulação de Delaunay.

Seja $\mu: M \subset \mathbb{R}^{3} \rightarrow \mathbb{R}$, onde $\mu$ é uma função de Morse e $M$ uma 2-variedade. A principal característica de $\mu$ é a relação entre os pontos críticos $\mu$ com a topologia de $M$.

Partindo de $\mu$, Edelsbrunner define um campo gradiente nos simplexos da triangulação de Delaunay e mostra que existe uma relação de ordem acíclica entre os simplexos que determina quais serão removidos.

O autor ainda demonstra que existe uma relação entre o campo gradiente de $\mu$ e os tipos de interceção entre os simplexos e seus duais. Na prática, os testes topológicos originados de $\mu$ são substituídos por testes geométricos. Então baseado nos tipos de interseção entre os simplexos e seus duais, um algoritmo de esculpimento foi proposto. 
Este algoritmo foi implementado em 1996 pela Raindrop Geomagic ${ }^{2}$ (patenteado nos Estados Unidos).

Giesen e John apresentam trabalhos na mesma linha de sofisticação Matemática de Edelsbrunner (Giesen e John, 2002) e (Giesen e John, 2003). O conceito matemático por trás destes trabalhos são os sistemas dinâmicos.

O algoritmo, que descreveremos de maneira sucinta, é construído baseado na observação que o grafo de Gabriel (definição 32) é um conjunto de pontos críticos da função 3.2 que será utilizada no processo de reconstrução e, principalmente, por oferecer boas aproximações para as superfícies.

Primeiramente, define-se uma função distância para o conjunto de pontos $P$ :

$$
h(x)=\min _{p \in P}\|x-p\|
$$

Giesen e John argumentam que esta função não pode ser utilizada como uma função para os métodos baseados em funções implícitas (ver seção 3.3) e pode ser provado que os pontos críticos (figura 3.7) de $h$ são as intersecções entre simplexos da triangulação de Delaunay com seus respectivos duais do diagrama de Voronoi.

A figura 3.8 apresenta um exemplo bidimensional da construção de $h$; os vértices da triangulação são mínimos locais (pois sempre interceptam seus duais); as intersecções marcadas com um quadrado (ם) são máximos locais (vértices de Voronoi localizados no interior de seus triângulos duais) e as arestas de Voronoi marcados com um círculo (•) são pontos de sela.

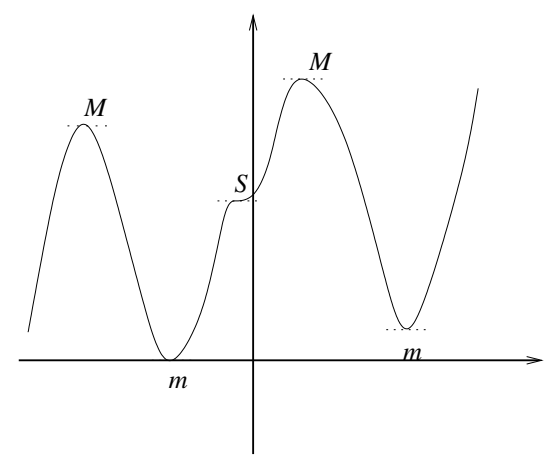

Figura 3.7: Os pontos críticos são os pontos em que a derivada da função se anula. $M$ representa os máximos locais, $m$ os mínimos locais e $S$ o ponto de sela.

\footnotetext{
${ }^{2}$ http://www.geomagic.com/.
} 


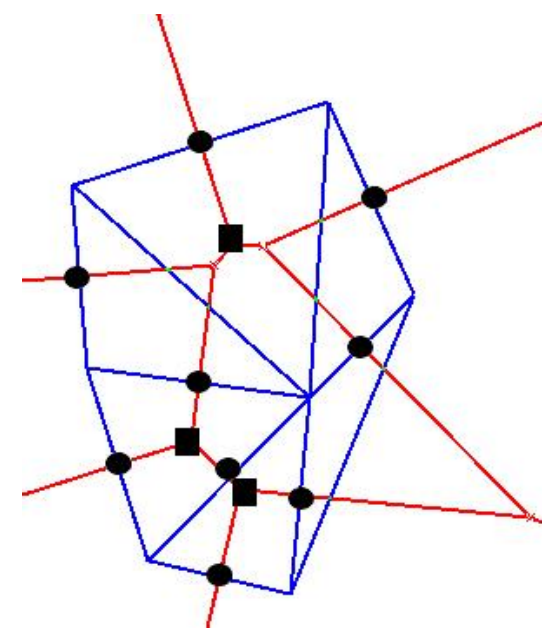

Figura 3.8: Exemplo que caracteriza os pontos críticos definido pela função 3.2.

A partir desta função, então é definido um sistema dinâmico:

Definição 49 (Sistema Dinâmico) Seja $f: \mathbb{R}^{3} \rightarrow \mathbb{R}$ uma função suave e $\nabla$ f o campo gradiente de $f$. A partir desta definição temos a seguinte equação diferencial ordinária:

$$
\frac{d}{d t} \phi(t, x)=\nabla f(\phi(t, x))
$$

Através da teoria de Equações Diferenciais Ordinárias, têm-se o seguinte mapa $\phi: \mathbb{R} \times$ $\mathbb{R}^{3} \rightarrow \mathbb{R}$ satisfazendo as propriedades:

1. $\phi(0, x)=x$;

2. $\phi(t, \phi(s, x))=\phi(t+s, x)$.

Podemos interpretar $\phi$ como a posição do ponto $x$ no tempo te denominamos $\phi$ por sistema dinâmico ou fluxo em $\mathbb{R}^{3}$.

Os autores definem um sistema dinâmico através da função $h$ definida em 3.2 impondo condições para $h$ se tornar suave (note que $h$ é apenas suave no interior das células de Voronoi).

Denomina-se por pontos fixos os pontos $x$ tal que $\phi(t, x)=x \forall t \in \mathbb{R}$. Podemos notar que os pontos fixos de $\phi$ são os pontos críticos de $h$. 
Após estas tarefas, os autores definem a órbita $\phi_{x}$ de cada ponto $x$ que descreve o movimento de $x$ ao longo do tempo e variedades estáveis como sendo, para cada ponto crítico $x$ de $h$, o conjunto de todos os pontos cujas órbitas terminam em $x$.

Definida esta teoria, os autores utilizam um subconjunto de variedades estáveis para definir o complexo de fluxo que é a reconstrução da superfície.

Uma etapa de pós-processamento, denominada complexo de fluxo reduzido também é proposta para melhorar a reconstrução através da eliminação de alguns simplexos.

\subsection{Métodos baseados em função implícita}

Estes métodos, também conhecidos como métodos baseados em conjunto zero de função, consistem em utilizar a amostragem para definir uma função distância com sinal $f$ e calcular o conjunto zero de $f$, que denotamos por $Z(f)$. A superfície é estimada através de uma superfície de nível de $f$.

Os pontos em $Z(f)$ devem ser, por hipótese, regulares (observação 3) ou o processo de reconstrução pode não gerar a superfície original do objeto.

O algoritmo descrito por Hoppe (Hoppe et al., 1992) é executado em dois estágios:

O primeiro consiste em definir uma função $f: D \subset \mathbb{R}^{3} \rightarrow \mathbb{R}$ em que $f$ estima uma distância com sinal para a superfície $S$ procurada. O conjunto $Z(f)$ é a estimativa para $S$. A segunda fase consiste em aproximar $Z(f)$ por um complexo simplicial.

A função distância definida por Hoppe é dada por $f(p)=\operatorname{dist}_{i}(p)=\left(p-o_{i}\right) \cdot \hat{n}_{i}$ sendo $o_{i}$ o centro (centróide) de uma região plana e $\hat{n}_{i}$ a normal unitária desta região. O centro do plano $o_{i}$ é definido pelos $k$ pontos mais próximos de $x_{i}$ ( $x_{i}$ pertence a nuvem de pontos), denotado por $V\left(x_{i}\right)$. O cálculo do vetor normal é feito pela matriz de covariância simétrica e semi-definida positiva definida por:

$$
\text { Cov }=\sum_{y \in V\left(x_{i}\right)}\left(y-o_{i}\right)^{t}\left(y-o_{i}\right)
$$

Pelo fato da matriz ser simétrica e semi-definida positiva (Isaacson e Keller, 1966), tem-se três autovalores reais e maiores ou iguais a zero, sejam eles $\lambda_{1} \leq \lambda_{2} \leq \lambda_{3}$. Então escolhe-se $\hat{n}$ como o autovetor associado a $\lambda_{3} ; v_{3}$ ou $-v_{3}$, de modo a manter os planos orientados. 
Para obter a isosuperfície, Hoppe utiliza uma variação do algoritmo Marching Cubes em que cada cubóide é decomposto em tetraedros (Hoppe et al., 1992).

Boissonnat e Cazals utilizam vizinhanças naturais e superfícies $r$-amostradas (definição 42) para provar garantias de reconstrução homeomorfa e próxima a superfície original (Boissonnat e Cazals, 2002).

Dado um conjunto de pontos $P \subset \mathbb{R}^{3}$, os vizinhos naturais $N_{x, P}$ de um ponto $x \in \mathbb{R}^{3}$ são dados pelo conjunto 3.5 :

$$
N_{x, P}=\left\{p \in P: V(x) \cap V_{p} \neq \emptyset\right\}
$$

Onde $V(x)$ é a célula de Voronoi de $x$ em $V_{P \cup\{x\}^{3}}$ e $V_{p}$ é a célula de Voronoi de $p$ de $V_{P}{ }^{4}$. Seja $A(x, p)$ o volume tomado por $x$ de $V_{p}$, definido por:

$$
A(x, p)=V(x) \cap V_{p}
$$

A coordenada natural associada ao ponto $p$ é a função contínua $\lambda_{p}: \mathbb{R}^{3} \rightarrow \mathbb{R}$ onde:

$$
\lambda_{p}(x)=\frac{A(x, p)}{\sum_{q \in P} A(x, q)}
$$

Os autores ressaltam algumas propriedades interessantes de $\lambda_{p}$ : Continuamente diferenciável, exceto em $p$ e qualquer $x \in \mathbb{R}^{3}$ é combinação convexa $\left(\sum_{p \in N_{x, P}} \lambda_{p}(x) p=x\right.$, ver equação 2.1) de seus vizinhos naturais. Boissonnat e Cazals assumem ainda que cada ponto $p$ está associado a uma normal unitária $n_{p}$. A função distância com sinal para cada ponto $p$ é definida por:

$$
h_{p}(x)=(p-x) \cdot n_{p}
$$

Uma função global é utilizada interpolando estas funções com as coordenadas naturais:

$$
h(x)=\sum_{p \in P} \lambda_{p}^{1+\delta}(x) h_{p}(x)
$$

\footnotetext{
${ }^{3}$ Diagrama de Voronoi de $P \cup\{x\}$.

${ }^{4}$ Diagrama de Voronoi de $P$.
} 
O termo $\delta$ (pequeno) é adicionado para tornar $h$ continuamente diferenciável para evitar pontos não regulares.

Neste algoritmo, aplica-se $h$ a todos os vértices das arestas de Voronoi. O conjunto de triângulos duais das arestas de Voronoi que possuem sinais diferentes definem a aproximação linear por partes da superfície.

Bajaj (Bajaj et al., 1995) propôs um método ${ }^{5}$ que opera em três fases:

A primeira fase, denominada pré-processamento, consiste em criar uma função distância com sinal, em que o sinal da função vem da classificação dos tetraedros da triangulação de Delaunay (como internos e externos). A classificação dos tetraedros é realizada com auxílio de uma $\alpha$-shape calculada sobre a amostragem (o ponto está fora se estiver contido em um tetraedro externo ou o ponto está dentro se estiver localizado no interior de um tetraedro interno). A distância da função é obtida com auxílio do diagrama de Voronoi.

$\mathrm{Na}$ aproximação, como é designada a segunda fase, o espaço é subdividido em tetraedros que contém porções do domínio. Os tetraedros são refinados até satisfazer condições de erro estabelecida pelo usuário. Nesta fase, garante-se uma aproximação de classe $C^{0}$.

A fase final, denominada suavização, consiste em suavizar a superfície obtida nas fases anteriores para uma superfície de classe $C^{1}$.

\subsection{Métodos incrementais}

O princípio dos métodos incrementais é: Dada uma aresta inicial (ou um conjunto de arestas iniciais), que denominamos por fronteira de avanço, construída pela conexão de dois pontos da nuvem e seguindo de maneira iterativa, obtém-se as demais arestas definindo uma superfície. A questão é definir as arestas iniciais do processo de reconstrução. Entre as possibilidades, tem-se a árvore geradora mínima euclidiana (definição 31) como um conjunto de arestas iniciais (Mencl e Müller, 1998). Os métodos incrementais também são conhecidos como métodos de avanço de fronteira.

Uma etapa de pré-processamento necessária nos métodos incrementais é o armazenamento dos pontos em alguma estrutura de dados espacial ( $k d$-tree, quad-tree ou grade volumétrica (Samet, 1990)) pois dada uma aresta da fronteira de avanço $e_{f}$, o algoritmo deve ser

\footnotetext{
${ }^{5}$ No trabalho, além do ajuste da superfície, é feita uma interpolação de dados escalares definidos sobre os vértices da malha.
} 
capaz de encontrar de maneira eficiente o conjunto de pontos candidatos a definir um novo triângulo com $e_{f}$. Testes de interseção também são freqüentes nestes métodos.

Bernardini (Bernardini et al., 1999) apresenta um algoritmo incremental denominado Ball-Pivotting Algorithm (BPA). Este método é conceitualmente simples. Consideremos uma 2-variedade em $\mathbb{R}^{3}$ e uma amostragem suficientemente densa desta variedade. Seja uma bola de raio $\rho$ que não atravesse a variedade sem tocar em pontos da amostragem.

O processo se inicia "colocando" esta bola de raio $\rho$ em contato com três pontos da amostragem (triângulo inicial). Mantendo a bola em contato com dois destes pontos, pivotea a bola até tocar um outro ponto. O pivotamento se dá ao redor de cada aresta da fronteira atual e a cada triplas de pontos tocadas pela bola pivoteada, define um novo triângulo.

A saída deste algoritmo é um subconjunto de $\alpha$-shape (Edelsbrunner e Mücke, 1994) e o autor argumenta que algumas das propriedades do $\alpha$-shape também são garantidas para o BPA.

Entre as principais vantagens apresentadas para este algoritmo é que sua saída é um subconjunto da triangulação de Delaunay obtida sem a necessidade do cálculo da triangulação, uma vez que este é um processo custoso.

Gopi apresenta um algoritmo denominado Triangulação de Delaunay Localizada (Gopi et al., 2000). Este nome é dado a este algoritmo pelo fato do cálculo local de triangulações de Delaunay 2D. São apresentados provas baseadas nas curvaturas da superfície e na distribuição dos pontos em que se garante a reconstrução homeomorfa e próxima a superfície original. $\mathrm{O}$ algoritmo suporta tanto reconstrução de variedades com ou sem bordo.

Quatro passos principais definem este algoritmo:

- Cálculo da normal: O primeiro passo neste algoritmo é calcular a normal de todas as amostras. Este passo também orienta consistentemente as normais das amostras para obter-se uma variedade orientada. O cálculo da normal é semelhante ao proposto por Hoppe (Hoppe et al., 1992) (capítulo 3, seção 3.3);

- Seleção dos pontos candidatos: Neste passo escolhe-se os pontos que podem ser os possíveis vizinhos a um vértice na triangulação final. Então calcula-se os pontos do conjunto $P_{p}$ vizinhos para cada ponto $p$.

- Cálculo da triangulação de Delaunay em Vizinhanças: Cada ponto em $P_{p}$ é projetado para o plano tangente de $p$ e este conjunto de pontos projetados é denotado por $P_{p}^{T}$. 
Então calcula-se a triangulação de Delaunay 2D local dos pontos de $P_{p}^{T}$ ao redor de $p$ em seu plano tangente. Este cálculo é repetido para todos os pontos $p$. O autor apresenta alternativas para evitar inconsistências na representação da superfície.

Petitjean e Boyer (Petitjean e Boyer, 2001) apresentam um método incremental no caso bi e tridimensional para pontos regulares e como um intermédio entre incremental e esculpimento, no caso tridimensional para pontos não regulares.

Em contraposição às garantias de reconstrução propostas por Amenta (Amenta et al., 1998b; Amenta et al., 2001b) que requerem os pontos e a variedade original, as garantias de reconstrução sugeridas por Petitjean e Boyer são baseadas apenas nas amostragens. Os autores argumentam que isto se dá pelo fato de que conexões de pontos adjacentes depende muito mais das propriedades locais da superfície reconstruída do que da forma original (Petitjean e Boyer, 2001).

Alicerçado nesta observação, são apresentados métodos de reconstrução a partir de pontos regulares para os espaços bi e tridimensionais. Quando o conjunto de pontos não é regular, combina-se heurísticas de esculpimento ao método incremental para obter a reconstrução e as garantias não são mais asseguradas.

A idéia por trás deste método é manter os simplexos que pertencem ao grafo de Gabriel (caso 2D) e ao hipergrafo de Gabriel extendido (caso 3D) para pontos regulares. Quando os pontos não são regulares, o autor propõe heurísticas para remover um conjunto de triângulos do $E G H$ que possivelmente não são os triângulos que representam a superfície.

Huang e Meng (Huang e Menq, 2002) propõem um algoritmo que não busca uma malha que seja um subconjunto da triangulação de Delaunay. Um dos principais diferenciais deste trabalho está na etapa de pós-processamento em que o autor relaciona conceitos de Geometria Diferencial para definir e estimar tanto a curvatura de arestas e a curvatura da nuvem de pontos que é estimativa da curvatura da superfície original.

A figura 3.9 ilustra a estimativa da curvatura da superfície (a estimativa é obtida a partir da definição de uma estrutura de vizinhança) (Huang e Menq, 2002) para um ponto em uma direção e curvatura para uma aresta (obtida através do ângulo definido entre as duas faces triangulares que compartilham a aresta). Em 3.9-a) tem-se a configuração original da malha. Em 3.9-b) tem-se as estimativas da curvatura da aresta $e$, representada pela curva $c$ e da superfície, representada pela curva $d$. Em 3.9-c) a malha é reestruturada localmente para que as curvaturas fiquem próximas. 


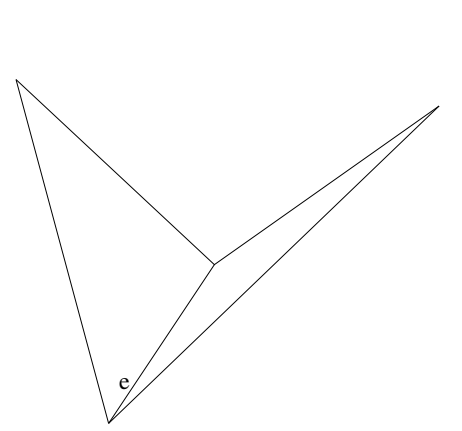

a)

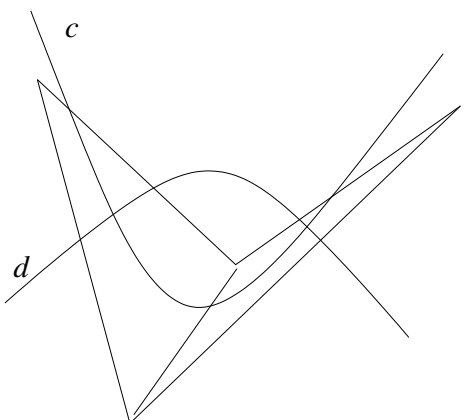

b)

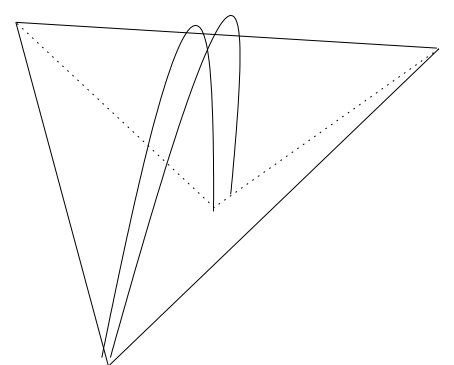

c)

Figura 3.9: Descrição do processo de estimativa das curvaturas da superfície e da malha proposta por Huang e Menq.

Mederos apresenta um trabalho em que é proposto uma redução das nuvens de pontos para em seguida realizar a reconstrução da superfície (Mederos et al., 2003).

Os principais passos deste algoritmo são:

1. Clusterização: Primeiro divide-se a nuvem de pontos em conjunto de clusters $^{6}$. O ponto principal desta etapa é que a variação da curvatura da superfície em cada cluster é pequena;

2. Redução: Encontra-se o ponto representativo para cada cluster. O conjunto de pontos representativos serão utilizados no algoritmo de reconstrução.

3. Triangulação: Aplica-se um método incremental para triangulação dos pontos representantes baseado no grafo dos vizinho mais próximo (definição 30).

Mederos tembém propõe um refinamento que melhor adapte a geometria do modelo (Mederos et al., 2003).

\footnotetext{
${ }^{6}$ Cluster são agrupamentos de pontos, nesse caso, que tem alguma semelhança entre si.
} 


\subsection{Métodos baseados em modelos deformáveis}

Nestes métodos de reconstrução, a partir de uma superfície inicial, aplicam-se deformações gerando uma aproximação para à nuvem de pontos. Estes métodos são rápidos e apresentam resultados satisfatórios se a superfície inicial não estiver muito distante da forma original.

Existem basicamente dois subconjuntos de métodos baseados em modelos deformáveis: O primeiro é baseado em Equações Diferenciais Parciais (E.D.P.'s) para deformação dos modelos iniciais (Zhao et al., 2000). No entanto estes trabalhos necessitam de discretizações das E.D.P.'s e resolução de grandes sistemas lineares. Já o segundo subconjunto de métodos é baseado em funções paramétricas (Bardinet et al., 1998).

Dada uma função paramétrica inicial, aplicam-se alterações nos parâmetros até atingir um valor satisfatório que melhor enquadre a função a nuvem de pontos. No entanto funções paramétricas são muito limitadas à variação da topologia e superfícies com muitos detalhes.

Bardinet (Bardinet et al., 1998) apresenta um trabalho baseado em superquádricas cuja principal vantagem é o número reduzido de parâmetros necessários para representar o objeto. No entanto, mesmo fornecendo boas aproximações para objetos pouco complexos, esta abordagem é limitada para a representação de superfícies com certo grau de complexidade, necessitando uma segunda fase de processamento, denominada deformação de forma livre FFD (free-form deformation).

A utilização de superquádricas requer algum conhecimento sobre a forma global do objeto. Bardinet argumenta que o trabalho está voltado para nuvens de pontos adquirida a partir de imagens médicas, em particular, do coração. Como exemplo, apresenta reconstruções do ventríloquo esquerdo, utilizando superelipsóides como forma inicial.

O superelipsóide pode ser representado pela função implícita:

$$
\left(\left(\left(\frac{x}{r_{1}}\right)^{2 / \lambda_{2}}+\left(\frac{y}{r_{2}}\right)^{2 / \lambda_{2}}\right)^{\lambda_{2} / \lambda_{1}}+\left(\frac{z}{r_{3}}\right)^{2 / \lambda_{1}}\right)^{\lambda_{1} / 2}=1
$$

Como conseqüência imediata, a equação do superelipsóide permite definir uma função $F: \mathbb{R}^{3} \rightarrow \mathbb{R}$, de maneira que: 
Sendo $p=(x, y, z)$

$$
F(x, y, z)=\left(\left(\left(\frac{x}{r_{1}}\right)^{2 / \lambda_{2}}+\left(\frac{y}{r_{2}}\right)^{2 / \lambda_{2}}\right)^{\lambda_{2} / \lambda_{1}}+\left(\frac{z}{r_{3}}\right)^{2 / \lambda_{1}}\right)^{\lambda_{1} / 2}
$$

Se $F(p)>1 \Rightarrow p$ está fora da superfície;

Se $F(p)=1 \Rightarrow p$ está sobre a superfície;

Se $F(p)<1 \Rightarrow p$ está dentro da superfície.

Isto significa que é possível avaliar se os pontos da nuvem estão próximos a superfície inicial.

No FFD o objeto a ser deformado é mergulhado em uma grade volumétrica ligando-a ao objeto (por um polinômio que define uma função deformação). A grade volumétrica então é deformada por meio de deslocamentos e a deformação é transmitida ao objeto pela função deformação.

Muitas variações de FFD podem ser encontradas na literatura. No entanto, Bardinet utilizou a definição clássica, por assegurar bons resultados e bom desempenho de tempo. $\mathrm{Na}$ FFD clássica utiliza-se polinômios de Bernstein (Isaacson e Keller, 1966) como funções de deformação e uma grade cartesiana volumétrica para definir a grade de controle.

\subsection{Considerações finais}

Apresentamos, neste capítulo, trabalhos recentes de reconstrução de objetos a partir de pontos não organizados, enquadrados em diferentes categorias (esculpimento, incrementais, deformáveis e funções implícitas). Também foram apresentadas as características mais pertinentes de cada um dos trabalhos.

No capítulo seguinte apresentaremos o conjunto de algoritmos que complementam o levantamento bibliográfico. A estes algoritmos denominamos família Crust. As definições e os teoremas pertinentes aos algoritmos desta família complementam o próximo capítulo. 


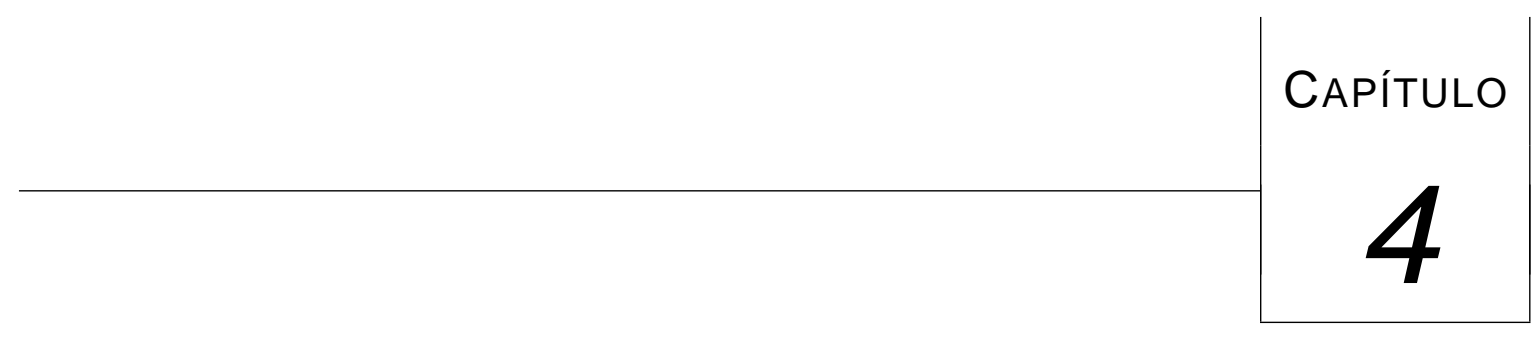

A família Crust

Neste capítulo apresentamos o conjunto de algoritmos desenvolvidos por Nina Amenta e outros autores para a reconstrução de variedades a partir de nuvens de pontos, resultados teóricos que garantem a reconstrução e comparações entre os métodos.

Na seção 4.1 apresentamos o grafo denominado $\beta$-skeleton, com a finalidade de comparação com o crust bidimensional, descrito na seção 4.3. Na seção 4.2 são apresentados resultados para a garantia de reconstrução do $\beta$-skeleton. Estes resultados também são empregados na demonstração do resultado de garantia do crust bidimensional, presente na seção 4.3 .

Posteriormente, será descrita a extensão do crust 2D para a reconstrução de superfícies a partir de nuvens pontos, denominado raw crust (Amenta e Bern, 1999). No entanto, as condições de garantia de reconstrução da forma original da superfície deste algoritmo são fracas, acarretando a necessidade de etapas de pós-processamento para garantir melhores resultados. Com estas etapas de pós-processamento o algoritmo passa a se chamar crust (versão 3D).

Em 2001 foi definido o algoritmo power crust (Amenta et al., 2001a), em que garantias mais fortes são oferecidas para a reconstrução a partir de uma nuvem de pontos. Neste algoritmo, além de obter a reconstrução da superfície, também é obtida uma aproximação linear por partes do eixo medial, denominada por Amenta de power shape.

Outros dois trabalhos complementam esta família: o cocone (Amenta et al., 2002) que otimiza o crust 3D em relação a tempo de execução e o tight cocone (Dey e Goswami, 2002a) 
que é uma etapa de pós-processamento do cocone e é utilizado para contornar os problemas deixados pelo cocone. A saída deste algoritmo é uma superfície water tight (definição 59).

Apresentamos as demonstrações de garantia dos algoritmos bidimensionais e omitimos as demonstrações para o caso tridimensional, apresentando apenas os resultados mais significativos.

\section{1 $\beta$-skeleton}

Em meados dos anos 80, Kirkpatrick e Radke (Kirkpatric e Radke, 1985) definiram um grafo denominado $\beta$-skeleton como uma medida de vizinhança entre pontos. Diversas estruturas de vizinhança têm sido propostas, como a árvore geradora mínima euclidiana, o grafo de Gabriel, o grafo do vizinho mais próximo e a própria triangulação de Delaunay (Stolfi, 1994).

No entanto, todas essas estruturas são fixas para um determinado conjunto de pontos. Assim como as $\alpha$-shapes descritas por Edelsbrunner (Edelsbrunner e Mücke, 1994), o $\beta$ skeleton de um conjunto de pontos varia conforme o valor do parâmetro $\beta$ definido pelo usuário, implicando em diferentes grafos para um mesmo conjunto de pontos.

Os exemplos apresentados por Kirkpatrick não se relacionam à reconstrução de curvas planares a partir de pontos. Amenta (Amenta et al., 1998a), vendo a real possibilidade de utilizar $\beta$-skeleton para a reconstrução de curvas planares, apresenta resultados teóricos que estabelecem a garantia de reconstrução da forma original da curva a partir de um conjunto de pontos planares.

Amenta argumenta que nenhum algoritmo de reconstrução 2D é capaz de reconstruir qualquer curva partindo de qualquer amostragem. Para garantir que a reconstrução da amostragem $P$ tenha a mesma topologia da superfície original, são necessárias algumas condições sobre $P$.

Segundo Nina Amenta, o $\beta$-skeleton permite obter a forma de uma curva $C$ a partir de uma amostragem cuja densidade varia conforme o local feature size (definição 41). As definições a seguir caracterizam o $\beta$-skeleton.

Definição 50 (Regiões Proibidas) Sejam $p_{1}, p_{2} \in P$. A região proibida de $p_{1}$ e $p_{2}$ é a união das duas circunferências de raio $\frac{\beta\left\|p_{2}-p_{1}\right\|}{2}$ tocando $p_{1}$ e $p_{2}$ (figura 4.1). 


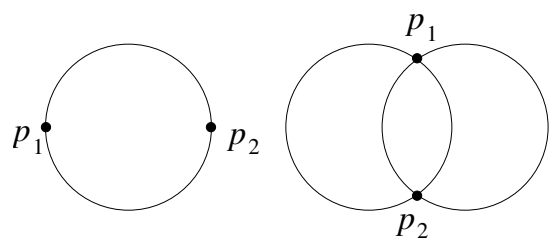

a)

b)

Figura 4.1: Regiões proibidas: a) $\beta=1$, b) $\beta>1$.

Definição 51 ( $\beta$-skeleton) Se a região proibida de $p_{1}$ e $p_{2} \in P$ é vazia de pontos de $P$, então a aresta de extremos $p_{1}$ e $p_{2}$ pertence ao $\beta$-skeleton de $P$.

Veltkamp (Veltkamp, 1992) apresentou o grafo $\gamma$-vizinhança como uma generalização do $\beta$-skeleton que permite que as circunferências das regiões proibidas tenham diferentes raios. Amenta (Amenta et al., 1998a) argumenta que seus resultados podem ser extendidos para o $\gamma$-vizinhança.

Observação $10 O \beta$-skeleton é um subconjunto da triangulação de Delaunay.

O algoritmo 3 determina o $\beta$-skeleton:

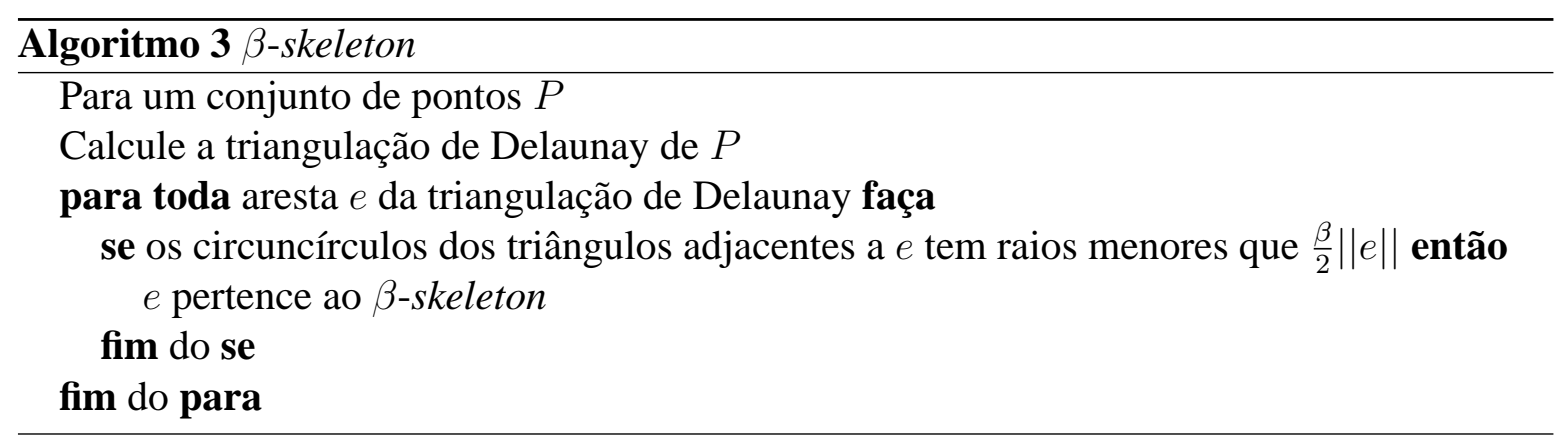

$\mathrm{Na}$ seção seguinte apresentamos os teoremas de reconstrução que serão utilizados para provar as garantias do $\beta$-skeleton e do crust $2 \mathrm{D}$.

\subsection{Garantindo a reconstrução}

Consideremos para demonstrações dos algoritmos bidimensionais apresentados neste capítulo uma curva suave $C$ e um conjunto de pontos $P \subset C$. 


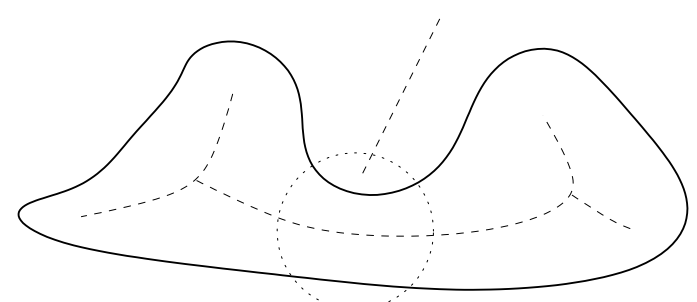

Figura 4.2: Interpretação geométrica do teorema 2. Em linhas contínuas temos a curva $C$, em tracejados, o eixo medial. A circunferência, em pontilhado, representa a interpretação do teorema.

Os seguintes resultados garantem a reconstrução da curva baseada no $\beta$-skeleton e também serão utilizados para demonstrar as garantias do crust 2D (seção 4.3). As demonstrações dos teoremas que apresentamos nesta seção são originais do trabalho de Amenta (Amenta et al., 1998a).

Teorema 2 Qualquer circunferência que contém no mínimo dois pontos de uma curva suave no plano apresenta as seguintes possibilidades de intersecção:

- Intercepta uma curva num segmento de curva ou;

- Contém um ponto do eixo medial ou;

- Ambos.

Interpretação geométrica na figura 4.2.

Teorema 3 Seja $P \subset C$, C uma curva suave em $\mathbb{R}^{2}$. Então qualquer circuncírculo dos triângulos de uma triangulação de Delaunay de P deve conter um ponto do eixo medial de C.

Observação 11 O teorema 3 não permite generalização para $\mathbb{R}^{n}, n>2$.

A observação 11 é interessante pois é um dos principais fatos que não permite generalizar de maneira direta alguns algoritmos bidimensionais em algoritmos tridimensionais para os métodos de esculpimento. 


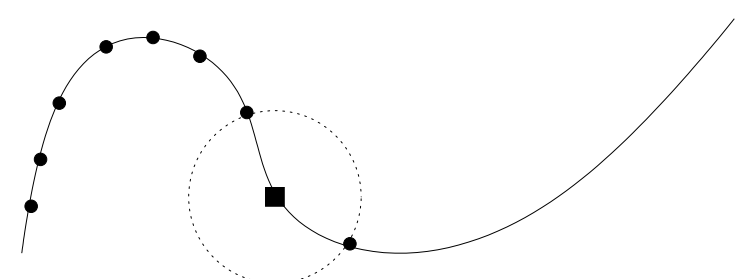

Figura 4.3: O círculo, em pontilhado, representa um disco de Voronoi curvo.

Observação 12 Os circuncírculos dos triângulos da triangulação de Delaunay também são conhecidos como discos de Voronoi. Os vértices das células de Voronoi são os centros dos discos de Voronoi. Cada disco de Voronoi contém três pontos da amostragem em sua fronteira (para pontos em posição geral).

A seguinte definição foi apresentada originalmente por Chew (Chew, 1993), a partir da idéia de poligonalizar uma curva utilizando circunferências vazias centradas na fronteira (ver observação 7, capítulo 3) e será utilizada nas próximas demonstrações.

Definição 52 (Disco de Voronoi Curvo) $O$ disco de Voronoi curvo é o disco máximo, vazio de pontos da amostragem, centrado num ponto da curva. O vértice de Voronoi curvo é o centro do disco de Voronoi curvo (figura 4.3).

A partir da representação na figura 4.4 pode-se extrair as relações trigonométricas presentes na observação 13, que serão utilizadas nos próximos teoremas.

\section{Observação 13 (Relações trigonométricas)}

Consideremos a figura 4.4 com circunferência de raio igual a um. Sejam os pontos ce $d$ sobre a circunferência, o ponto b o centro da circunferência, $x$ o ângulo $\widehat{d b c} e$ a a base da altura do triângulo bcd pela aresta perpendicular a aresta bc. Então temos as seguintes relações:

- $\operatorname{sen}(x)=\|d-a\|$;

- $\|d-c\|=2 \operatorname{sen}(x / 2)$ (note que o triângulo bcd é isósceles, e $m$ é o ponto médio de $\|d-c\|)$;

- $y=x / 2$ (o ângulo $z$ é comum aos triângulos $b c m$ e acd e que os dois triângulos possuem um ângulo reto). 


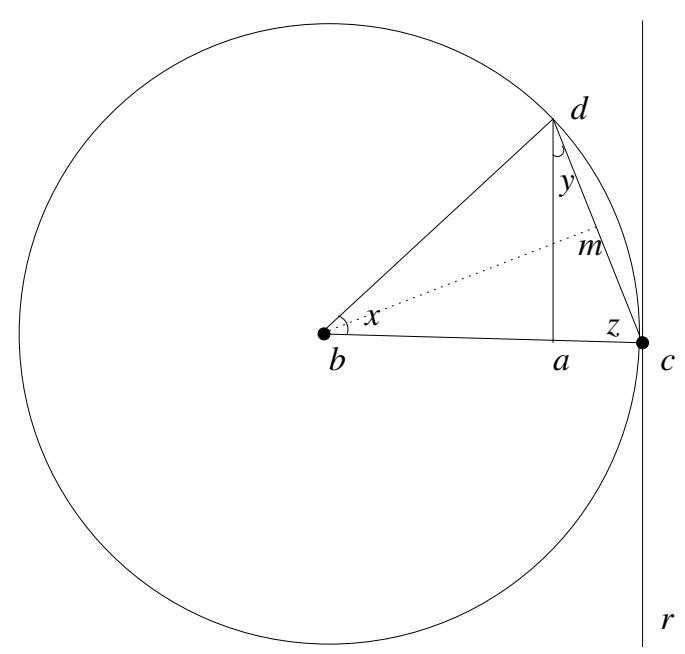

Figura 4.4: Descrição geométrica que caracteriza a observação 13.

Os teoremas 4 e 5 garantem que para uma curva $r$-amostrada, a triangulação de Delaunay contém o subconjunto de arestas que determina a reconstrução da curva.

Teorema 4 Seja C uma curva suave no plano r-amostrada com $r \leq 1$. Existe um disco de Voronoi curvo tocando cada par de pontos adjacentes.

Teorema 5 Seja $P \subset C$, $P$ uma $r$-amostragem de uma curva suave $C$ no plano, com $r<1$. A triangulação de Delaunay de P contém uma aresta entre cada par de pontos adjacentes.

Observação 14 Seja $C \subset \mathbb{R}^{2}, P \subset C$ uma r-amostragem de $C$. A reconstrução pode não ser única se $r \geq 1$.

Para $r$ consideravelmente pequeno, é possível mostrar que existe uma única reconstrução em que o $\beta$-skeleton está enquadrado. Este fato será demonstrado nos próximos teoremas.

O teorema 6 é utilizado como argumento na demonstração do teorema 7.

Teorema 6 Uma circunferência tangente a uma curva suave $C$ em um ponto p com raio no máximo $L S F(p)$ contém nenhum ponto de $C$ em seu interior.

Os teoremas 7 e 8 são utilizados nas demonstrações dos teoremas finais que apresentarão os valores adequados de $r$ e $\beta$ para a obtenção da forma original da curva. 


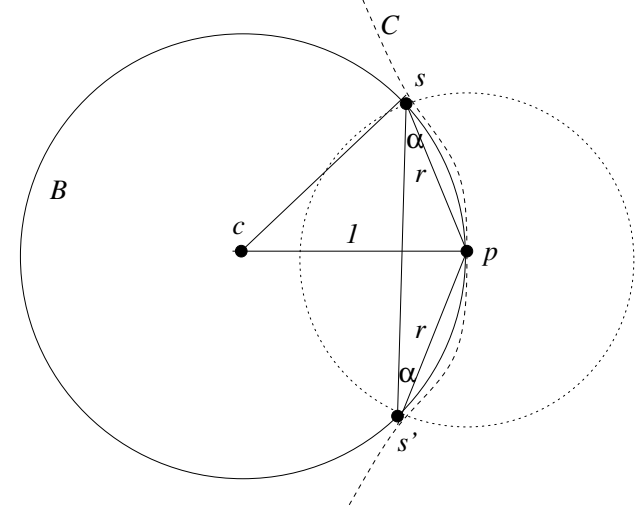

Figura 4.5: Figura utilizada no teorema 7.

Teorema 7 Para uma curva $r$-amostrada no plano, com $r<1$, o ângulo formado no vértice de Voronoi curvo entre dois pontos adjacentes da amostragem é, no mínimo, $\pi-2 \operatorname{arcsen}(r / 2)$ (figura 4.5).

Prova: Consideremos a figura 4.5. Seja $p$ vértice de um disco de Voronoi curvo e uma circunferência $B$, centrada em $c$, cujo raio é $L F S(p)=1$, sem perda de generalidade. Pelo teorema 6, temos que $C$ não intercepta o interior de $B$. Então, o ângulo mais agudo possível é alcançado quando os pontos são adjacentes a fronteira de $B$ a uma distância $r$ de $p$. Temos que $\hat{p}+2 \alpha=\pi \Rightarrow \hat{p}=\pi-2 \alpha \cdot{ }^{1}$ Pela observação 13 , temos que $\alpha=\operatorname{arcsen}(r / 2)$, implicando $p=\pi-2 \operatorname{arcsen}(r / 2)$.

De maneira similar pode ser demonstrado o resultado seguinte:

Teorema 8 Seja C uma curva r-amostrada no plano, $r<1$, o ângulo gerado por três pontos adjacentes, é no mínimo $\pi-4 \operatorname{arcsen}(r / 2)$.

As regiões proibidas das arestas também podem ser definidas em termos dos ângulos entre os dois círculos da região:

Observação 15 Sejam $p_{1}$ e $p_{2} \in \mathbb{R}^{2}, \beta \geq 1$ e $\theta=\operatorname{arcsen}(1 / \beta)$ e as duas circunferências de raios $\left\|p_{2}-p_{1}\right\| \beta / 2$. As tangentes $t_{1}$ e $t_{2}$ em $p_{1}$ e $p_{2}$ definem um ângulo de $2 \theta$ em $p_{1}$ e $p_{2}$ (figura 4.6).

\footnotetext{
${ }^{1} \hat{p}$ é o ângulo no interior de $B$.
} 


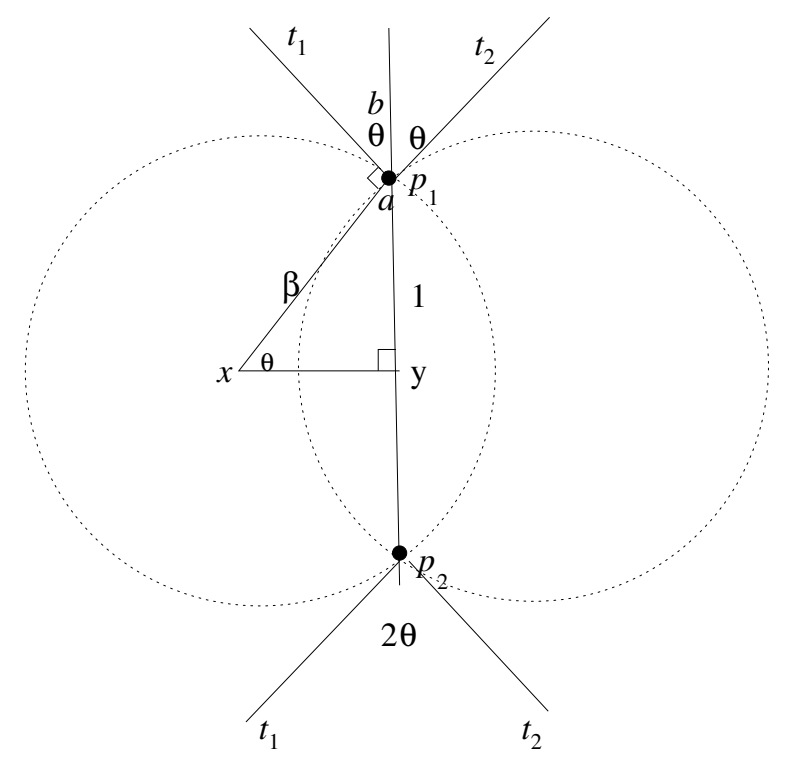

Figura 4.6: Descrição geométrica da observação 15.

De fato: Seja o triângulo $t=x y p_{1}$, o ângulo interno a $t$ em $p_{1}$ e os ângulos $a$ e $b$ como representados na figura 4.6.

Temos as seguintes relações:

- $a+b+\pi / 2=\pi$

- $\theta+\pi / 2+a=\pi$

Subtraindo as duas equações acima, temos que $b=\theta$. Devido à simetria das retas tangentes aos círculos que definem a região proibida, temos a observação 15 satisfeita.

Consideremos a figura 4.7 para a descrição e demonstração do teorema 9:

Teorema 9 Sejam $p_{1}, p_{2}, p_{3}$ pontos sucessivos sobre $C$. Quando $\theta>4 \operatorname{arcsen}(r / 2), p_{3}$ não pertence a região proibida definida pela aresta $p_{1} p_{2}$.

Prova: Pelo teorema 8 temos que o ângulo mínimo que pode ser definido por $\widehat{p_{1} p_{2} p_{3}}$ é $\pi-4 \operatorname{arcsen} r / 2$.

Note que se $\widehat{p_{1} p_{2} p_{3}}$ for maior que $\pi-\theta$, (ver figura 4.7), então $p_{3}$ não pertencerá à região proibida definida por $p_{1}$ e $p_{2}$; logo, $p_{3}$ estará fora da região. 


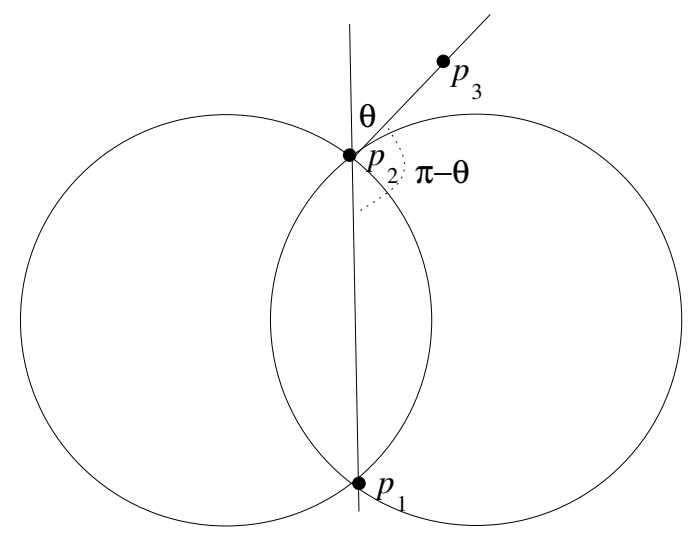

Figura 4.7: Descrição geométrica do teorema 9.

Daí $\widehat{p_{1} p_{2} p_{3}} \geqslant \pi-(\pi-4 \operatorname{arcsen}(r / 2))$, o que conclui a prova.

Os dois teoremas seguintes são utilizados na demonstração dos teorema que garantem a reconstrução do $\beta$-skeleton.

Teorema 10 A região proibida de uma aresta entre dois pontos adjacentes sobre uma curva $C$ r-amostrada não pode conter um ponto do eixo medial, quando $\theta>$ $>\operatorname{arcsen}(2 \operatorname{sen}(2 \operatorname{arcsen}(r / 2)))$.

Teorema $11 O \beta$-skeleton de uma curva suave $C$ r-amostrada não contém arestas entre qualquer par de pontos não adjacentes, quando $\theta<\arccos (2 r)-2 \operatorname{arcsen}(r / 2)$.

Teorema 12 Seja $C$ uma curva suave r-amostrada, com $r<0.297$. $O \beta$-skeleton de $C$ contém exatamente as arestas entres vértices adjacentes, para $\beta=1.70$ (figura 4.8).

Prova: Pelo teorema 11 temos que não existem arestas entre vértices não adjacentes para:

$$
\theta<\arccos (2 r)-2 \operatorname{arcsen}(r / 2)
$$

Sejam $p_{1}$ e $p_{2}$ dois pontos adjacentes e sejam $p_{0}$ e $p_{3}$ adjacentes a $p_{1}$ e $p_{2}$ respectivamente. Pelo teorema 9 , nem $p_{0}$ e $p_{3}$ pertencem às regiões proibidas quando:

$$
\theta>4 \operatorname{arcsen}(r / 2)
$$




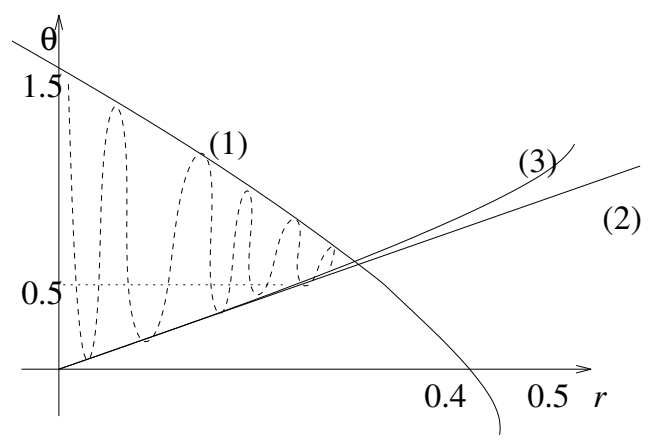

Figura 4.8: A garantia da reconstrução da curva original se dá para valores na região hachurada.

Se existir algum $p_{i}$ pertencente a região proibida, não sendo $p_{0}$ e $p_{3}$, isto implicaria que um dos círculos da região proibida intercepta na curva $C$ em no mínimo duas componentes conexas (uma contendo $p_{1}$ e outra contendo $p_{i}$ ) e portanto pelo teorema 2 , contém um ponto do eixo medial. No entanto, pelo teorema 10 isto não ocorre quando:

$$
\theta>\operatorname{arcsen}(2 \operatorname{sen} 2(\operatorname{arcsen}(r / 2)))
$$

Fazendo a intercessão da região definida pelas inequações, 4.1, 4.2 e 4.3, temos que existe uma escolha adequada para $r<0.297$.

O valor de $\theta$ que permite pontos mais esparsos é obtido quando se maximiza $r$, que equivale a aproximadamente $\theta=0.637$, equivalente a $\beta=1.70$.

\subsection{Crust 2D}

Nesta seção apresentamos definições e teoremas relacionados ao crust bidimensional. Resultados presentes na seção 4.2 serão utilizados nesta seção.

Definição 53 (Crust) Consideremos $P \subset C$ e $V$ os vértice das células do diagrama de Voronoi de P. Seja $P^{\prime}=P \cup V$ e consideremos a triangulação de Delaunay de $P^{\prime}$. Uma aresta de Delaunay pertence ao crust de P se ambos os pontos finais da aresta pertencem a $P$.

O algoritmo 4 apresenta o algoritmo para obter o crust 2D. 


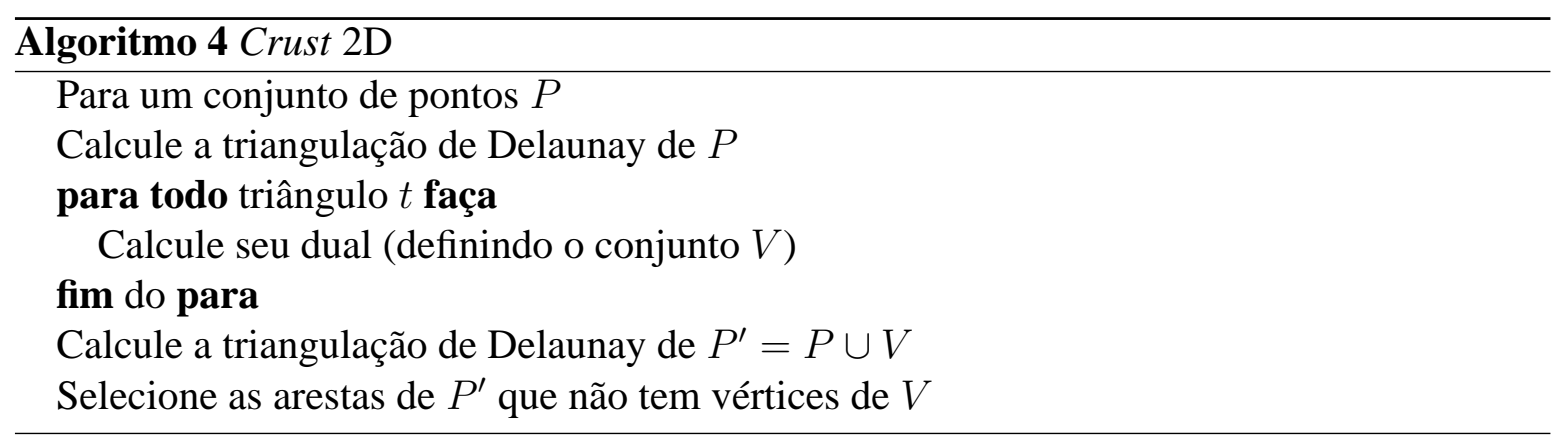

Observação 16 Se uma aresta entre dois pontos de P pertence à triangulação de Delaunay de $P^{\prime}$, então esta pertence à triangulação de Delaunay de $P$, portanto o crust de $P$ está contido na triangulação de Delaunay de P.

Amenta demonstra que, para uma curva $r$-amostrada e para um valor de $r$ suficientemente pequeno, todas as arestas desejadas pertencem ao crust e que as indesejáveis não pertencem. Tais teoremas são enunciados e demonstrados a seguir (Amenta et al., 1998a).

Teorema 13 Dada uma curva suave r-amostrada, com $r<0.40$, o crust contém as arestas entre cada par de amostras adjacentes.

Demonstração: Pela definição, uma aresta pertence ao crust se e somente se existe um círculo tocando os extremos da aresta vazio de outros pontos da amostragem e vértices de Voronoi. Afirmamos que isto é verdade para cada disco de Voronoi curvo sobre uma curva $r$-amostrada, pois um disco de Voronoi curvo toca cada par de vértices adjacentes (teorema 4). Seja $B$ um disco de Voronoi curvo centrado em $p$. Por definição, $B$ não contém pontos da amostragem. Então temos que mostrar que $B$ não contém vértices de Voronoi. Consideremos a figura 4.9. O ponto $v$ é um vértice de Voronoi que assumimos, por contradição, estar no interior de $B$. Assumimos sem perda de generalidade $\operatorname{LF} S(p)=1$. Como $v$ é um vértice de Voronoi, o raio $R$ do círculo de Voronoi $V$ de centro em $v$ é no máximo a distância das amostras induzidas por $p$. Este círculo de Voronoi deve conter um ponto do eixo medial (teorema 3). Por outro lado, a circunferência $B^{\prime}$ de raio $L F S(p)=1$ de centro $p$ não contém pontos do eixo medial, pela definição de Local Feature Size. Tomemos $r$ tal que $V$ esteja contido inteiramente dentro de $B^{\prime}$, definindo a contradição. Qualquer ponto em $V$ está a uma distância no máximo $r+R$ de $p$, e $R$ é maximizado quando $v$ está na fronteira de $B$. Neste caso, $R$ é o comprimento da base de um triângulo isósceles cujas outras arestas têm comprimento $r$. Como a curva é suave em $p$ (teorema 7), o ângulo $\theta$ em $p$ é, no máximo, $0.5(\pi+2 \operatorname{arcsen}(r / 2)$ e $R / 2 \leq r \operatorname{sen}(\theta / 2)$. Juntando as duas condições sobre os ângulos temos que: $r+2 r \operatorname{sen}\left(\frac{\pi+2 \operatorname{arcsen}(r / 2)}{4}\right) \leq 1$. Se 
$r \in[0,1]$, o valor da expressão acima é no máximo $\pi / 2$, e tal expressão é crescente neste intervalo. Então, para $r \leq 0.40$ temos a inequação satisfeita.

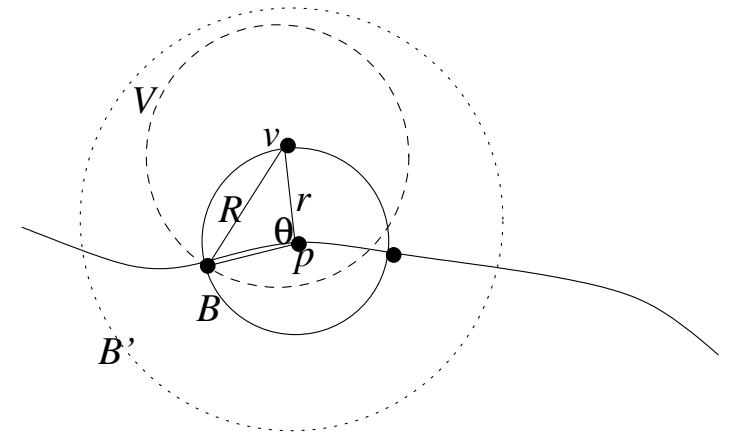

Figura 4.9: Construindo a contradição do teorema 13.

Teorema 14 Dada uma curva suave r-amostrada com $r<0.252$, o crust não contém arestas de pontos não adjacentes.

Demonstração: Consideremos a figura 4.10 para demonstração do teorema. Temos que mostrar que não existem círculos vazios de amostras e vértices de Voronoi tocando quaisquer dois pontos não adjacentes. Assumiremos, por contradição, que existe um círculo $B$ que contém algum ponto em seu interior. Consideremos os dois círculos $V$ e $V^{\prime}$ tocando $s$ e $t$ e centrados em $v$ e $v^{\prime}$ em que $B$ interceptam o bissetor perpendicular de $s$ e $t$. Afirmamos que se $B$ é vazio de vértices de Voronoi, então $V$ e $V^{\prime}$ são vazios de pontos de $P$. Se um deles fosse não vazio, poderia conter um ponto $s^{\prime} \in P$ determinando um círculo mínimo tocando $s, t$ e $s^{\prime}$, vazio de todos outros pontos e, portanto induzindo a ter um vértice de Voronoi dentro de $B$. Consideremos a figura 4.11, que é um zoom da figura 4.10 na região do ponto $s$. $\mathrm{O}$ ângulo $\theta$ entre os círculos tangentes aos círculos $V$ e $V^{\prime}$ em $s$ é igual a $\pi / 2$ (devido aos fatos do semi-círculo inferior de $B$, contendo $s$, ser conjunto dos pontos que formam um ângulo raso com $v$ e $v^{\prime}$ e as tangentes serem perpendiculares a $v s$ e $v^{\prime} s$. O ângulo $\widehat{s_{1} s s_{2}}$ é, no mínimo, $\pi-4 \operatorname{arcsen}(r / 2)$ (teorema 8). Sem perda de generalidade, seja $V$ o círculo tal que o ângulo $\theta$ entre a tangente de $V$ e $s$ e a corda $\left(s, s_{1}\right)$ ou $\left(s, s_{2}\right)$ é maior que o ângulo correspondente do outro lado. Então:

$$
\theta \geq 1 / 2(\pi-4 \operatorname{arcsen}(r / 2)-\pi / 2)=\pi / 4-2 \operatorname{arcsen}(r / 2)
$$

Se assumirmos, sem perda de generalidade, que o raio de $V$ é um, o limite de $\theta$, então pela observação 13: 


$$
\left\|s-s_{2}\right\| \geq 2 \operatorname{sen}(\pi / 4-2 \operatorname{arcsen}(r / 2))
$$

Existe um disco de Voronoi curvo $p$ entre $s$ e $s_{2}$, (teorema 4) e portanto como a curva é $r$-amostrada. Substituindo a equação 4.5 na definição de Local Feature Size temos:

$$
\operatorname{sen}(\pi / 4-2 \operatorname{arcsen}(r / 2)) \leq r . L F S(p)
$$

Agora temos um limite superior para $\operatorname{LFS}(p)$, de modo que é estabelecida a contradição. Os pontos $s$ e $t$ pertencem a duas diferentes componentes conexas da intersecção $C \cap V$, portanto $V$ contém um ponto do eixo medial (teorema 2 ).

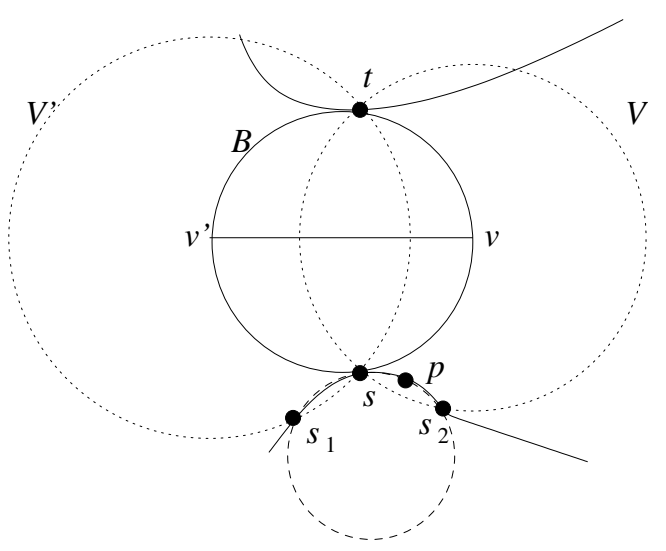

Figura 4.10: Representação geométrica da contradição do teorema 14.

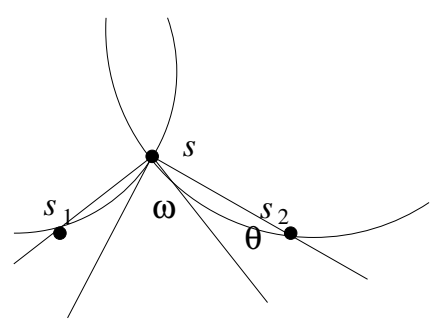

Figura 4.11: Nota-se que o ângulo $\theta$ é maior que seu correspondente ângulo do outro lado.

O ponto $p$ está no interior de $V$, com raio um, então $\operatorname{LFS}(p) \leq 2$. Portanto:

$$
\operatorname{sen}(\pi / 4-2 \operatorname{arcsen}(r / 2)) \leq 2 r
$$

A equação 4.7 é crescente para $r \in[0,1]$. Escolhendo $0 \leq r \leq 0.252$ temos a desigualdade violada, implicando numa contradição. 


\subsection{Comparações entre o crust e o $\beta$-skeleton}

Como análise dos métodos de reconstrução de curvas planares apresentados temos as seguintes considerações, na qual a curva suave é $r$-amostrada:

- A triangulação de Delaunay contém as arestas que definem a reconstrução de uma curva suave para $r \leq 1$;

- Para $r \leq 0.40$ o crust contém a reconstrução da curva suave;

- Para $r \leq 0.279$ o $\beta$-skeleton é a reconstrução da curva suave;

- Para $r<0.252$ o crust é a reconstrução da curva suave.

Conforme os itens acima podemos concluir que o $\beta$-skeleton tem uma garantia melhor de reconstrução em relação ao crust. No entanto, pelos exemplos obtidos, notamos que o crust tende a adicionar arestas que podem ser úteis para a reconstrução (figuras 6.3 à 6.7).

O problema principal desta discussão é se existe a possibilidade de generalização destes algoritmos para o espaço Euclidiano tridimensional. O crust foi extendido para $\mathbb{R}^{3}$, no entanto no caso do $\beta$-skeleton, não se conhece trabalhos descrevendo a tentativa de implementação para $\mathbb{R}^{3}$. O trabalho de Adamy (Adamy et al., 2002), apresentado no capítulo 3, seção 3.2, utiliza um conceito em que a idéia do $\beta$-skeleton está embutida.

\subsection{Crust 3D}

Como extensão do algoritmo crust 2D para o espaço tridimensional, foram apresentados dois trabalhos que se complementam. Um apresenta resultados teóricos garantindo a reconstrução (Amenta e Bern, 1999) e no segundo é discutida a complexidade do algoritmo, sua eficiência e aspectos de implementação (Amenta et al., 1998b). Este algoritmo é denominado raw crust.

O raw crust apresenta garantias de reconstrução da forma original da superfície. No entanto, são garantias fracas, acarretando a necessidade de amostragens muito densas. Para 
contornar este problema, etapas de pós-processamento são propostas para obtenção de melhores resultados. Adicionando estas etapas, o algoritmo passa a ser denominado de crust (em sua versão $3 \mathrm{D})^{2}$.

A generalização do algoritmo não é direta para a reconstrução de uma superfície suave imersa em $\mathbb{R}^{3}$. Pode ser notado que o vértice de Voronoi (centro da circunsfera) de um tetraedro sliver pode estar arbitrariamente próximo à superfície. Com isto, este vértice de Voronoi poderia acarretar na inexistência de um tetraedro que conteria uma face da reconstrução.

Para solucionar este problema, a saída foi considerar os pólos:

Definição 54 (Pólos) Seja $S$ uma superfície suave, p um ponto de $P \subset S$ e $V_{p}$ sua célula de Voronoi. Definimos como pólos os dois vértices de $V_{p}$ mais distantes de p, porém um interior e outro exterior a $S$.

Definição 55 (Crust - versão 3D) Seja o conjunto de pontos $P \subset \mathbb{R}^{3}$ e $V_{p}$ os vértices de Voronoi dos pontos de P que são pólos. Define-se por crust de P os triângulos da triangulação de Delaunay de $P \cup V_{p}$, onde todos os vértices pertencem a $P$.

O algoritmo para obtenção do raw crust é em linhas gerais:

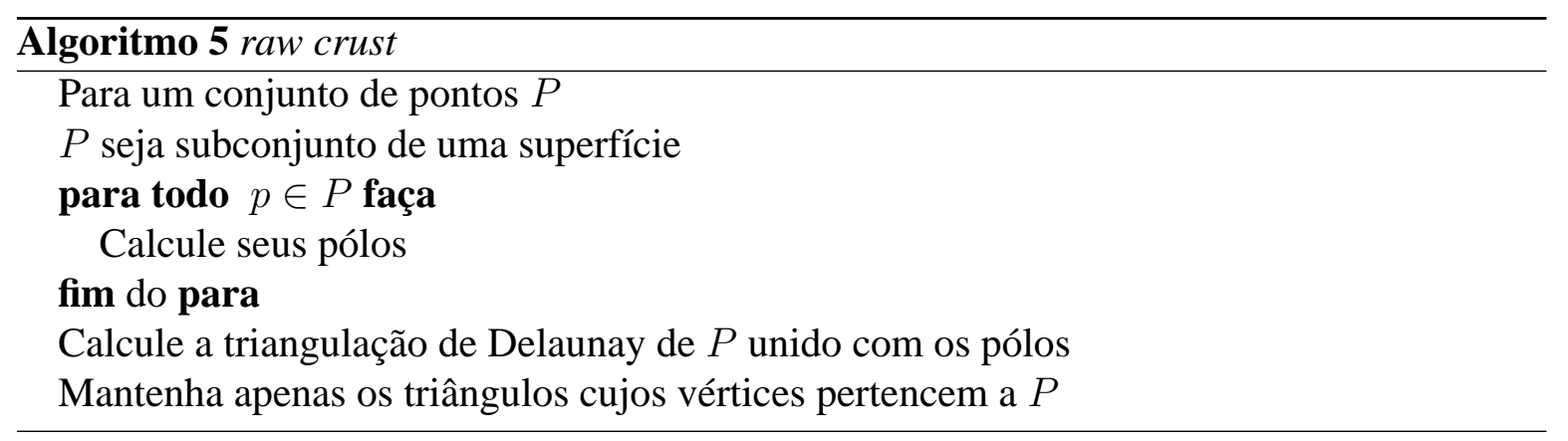

O algoritmo original proposto por Amenta para detecção dos pólos, para o algoritmo 5, é dado pelo algoritmo 6 .

Na prática não utilizamos o algoritmo 6 para a detecção dos pólos. Nós adicionamos o conjunto de pontos num bounding box e tratamos tanto pontos do fecho convexo quanto do interior ao fecho convexo de maneira similar. Esta estratégia do bounding box aplicada ao algoritmo de detecção dos pólos também é utilizado no algoritmo power crust, que apresentamos na seção 4.6. A seguir apresentamos o teorema de garantia do raw crust:

\footnotetext{
${ }^{2}$ Podemos observar que a definição formal de crust coincide com o algoritmo proposto por Amenta, denominado raw crust e que quando se fala no algoritmo crust este possui etapas de pós-processamento.
} 


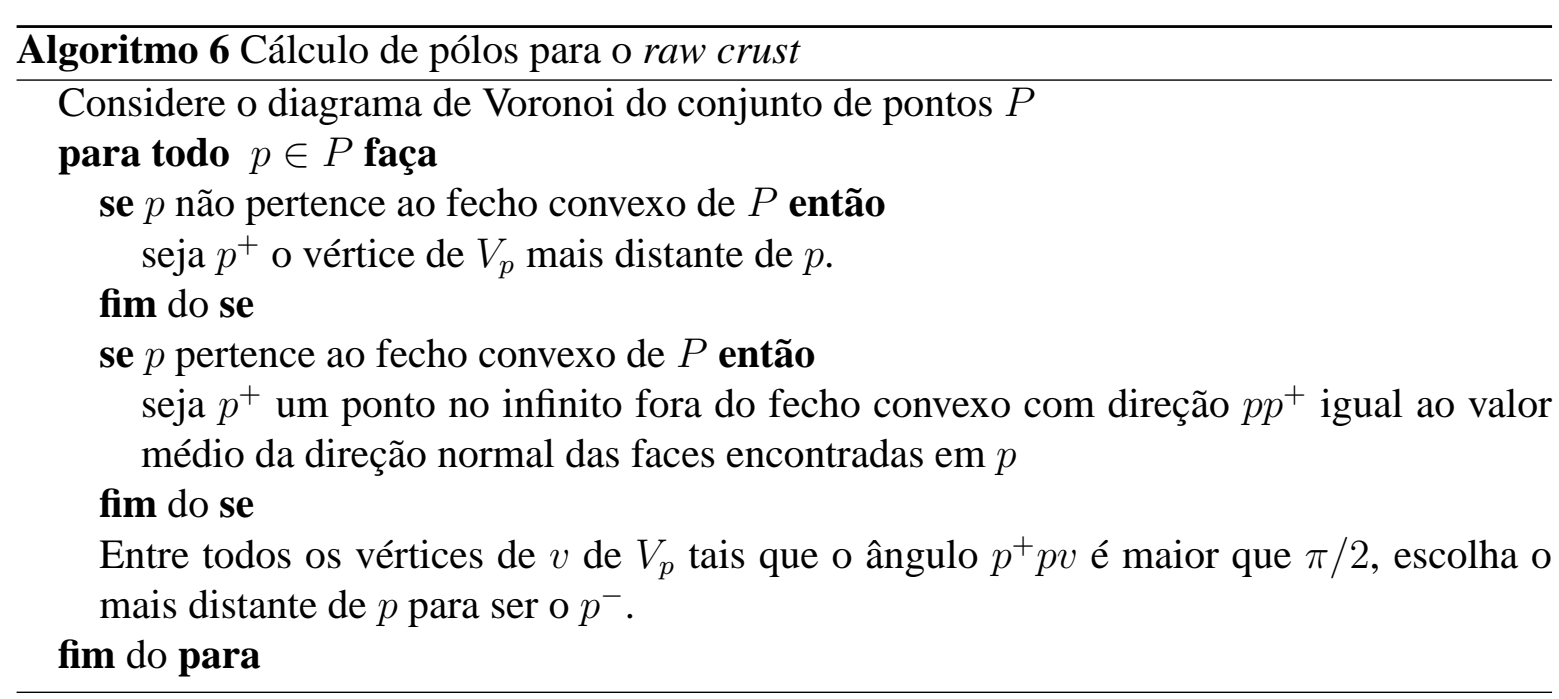

Teorema 15 (Garantia do raw crust (Amenta et al., 1998b)) Seja P um conjunto de pontos de uma superfície suave r-amostrada S. Se $r<0.06$ então:

1. O raw crust de P contém um conjunto de triângulos topologicamente equivalente a $S$.

2. Cada ponto do raw crust tem distância $5 r L F S(p)$ a algum ponto $p$ de $S$.

Notamos que a garantia do raw crust é fraca $(r<0.06)$. Isto implica na necessidade de uma amostragem de pontos extremamente densa para a convergência do processo. Duas etapas de pós-processamento foram propostas (Amenta et al., 1998b) para tornar a reconstrução mais eficiente:

- Filtering by Normal: Remove os triângulos tal que o ângulo entre sua normal e o vetor definido pelo pólo mais distante e um vértice do triângulo formam um ângulo muito grande (os autores argumentam sobre um ângulo próximo de $\frac{\pi}{2}$, diminuindo-o até começar a surgir buracos na superfície).

- Trimming: Orienta os triângulos e pólos consistentemente, isto é, todos os triângulos possuirão orientação no sentido anti-horario e os pólos que pertencem ao exterior da superfície serão marcados como externos e os que pertencem ao interior como internos. Também nesta etapa de pós-processamento extrai-se nesta etapa uma variedade linear por partes sem bordo.

Maiores detalhes de implementação e descrição destas etapas de pós-processamento podem ser encontrados nos trabalhos que descrevem o crust (Amenta et al., 1998b) e (Amenta e Bern, 1999). 
Amenta demonstra que para uma superfície $r$-amostrada o método de detecção dos pólos (algoritmo 6) é eficiente. Notemos que o pólo $p^{+}$sempre existe e o pólo $p^{-}$também sempre existirá, pois estará do lado oposto ao semi-espaço definido pela face e que contém $p^{+}$e este lado certamente contém vértices da célula de Voronoi. Podemos também observar que as células de Voronoi são finas e compridas e com isto os pólos podem ser utilizados como aproximação para os vetores normais da superfície (figura 4.12), conseqüentemente podem ser aplicados aos métodos baseados em função implícita (Hoppe et al., 1992) e (Boissonnat, 1988).

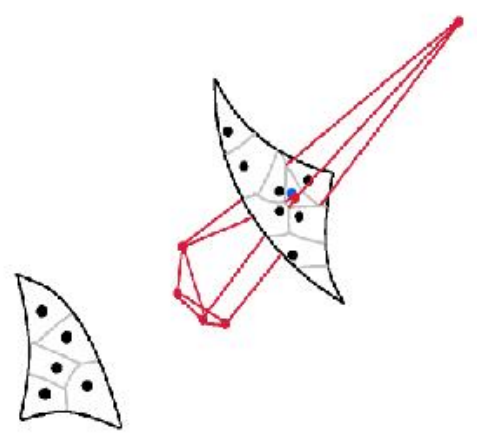

Figura 4.12: A célula de Voronoi para superfícies $r$-amostradas são finas e compridas (fonte: http://www.cs.utexas.edu/users/amenta/powercrust/).

\subsection{Power crust}

Dois trabalhos descrevem o algoritmo power crust, o primeiro trabalho descreve fundamentos teóricos, resultados de garantia da reconstrução e um algoritmo teórico para rotulação das bolas polares (definição 56) (Amenta et al., 2001b). O segundo descreve detalhes do algoritmo e características da implementação (Amenta et al., 2001a). Neste último, um algoritmo prático para nomeação das bolas polares é apresentado, pois na prática nomear corretamente as bolas polares como internas e externas não é uma tarefa trivial. Também são apresentadas extensões do algoritmo para tratamento de amostragens ruidosas, erros de aproximação de ponto flutuante e representações de variedades com bordo.

A idéia principal do algoritmo power crust é produzir uma aproximação linear por partes do eixo medial utilizando triangulação de Delaunay com peso (definição 38) e o power diagrama (definição 37) para a obtenção de uma variedade linear por partes da superfície. 
Observação 17 (Power crust bidimensional) Não apresentaremos separadamente a descrição do power crust bidimensional do tridimensional por dois principais motivos: O primeiro é que a generalização do algoritmo bidimensional para o tridimensional é feita diretamente, mas isto não implica que a implementação também foi generalizada de maneira direta, uma vez que outros problemas surgiram na versão $3 D$, por exemplo cálculo de duais e problemas de ordem numérica. O segundo ponto é que não existem na literatura resultados teóricos para o algoritmo bidimensional, mas na prática este algoritmo apresenta resultados mais satisfatórios que o crust e o $\beta$-skeleton (ver figuras de 6.3 à 6.7).

A seguir apresentaremos definições necessárias na caracterização do power crust.

Definição 56 (Bolas Polares) As esferas de centro nos pólos e tocando os pontos da amostragem mais próximos são denominados bolas polares.

Definição 57 (Power Crust) $O$ power diagrama ${ }^{3}$ divide o espaço em um conjunto de células que podemos classificar como internas ou externas à superfície. O conjunto de faces poligonais que separam as células internas das externas é chamado de power crust.

Definição 58 (Power Shape) $O$ power shape é definido como o dual do power crust e é uma aproximação para o eixo medial.

Observação 18 Os simplexos que definem o power shape são os duais das faces do power diagrama que não definem o power crust.

Apresentamos, para o caso bidimensional, as etapas do algoritmo power crust na figura 4.13. Para o caso bidimensional, consideramos as bolas polares originadas de todos os vértices de Voronoi. Em (a) temos a curva original, seu eixo medial e uma circunferência bitangente a curva de centro num ponto do eixo medial. Em (b) a amostragem e seu diagrama de Voronoi. Em (c) circunferências nas bolas polares e tocando as amostras mais próximas. Em (d) o power diagrama do conjunto bolas polares. Em (e) o power crust e a aproximação do eixo medial interno, aqui denominado por power shape, obtido pelas arestas definidas pelas bolas polares internas.

O seguinte teorema demonstrado por Amenta (Amenta et al., 2001b) dá uma idéia intuitiva que o power diagrama pode ser utilizado para reconstrução:

\footnotetext{
${ }^{3} \mathrm{O}$ power crust é calculado considerando as bolas polares como vértices.
} 

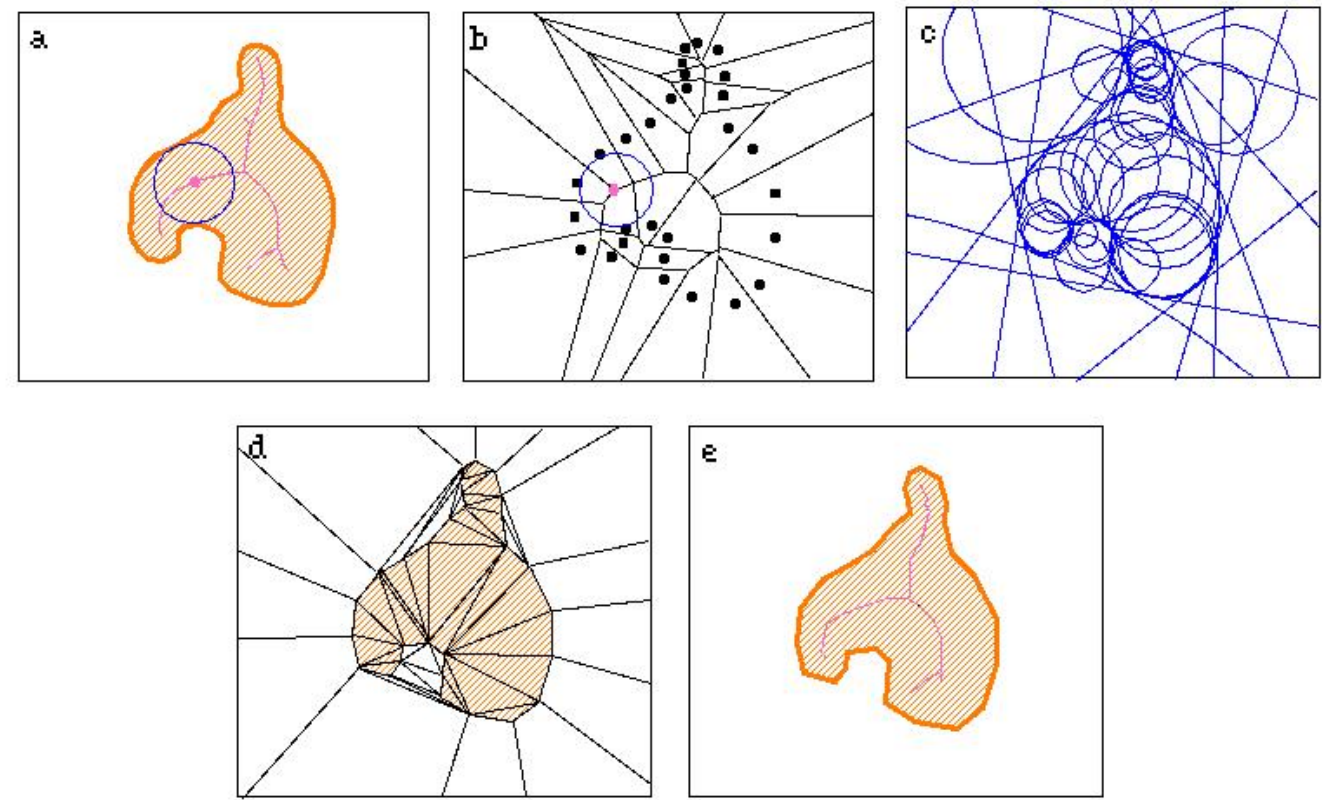

Figura 4.13: (Fonte: http://www.cs.utexas.edu/users/amenta/powercrust/) Descrição do power crust em sua versão 2D.

Teorema 16 Dado o diagrama de Voronoi $V$ de uma nuvem de pontos em $\mathbb{R}^{n}$, o power diagrama de todos os vértices de $V$, sendo os pesos dos vértices a distância ao quadrado do vértice de Voronoi à amostra mais próxima, é a triangulação de Delaunay da nuvem de pontos.

A figura 4.13-(d) exemplifica o teorema 16 e apresenta o power diagrama das bolas polares (considerando todos os vértices de Voronoi). Se aplicarmos a triangulação de Delaunay na mesma amostragem que deu origem às bolas polares, notaremos que a triangulação de Delaunay (tradicional) é a igual ao power diagrama.

Os seguintes teoremas demonstrados por Amenta (Amenta et al., 2001b) garantem que o power crust, para uma $r$-amostragem com $r$ suficientemente pequeno é uma representação homeomorfa e próxima a superfície original.

Observação 19 (Condição de amostragem) Amenta assume que as amostragens utilizadas nas demonstrações das garantias são sempre $r$-amostragens, com $r \leq 0.1$ e que as variedades são sem bordo. 


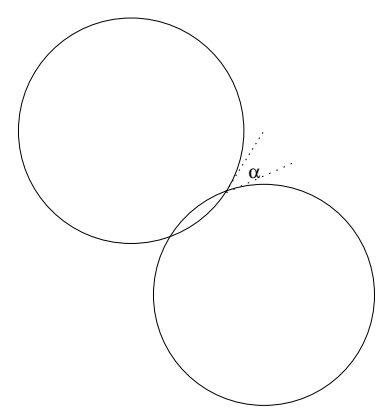

Figura 4.14: Ângulo $\alpha$ formado entre a intersecção de duas bolas polares.

Teorema 17 (Intersecção rasa) Seja $S$ uma superfície suave r-amostrada, com r suficientemente pequeno. $O$ ângulo $\alpha$ entre uma bola polar interna e externa é no máximo $r^{\prime}=\frac{r}{1-r}=$ $O(r)$.

Este teorema diz que a intersecção das bolas polares internas e externas, quando existir, é rasa (figura 4.14). Uma outra idéia por trás deste teorema é que as bolas polares internas estão quase inteiramente contidas no interior do objeto. Amenta apresenta um trabalho em que relata que a união das bolas polares internas é uma aproximação para o objeto (Amenta e Kolluri, 2000). A figura 4.15 apresenta exemplos desta situação.

Os vértices da amostragem de pontos, em geral, não são os vértices do power crust, mas Amenta apresenta o seguinte resultado que garante que os pontos da amostragem estão sobre a reconstrução:

Teorema 18 Cada ponto da amostragem pertence ao power crust.

Os teoremas 19 e 20, demonstrados por Amenta garantem que dada uma $r$-amostragem com $r$ pequeno, o power crust é próximo e homeomorfo à superfície original.

Teorema 19 (Proximidade) Qualquer ponto u de uma face do power crust está a uma distância de no máximo $O(r) L F S(x)$ para algum $x$ da superfície.

Teorema 20 (Homeomorfismo) Existe uma deformação contínua que transforma o power crust na superfície.

Observação 20 A saída do algoritmo power crust é sempre uma variedade sem bordo. No capítulo 5 apresentaremos maneiras de obter variedades com bordo utilizando o power crust. 

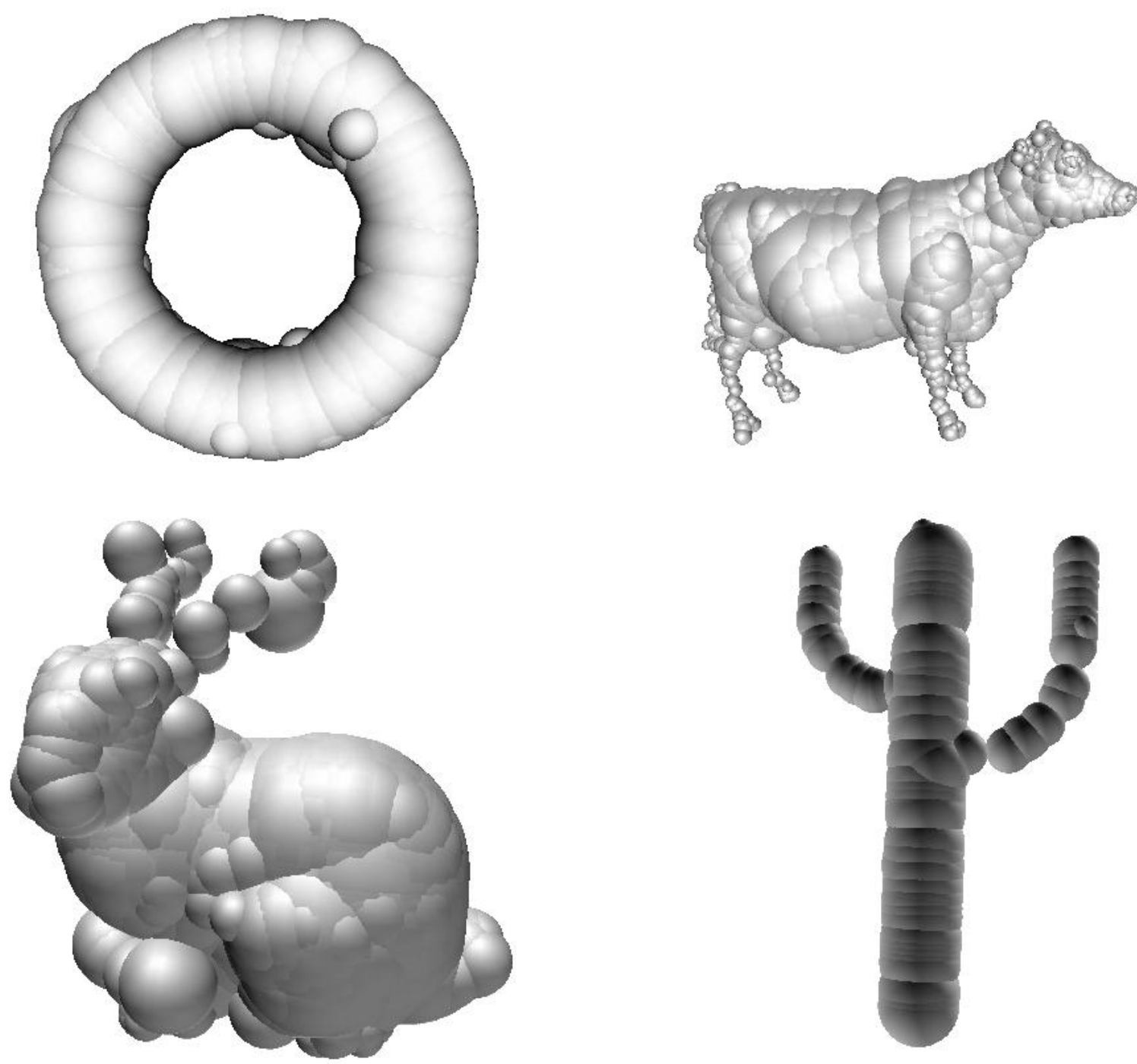

Figura 4.15: Exemplos em que a união de bolas polares internas determinam aproximações dos objetos.

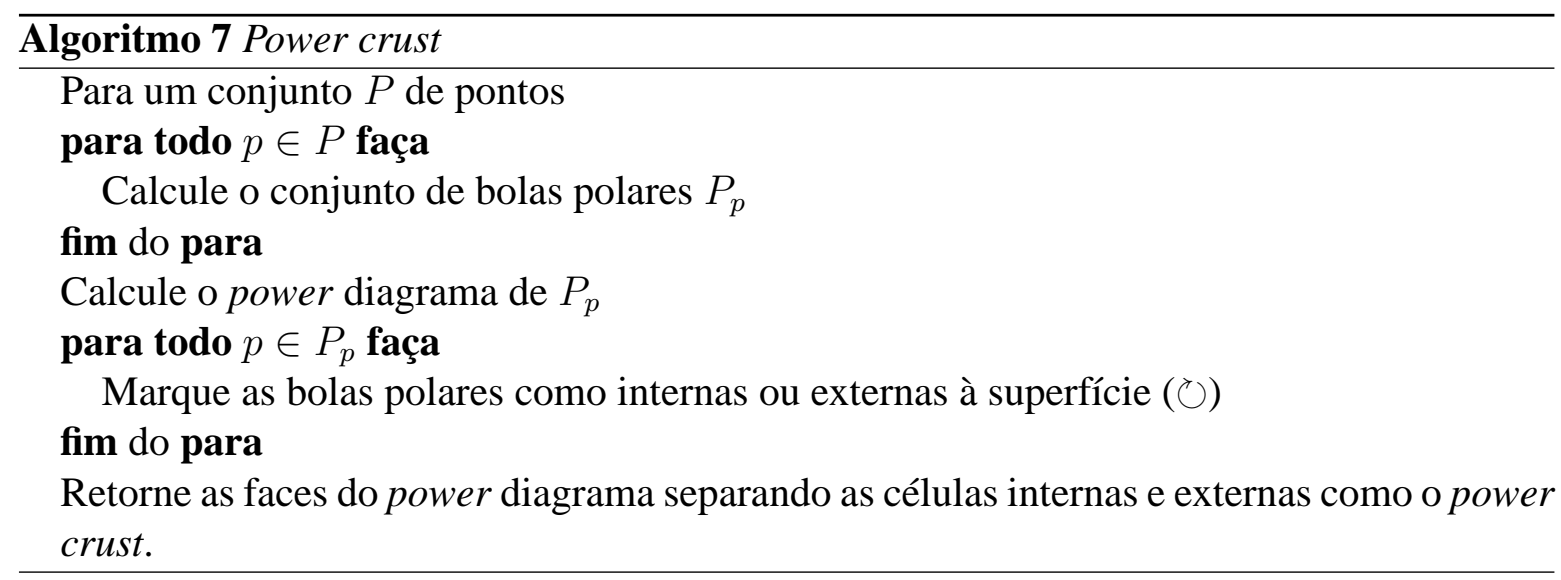


Em linhas gerais, o algoritmo 7 caracteriza o power crust:

Amenta (Amenta et al., 2001a) demonstra resultados teóricos assegurando que, a partir de uma superfície $r$-amostrada, com $r$ suficientemente pequeno, pode-se classificar corretamente as bolas polares como internas e externas a superfície com base no ângulo formado pela intersecção de uma bola polar externa e uma interna (Amenta et al., 2001b).

No algoritmo 7 (linha denotada por $\circlearrowright$ ) acrescentamos o algoritmo 8 que nomeia as bolas polares.

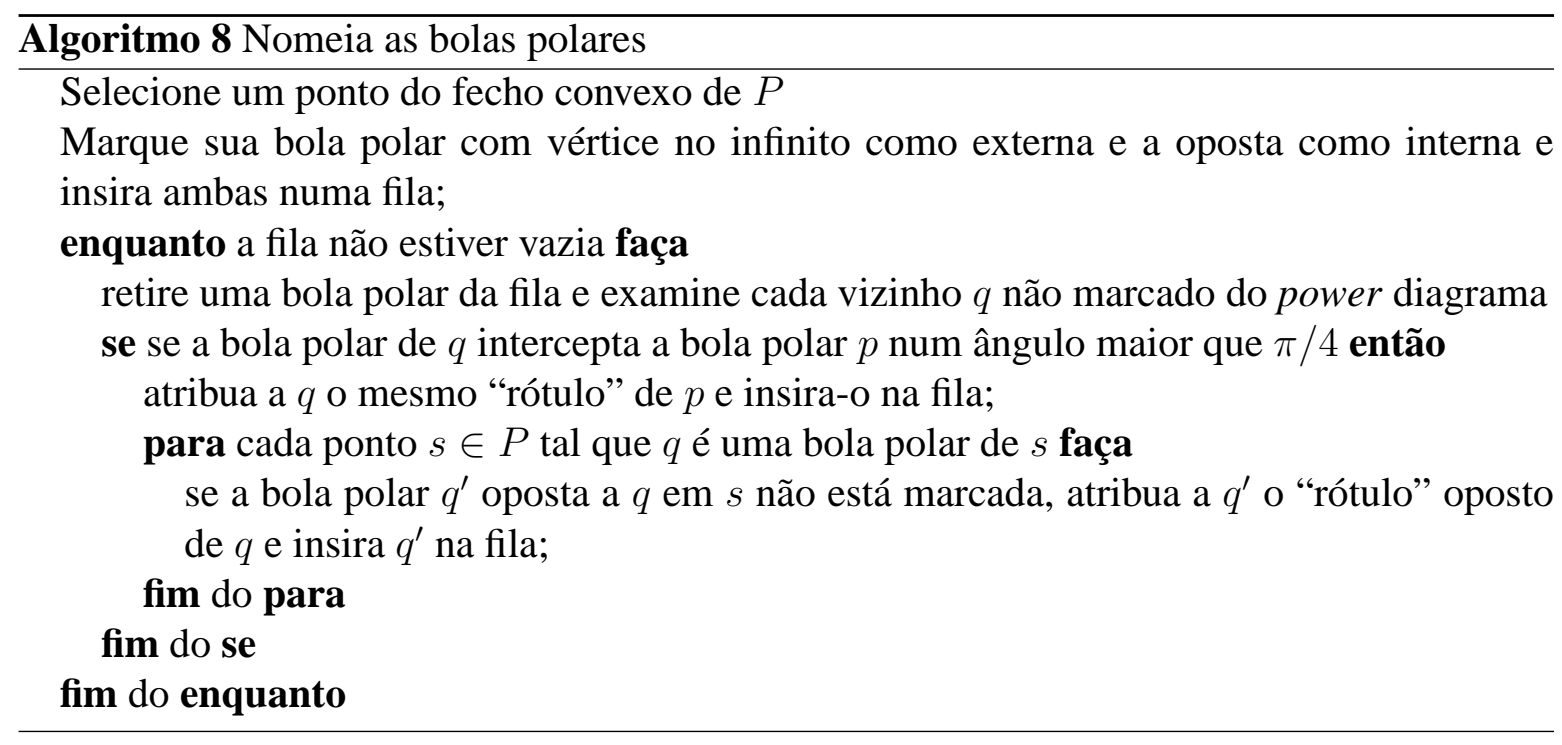

Amenta apresenta o seguinte teorema (Amenta et al., 2001b) que prova que o algoritmo 8 é correto:

Teorema 21 Toda bola polar recebe um rótulo pelo algoritmo, e mais, as bolas polares são rotuladas corretamente, isto é, bolas polares internas (externas) são rotuladas como internas (externas).

Os dois seguintes teoremas caracterizam o formato de uma célula de Voronoi, dado uma $r$-amostragem de uma superfície. O teorema 22 constata a largura e o teorema 23 constata o comprimento de uma célula de Voronoi. Estes teoremas são utilizados no capítulo 5 para caracterizar quando um ponto da amostragem é ruído. No capítulo 7 utilizamos estes resultados como auxílio no processo de detecção contornos de imagens. 
Teorema 22 Seja $P$ uma r-amostragem de uma superfície $S$, para $r$ suficientemente pequeno. Para qualquer $p \in P$ tal que $\beta>\operatorname{arcsen} r^{\prime}$, temos que:

$$
\|p-v\| \leq \frac{r^{\prime}}{\operatorname{sen}\left(\beta-\operatorname{arcsen} r^{\prime}\right)} L F S(p)
$$

Em que $r^{\prime}=\frac{r}{1-r}$, v representa os vértices da célula de Voronoi de $p$ e $\beta$ é o ângulo entre o vetor normal em p e o vetor $\overrightarrow{p v}$.

Teorema 23 A distância de cada pólo à sua amostra p é no mínimo LFS $(p)$.

\subsection{Cocone}

Apesar de garantias teóricas de reconstrução e dos modelos gerados através do crust (Amenta et al., 1998b) serem satisfatórias, o cálculo necessário para realizar duas triangulações de Delaunay é a principal desvantagem deste algoritmo.

Amenta propôs um algoritmo baseado no crust mas que utiliza apenas uma triangulação de Delaunay no processo de reconstrução. Este algoritmo é denominado cocone (Amenta et al., 2002). As provas apresentadas para garantia de reconstrução do cocone também são simplificadas.

Um cocone $C_{p}$ de um ponto $p$ de uma amostragem é definido como o duplo cone, sendo $p$ seu ápice e o ângulo entre a normal do ponto $p$ e a lateral do cone igual $\frac{3 \pi}{8}$ (figura 4.16).

Como o pólo de $p^{+}$de $p$ aproxima o vetor normal $n$ em $p$, o cocone aproxima uma vizinhança do plano tangente em $p$. Para cada ponto $p$, o algoritmo determina todas as arestas de Voronoi de $V_{p}$ que são interceptadas pelo cocone $C_{P}$. Os triângulos duais destas arestas de Voronoi constituem o conjunto de triângulos que definem a reconstrução.

Os três teoremas que apresentamos a seguir, demonstrados por Amenta (Amenta et al., 2002), garantem homeomorfismo e proximidade do cocone.

O primeiro teorema nos diz que os triângulos candidatos a representação da superfície tendem a apresentar uma forma de um triângulo equilátero:

Teorema 24 (Condição de triângulos pequenos) Seja $R$ o circunraio de qualquer triângulo $t$ de uma r-amostragem. Então para cada vértice $p$ de $t$ tem-se: $R \leq \frac{1.3 r}{1-r} l f s(p)$, para $r \leq 0.09$. 


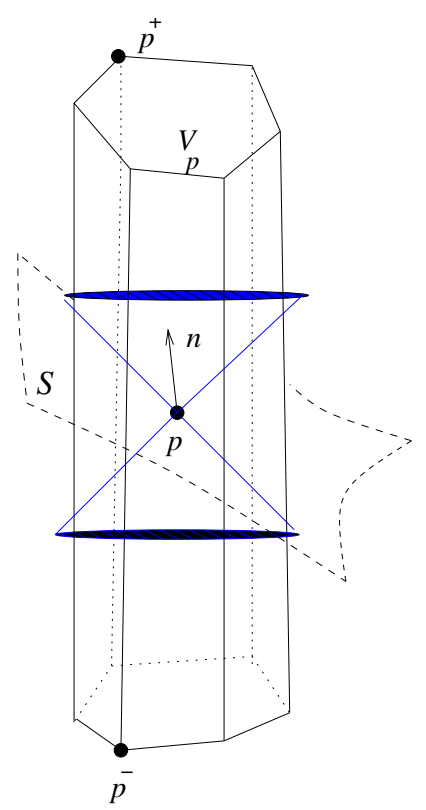

Figura 4.16: Cocone (em azul) de ápice em $p$. $n$ é o vetor normal, $p^{+}$e $p^{-}$são os pólos de $p$. $V_{P}$ é a célula de Voronoi de $p$.

O segundo teorema trata que tais triângulos com circunraio pequeno tendem a serem tangentes à superfície, isto é:

Teorema 25 (Condição de triângulos tangentes à superfície) Consideremos uma superfície $S$ r-amostrada, com $r \leq 0.09$. Se $n_{t}$ é o vetor normal de um triângulo te $x$ um vértice de t então o ângulo $\angle n_{t} n_{x} \leq \alpha+\operatorname{arcsen} \frac{2}{\sqrt{3}} \operatorname{sen} 2 \alpha$, onde $\alpha \leq \operatorname{arcsen} \frac{1.3 r}{1-r}$ e o ângulo $\angle n_{t} n_{x}$ é o menor ângulo entre os vetores $n_{t} e n_{x}$.

O último teorema apresenta para quais valores de $r$, em uma superfície $r$-amostrada temse a garantia da reconstrução.

Teorema 26 (Homeomorfismo) Seja uma superfície $S$ r-amostrada com $r \leq 0.06$. Então a reconstrução pelo algoritmo cocone é homeomorfa à $S$.

Além da utilização de apenas uma triangulação de Delaunay, este algoritmo também elimina a etapa de pós-processamento filtering by normal, proposta por Amenta (Amenta et al., 1998b), pois esta já é alcançada diretamente pelo cocone. Apenas a segunda etapa de pósprocessamento trimming é aplicada ao cocone. 


\subsection{Tight cocone}

O tight cocone, proposto por Dey e Goswami, é uma etapa de pós-processamento do cocone (Dey e Goswami, 2002a). A saída deste algoritmo é uma superfície denominada water tight:

Definição 59 (Water Tight (Dey e Goswami, 2002a)) Uma superfície é denominada water tight se é um 2-complexo simplicial em $\mathbb{R}^{3}$ cujo espaço gerado é o mesmo que a fronteira de uma 3-variedade em $\mathbb{R}^{3}$ (figura 4.17).

a)
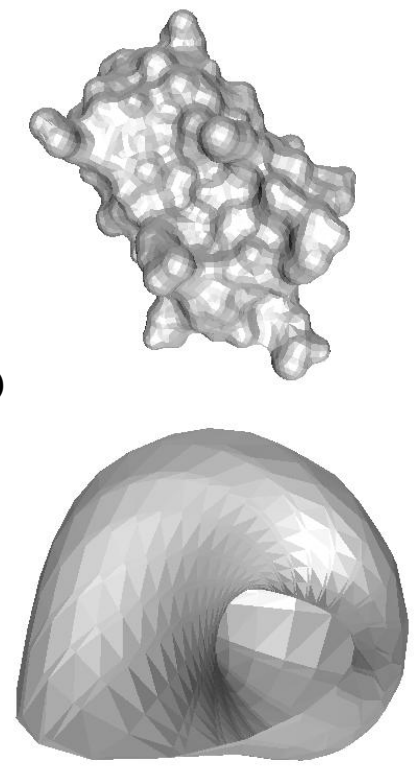

c)

Figura 4.17: a) e b) exemplos de superfícies water tight, c) e d) superfícies não water tight.

A idéia geral deste algoritmo é nomear os tetraedros de Delaunay como internos e externos, baseado na superfície obtida pelo cocone. Os tetraedros nomeados como externos são removidos e a fronteira dos tetraedros nomeados como internos definem a fronteira de uma superfície water tight. Este fato é possível devido ao princípio da localidade (Dey e Goswami, 2002a) que assegura que regiões mal amostradas são locais.

Isto significa que o cocone calcula a maioria da superfície esperada, com buracos que são localmente reparáveis. Claro que se este princípio não for satisfeito, a saída do tight cocone pode não ser uma boa representação da superfície original.

Dey apresenta discussões sobre das implementações do cocone e do tight cocone (Dey et al., 2001) e (Dey e Goswami, 2002b). 


\subsection{Considerações finais}

Neste capítulo apresentamos o conjunto de algoritmos que apresentaram os primeiros resultados de garantia de reconstrução homeomorfa e próxima à variedade original. Definições e resultados que garantem a reconstrução das formas originais de curvas e superfícies também foram apresentadas.

Existem alguns levantamentos bibliográficos na literatura que também relatam trabalhos de reconstrução. Edelsbrunner apresentou um trabalho que descreve um conjunto de algoritmos de reconstrução via triangulação de Delaunay (Edelsbrunner, 1998). Neste trabalho o autor buscou apenas descrever algoritmos, sem realizar comparações e focar em outras técnicas de reconstrução além das baseadas em esculpimentos. Dey apresenta um recente levantamento bibliográfico em que as primeiras comparações teóricas entre algoritmos são realizadas (Dey, 2002). Neste trabalho Dey focou em algoritmos que apresentam garantias de reconstrução. Gois apresenta um levantamento bibliográfico de técnicas de esculpimento com comparações práticas, além de comparações teóricas e descrições dos algoritmos (Gois et al., 2003).

No capítulo seguinte discutiremos as implementações que realizamos. 


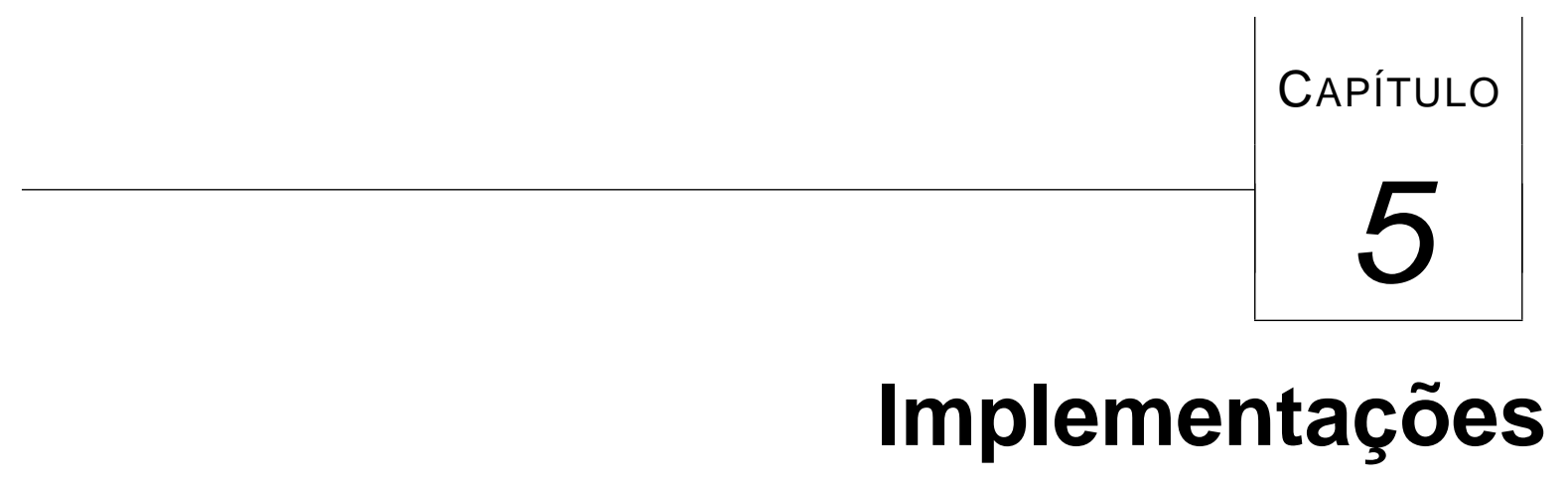

Neste capítulo descrevemos um conjunto de características das implementações que realizamos, focando principalmente no power crust.

Não entramos em detalhes das implementações, pois acreditamos que a descrição dos algoritmos no capítulo 4, juntamente com os comentários realizados neste capítulo oferecem uma idéia base em relação às implementações.

Durante as implementações, estivemos em constante contato com os autores dos trabalhos e com o comitê da biblioteca CGAL para esclarecimento de eventuais duvidas e sugestões. Os principais colaboradores foram Nina Amenta (amenta@cs.ucdavis.edu), Andreas Fabri (Andreas.Fabri@sophia.inria.fr) e Sylvain Pion (Sylvain.Pion@mpi-sb.mpg.de).

\subsection{As triangulações}

A triangulação de Delaunay é o processo mais custoso nas técnicas de geração de malhas superficiais a partir de nuvens de pontos quando se utiliza técnicas de esculpimento. A escolha de um algoritmo robusto e de estruturas de dados eficientes é de fundamental importância para a manutenção da triangulação e nos processos de esculpimento.

Choi e Amenta (Choi e Amenta, 2002) argumentam que existem algoritmos em que a triangulação de Delaunay em $\mathbb{R}^{3}$ pode alcançar tempo linear na prática para pontos gerados aleatoriamente, no entanto, para pontos distribuídos sobre uma superfície este tempo pode se 
tornar quadrático. Choi também faz comparações entre as triangulações de Delaunay mais utilizadas na literatura para dados distribuídos em superfícies.

A biblioteca que utilizamos para obtermos as triangulações de Delaunay tradicional e com peso são as presentes na biblioteca CGAL - Computational Geometry Algorithms Library, versão 2.4 (CGAL, 2004) que contém diversas triangulações implementadas de maneira eficiente, robusta e flexível a alterações e adaptações (Boissonnat, 1988).

Em 4 de novembro de 2003 uma nova versão da biblioteca CGAL começou a ser distribuída (versão 3.0). Não realizamos testes ainda com esta nova versão. Mas acreditamos que não surgirão grandes dificuldades de migração para a nova versão, pois as classes não sofreram modificações significativas. Apenas os algoritmos bidimensionais que teremos que redefinir a interface gráfica de entrada e saída pois na versão que utilizamos possuía a interface LEDA (ver seção seguinte) e na atual versão não está disponível mais esta interface, apenas interfaces baseadas no $\mathrm{Qt}^{1}$.

Além dos pontos citados acima, outros foram de fundamental importância na escolha da biblioteca CGAL: As classes presentes na biblioteca são muito bem documentadas e estão disponíveis on-line no site http://www.cgal.org. Existem interfaces para outras bibliotecas (por exemplo LEDA ${ }^{2}$ ) e dispositivos de entrada e saída de dados. CGAL é escrita em C++ padrão e pode ser compilada sob diversos sistemas operacionais (compilamos e testamos os códigos bi e tridimensionais que implementamos nos sistemas operacionais Windows XP e Linux-Slackware). Existe uma lista de discussão em que colaboramos e recebemos colaborações de usuários de todo o mundo e desenvolvedores da biblioteca.

O último ponto, e não menos importante, é o suporte a classes com aritmética de precisão arbitrária, uma vez que diversos cálculos geométricos são necessários para realizar as triangulações de Delaunay tradicional e com peso, e trabalhar com tipos numéricos convencionais se torna inviável nas triangulações de conjuntos de pontos que representem superfícies.

Uma otimização pode ser realizada na etapa de inserção de pontos na triangulação de Delaunay, uma vez que a triangulação é um processo custoso nos métodos de esculpimento. CGAL oferece uma estratégia de otimização da triangulação de Delaunay na etapa de inserção dos pontos denominada Hierarchy Triangulation. No site da biblioteca CGAL encontrase explicações desta estratégia de inserção e como utilizá-las. O processo de otimização para triangulação de Delaunay com peso ainda não foi desenvolvido para a bilbioteca.

\footnotetext{
${ }^{1}$ http://trolltech.com/qt.

${ }^{2}$ http://www.mpi-sb.mpg.de/LEDA/index.html.
} 
A seguir faremos comentários gerais sobre as implementações que realizamos.

\subsection{Entrada/Saída}

Os arquivos de entrada (as nuvens de pontos) dos algoritmos implementados são formados pelas coordenadas dos pontos, por exemplo o arquivo formado por 5 pontos em $\mathbb{R}^{3}$ é dado da seguinte maneira:

$$
\begin{array}{lll}
5.200 & 1.300 & 1.700 \\
3.200 & 4.700 & 1.200 \\
1.500 & 1.300 & 7.900 \\
1.500 & 3.700 & 0.000 \\
-8.000 & 0.200 & -7.000
\end{array}
$$

Ou 5 pontos em $\mathbb{R}^{2}$ para os algoritmos bidimensionais:

$$
\begin{aligned}
& 0.000 \quad 2.300 \\
& 1.200 \quad 3.200 \\
& -4.300 \quad 2.500 \\
& 1.7002 .200 \\
& 1.600 \quad 2.200
\end{aligned}
$$

Podemos variar o número de casas decimais. Na literatura arquivos de nuvens de pontos, como descrito anteriormente, em geral, possuem extensão .pts.

As implementações bidimensionais ainda permitem que o usuário entre com os pontos através de cliques com o mouse na janela de entrada/saída gráfica CGAL/LEDA, também escrita em $\mathrm{C}++$ padrão.

Para a visualização dos dados tridimensionais, podemos optar por saídas em três formatos: .vtk, .off e .vrml.

Os arquivos com extensão . vtk são formatos de arquivo para a biblioteca gráfica VTK Visualization Tool $\mathrm{Kit}^{3}$ desenvolvida com base no Opengl.

\footnotetext{
${ }^{3} \mathrm{http}: / /$ www.vtk.org
} 
O Geomview ${ }^{4}$ é um software para sistemas Linux que utilizamos para visualização de dados tridimensionais. Os arquivos de entrada do Geomview possuem extensão .off.

Uma vantagem de utilizar o Geomview com a biblioteca CGAL é a existência de classes implementadas na biblioteca que permitem utilizar o Geomview como dispositivo de saída através de operadores sobrecarregados da linguagem $\mathrm{C}++$.

Já a extensão.$v r m l^{5}$ é interessante, pois permite visualizar e realizar operações (por exemplo translação, rotação) nos objetos através de navegadores da internet que possuam plug-in's específicos.

Informações sobre como estes arquivos são representados são encontradas nos sites citados anteriormente.

\subsection{Algoritmos bidimensionais}

A implementação dos algoritmos bidimensionais ofereceu maturidade para compreendermos e implementarmos as versões tridimensionais dos algoritmos. Implementamos três algoritmos bidimensionais, $\beta$-skeleton (existe somente a versão 2D), crust e power crust.

Através destas implementações constatamos diversas características que apareceram também no caso tridimensional e também foram úteis para determinarmos o formato das classes dos algoritmos.

\subsection{Raw crust}

Em nossa implementação do raw crust ao invés de realizarmos uma triangulação com $n$ pontos (triangulação dos pontos da amostragem) e em seguida outra com cerca de $3 n$ pontos (triangulação dos pontos da amostragem unido com os pólos), realizamos apenas uma triangulação de $3 n$ pontos em que os $n$ primeiros pontos são originados da amostragem e os outros $2 n$ pontos, inseridos em seguida, são os pólos. Como não implementamos os pósprocessamentos, a estrutura que utilizamos para gerar a reconstrução desta forma é mais simples. Isto nos permitiu analisar o quanto é vantajoso as etapas de pós-processamento.

\footnotetext{
${ }^{4}$ http://www.geomview.org

${ }^{5}$ http://www.vrml.org/
} 
O raw crust, em geral, gera modelos com menos buracos que o crust. No entanto, surge um número excessivo de tetraedros slivers nas soluções do raw crust. A tabela 5.1 apresenta o número de tetraedros slivers e o número de triângulos presentes nos modelos.

\begin{tabular}{|c|c|c|c|c|}
\hline & Elipsóide & Toro & Salsichas & Mão \\
\hline slivers & 6 & 363 & 1203 & 16723 \\
\hline triângulos & 188 & 1724 & 5897 & 106530 \\
\hline
\end{tabular}

Tabela 5.1: Raw crust: Através desta tabela é possível verificar o número de tetraedros slivers e o número de faces presentes em alguns modelos.

Na triangulação de Delaunay de pontos amostrados sobre superfícies, em geral, os tetraedros pertencentes ao interior são finos e compridos, e o principal problema é o número excessivo de tetraedros slivers na superfície (na figura 5.1 podemos notar, em vermelho, tetraedros slivers pertencentes a fronteira do objeto). A presença de tetraedros slivers pode acarretar em problemas de aproximação numérica, pois os testes geométricos da triangulação de Delaunay envolvem cálculos de determinantes. Este problema não só aparece no algoritmo raw crust, mas na quase totalidade dos algoritmos baseados em esculpimento presentes na literatura.
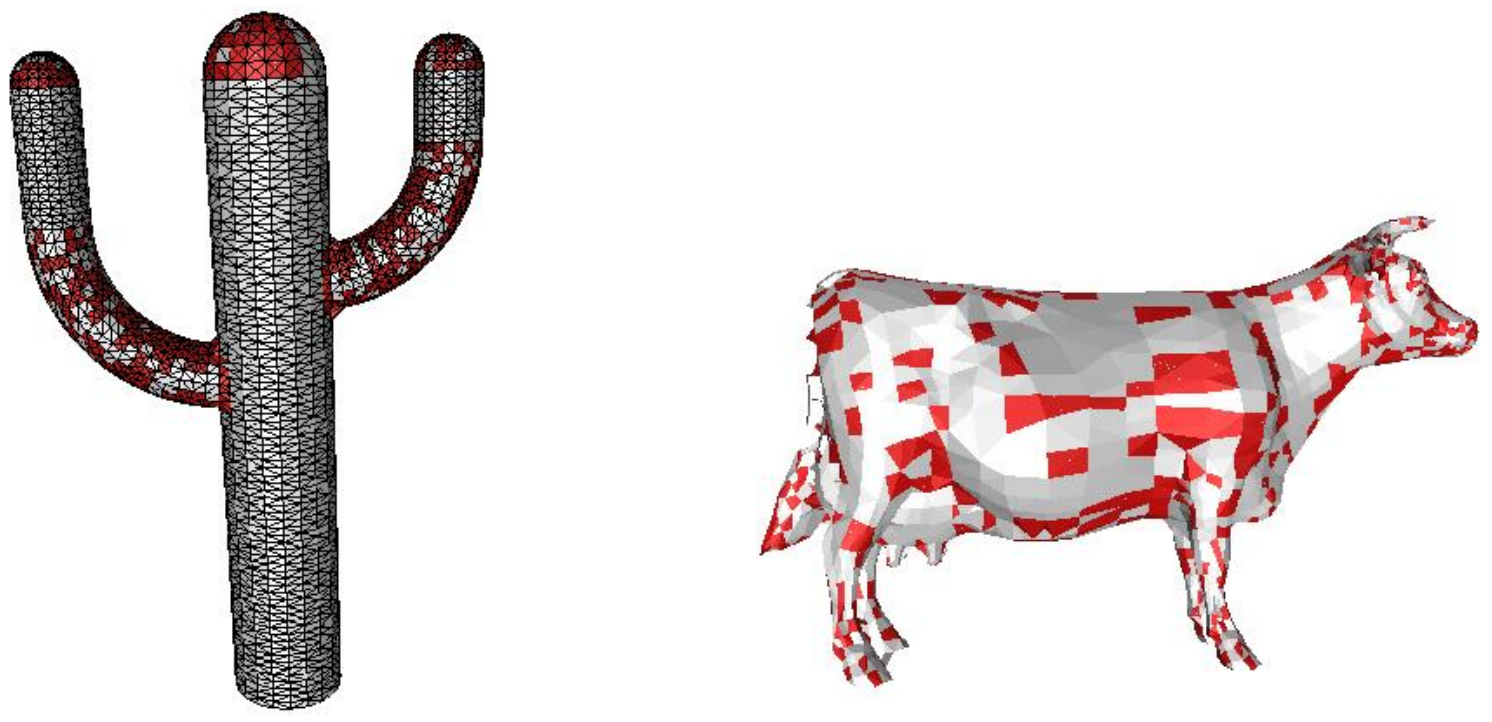

Figura 5.1: Tetraedros slivers presentes na superfície dos objetos (em vermelho).

\subsection{Power crust}

Questões referentes a aproximação numérica devem ser destacadas na implementação do power crust. Os tetraedros presentes na triangulação de Delaunay com peso necessária para 
obter o power crust são, em geral, extremamente finos e compridos e algumas vezes até computacionalmente planares, o que muitas vezes compromete o processo de reconstrução, sendo necessário realizarmos pequenas perturbações nas amostras antes de executarmos a primeira triangulação de Delaunay necessária para o power crust.

Com o intuito de obter estimativas para os vértices das células de Voronoi infinitas, adicionamos oito vértices na triangulação definindo um bounding box que contém a nuvem de pontos em seu interior. Conforme aumentamos o tamanho do bounding box obtemos estimativas mais precisas dos pólos, no entanto, existe uma tendência de ocorrerem erros numéricos com maior freqüência. Para o caso bidimensional colocamos o bounding box até 500 vezes o tamanho do menor bounding box que contém o conjunto de pontos. Para o caso tridimensional colocamos entre 5 a 10 vezes o menor bounding box para obtermos resultados satisfatórios.

\section{Cálculo da intersecção entre as esferas}

Para encontrarmos o ângulo entre as duas esferas procedemos da seguinte maneira:

Consideremos a figura 5.2 como sendo um corte de duas esferas que se interceptam. Sejam as esferas $e_{1}$ e $e_{2}$ com raios $r_{1}$ e $r_{2}$ e centros $c_{1}$ e $c_{2}$ respectivamente. A intersecção de $e_{1}$ e $e_{2}$ é um círculo $m$, representado pela figura 5.2 como um segmento de reta (devido ao corte). Este círculo tem centro $c_{3}$ e raio $r_{3}$. Sejam $d=\left\|c_{1}-c_{2}\right\|, d_{1}=\left\|c_{1}-c_{3}\right\| \mathrm{e}$ $d_{2}=\left\|c_{2}-c_{3}\right\|$.

Então temos o sistema de equações:

$$
\left\{\begin{array}{l}
d_{1}+d_{2}=d \\
d_{1}^{2}+r_{3}^{2}=r_{1}^{2} \\
d_{2}^{2}+r_{3}^{2}=r_{2}^{2}
\end{array}\right.
$$

Com incógnitas $d_{1}, d_{2}$ e $r_{3}$. Então sejam $k$ um ponto qualquer do círculo $m$ e $\beta=\widehat{c_{1} k c_{2}}$. O ângulo entre as esferas é $\alpha=\pi-\beta$, pelo fato da superfície das esferas serem perpendiculares aos segmentos $\overline{c_{1} k}$ e $\overline{c_{2} k}$ em $k$.

Não foi necessário implementar um método de resolução do sistema de equações 5.1. Através de substituições das equações em 5.1 conseguimos obter expressões para as incógnitas. 


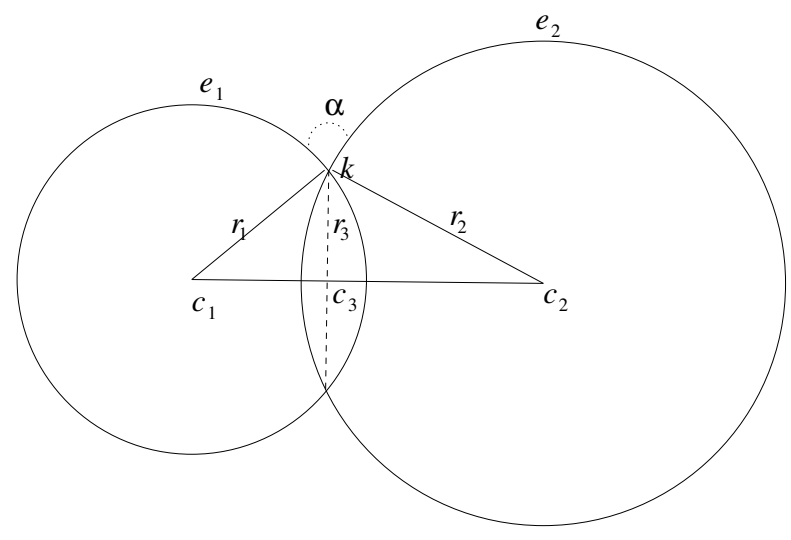

Figura 5.2: Ângulo entre as esferas: exemplo bidimensional.

\section{Rotulação dos pólos: Algoritmo prático}

Quando a superfície é bem amostrada, o algoritmo de rotulação das bolas polares (algoritmo 8, que chamaremos de algoritmo teórico) é provado ser correto utilizando dois fatos: O primeiro é que as intersecções entre bolas polares internas e externas, quando existem, é pequena e o outro é que, para cada amostra, uma bola polar é interna e a outra é externa.

Neste algoritmo ocorrem falhas facilmente devido ao fato das condições de amostragem geralmente não serem verificadas e o algoritmo ser muito sensível a perturbações nas amostras. Se uma bola polar receber um rótulo errado, o erro se propaga e a reconstrução fica comprometida. Para solucionar este problema Amenta (Amenta et al., 2001a) sugere uma heurística baseada numa lista de prioridade em que as bolas polares mais confiáveis são rotuladas primeiro. Esta heurística é explicada a seguir:

Para cada bola polar mantemos dois valores $0 \leq$ in $\leq 1$ e $0 \leq$ out $\leq 1$, que representam a possibilidade da bola polar ser interna ou externa respectivamente, em que 0 é incerteza e 1 é certeza. O processo é inicializado atribuindo às bolas originadas das amostras do bounding box out $=1$ e $i n=0$. Os pólos restantes inicializamos $i n=o u t=0$.

Todas as bolas polares são colocadas numa lista de prioridade, com prioridade determinada pelos valores in e out. Se apenas um dos valores é não nulo, nós utilizamos o valor não nulo como a prioridade. Se ambos os valores são não nulos a rotulação desta bola polar deve ocorrer o mais tarde possível e são dadas a estas bolas a prioridade de $1-\mid$ in - out $\mid$. Note que este valor está no intervalo $[0,1]$. 
A cada iteração o algoritmo remove-se o topo da lista e rotula-o conforme o maior valor entre in e out. Então propaga os novos valores de in e out para o restante da lista de prioridade, alterando as prioridades das bolas polares.

Dois testes são realizados para alteração das prioridades da lista, que descrevemos a seguir.

O primeiro é baseado no ângulo $\beta$ formado pelo centro da bola polar $p$, do topo da lista, cada amostra $s$ (que tem $p$ como pólo) e a segunda bola polar $q$ de cada $s$. Na figura 5.3 apresentamos um exemplo bidimensional do primeiro teste de alteração da lista de prioridades.

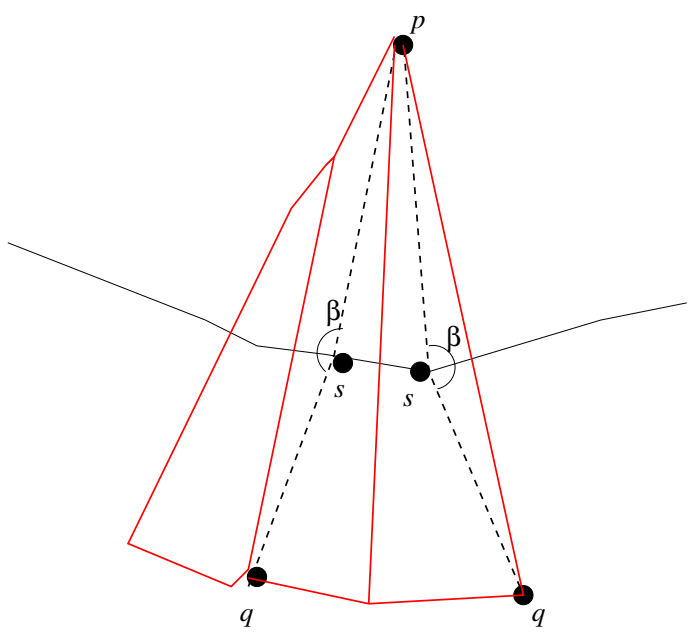

Figura 5.3: Diagrama de Voronoi em vermelho, em linhas contínuas pretas, arestas de Delaunay. Nomeado a bola polar $p$, alteram-se as prioridades das bolas polares $q$, pelo valor do ângulo $\beta=\widehat{p s q}$.

Notemos que o ângulo $\beta \in[\pi / 2, \pi]$ (pela definição do algoritmo de detecção dos pólos). Conforme o ângulo $\beta$ se aproxima de $\pi$ a chance é maior de $q$ ter rótulo oposto ao de $p$. Para medir o peso da conexão entre os pólos $p$ e $q$, utilizamos: $0 \leq-\cos (\beta) \leq 1$.

A segunda é baseada na intersecção entre as bolas polares. Conforme o teorema 17, a intersecção entre uma bola polar interna e uma externa é rasa. Então se a intersecção for funda é mais provável que $p$ e $q$ tenha o mesmo rótulo. Então como medida de conexão entre $p$ e $q$ é $0 \leq-\cos (\alpha) \leq 1$, em que $\alpha$ é o ângulo formado pelas duas bolas polares (figura 4.15).

A discussão acima é sumarizada no algoritmo 9. O algoritmo 10 representa o critério de atualização da lista de prioridades. 

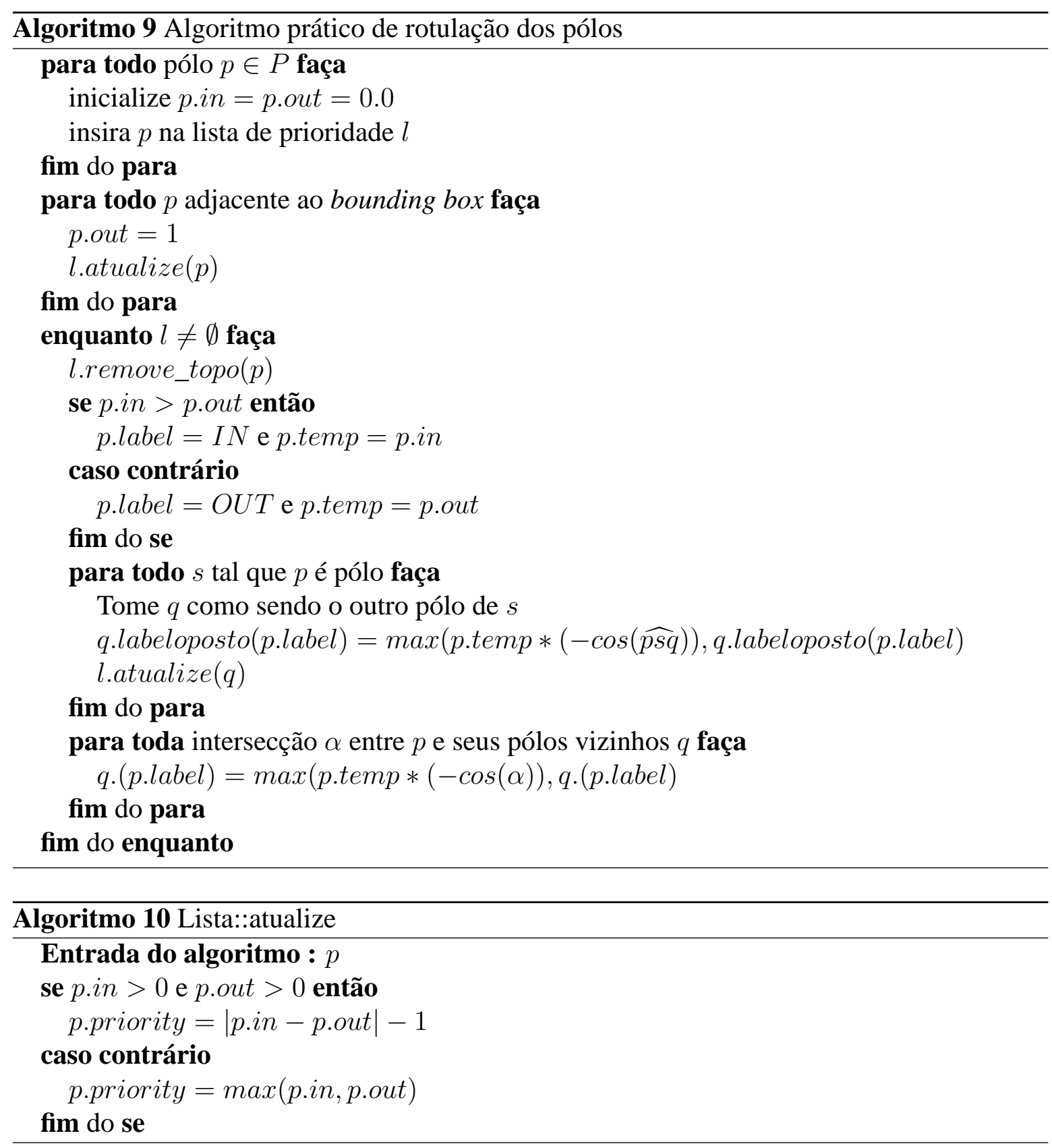

Para o caso bidimensional, foram implementados ambos algoritmos teórico e prático de rotulação dos pólos. Resultados destas implementações estão presentes na figura 5.4.

\section{Cálculo do dual com peso}

A versão 2.4 da bilbioteca CGAL não possui uma implementação do cálculo de duais de tetraedros da triangulação de Delaunay com peso (na atual versão 3.0 também não está 
a)
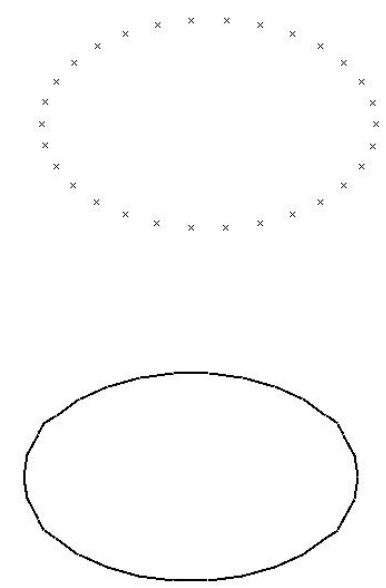

d)

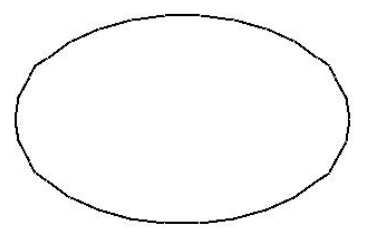

g)

h)

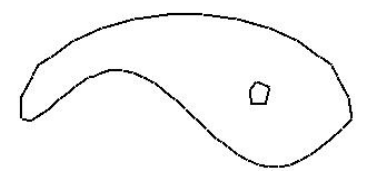

b)

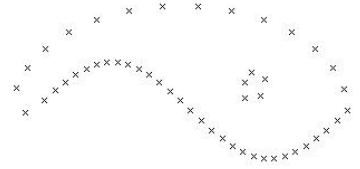

e) c)
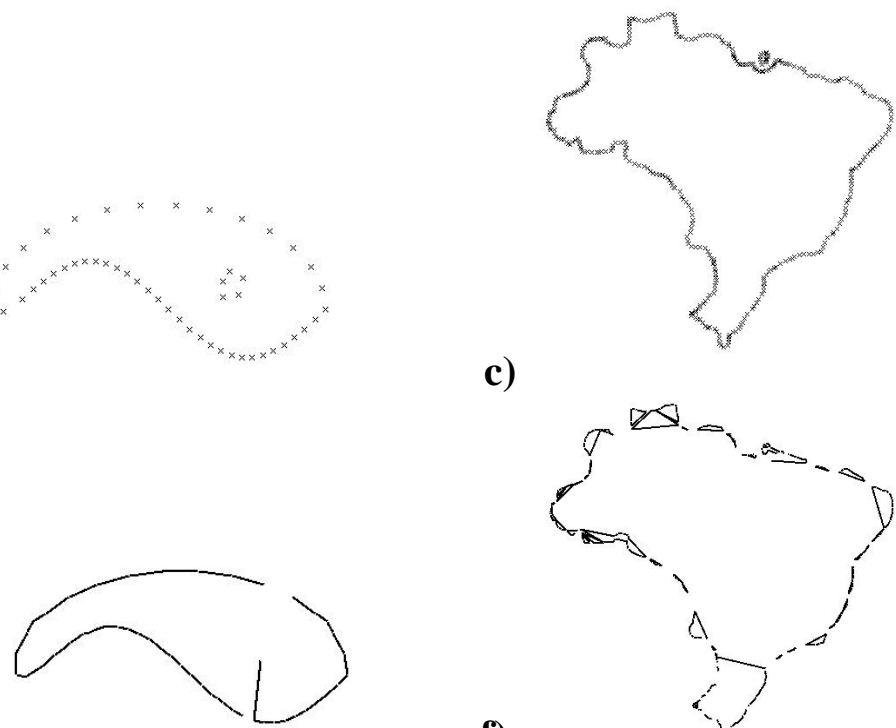

f)

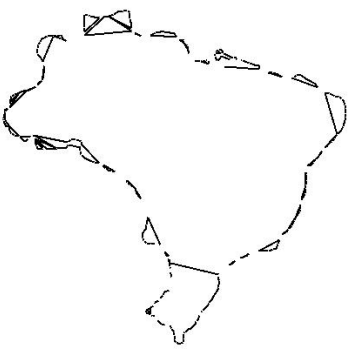

i)

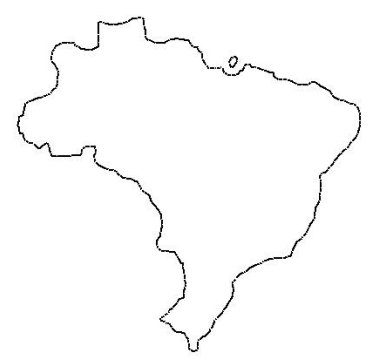

Figura 5.4: Comparação entre o algoritmo de rotulação dos pólos teórico (algoritmo 8) e prático (algoritmo 9): Em a) b) e c) o conjunto de pontos, em d) e) e f) a saída do algoritmo quando aplicado o algoritmo teórico, em g) h) e i) quando aplicado o algoritmo prático.

disponível), também conhecidos como ortocentros. A seguir descrevemos o cálculo do ortocentro e a estratégia que utilizamos para reduzir o número de operações aritméticas.

Seja o tetraedro $t$ com vértices com peso $\hat{p_{1}}=\left(x_{1}, y_{1}, z_{1}, w_{1}^{2}\right), \hat{p_{2}}=\left(x_{2}, y_{2}, z_{2}, w_{2}^{2}\right), \hat{p_{3}}=$ $\left(x_{3}, y_{3}, z_{3}, w_{3}^{2}\right)$ e $\hat{p}_{4}=\left(x_{4}, y_{4}, z_{4}, w_{4}^{2}\right)$ e com ortocentro $\hat{o}=\left(o_{x}, o_{y}, o_{z}, w_{o}^{2}\right)$. Apresentamos a construção da expressão que determina o ortocentro:

Sejam os determinantes:

$$
a=\left|\begin{array}{llll}
x_{1} & y_{1} & z_{1} & 1 \\
x_{2} & y_{2} & z_{2} & 1 \\
x_{3} & y_{3} & z_{3} & 1 \\
x_{4} & y_{4} & z_{4} & 1
\end{array}\right|
$$




$$
\begin{aligned}
& b_{x}=+\left|\begin{array}{llll}
x_{1}{ }^{2}+y_{1}{ }^{2}+z_{1}^{2}-w_{1}^{2} & y_{1} & z_{1} & 1 \\
x_{2}{ }^{2}+y_{2}{ }^{2}+z_{2}^{2}-w_{2}^{2} & y_{2} & z_{2} & 1 \\
x_{3}^{2}+y_{3}{ }^{2}+z_{3}^{2}-w_{3}^{2} & y_{3} & z_{3} & 1 \\
x_{4}{ }^{2}+y_{4}{ }^{2}+z_{4}{ }^{2}-w_{4}{ }^{2} & y_{4} & z_{4} & 1
\end{array}\right| \\
& b_{y}=-\left|\begin{array}{lccc}
x_{1}{ }^{2}+y_{1}{ }^{2}+z_{1}^{2}-w_{1}^{2} & x_{1} & z_{1} & 1 \\
x_{2}^{2}+y_{2}^{2}+z_{2}^{2}-w_{2}^{2} & x_{2} & z_{2} & 1 \\
x_{3}^{2}+y_{3}^{2}+z_{3}^{2}-w_{3}^{2} & x_{3} & z_{3} & 1 \\
x_{4}{ }^{2}+y_{4}{ }^{2}+z_{4}{ }^{2}-w_{4}{ }^{2} & x_{4} & z_{4} & 1
\end{array}\right| \\
& b_{z}=+\left|\begin{array}{llll}
x_{1}^{2}+y_{1}^{2}+z_{1}^{2}-w_{1}^{2} & x_{1} & y_{1} & 1 \\
x_{2}^{2}+y_{2}^{2}+z_{2}^{2}-w_{2}^{2} & x_{2} & y_{2} & 1 \\
x_{3}^{2}+y_{3}^{2}+z_{3}^{2}-w_{3}^{2} & x_{3} & y_{3} & 1 \\
x_{4}^{2}+y_{4}^{2}+z_{4}^{2}-w_{4}^{2} & x_{4} & y_{4} & 1
\end{array}\right|
\end{aligned}
$$

Consideremos $o_{x}=\frac{b_{x}}{2 a}, o_{y}=\frac{b_{y}}{2 a}$ e $o_{z}=\frac{b_{z}}{2 a}$. O ortocentro é dado por:

$$
\hat{o}=\left(o_{x}, o_{y}, o_{z},\left(o_{x}-x_{1}\right)^{2}+\left(o_{y}-y_{1}\right)^{2}+\left(o_{z}-z_{1}\right)^{2}-w_{1}^{2}\right)
$$

Observação 21 O principal problema no cálculo do ortocentro é que o determinante em 5.2 pode ser um valor muito próximo de zero, caso os pontos sejam praticamente coplanares. A classe numérica que utilizamos para representar pontos flutuante com precisão arbitrária não suporta divisão exata e converte numerador e denominador para double padrão da linguagem $C++$, podendo anular o denominador.

Para contornar o problema constatado na observação 21 adotamos as seguintes estratégias: A primeira é quando identificamos que a divisão será por zero, realizamos uma pequena perturbação em uma das coordenadas dos vértices do tetraedro de maneira que este vértice se afaste do plano definido pelos três outros vértices do tetraedro.

A segunda estratégia é o teste de ortogonalidade, em que verificamos a ortogonalidade do ortocentro com seu tetraedro. Este teste verifica se o ortocentro calculado é ortogonal aos quatro vértices do tetraedro. 
Estas estratégias não são sugeridas no trabalho original de Amenta, pois a triangulação e os predicados numéricos utilizados na implementação do power crust fornecem resultados satisfatórios (Amenta et al., 2001a).

Utilizamos uma estratégia para reduzir o número de operações aritméticas dos cálculos (utilizada pela biblioteca CGAL no cálculo do circuncentro) que é aplicar uma translação ao tetraedro de modo que um de seus vértices fique na origem do sistema de coordenadas cartesianas. Com esta operação reduzimos a ordem do determinante, que é de 4, para 3 , implicando na redução do número de operações significativamente. A figura 5.5 apresenta o esquema de translação do tetraedro para redução do número de operações.

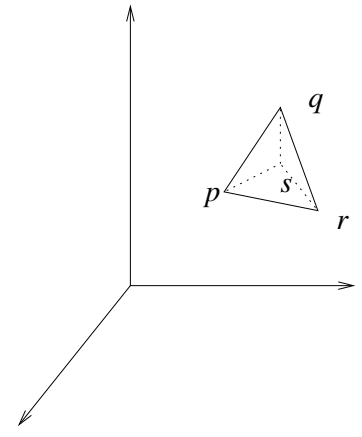

a)

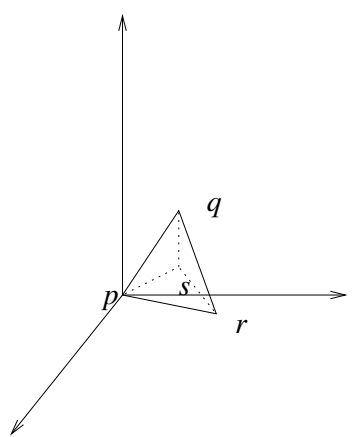

b)

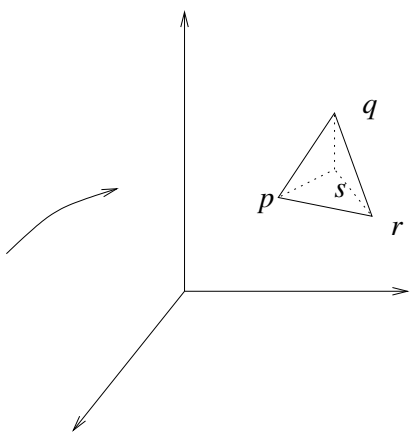

c)

Figura 5.5: Estratégia para redução dos cálculos necessários para determinação do ortocentro: a) situação inicial, b) nesta etapa realiza-se a translação do tetraedro para a origem do sistema de coordenadas e é feito o cálculo do ortocentro para o tetraedro transladado, c) translada-se novamente o tetraedro para sua posição inicial e conseqüentemente seu ortocentro.

\section{Identificação de buracos}

A saída do power crust é uma variedade sem bordo. No entanto alguns conjuntos de dados são originados de variedades com bordo. Podemos observar que as faces do power crust que "tampam" o bordo da variedade estão entre bolas polares cujas intersecções são fundas. Este fato ocorre pois, neste caso, esferas internas "pulam" para fora do objeto. Definimos então um parâmetro para omitir as faces do power crust cuja intersecção entre as bolas polares são fundas. A figura 5.6 apresenta um exemplo desta aplicação. 
a)

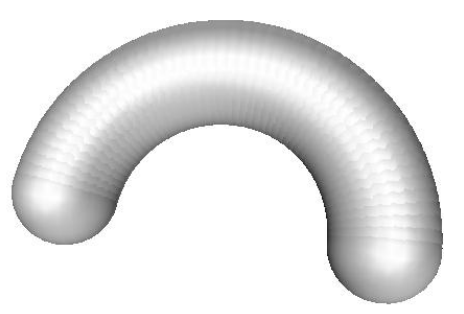

b)

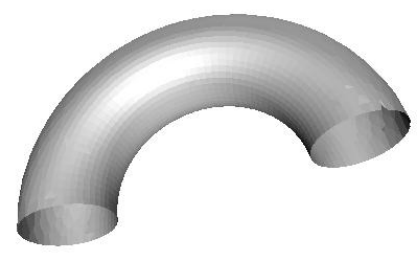

c)

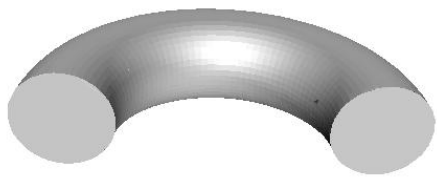

Figura 5.6: Representando variedade com bordo: a) exemplo de meio toro. Note que nos extremos do objeto as bolas polares internas estão entre o interior e o exterior, b) omitindo as faces do power diagrama destas esferas e c) versão original do power crust do objeto.

\section{Extensões}

Implementamos duas extensões para o power crust: A suavização dos pontos com o intuito de gerar elementos mais regulares e triangulação das faces com mais de três vértices uma vez que a saída do power crust não é uma malha triangular.

\section{Suavização}

Aplicamos um método de suavização das coordenadas para obter uma malha com elementos mais regulares e os vértices melhor distribuídos. O filtro que aplicamos é denominado suavização laplaciana.

$\mathrm{O}$ algoritmo procede da seguinte maneira: Dado um vértice $v$, seja $V_{v}=\left\{v_{1}, \ldots, v_{k}\right\}$ os vértices no link de $v$ (definição 24). As coordenadas de $v$ são alteradas segundo a média aritmética das coordenadas dos vértices de $V_{v}$.

O filtro laplaciano não pode ser aplicado a todos os vértices. A seguir apresentamos as duas exceções:

1. Vértices do bordo: Se a variedade tiver bordo, não realizamos alterações nas coordenadas do bordo;

2. Vértices de quinas $e$ interiores: Para cada aresta $e$ incidente em $v$ analisamos se a variação do ângulo entre as normais de cada face que compartilham $e$ é maior que um valor limite (em geral utilizamos $45^{\circ}$ ). Se ocorrem exatamente duas variações de ângulos maiores que o valor limite e se o ângulo entre as duas arestas é menor que um limitante para o ângulo entre as arestas (em geral $15^{\circ}$ ) (figura 5.7-a) ) então a suavização 
é realizada ao longo destas duas arestas. Se ocorrem mais de duas variações maiores que o valor limite não alteramos a coordenada do vértice (figura 5.7-b) ).

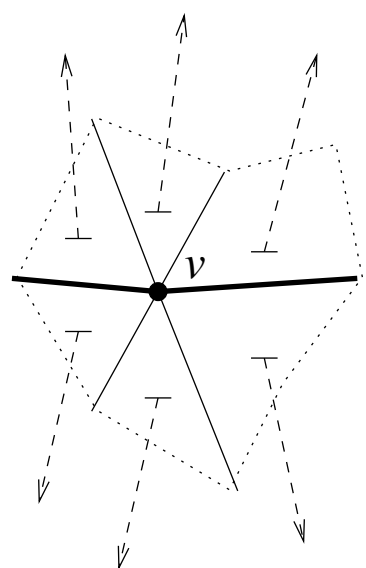

a)

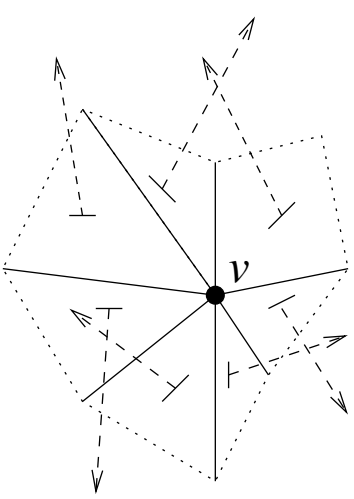

b)

Figura 5.7: Exemplos de ângulos entre as faces: a) apenas duas arestas (negrito) sofrem grande variação entre as normais das faces que as compartilham, b) várias arestas sofrem variações entre as normais das faces.

As características geométricas da malha podem ser perdidas quando aplicamos muitas vezes o filtro laplaciano (figura 5.8).

\section{Triangulação da malha híbrida}

Com o intuito de obter uma malha triangular a partir da saída do power crust, implementamos um método de triangular os polígonos diferentes de triângulos. No entanto, esta rotina não garante que a solução seja satisfatória. Aliando o método de suavização com a triangulação da malha híbrida é possível obter malhas com elementos mais regulares (figura 5.9).

A principal desvantagem deste pós-processamento é o aumento do número de vértices e faces da malha. Um fato a ser investigado é utilizar algoritmos de clusterização (Mederos et al., 2003) como etapa de pré-processamento para selecionar pontos mais significativos para a reconstrução, realizar o power crust dos pontos significativos e, em seguida, aplicar as operações de pós-processamento. Acreditamos que estas etapas pré e pós-processamento aliadas ao power crust podem gerar um algoritmo eficiente, e o tempo de execução diminuiria significativamente. 
a)

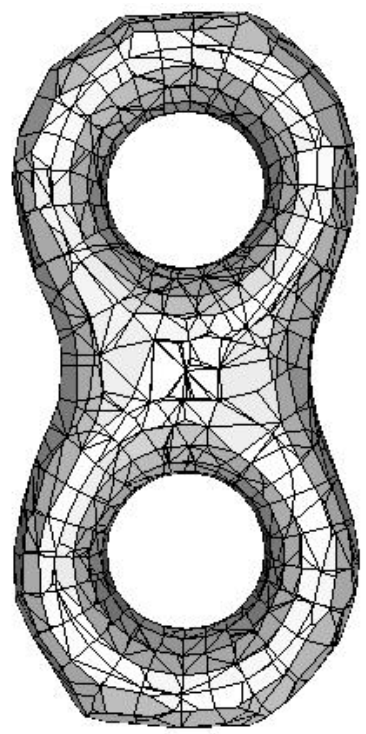

b)

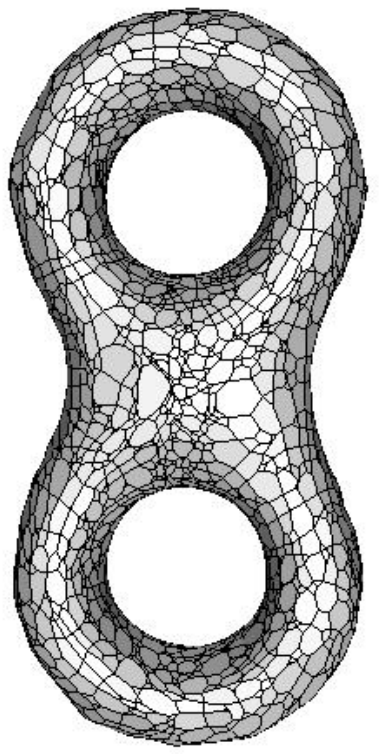

c)

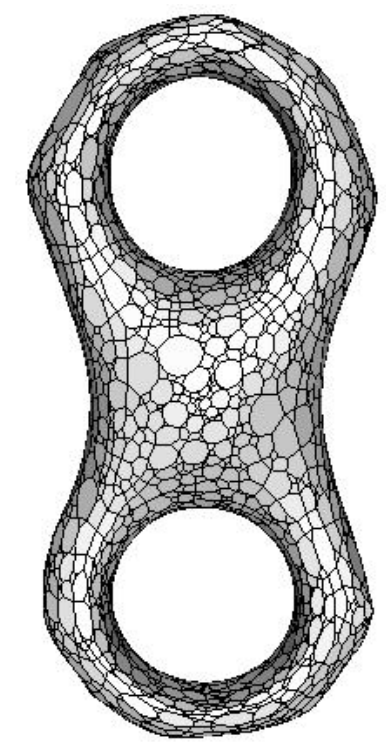

Figura 5.8: Aplicação do filtro laplaciano: a) objeto original, b) aplicação de 500 vezes o filtro laplaciano, c) aplicação de 10000 o filtro laplaciano.

Para estas etapas de pós-processamento utilizamos a estrutura de dados half-edge implementada na biblioteca CGAL 2.4 pelo fato dela suportar operações topológicas sobre uma 2 -variedade em $\mathbb{R}^{3}$. No entanto para o filtro laplaciano optamos em utilizar a classe presente na biblioteca VTK 4.2 devido ao fato da biblioteca CGAL não permitir que o usuário altere as coordenadas dos vértices.

\subsection{Ruídos}

Uma situação em que o teorema 22 (capítulo 4) falha é na existência de amostragens ruidosas. Neste caso, algumas células de Voronoi são arredondadas, ou são longas e perpendiculares num sentido, mas não no outro.

Ao invés de assumirmos que o teorema 22 é sempre válido, testamos o formato da célula de Voronoi para cada ponto $p$ da amostragem. O usuário atribui uma estimativa $\lambda$ para $r^{\prime}=$ $\frac{r}{1-r}$ de modo a obter um limite inferior para o $L F S(p)$. A seguinte expressão é utilizada para estimar o $L F S(p)$.

$$
L F S(p) \geq \min _{v \in V_{p}}\left\{\frac{\|p-v\| \operatorname{sen}(\beta-\lambda)}{\lambda}\right\}
$$


a)
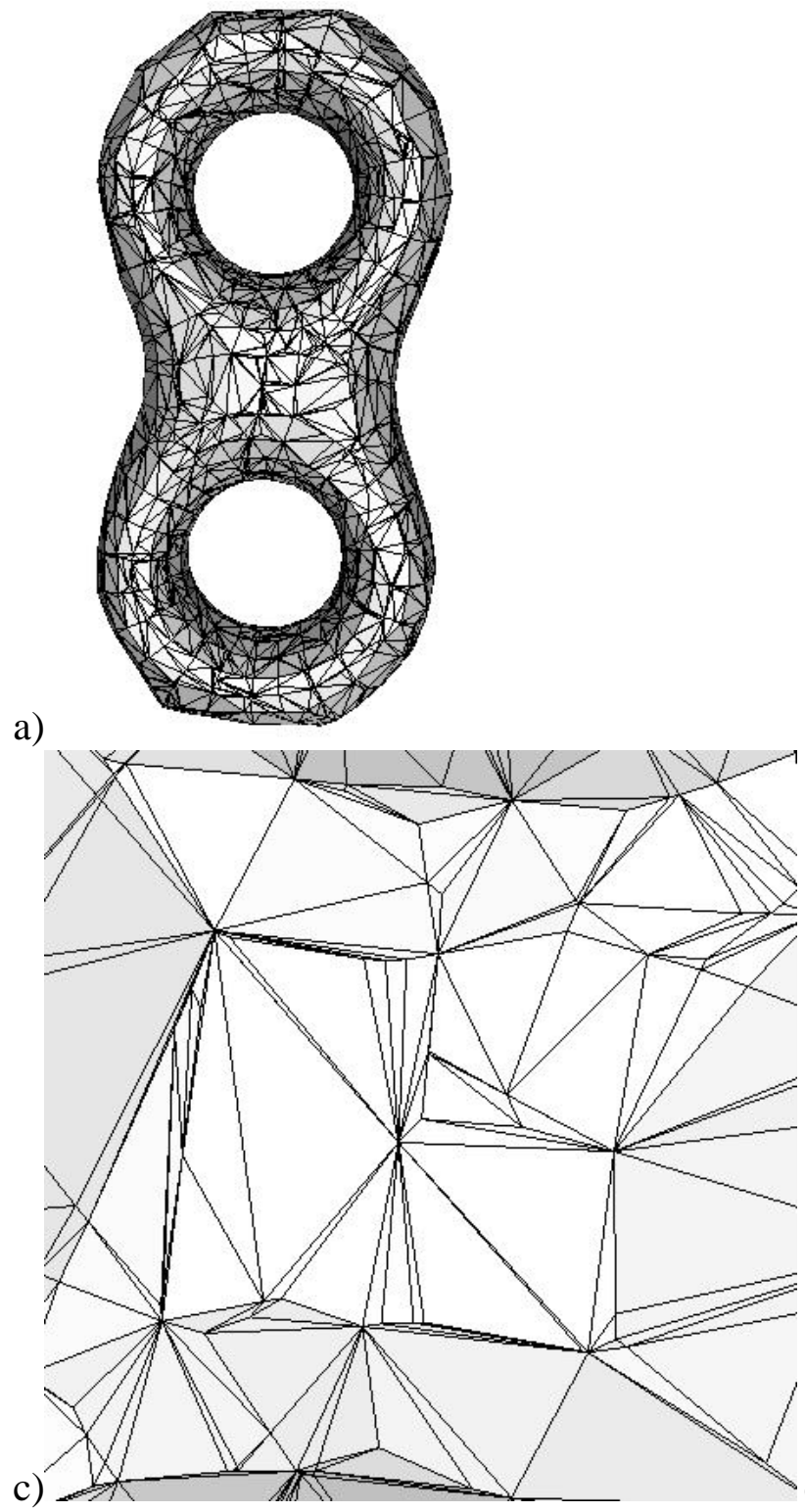

b)
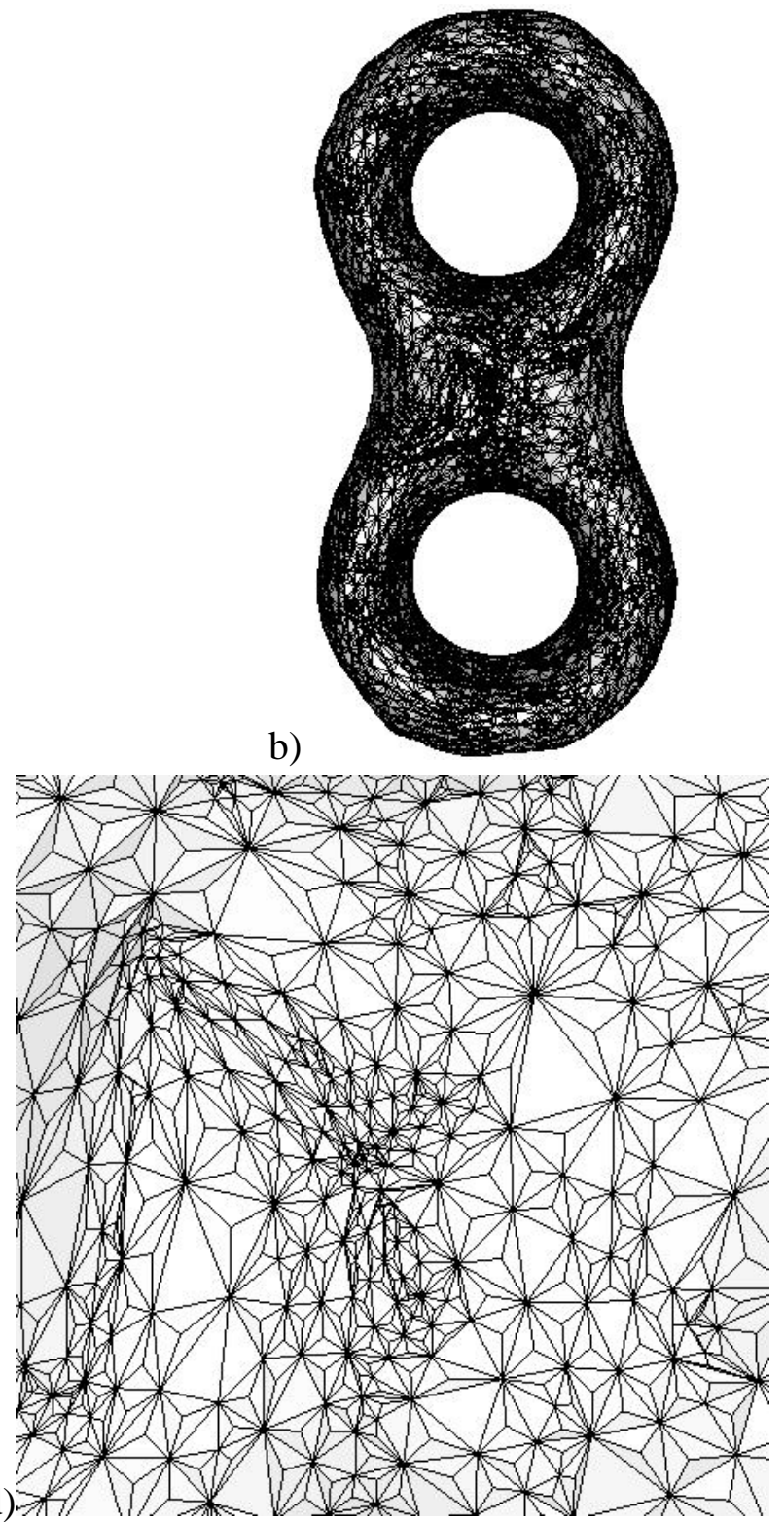

Figura 5.9: Geração de uma malha triangular a partir de uma malha híbrida: a) malha triangular do objeto apresentado na figura 5.8-a), b) malha triangular com aplicação do filtro laplaciano com 1000 iterações, c) “zoom in" de a) e d) "zoom-in" de b) na mesma posição de c).

O conjunto $V_{v}$ contém os vértices da célula de Voronoi de $p$. O ângulo $\beta$ é o menor ângulo entre uma amostra $p$ e dois vértices de Voronoi da célula de $p$.

Este resultado é derivado do teorema 22 em que substituímos $\operatorname{arcsen} \lambda$ por $\lambda$ pois $\operatorname{arcsen} \lambda \cong$ $\lambda$ quando $\lambda$ assume pequenos valores $(0 \leq \lambda \leq 0.6)$. 
De acordo com o teorema 23 para um pólo $x,\|p-x\| \geq L F S(p)$. Se a distância do pólo viola este limite inferior, a célula de Voronoi possui forma indesejável e descartamos $p$. A figura 5.10 apresenta um exemplo bidimensional da aplicação deste filtro de ruídos.

a)

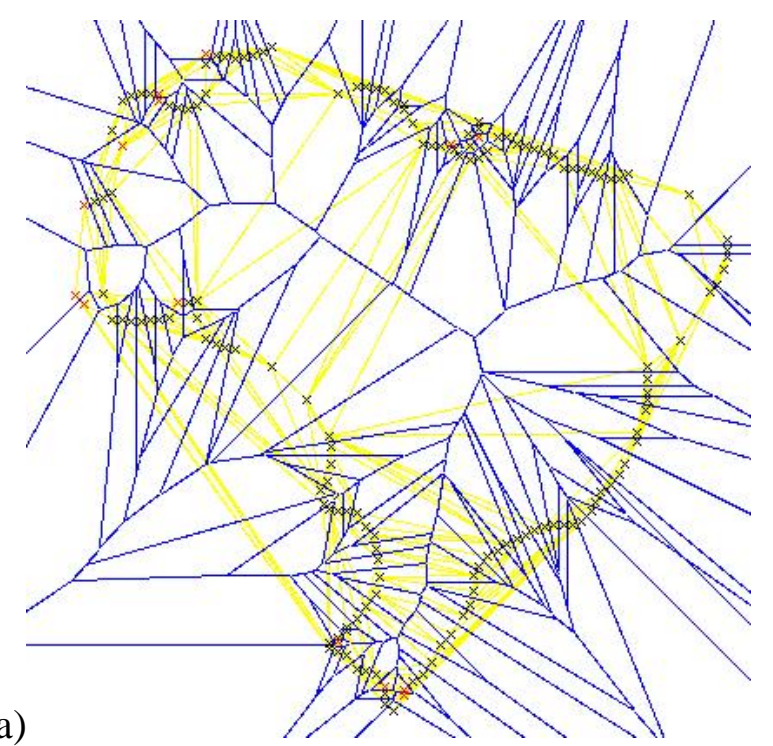

b)

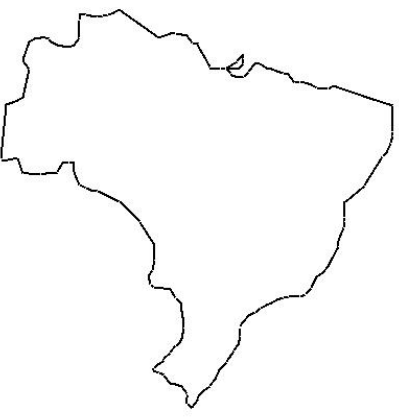

c)

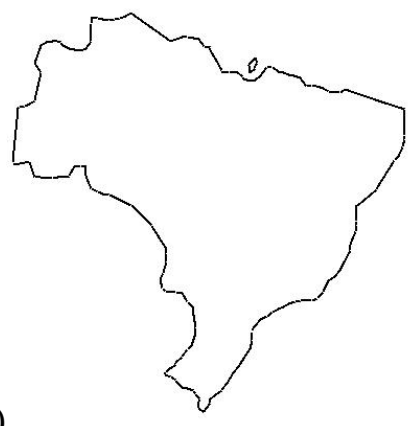

Figura 5.10: Exemplo do teste das células de Voronoi para detecção de ruídos: a) triangulação de Delaunay do conjunto de pontos (em vermelho as identificações de ruídos), b) reconstrução sem a remoção dos ruídos, c) reconstrução com a remoção dos ruídos.

No capítulo 7 apresentamos exemplos em que aplicamos este critério em conjunto com o crust e o power crust para detecção de contornos de imagens.

\subsection{Considerações finais}

Neste capítulo apresentamos algumas características das implementações que realizamos. No capítulo seguinte mostramos comparações que realizamos entre os algoritmos que implementamos e outros presentes na literatura. 


\section{$\frac{-10}{6}$ \\ Comparações e exemplos}

Neste capítulo apresentamos comparações teóricas e práticas entre algoritmos de esculpimento que utilizam as triangulações presentes na biblioteca CGAL 2.4. Os algoritmos comparados são: $\alpha$-shapes ${ }^{1}$, cocone e tight cocone ${ }^{2}$, raw crust e power crust. Também apresentamos comparações entre o power crust original $^{3}$ e nossa implementação do power crust.

Dey apresenta uma comparação teórica entre os algoritmos (comparações entre algoritmos de esculpimento e função implícita) (Dey, 2002). Vale lembrar que comparações de ordem prática não são encontradas na literatura. Existe este interesse em realizar comparações teóricas e práticas simultaneamente pois a pergunta "quando um método é mais eficiente que o outro" está presente em diversas áreas do conhecimento e, em Reconstrução de Superfícies, esta questão tem que ser mantida sendo que muitas vezes um algoritmo que apresenta resultados teóricos satisfatórios, na prática pode apresentar desepenho inferior a um outro algoritmo que não possui garantias teóricas tão satisfatórias (note que isto acontece com o $\beta$-skeleton e o crust no caso bidimensional - capítulo 4).

Realizamos um teste de reconstrução para verificar a capacidade dos algoritmos em identificar múltiplas componentes. Aplicamos os algoritmos em dois elipsóides (um contido no interior do outro) e uma cabeça de um homem e o seu cérebro. Todos os algoritmos conseguiram identificar as duas componentes com exeção do tight cocone que ignorou o elipsóide e o cérebro localizados no interior das amostragens (figura 6.1).

\footnotetext{
${ }^{1}$ Demo presente na biblioteca CGAL: http://www.cgal.org.

${ }^{2}$ Implementados por Tamal K. Dey: http://www.cis.ohio-state.edu/ tamaldey.

${ }^{3}$ A versão original do power crust está no site http://www.cs.utexas.edu/users/amenta/powercrust.
} 
a)

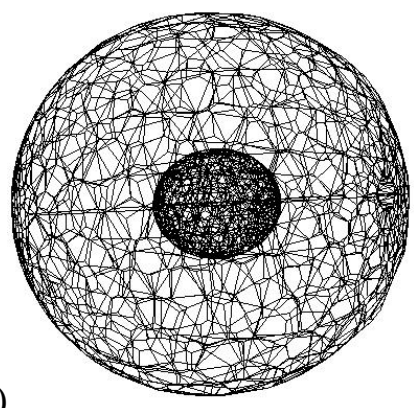

c)

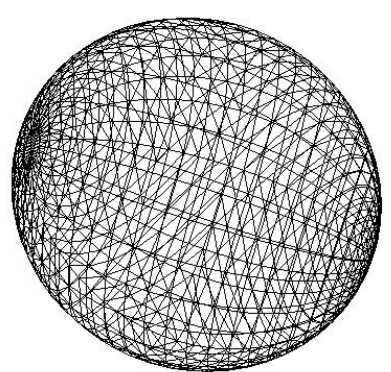

b)

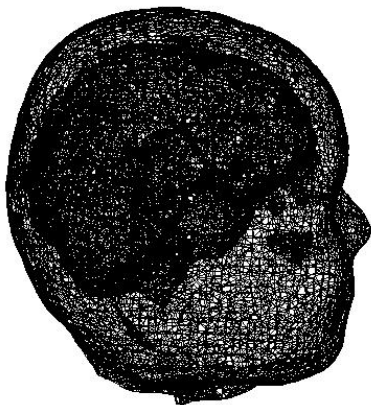

d)

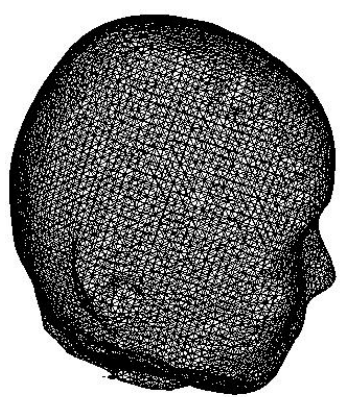

Figura 6.1: Reconstrução de múltiplas componentes conexas: Em a) e b) observamos a reconstrução utilizando o power crust e em c) e d) reconstrução utilizando o tight cocone que ignorou completamente as componentes conexas internas.

Alguns conjuntos de pontos aplicados ao tight cocone não retornam saída, por exemplo, se aplicarmos os conjuntos de pontos que resultaram nas figuras 6.9-a) (obtida pelo raw crust) e 7.3-a) (obtida pelo power crust).

$\mathrm{Na}$ tabela 6.1 apresentamos informações teóricas sobre os algoritmos. A segunda coluna se refere ao tipo de malha superficial gerada por cada método. A terceira coluna apresenta resultados teóricos referentes à garantia de homeomorfismo. A última coluna diz se os algoritmos, em geral, fornecem resultados geometricamente próximos à superfície original. Naturalmente as informações fornecidas na tabela 6.1 são garantidas apenas para variedades bem amostradas, lembrando que para o $\alpha$-shape uma boa amostragem é considerada para pontos regularmente espaçados e para a família crust são os baseados em $r$-amostragens, com $r$ suficientemente pequeno.

Discutimos o custo computacional na tabela 6.2. Na coluna 2 apresentamos o número de triangulações de Delaunay, em que $n$ é número de pontos considerados durante o processo de triangulação. Na coluna 3 o número de cálculos de duais e o número de pontos envolvidos para cada cálculo. Na última coluna os cálculos geométricos mais custosos para cada algo- 


\begin{tabular}{|c|c|c|c|}
\hline Algoritmo & Tipo de Malha & $\begin{array}{c}\text { Garantias } \\
\text { de homeomorfismo }\end{array}$ & Geometricamente próximo \\
\hline$\alpha$-shapes & Triangular & Não & Sim \\
\hline raw crust & Triangular & Sim & Sim \\
\hline cocone & Triangular & Sim & Sim \\
\hline tight cocone & Triangular & Sim & Sim \\
\hline power crust & Híbrida $^{4}$ & Sim & Sim \\
\hline
\end{tabular}

Tabela 6.1: Informações teóricas dos algoritmos. A segunda coluna refere ao tipo de malha, a terceira coluna indica se o algoritmo apresenta garantias teóricas e a última coluna diz se, em geral, os algoritmos apresentam semelhanças geométricas.

ritmo. As principais vantagens e desvantagens mais significativas de cada um dos algoritmos apresentamos na tabela 6.3.

\begin{tabular}{|c|c|c|c|}
\hline Algoritmo & $\begin{array}{c}\text { Delaunay/ } \\
\text { Número } \\
\text { de pontos }\end{array}$ & $\begin{array}{c}\text { Voronoi/ } \\
\text { Número } \\
\text { de pontos }\end{array}$ & $\begin{array}{c}\text { Cálculos geométricos } \\
\text { mais custosos }\end{array}$ \\
\hline$\alpha$-shapes & $1 / n$ & $0 / 0$ & Inraios \\
\hline raw crust & $1 / 3 n$ & $1 / n$ & Duais \\
\hline cocone & $1 / n$ & $1 / n$ & Duais e ângulos entre vetores \\
\hline tight cocone & $1 / n$ & $1 / n$ & Duais e ângulos entre vetores \\
\hline power crust & $2 / n$ e $2 n$ & $2 / n$ e $2 n$ & $\begin{array}{c}\text { Duais, ângulos entre vetores, } \\
\text { ângulos entre esferas e } \\
\text { funções trigonométricas }\end{array}$ \\
\hline
\end{tabular}

Tabela 6.2: Custo computacional.

Nas tabelas 6.4 e 6.5 apresentamos comparações de resultados práticos que aplicamos aos algoritmos. Executamos os testes em um dual Athlon 2200+ com 1Gb de memória RAM.

Na tabela 6.6 comparamos o tempo entre a nossa implementação do power crust e a implementação original (Amenta et al., 2001a) cujo algoritmo de triangulação é denominado $H u l l^{5}$, um código aberto com aritmética exata para cálculo da triangulação de Delaunay. Amenta realizou adaptações a este código para gerar uma triangulação de Delaunay com peso. Este algoritmo possui estratégias de otimização de inserção de pontos que implica na redução do tempo de processamento (Choi e Amenta, 2002).

Para esta comparação aplicamos a estratégia de otimização da triangulação de Delaunay da biblioteca do CGAL, denominado Hierarchy Triangulation ${ }^{6}$. Para a triangulação de De-

\footnotetext{
${ }^{5}$ Implementado por Ken Clarkson: http://www.cs.sunysb.edu/ algorith/implement/clarkson/implement.shtml

${ }^{6}$ No site da biblioteca CGAL encontra-se a descrição desta estratégia de otimização.
} 


\begin{tabular}{|c|c|c|}
\hline Algoritmo & Vantagem & Desvantagem \\
\hline$\alpha$-shapes & Heurística simples & $\begin{array}{c}\text { Não garante homeomorfismo, } \\
\text { definição de valores de } \alpha \mathrm{e} \\
\text { muito lenta a implementação do CGAL* }\end{array}$ \\
\hline raw crust & Geometricamente semelhante & $\begin{array}{c}\text { Número pontos na triangulação, duais e } \\
\text { amostragem densa para } \\
\text { garantir variedade }\end{array}$ \\
\hline cocone & $\begin{array}{l}\text { Melhora o crust e } \\
\text { rapidez }\end{array}$ & $\begin{array}{l}\text { Na prática deixa a superfície } \\
\text { com buracos }\end{array}$ \\
\hline tight cocone & $\begin{array}{l}\text { Busca obter uma variedade e } \\
\text { rapidez }\end{array}$ & $\begin{array}{l}\text { Pode deixar na reconstrução } \\
\text { triângulos indesejáveis, } \\
\text { isola pontos da amostragem e } \\
\text { não identifica superfícies } \\
\text { internas a outras superfícies }\end{array}$ \\
\hline power crust & Obtém-se uma variedade & $\begin{array}{l}\text { Muitos cálculos geométricos, } \\
\text { criação de pontos } \\
\text { Steiner** e } \\
\text { problemas numéricos }\end{array}$ \\
\hline
\end{tabular}

Tabela 6.3: Vantagens e desvantagens de cada método (*esta implementação é lenta, pois o algoritmo pré-calcula 100 valores de $\alpha$ ), (** pontos Steiner são os pontos utilizados por um algoritmo que não são parte da amostragem).

\begin{tabular}{|c|c|c|c|c|c|}
\hline Algoritmo & $\begin{array}{c}\text { Lebre } \\
1000^{*}\end{array}$ & $\begin{array}{c}\text { Dragão } \\
10000^{*}\end{array}$ & $\begin{array}{c}\text { Mão } \\
35000^{*}\end{array}$ & $\begin{array}{c}\text { Cavalo } \\
48000^{*}\end{array}$ & $\begin{array}{c}\text { Buda } \\
55000^{*}\end{array}$ \\
\hline$\alpha$-shape & não & não & não & não & não \\
\hline raw crust & não & não & não & não & não \\
\hline cocone & não & não & não & não & não \\
\hline tight cocone & não & sim & não & sim & não \\
\hline power crust & sim & $\operatorname{sim}$ & sim & sim & sim \\
\hline
\end{tabular}

Tabela 6.4: Teste prático: Para quais modelos garantiu-se homeomorfismo (* número de pontos).

\begin{tabular}{|c|c|c|c|c|c|}
\hline Algoritmo & $\begin{array}{c}\text { Lebre } \\
1000 *\end{array}$ & $\begin{array}{c}\text { Dragão } \\
10000 *\end{array}$ & $\begin{array}{c}\text { Mão } \\
36000 *\end{array}$ & $\begin{array}{c}\text { Cavalo } \\
48000 *\end{array}$ & $\begin{array}{c}\text { Buda } \\
55000 *\end{array}$ \\
\hline$\alpha$-shape & 1.88 & 313.38 & 2270.01 & 3870.79 & 4912.01 \\
\hline raw crust & 1.13 & 30.34 & 121.05 & 172.00 & 145.52 \\
\hline cocone & 0.40 & 13.00 & 45.00 & 101.00 & 55.00 \\
\hline tight cocone & 0.51 & 14.50 & 51.01 & 57.6 & 26.1 \\
\hline power crust & 2.12 & 43.43 & 120.75 & 185.09 & 208.94 \\
\hline
\end{tabular}

Tabela 6.5: Tempo de execução em segundos (* número de pontos). 
a)

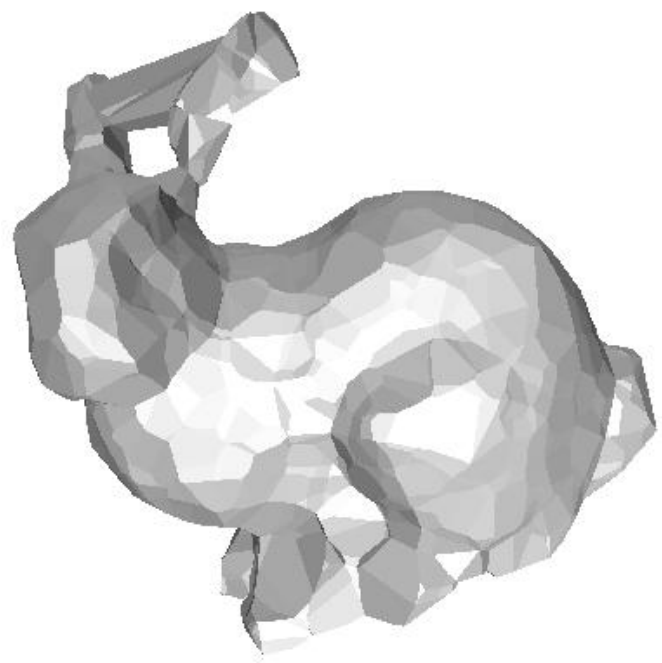

b)

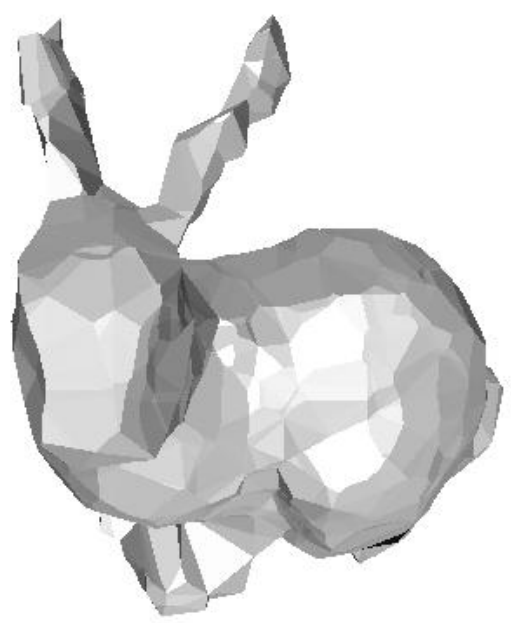

Figura 6.2: Resultados diferentes das implementações do power crust: Em a) temos a reconstrução da lebre (1000 pontos) com a versão original do power crust, em b) temos a nossa implementação.

launay com peso da biblioteca CGAL ainda não existe uma estratégia de otimização (a versão 3.0 da biblioteca também não apresenta estratégia de otimização para a Delaunay com peso). Com isto observamos que o algoritmo original é mais rápido, principalmente pelo fato dele utilizar as duas triangulações otimizadas.

Para alguns modelos, resultados diferentes foram obtidos por nossa implementação do power crust e a versão original do power crust. A figura 6.2 apresenta um exemplo.

\begin{tabular}{|c|c|c|c|c|c|}
\hline Algoritmo & $\begin{array}{c}\text { Lebre } \\
1000^{*}\end{array}$ & $\begin{array}{c}\text { Dragão } \\
10000^{*}\end{array}$ & $\begin{array}{c}\text { Mão } \\
36000^{*}\end{array}$ & $\begin{array}{c}\text { Cavalo } \\
48000^{*}\end{array}$ & $\begin{array}{c}\text { Buda } \\
55000^{*}\end{array}$ \\
\hline Hull & 1.7 & 20.01 & 58.4 & 91.01 & 110.6 \\
\hline$C G A L$ & 1.9 & 29.97 & 74.9 & 114.75 & 120.0 \\
\hline
\end{tabular}

Tabela 6.6: Tempo de execução em segundos (* número de pontos): Comparação entre a implementação original do power crust (Hull e a nossa implementação (CGAL).

Um fato interessante é que o power crust consegue capturar um maior nível de detalhes dos objetos em relação a outras técnicas de esculpimento, além de não apresentar buracos indesejáveis na superfície dos objetos, sendo que apareceram na quase totalidade dos métodos. As imagens apresentadas na seção 6.1 ilustram esses fatos. 


\subsection{Exemplos}

Nesta seção apresentamos um conjunto de exemplos bi e tridimensionais. As figuras 6.3 a 6.7 apresentam exemplos de reconstrução utilizando o $\beta$-skeleton ${ }^{7}$, crust e o power crust bidimensionais.

Podemos notar que na figura 6.3-d) a reconstrução obtida pelo power crust não está próxima do objeto original. Este é um exemplo de reconstrução homeomorfa, mas não próxima ao objeto original. Esta situação ocorre pelo fato da amostragem possuir poucos pontos.

As figuras de 6.8 a 6.12 apresentam exemplos de reconstruções obtidas pelo $\alpha$-shape (implementação da biblioteca CGAL), raw crust, cocone e tight cocone (implementados por Tamal K. Dey : http://www.cis.ohio-state.edu/ tamaldey.) e power crust.

a)

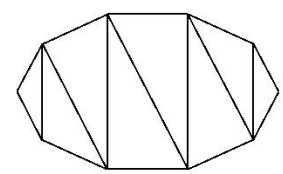

b)

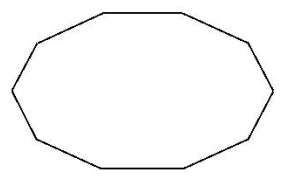

c)

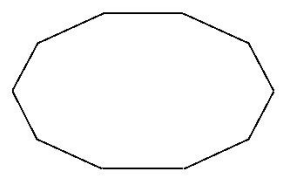

d)

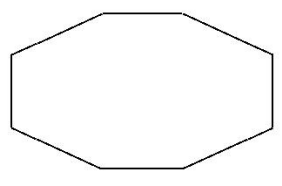

Figura 6.3: Reconstrução de curvas: a) triangulação de Delaunay do conjunto de pontos, b) $\beta$-skeleton, c) crust e d) power crust (a reconstrução não está próxima).

a)

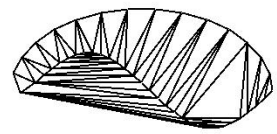

b)

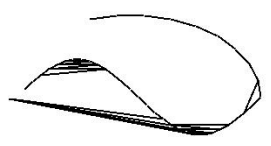

Figura 6.4: Reconstrução de curvas: a) triangulação de Delaunay do conjunto de pontos, b) $\beta$-skeleton, c) crust e d) power crust.

a)

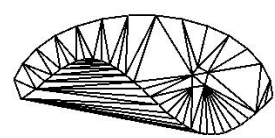

b)

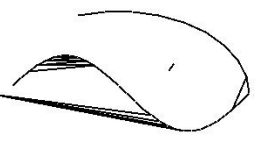

c)

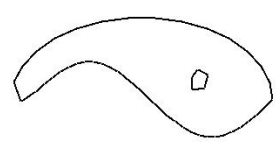

d)

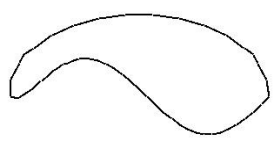

d)

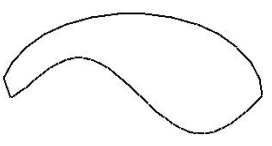

c)

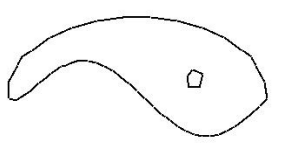

Figura 6.5: Reconstrução de curvas: a) triangulação de Delaunay do conjunto de pontos, b) $\beta$-skeleton, c) crust e d) power crust.

\footnotetext{
${ }^{7} \mathrm{O}$ valor de $\beta$ é 1.70 (ver teorema 12 ).
} 
a)

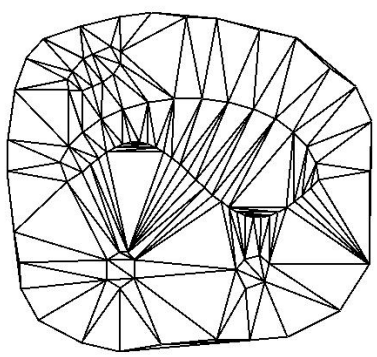

c)

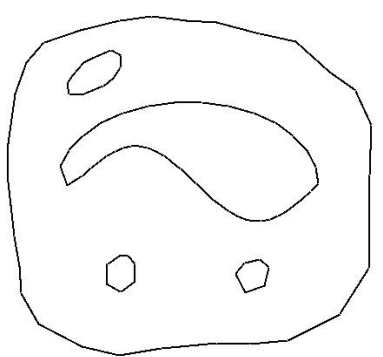

Figura 6.6: Reconstrução de curvas: a) triangulação de Delaunay do conjunto de pontos, b) $\beta$-skeleton, c) crust e d) power crust.

a)

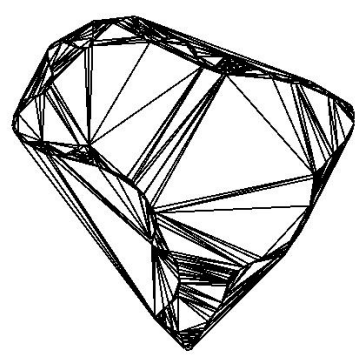

c)

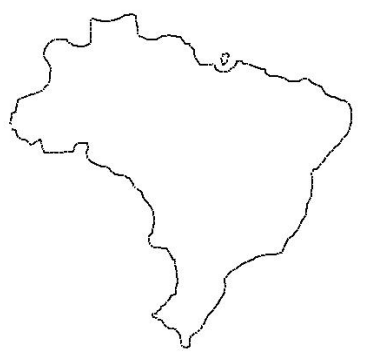

Figura 6.7: Reconstrução de curvas: a) triangulação de Delaunay do conjunto de pontos, b) $\beta$-skeleton, c) crust e d) power crust.

b)

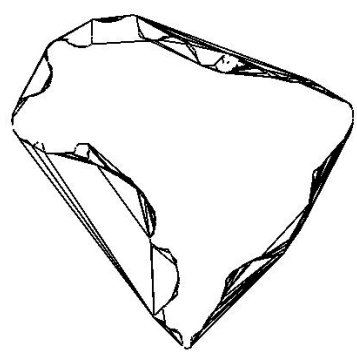

d)
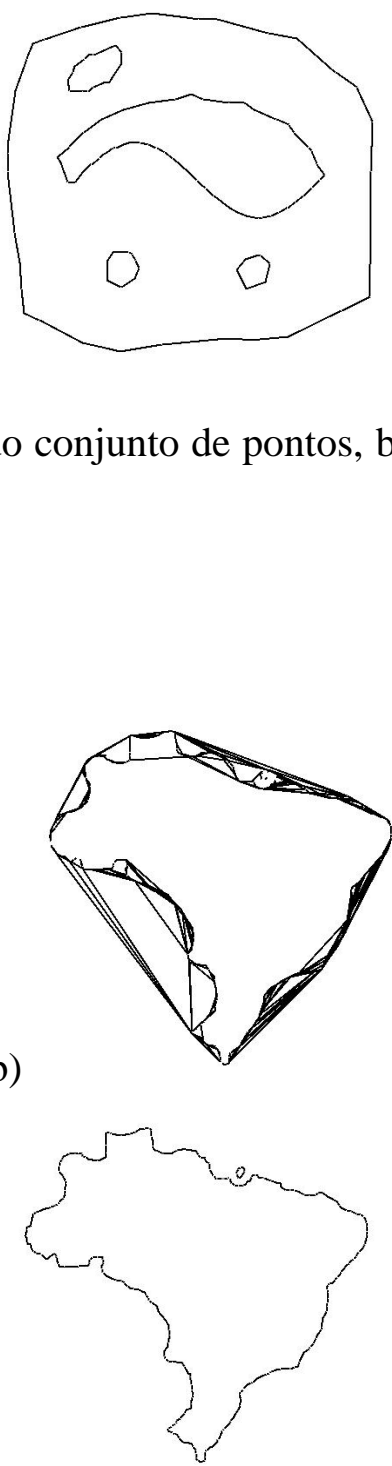
a)

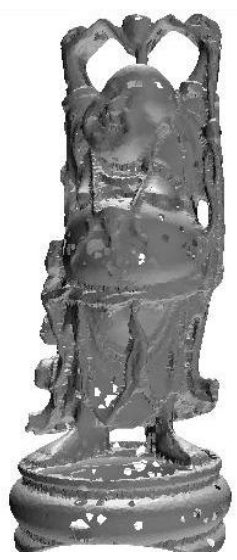

b)

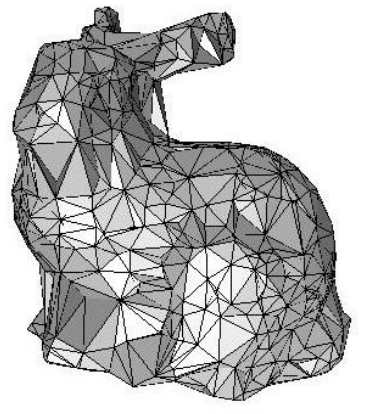

e)

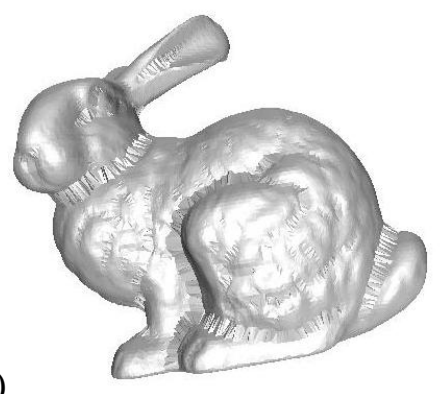

f)

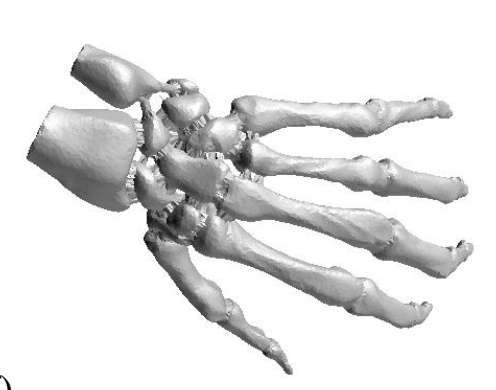

c)
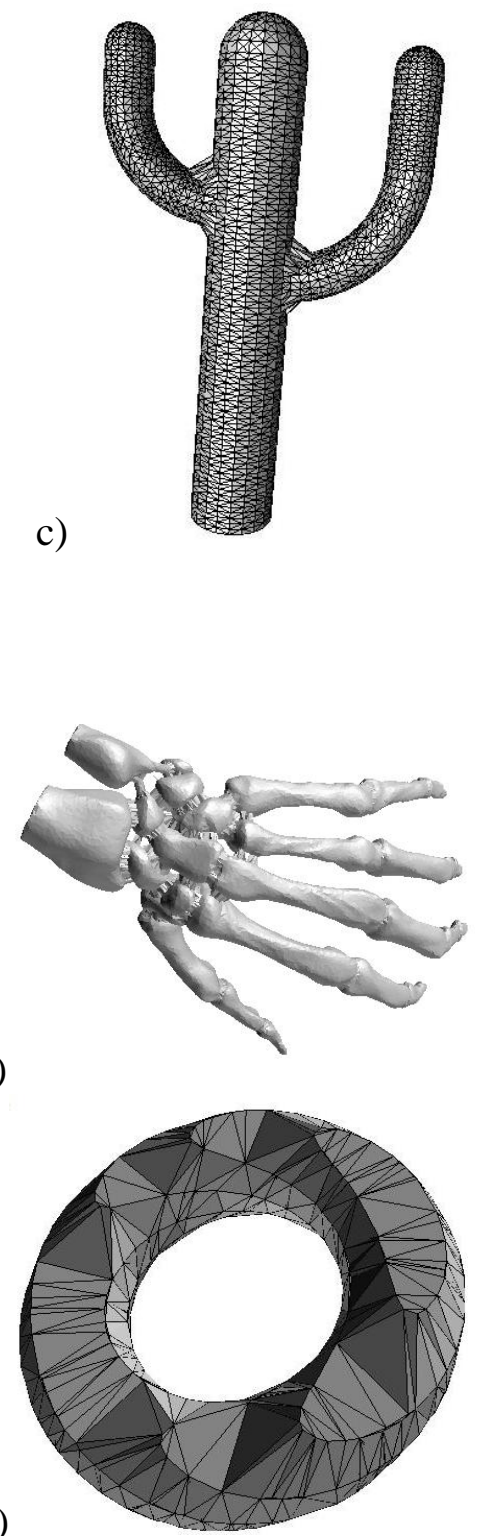

g)

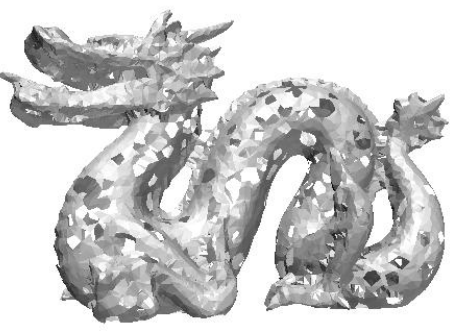

h)

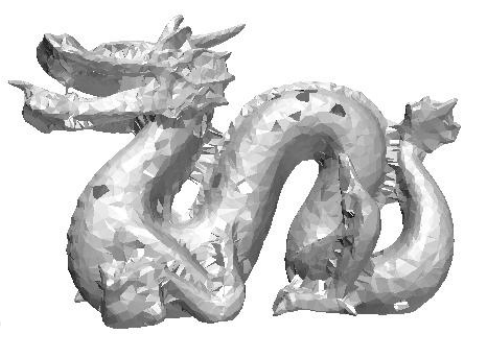

i)

Figura 6.8: Exemplos de $\alpha$-shape: Nestes exemplos buscamos os melhores valores de $\alpha$ para representação dos objetos. a) Buda (50000 pontos com $\alpha=40)$, b) lebre (1000 pontos com $\alpha=50)$, c) cacto (3500 pontos com $\alpha=18)$, d) salsichas (1700 pontos com $\alpha=17$ ), e) lebre (30000 pontos $\operatorname{com} \alpha=40)$, f) mão (36000 pontos $\operatorname{com} \alpha=37)$, g) e f) dragão com diferentes valores de $\alpha$ (10000 pontos com $\alpha=35$ e $\alpha=44$ respectivamentes) e h) toro (500 pontos com $\alpha=50$ ). Vale lembrar que o intervalo dos possíveis valores de alpha para esta implementação é [0,100], em que 0 é a nuvem de pontos e 100 é o fecho convexo. 


\subsection{Considerações finais}

Neste capítulo apresentamos comparações teóricas e práticas entre algoritmos baseados em esculpimento. Comparamos as implementações baseadas nas triangulações presentes na biblioteca CGAL. Para finalizar apresentamos diversos exemplos de objetos gerados por nossos algoritmos e outros presentes na literatura que também utilizam a biblioteca CGAL.

No capítulo seguinte apresentamos algumas aplicações dos algoritmos implementados. 


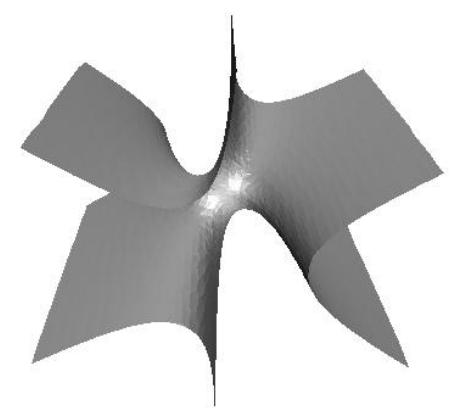

a)
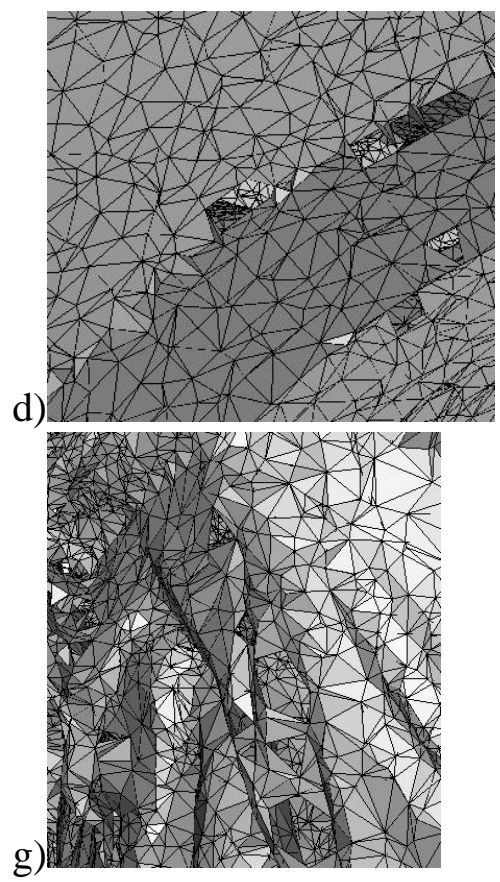

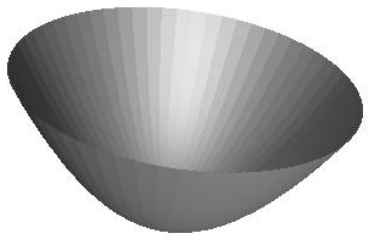

b)

e)

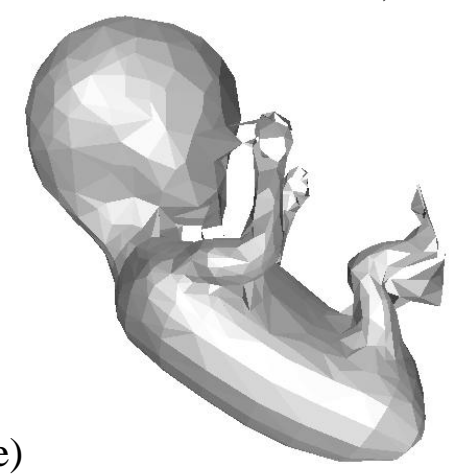

h)

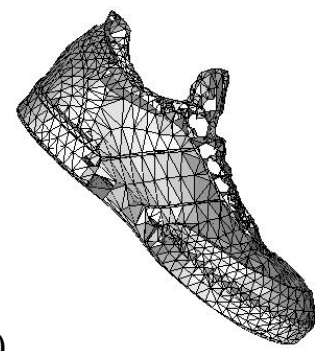

f)
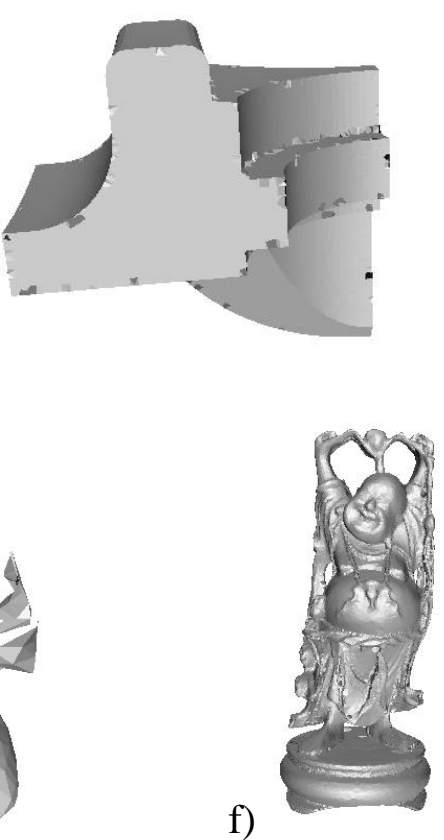

c)

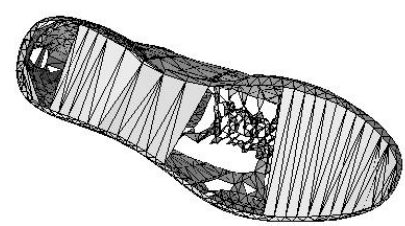

i)

Figura 6.9: Exemplos do raw crust: a) sela (1900 pontos), b) parabolóide (1400 pontos) c) peça mecânica (4100 pontos), d) "zoom-in" de c), e) feto (1000 pontos), f) Buda (50000 pontos), g) “zoom-in" de f), h) tênis (2000 pontos), i) sola do tênis de h). 
a)
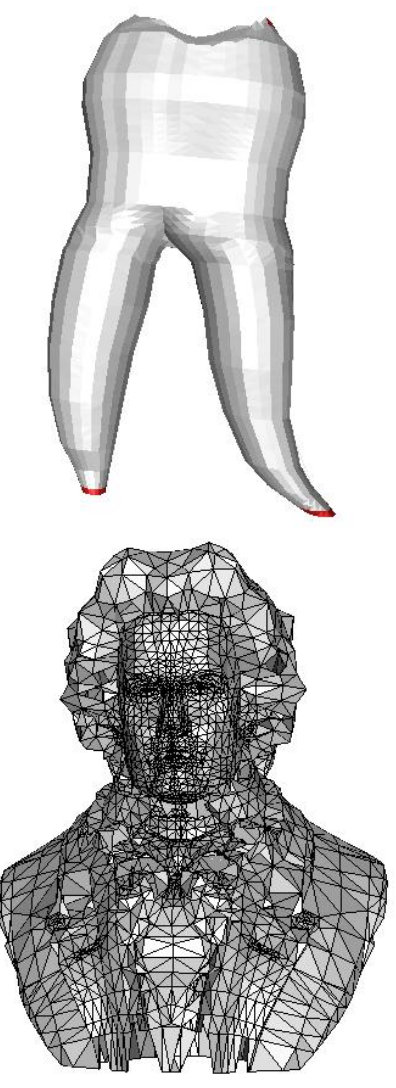

d)

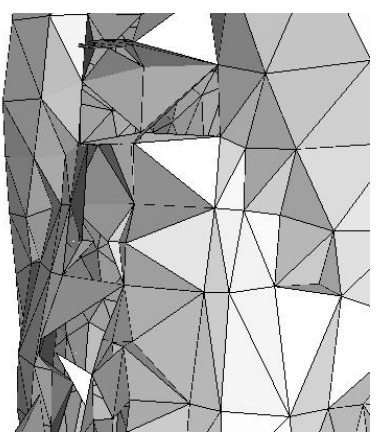

b)
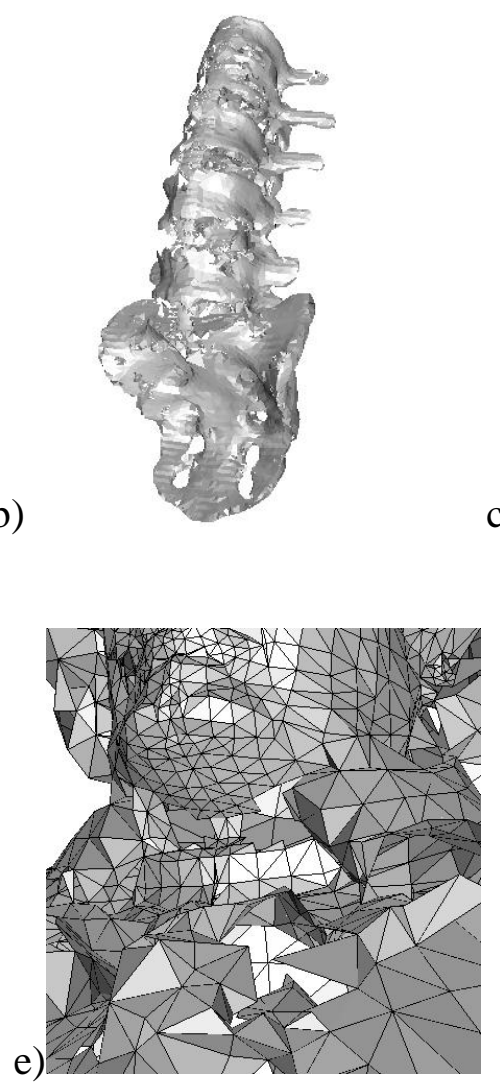

h)

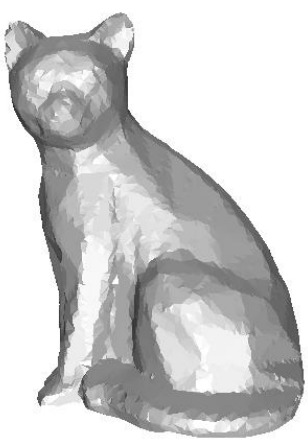

c)
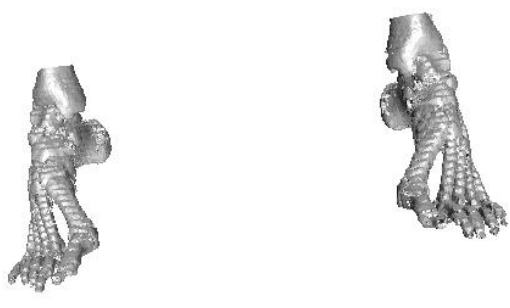

f)

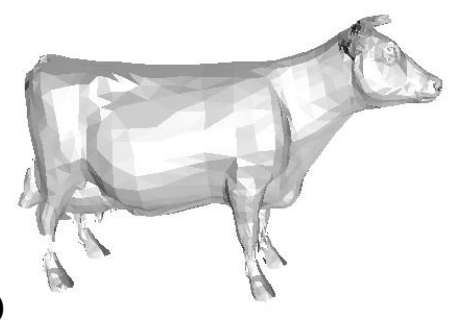

i)

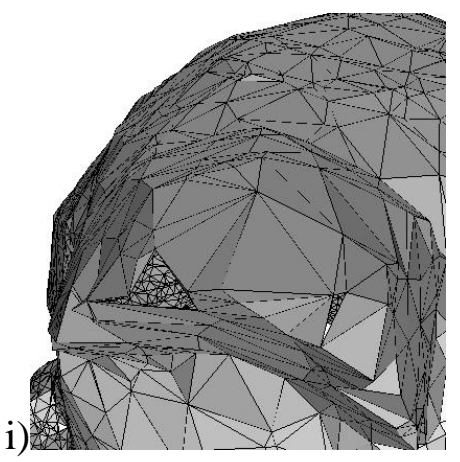

Figura 6.10: Exemplos do cocone: a) dente (4000 pontos), b) espinha dorsal (22000 pontos), c) pés (120000 pontos), d) Beethovem (2600 pontos), e) "zoom-in" de d) (presença de buracos), f) vaca (3000 pontos), g) “zoom-in” de f) (presença de buracos), h) gato (10000 pontos), i) "zoom-in” de h) (presença de buracos). 
a)

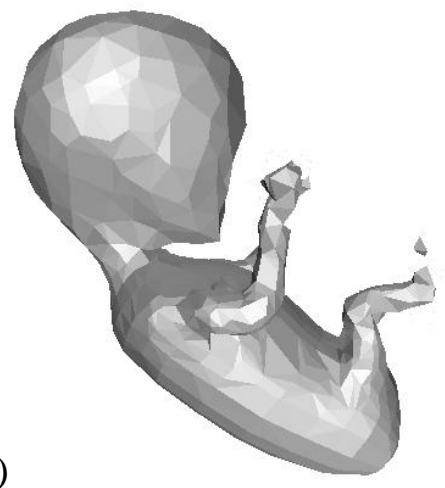

d)
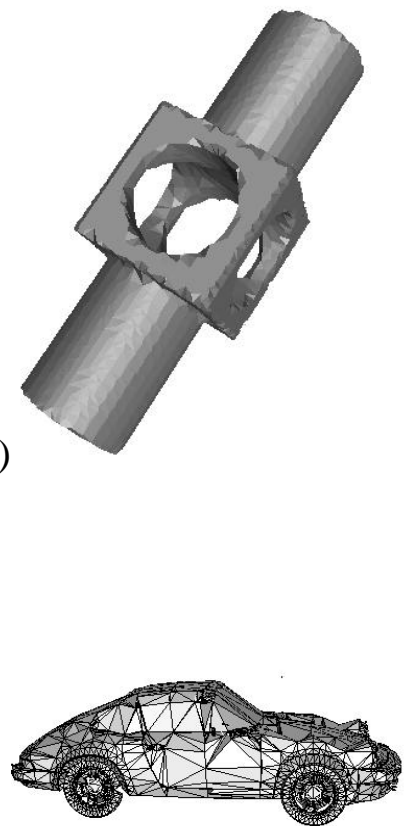

g) b)
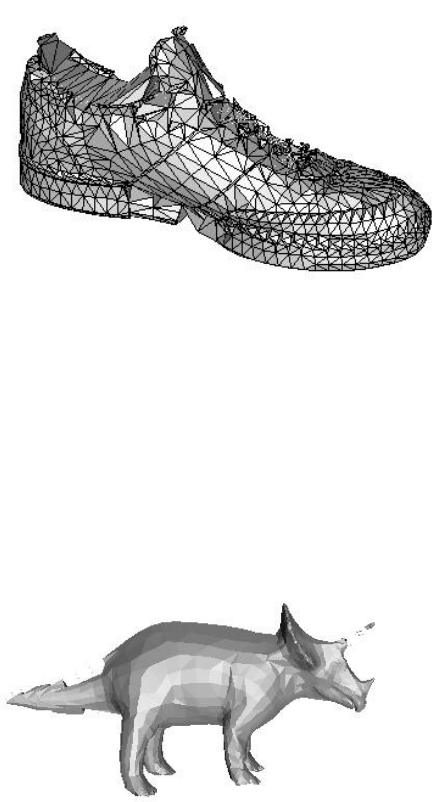

e)

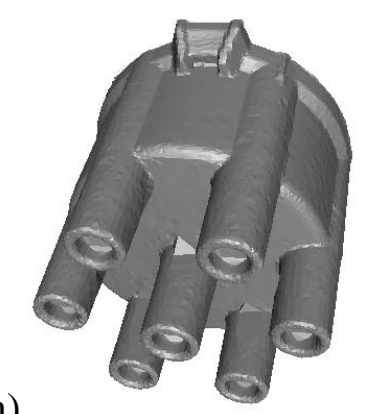

c)
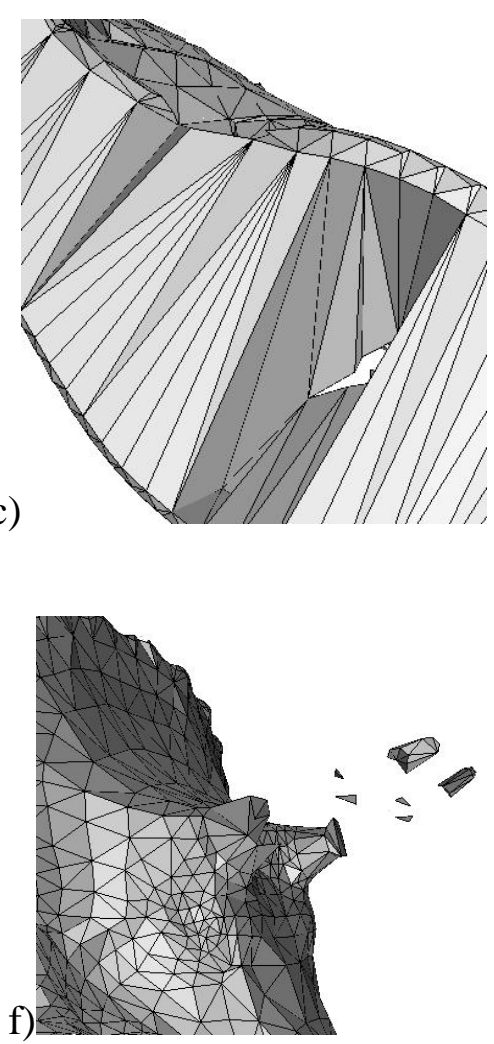

i)

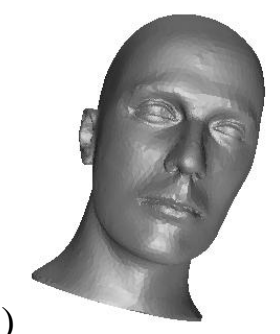

Figura 6.11: Exemplos do tight cocone: a) feto (1000 pontos), b) tênis (2000 pontos) c) "zoom-in" de b) (presença de buracos), d) peça mecânica (4100 pontos), e) tricerátopes (2800 pontos), f) “zoom-in” de e), g) porche ( 6100 pontos), h) distribuidor (12700 pontos ), i) manequim (12700 pontos). 
a)

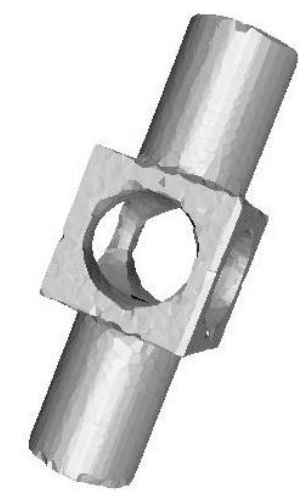

d)
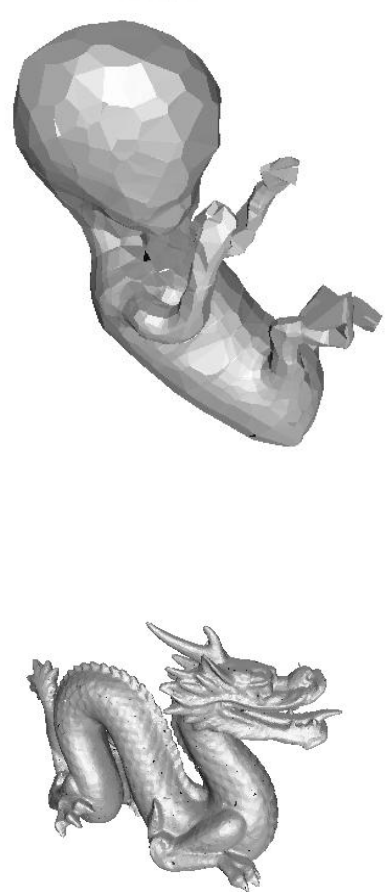

g)

Figura 6.12: Exemplos do power crust: a) peça mecânica (4100 pontos), b) mão (36000 pontos), c) bomba de óleo (31000 pontos), d) feto (1000 pontos), e) espinha dorsal (22000 pontos), f) dragão (1400 pontos), g) dragão (10000 pontos), h) Buda (10000 pontos), i) monstro (24800 pontos). b)

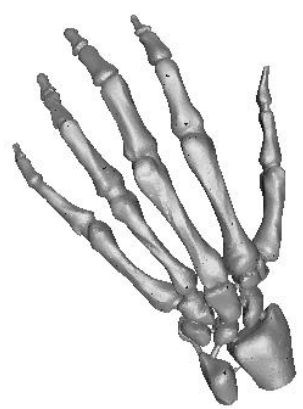

e)

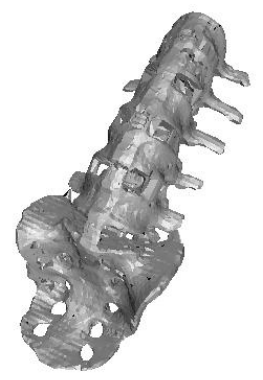

h)

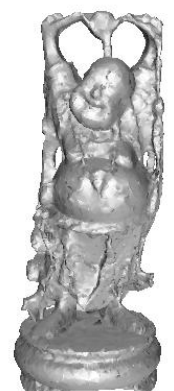

i)

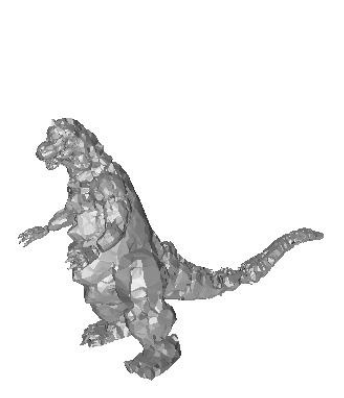

f)

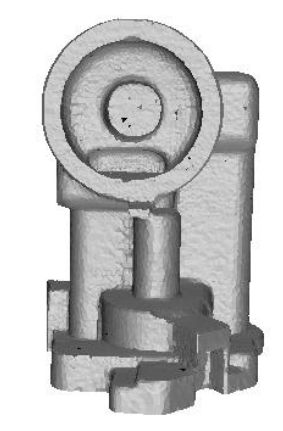

)

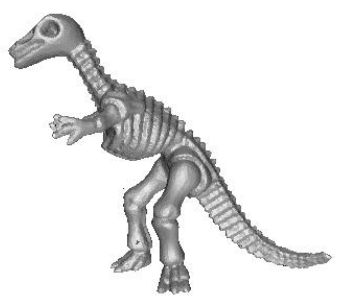




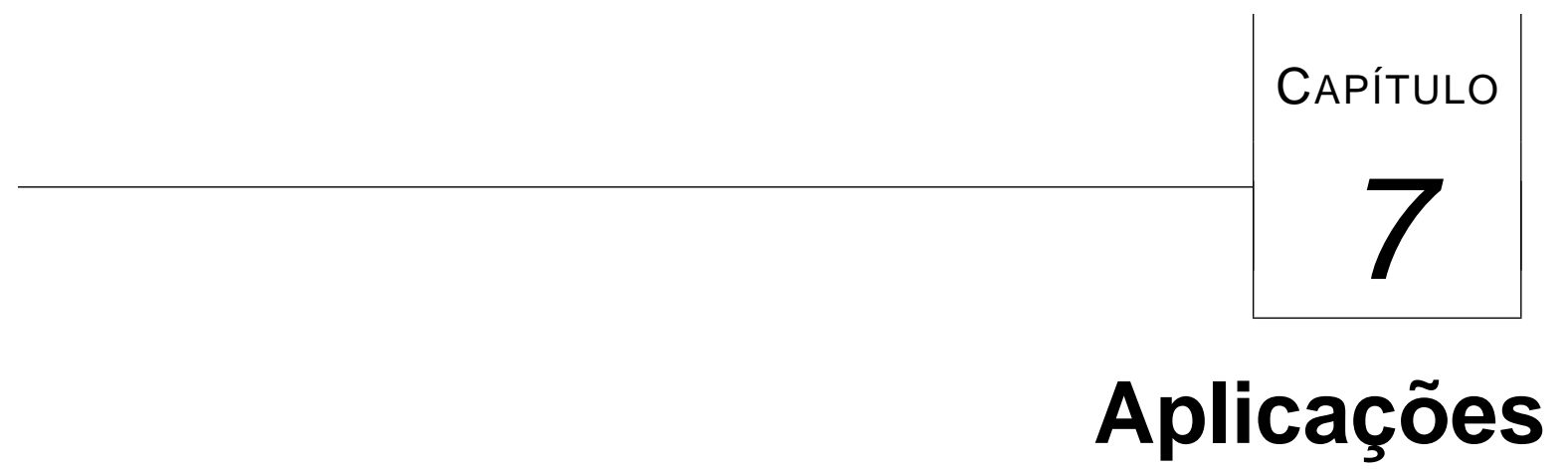

Neste capítulo apresentamos duas aplicações dos estudos realizados neste trabalho: Na primeira utilizamos os modelos obtidos por nossas implementações na simulação numérica de uma Equação Diferencial Parcial (equação do calor tridimensional) e na segunda, em Processamento de Imagens (detecção de contornos de interesse em imagens). Não descrevemos detalhes das implementações e do arcabouço teórico das áreas citadas acima, pois nosso interesse consiste em ilustrar tanto a aplicabilidade quanto a interdisciplinaridade dos nossos estudos.

\subsection{Simulação numérica de E.D.P.'s}

Nesta seção apresentamos uma simulação numérica baseada em Volumes Finitos (Maliska, 1995) da equação parabólica do calor tridimensional dada por:

$$
\frac{\partial T}{\partial t}=\alpha\left(\frac{\partial^{2} T}{\partial x^{2}}+\frac{\partial^{2} T}{\partial y^{2}}+\frac{\partial^{2} T}{\partial z^{2}}\right)
$$

onde $T$ é a temperatura, $(x, y, z)$ é a posição no espaço e $t$ é a variável temporal. O valor $\alpha \in \mathbb{R}$ é o coeficiente de difusividade térmica.

Realizamos as seguintes etapas para obter a solução numérica da equação do calor tridimensional: 
1. Geração das 2-variedades lineares por partes: Utilizamos nossa implementação do power crust para obter 2-variedades como fronteira para os modelos volumétricos gerados na etapa seguinte;

2. Geração da malha volumétrica: As saídas geradas do algoritmo power crust (formato .vrml) foram as entradas para o programa ICEM CFD $4.2^{1}$ para geração de uma malha volumétrica tetraedral.

3. Utilização de uma estrutura de dados topológica para simulação numérica: Carregamos os modelos tridimensionais gerados pelo ICEM CFD na estrutura de dados volumétrica topológica Singular Half-Face - SHF (Bíscaro, 2001) que possui um solver ${ }^{2}$ da equação do calor tridimensional, utilizando a técnica de volumes finitos.

4. Visualização: Visualizamos os dados com a biblioteca VTK 4.2.

As condições de fronteira que aplicamos para os modelos foram:

- Condição de fronteira do tipo Dirichlet: Condição de fronteira do tipo Dirichlet é a determinação da temperatura nos vértices da fronteira do objeto. As regiões vermelhas nas figuras 7.1-a), 7.2-a) e 7.3-a) representam as condições do tipo Dirichlet aplicadas aos modelos nos quais realizamos as simulações numéricas.

- Condição de fronteira do tipo Neumann: Aplicamos a condição inicial do tipo Neumann no restante das faces dos objetos. A condição de fronteira do tipo Neumann é dada pelo fluxo de calor da face de cada tetraedro, que representamos por: $q=-k \frac{\partial T}{\partial n}$ onde $q$ é o fluxo de calor, $k$ é uma constante de difusidade térmica e $\frac{\partial T}{\partial n}$ é a derivada da temperatura em relação a normal da face.

A figura 7.1, que representa metade de um toro, contém 59400 tetraedros, a figura 7.2, que representa uma chaleira, contém 116645 tetraedros e a figura 7.3, que representa um abajour, contém 100360 tetraedros. O espaçamento no tempo para cada iteração foi $\delta t=0.0005 \mathrm{e}$ 2000 iterações para cada objeto.

Colocamos condição de fronteira do tipo Dirichlet com valor fixo de 10.0 e no restante das faces foram colocadas condições de Neumman com fluxo igual a zero. Isto significa que,

\footnotetext{
${ }^{1}$ http://www.icemcfd.com/

${ }^{2}$ Solver é a implementação do método de numérico de uma equação diferencial.
} 
fisicamente o objeto não troca calor com o meio, implicando que os valores da temperatura tendem a convergir para um estado estacionário a medida que aumenta o número de iterações.

Maiores detalhes da discretização e condições de fronteira do problema são encontrados no trabalho de Bíscaro (Bíscaro, 2001). As figuras de 7.1 a 7.3 apresentam exemplos da simulação da equação do calor.

\subsection{Detecção de contornos via Geometria Computacional}

Outra aplicação interessante consiste na utilização de propriedades da Geometria Computacional em Processamento de Imagens. Informações sobre os termos apresentados nesta seção podem ser encontradas no livro "Introdução aos Espaços de Escala (EDPs em Processamento de Sinais)" (Teixeira, 2001). O principal objetivo desta aplicação é a obtenção de reconstruções por poligonais que representem os contornos de interesse de imagens através da análise dos simplexos de uma triangulação gerada sobre a imagem. Em geral os trabalhos propostos na literatura para detecção de contornos em imagens não geram como saída uma reconstrução poligonal, mas sim um conjunto de pixels que representa os contornos das imagens. Procuramos substituir a análise dos thresholds atribuídos aos pixels pela análise de thresholds em simplexos gerados sobre a imagem. Apresentaremos esta idéia e os resultados obtidos a seguir. Uma forma mais interessante, ainda em fase de desenvolvimento, seria a utilização de um critério "puramente geométrico" para a detecção de contornos das imagens.

Nosso interesse por esta aplicação se deu ao observar a possibilidade de utilizar o estudo realizado por Amenta para remoção de ruídos em amostragens de superfícies (ver capítulo 5, seção 5.6) para remoção de ruídos em imagens. Pelo fato do tratamento de imagens ruidosas ser um problema clássico na detecção de contornos em imagens, buscando desenvolver métodos que avaliam se um pixel é ruído baseado em propriedades de Geometria Computacional.

Dada uma imagem bidimensional, propomos um método que representamos o contorno desta imagem é apresentado por um conjunto de arestas da triangulação de Delaunay com peso gerada sobre a imagem. Poucos trabalhos são encontrados na literatura que utilizam triangulações no auxílio de detecção de contornos. Podemos citar, por exemplo, o trabalho proposto por Hermes e Buhmann (Hermes e Buhmann, 2003).

Em geral, para determinar o conjunto de pixels que fazem parte do contorno da imagem, aplicamos alguma convolução discreta (por exemplo Laplaciano, Sobel, Laplaciano do Gaus- 
a)

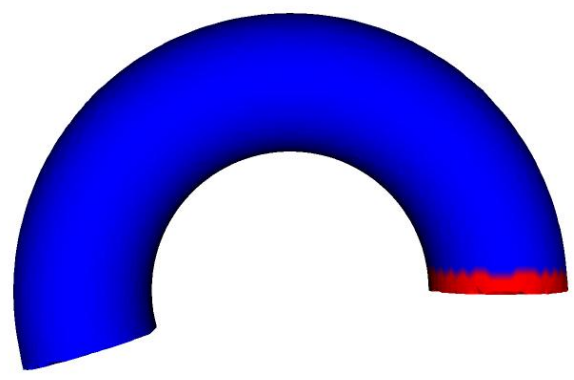

c)

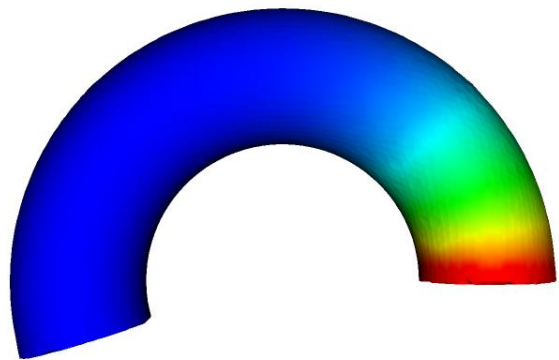

e)

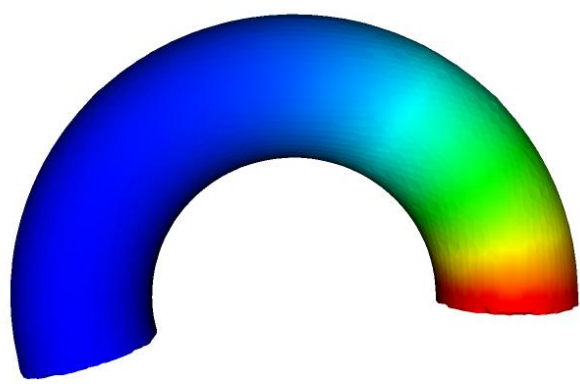

g)

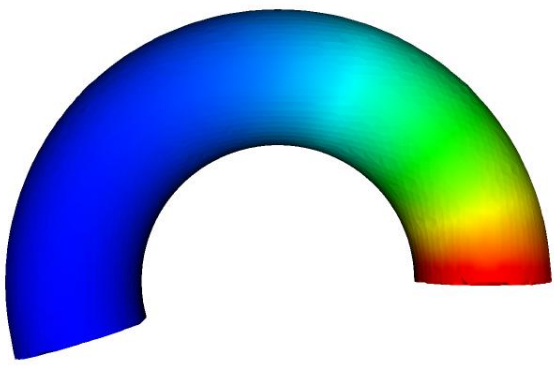

b)

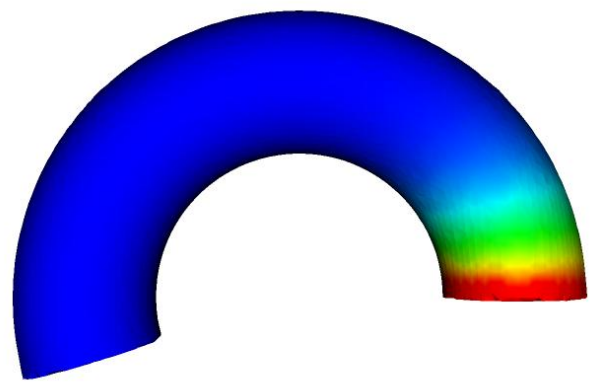

d)

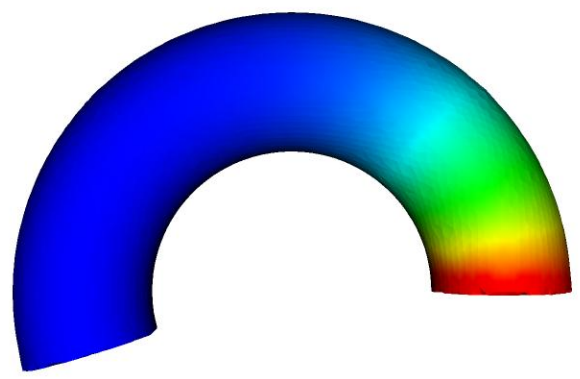

f)

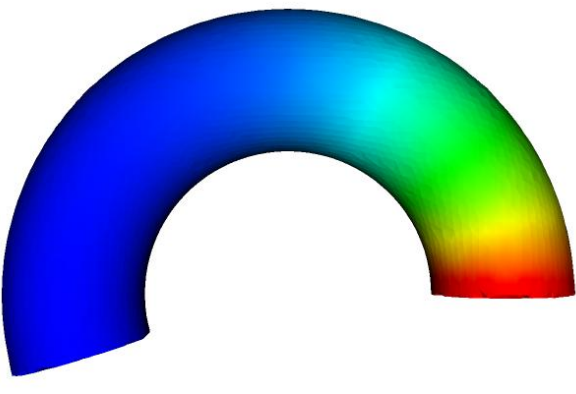

h)

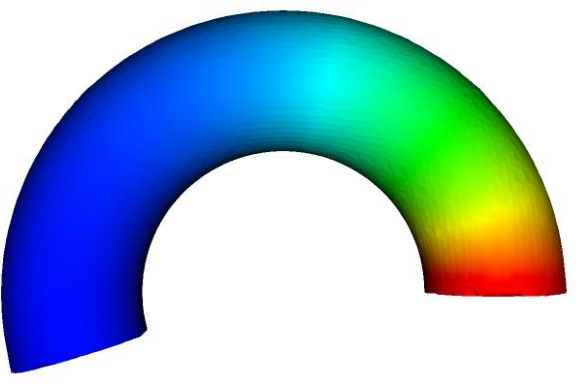

Escala de temperatura

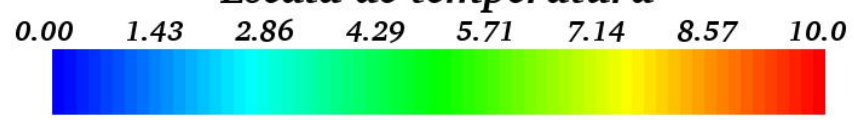

Figura 7.1: Exemplo da aplicação da equação do calor à metade de um tóro: a) condição inicial, b) 200 iterações, c) 600 iterações, d) 800 iterações, e) 1200 iterações, f) 1400 iterações, g) 1600 iterações, h) 2000 iterações. 
a)
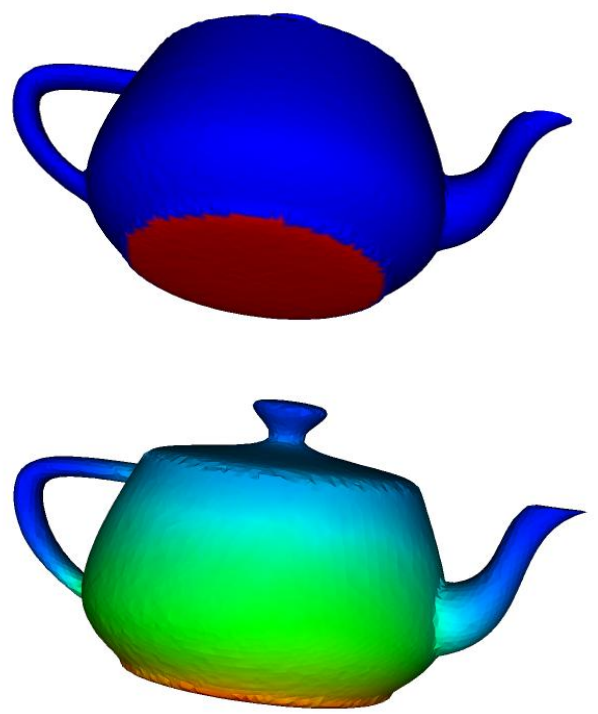

c)

e)

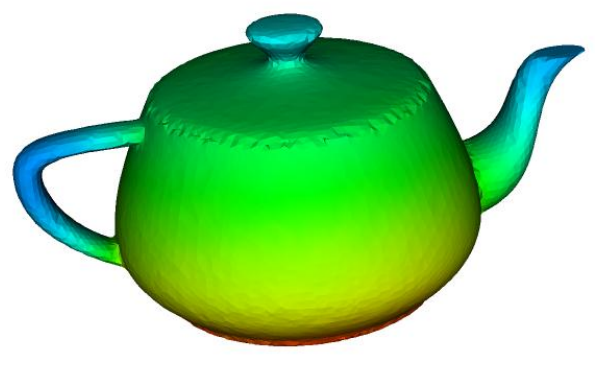

g)

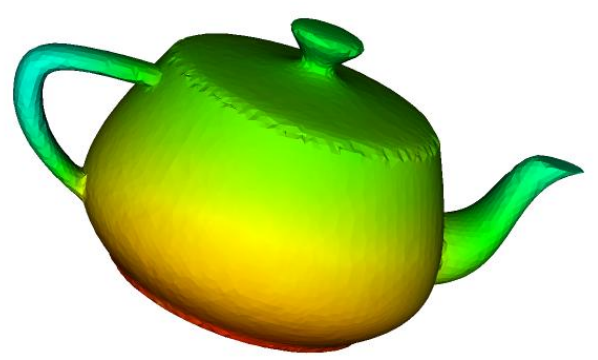

Escala de temperatura

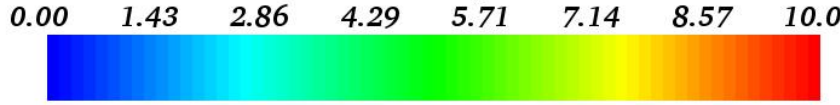

Figura 7.2: Exemplo da aplicação da equação do calor: a) condição inicial, b) 200 iterações, c) 600 iterações, d) 1000 iterações, e) 1200 iterações, f) 1600 iterações, g) 1700 iterações, h) 2000 iterações. b)

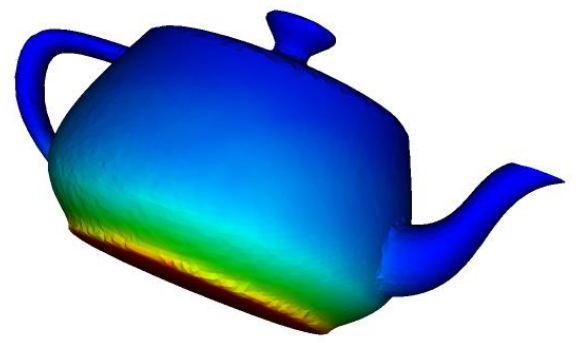

d)

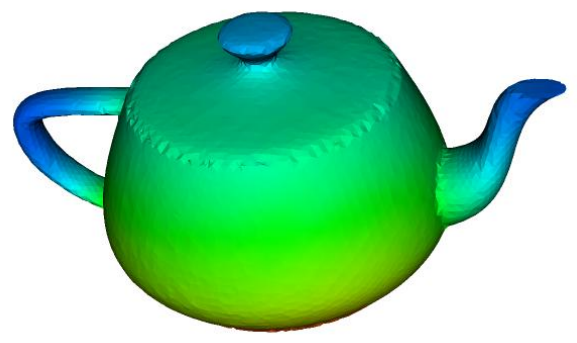

f)

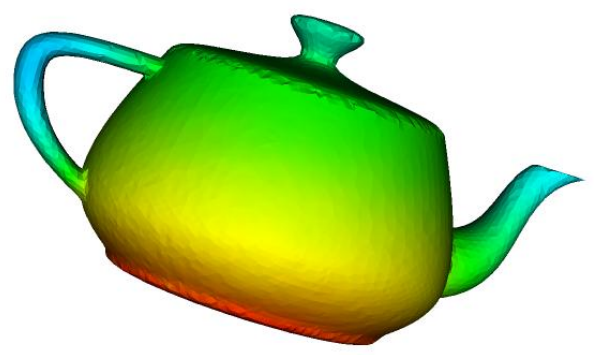

h)

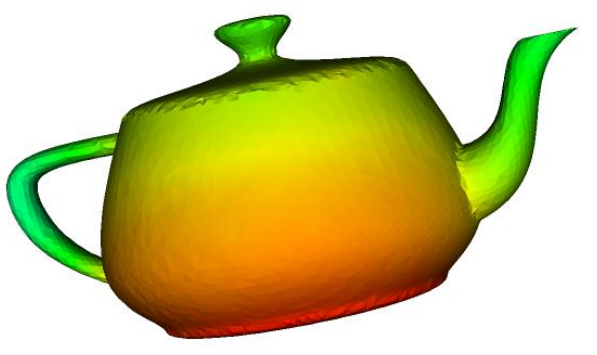


a)

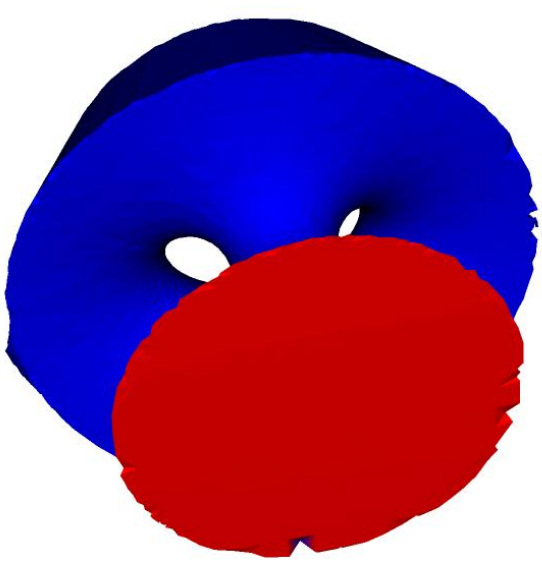

c)

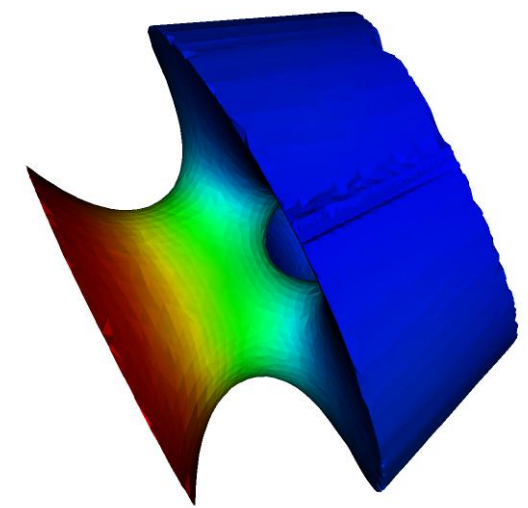

e)

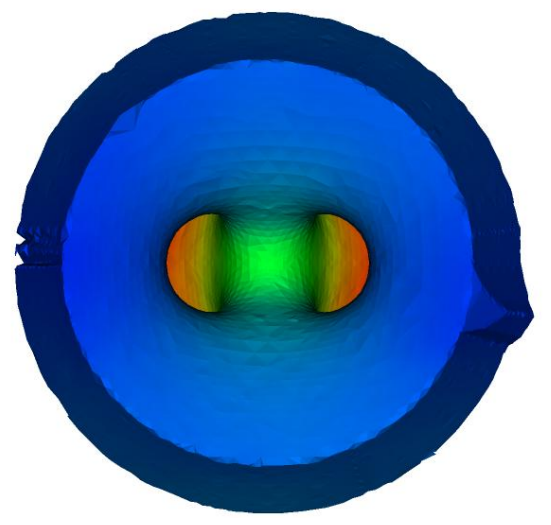

b)

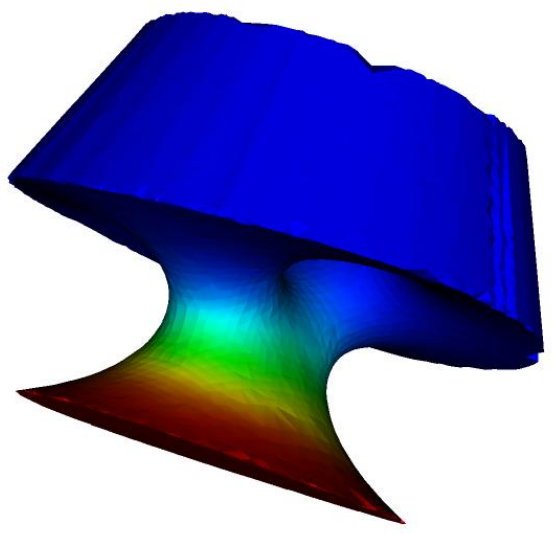

d)

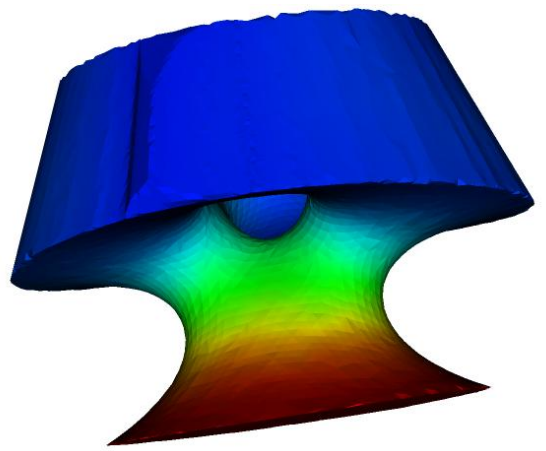

f)

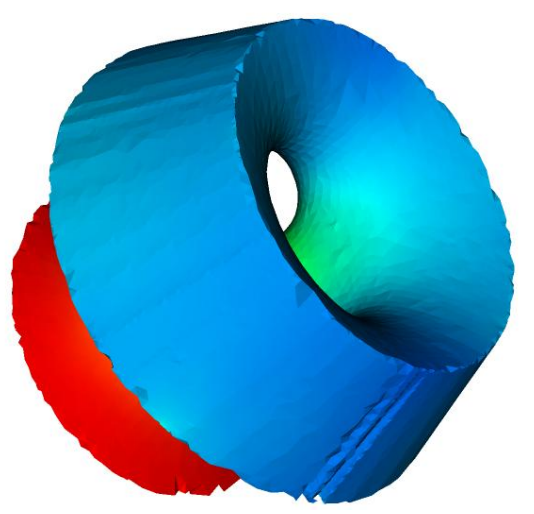

Escala de temperatura

$\begin{array}{llllllll}0.00 & 1.43 & 2.86 & 4.29 & 5.71 & 7.14 & 8.57 & 10.0\end{array}$

Figura 7.3: Exemplo da aplicação da equação do calor: a) condição inicial, b) 200 iterações, c) 800 iterações, d) 1000 iterações, e) 1400 iterações, f) 2000 iterações. 
siano) a cada pixel da imagem. Se o valor da convolução no pixel pertence a um intervalo de valores estipulado pelo usuário, conhecido como threshold, este pixel é parte do contorno.

A seguir descrevemos o processo para detecção de contornos via triangulação de Delaunay com peso.

Dada uma imagem, o processo é inicializado gerando uma triangulação de Delaunay com peso considerando os pixels da imagem como os vértices da triangulação. O primeiro passo está na investigação do peso adequado a cada ponto. Testamos aplicando pesos conforme o valor da convolução aplicada ao pixel (a tabela 7.1, a seguir, apresenta as convoluções que aplicamos em nossos testes: Laplaciano-a), Sobel-b) ${ }^{3}$ e Laplaciano do Gaussiano (Log)c)). Os resultados destas triangulações de Delaunay com peso estão nas figuras 7.4. Podemos observar que os detalhes da imagem são obtidos conforme a proporção dos pesos nos vértices, isto é, conforme se aumenta o peso, a tendência é perder características da imagem.

A triangulação de Delaunay com peso permite representar os contornos da imagem com um número reduzido de vértices e arestas.

Otimizamos o tempo da triangulação de Delaunay com peso aplicando uma etapa de préprocessamento em que ordenamos decrescentemente os pontos pelo seus pesos. Isto torna a triangulação mais rápida pois não se insere os pontos com peso pequeno próximos aos contornos da imagem (pois serão pontos redundantes) e, conseqüentemente, não é necessário atualizar a triangulação para estes pontos. Este pré-processamento também reduz a possibilidade de ocorrerem erros numéricos durante o processo de triangulação.

Em seguida, utilizamos duas estratégias para detecção do contorno: Na primeira utilizamos algoritmos tradicionais de reconstrução de curvas bidimensionais, tais como o crust e o power crust juntamente com o critério de remoção de ruídos proposto por Amenta, descrito no capítulo 5, seção 5.6, para detecção dos contornos. Na segunda analisamos os pesos dos vértices e a variação dos valores da convolução sobre o segmento de reta que une os dois centróides das faces incidentes a cada aresta (figura 7.5).

Consideremos a figura 7.5 como sendo a representação de cada aresta $e$ na triangulação de Delaunay com peso para a descrição do algoritmo 11 que apresenta o processo de detecção das arestas da triangulação de Delaunay com peso. Temos na figura 7.5 que $v_{1}$ e $v_{2}$ são os vértices de $e, M$ é o ponto do segmento de extremos dos centróides $c_{1}$ e $c_{2}$ das faces $f_{1}$ e $f_{2}$

\footnotetext{
${ }^{3} \mathrm{O}$ valor da convolução em cada pixel é dada pela soma em módulo da aplicação das matrizes Sobel $_{x}$ e Sobel $_{y}$ ao pixel.
} 

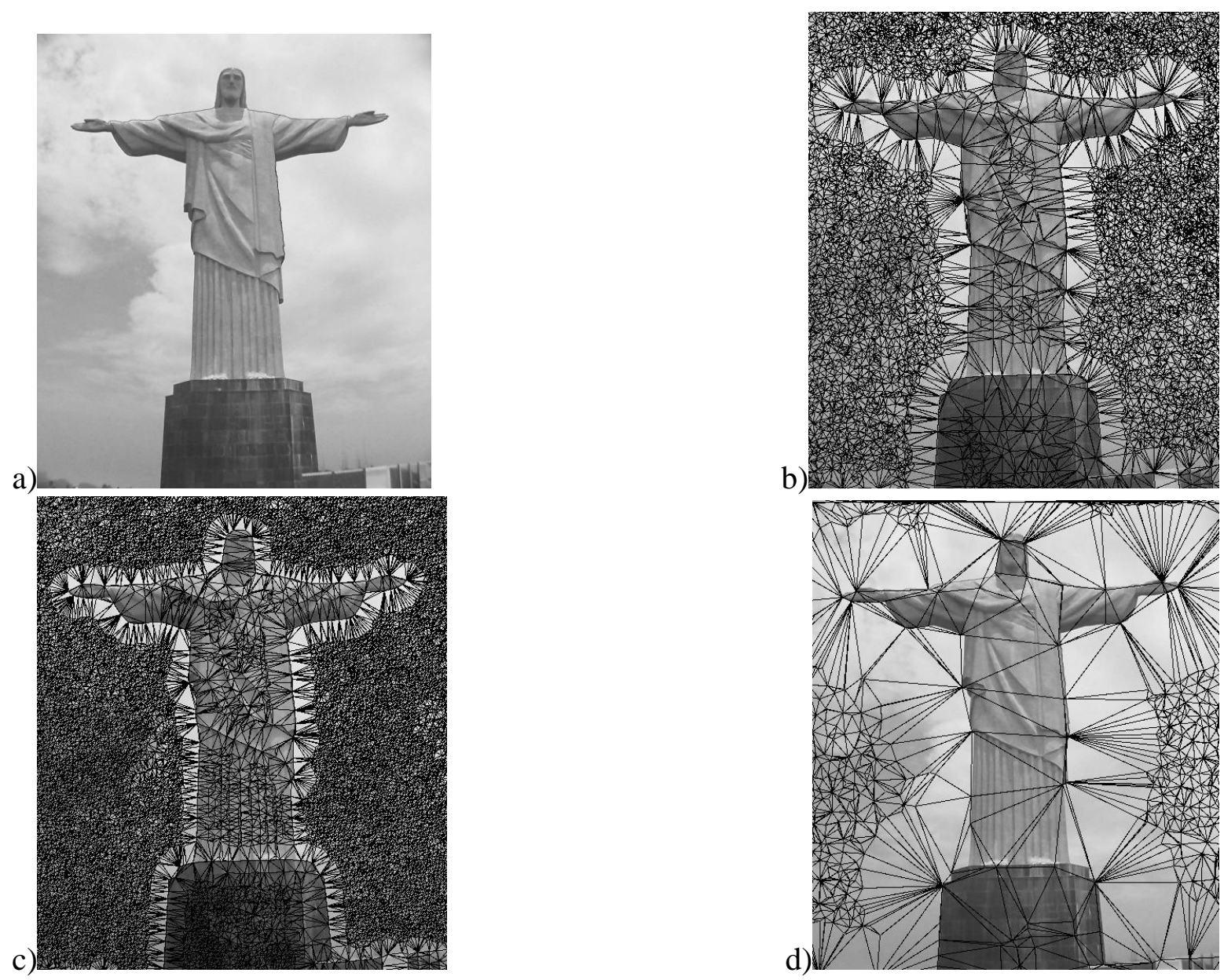

Figura 7.4: Exemplo de triangulações de Delaunay com peso sobre uma imagem cujos pesos dos vértices são o valor da convolução no pixel: a) imagem original, b) peso obtido pelo Laplaciano, c) peso obtido pelo Sobel e d) peso obtido pelo Log.

respectivamente, com maior valor obtido pela convolução e $C$, a curva tracejada, é o contorno da imagem.

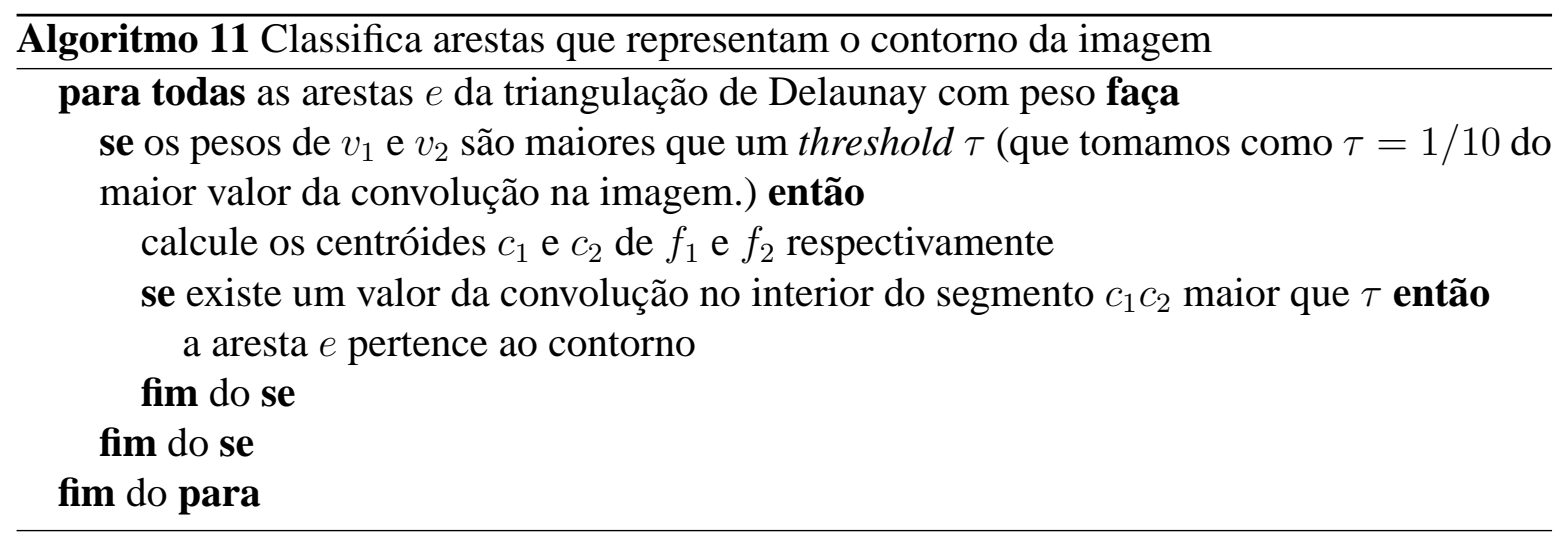


a)

$$
\text { Laplaciano }=\left(\begin{array}{ccccc}
-1 & -1 & -1 & -1 & -1 \\
-1 & -1 & -1 & -1 & -1 \\
-1 & -1 & 24 & -1 & -1 \\
-1 & -1 & -1 & -1 & -1 \\
-1 & -1 & -1 & -1 & -1
\end{array}\right)
$$

b)

$$
\text { Sobel }_{x}=\left(\begin{array}{ccc}
-1 & 0 & 1 \\
-2 & 0 & 2 \\
-1 & 0 & 1
\end{array}\right) \quad \text { Sobel }_{y}=\left(\begin{array}{ccc}
1 & 2 & 1 \\
0 & 0 & 0 \\
-1 & -2 & -1
\end{array}\right)
$$

c)

$$
\log =\left(\begin{array}{ccccccccc}
0 & 0 & 3 & 2 & 2 & 2 & 3 & 0 & 0 \\
0 & 2 & 3 & 5 & 5 & 5 & 3 & 2 & 0 \\
3 & 3 & 5 & 3 & 0 & 3 & 5 & 3 & 3 \\
2 & 5 & 3 & -12 & -23 & -12 & 3 & 5 & 2 \\
2 & 5 & 0 & -23 & -40 & -23 & 0 & 5 & 2 \\
2 & 5 & 3 & -12 & -23 & -12 & 3 & 5 & 2 \\
3 & 3 & 5 & 3 & 0 & 3 & 5 & 3 & 3 \\
0 & 2 & 3 & 5 & 5 & 5 & 3 & 2 & 0 \\
0 & 0 & 3 & 2 & 2 & 2 & 3 & 0 & 0
\end{array}\right)
$$

Tabela 7.1: Matrizes de convolução utilizadas pelo método desenvolvido para detecção de contornos em imagens via Geometria Computacional.

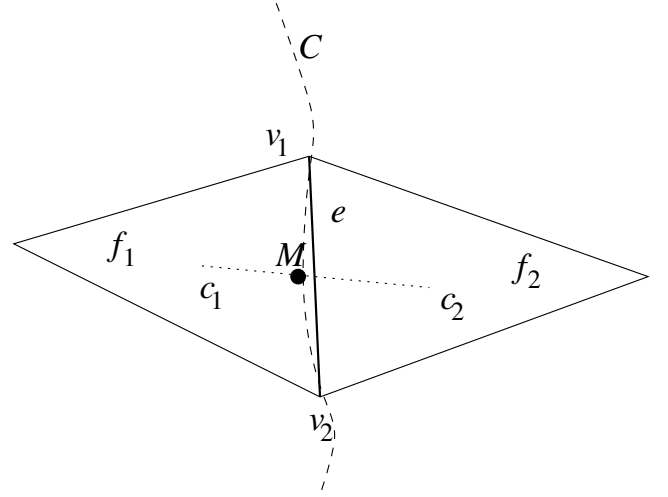

Figura 7.5: Representação de uma aresta $e$ da triangulação de Delaunay com peso.

Propomos uma etapa de pós-processamento para a estratégia baseada na análise das arestas da triangulação de Delaunay com peso. Para o conjunto de arestas retornado pelo algoritmo 11, analisamos a média da intensidade dos pixels dos dois triângulos incidentes a cada aresta e verificamos se a diferença entre as intensidades é um valor maior do que um threshold estipulado pelo usuário. Um exemplo deste teste é apresentado na figura 7.6. 

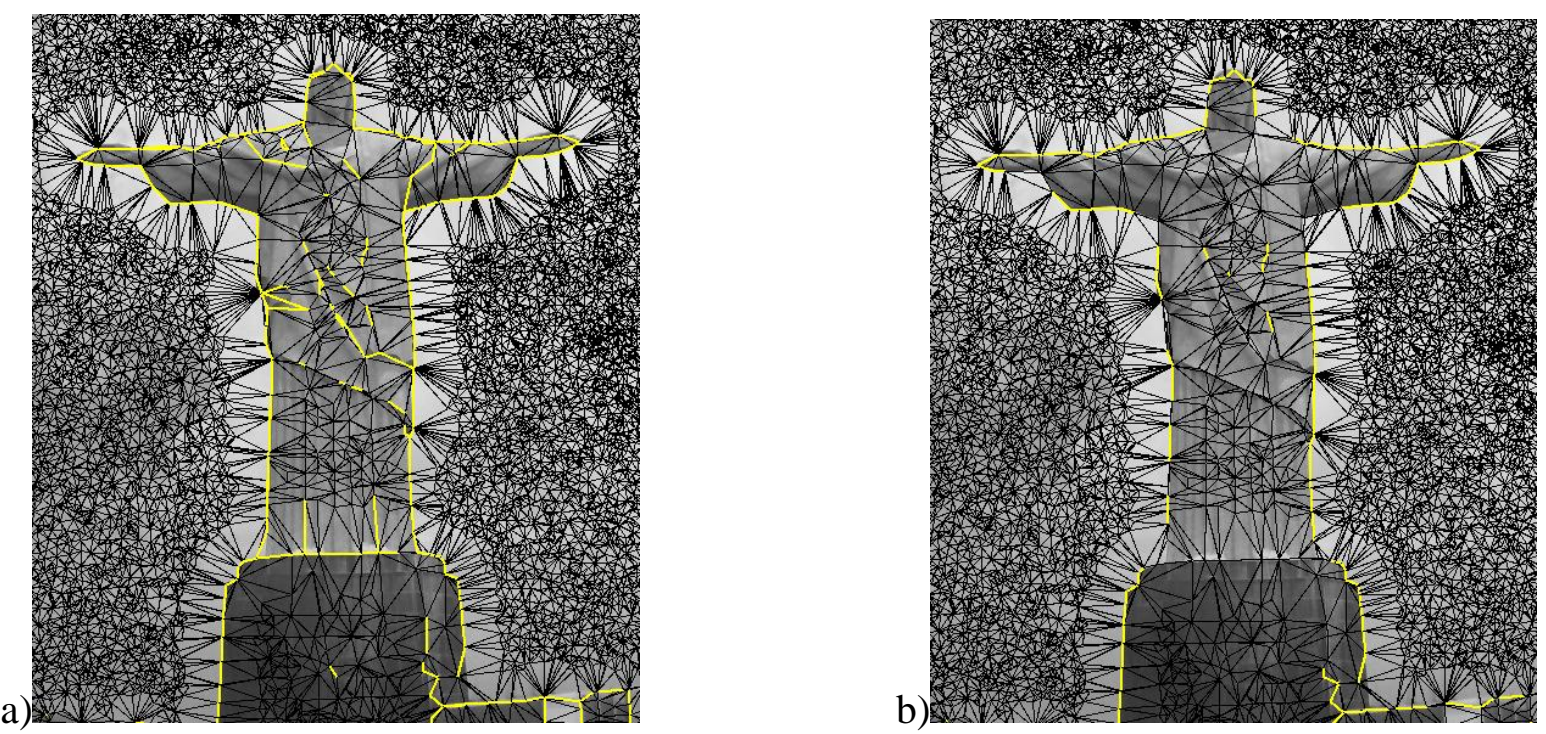

Figura 7.6: Aplicação da etapa de pós-processamento que analisa a variação das intensidades das cores nos triângulos: a) imagem sem o pós-processamento, b) imagem aplicada o pósprocessamento.

Podemos utilizar como parâmetros para a triangulação de Delaunay com peso para obter outros resultados: A fração $\tau$ (threshold aplicada ao peso dos vértices) apresentada no algoritmo 11 e um valor real positivo $\alpha$ que multiplica o peso de cada ponto. A figura 7.7 apresenta um exemplo $\operatorname{com} \alpha=0.1$ vezes o valor do laplaciano em cada ponto da imagem.

a)

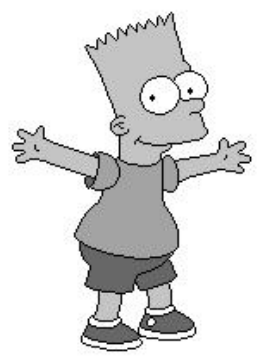

b)

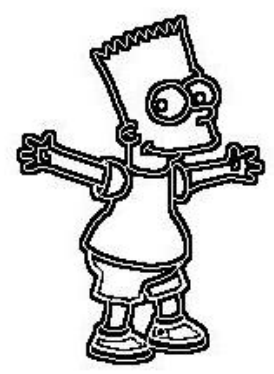

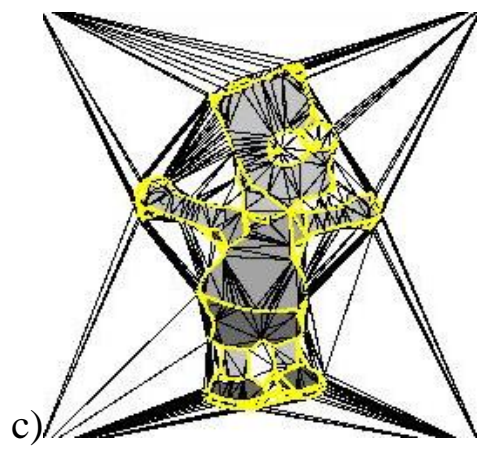

Figura 7.7: Exemplo de resultados da detecção de contornos via triangulação de Delaunay com peso 7.4: a) imagem original, b) Laplaciano da imagem, c) triangulação de Delaunay com peso sobre a imagem cujos pesos dos pontos são $\alpha=0.1$ do laplaciano no ponto.

A figura 7.8 apresenta exemplos de reconstrução via triangulação de Delaunay com peso.

O estudo desta técnica nos leva à seguinte observação, que estamos estudando para tornála um teorema, e conseqüentemente, apresentar resultados teóricos da eficiência desta técnica. 

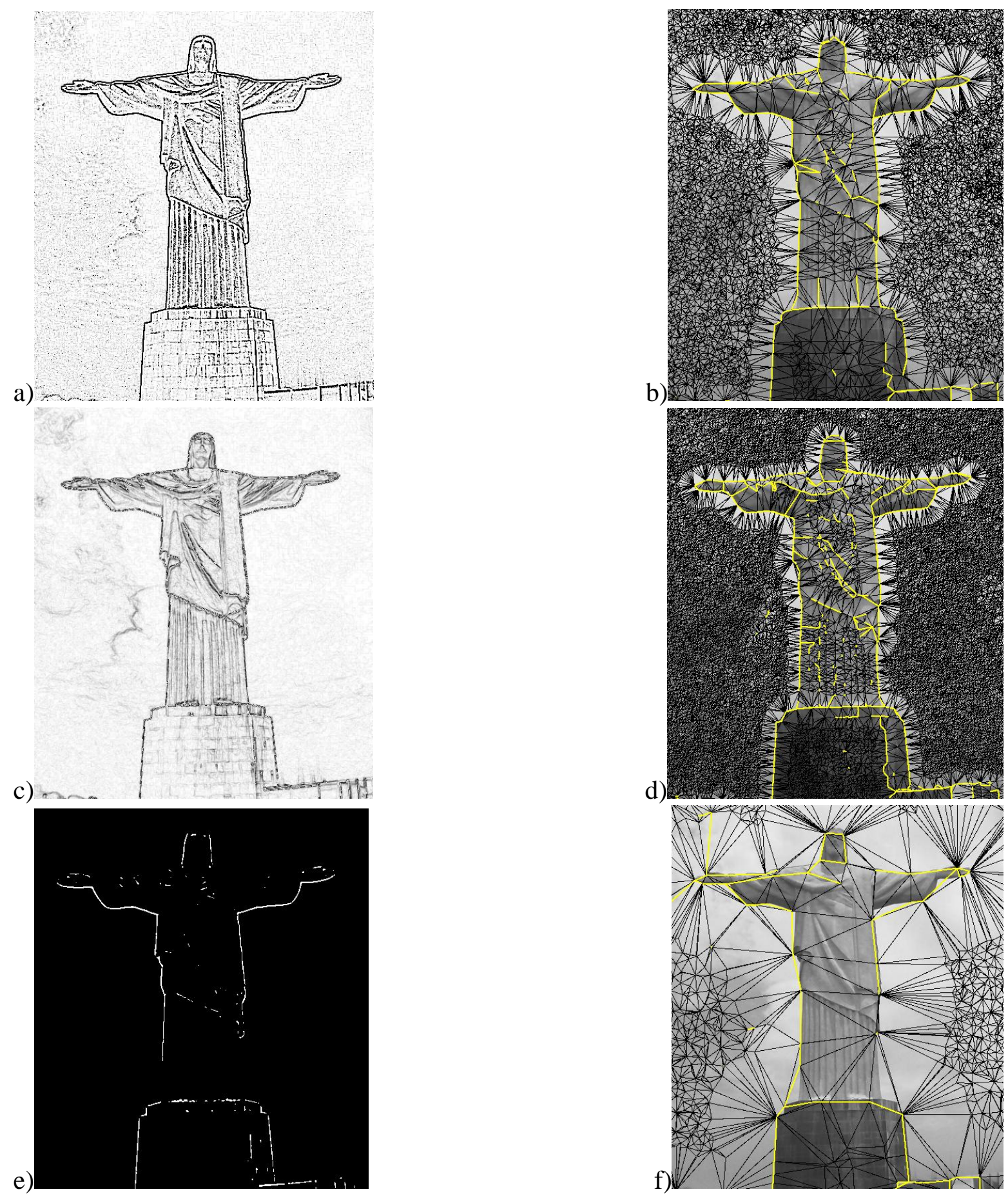

Figura 7.8: Exemplo de resultados detecção de contornos via a triangulação de Delaunay com peso da imagem 7.4: a) Laplaciano, b) detecção do contorno com pesos originados do Laplaciano, c) Sobel, d) detecção do contorno com pesos originados do Sobel, e) Laplaciano do Gaussiano, f) detecção do contorno com pesos originados do Laplaciano do Gaussiano. 

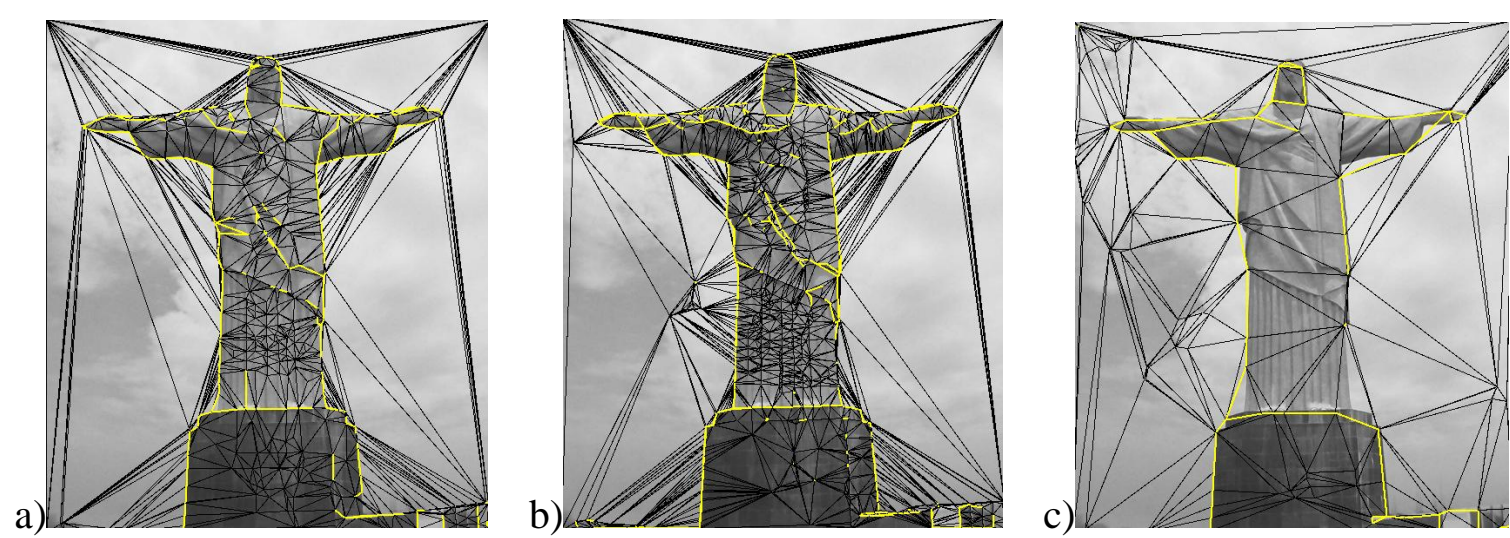

Figura 7.9: Aplicando o threshold aos pesos durante o processo de triangulação não inserindo pontos com peso inferior a $\tau$ : a) Laplaciano, b) Sobel, c) Laplaciano do Gaussiano.

Observação 22 Os pesos atribuídos não foram normalizados. Acreditamos que existem uma normalização e uma distribuição de pesos em função da curvatura do contorno da imagem que garantem detecções de contorno eficientes.

Realizamos testes em que não adicionávamos os pontos da triangulação com peso menor que o valor de $\tau$. A figura 7.9 apresenta resultados destes testes. A principal vantagem de utilizar threshold nesta etapa está na velocidade do algoritmo. No entanto os triângulos gerados por estes modelos são grandes e a utilização da etapa de pós-processamento que verifica a diferença entre as intensidades dos pixels nos triângulos adjacentes a cada aresta pode gerar resultados não satisfatórios.

A figura 7.10 apresenta exemplos da aplicação do crust e do power crust para a reconstrução dos contornos das imagens sobre os vértices originados das classificações das arestas. Inserimos os pontos médios das arestas para obter melhores resultados de reconstrução. Vale lembrar que garantias de resultados satisfatórios do crust e do power crust são para curvas suaves (observação 4) e não para curvas com intersecções, e que o critério de remoção de ruídos garante eficiência apenas sobre $n$-variedades e espaços $n+1$ dimensionais. Isto implica, que na prática, é difícil garantir bons resultados desta estratégia.

A figura 7.11 apresenta um exemplo da técnica de detecção de contornos via triangulação de Delaunay com peso para uma imagem ruidosa cujos pesos da triangulação foram atribuídos em função do laplaciano. 


\subsection{Considerações finais}

Neste capítulo apresentamos aplicações de nossos estudos em E.D.P.'s e Processamento de Imagens. Não descrevemos detalhes das implementações, pois nosso interesse estava em apresentar tanto a aplicabilidade quanto a interdisciplinaridade dos nossos estudos. No algoritmo apresentado para detecção de contornos via Geometria Computacional buscamos substituir os thresholds dos pixels por thresholds associados à propriedades de Geometria Computacional. Ainda estamos iniciando estes estudos e acreditamos que resultados teóricos e práticos satisfatórios serão alcançados.

No capítulo seguinte concluímos este trabalho ressaltando os principais tópicos e apresentando direções de pesquisas futuras. 

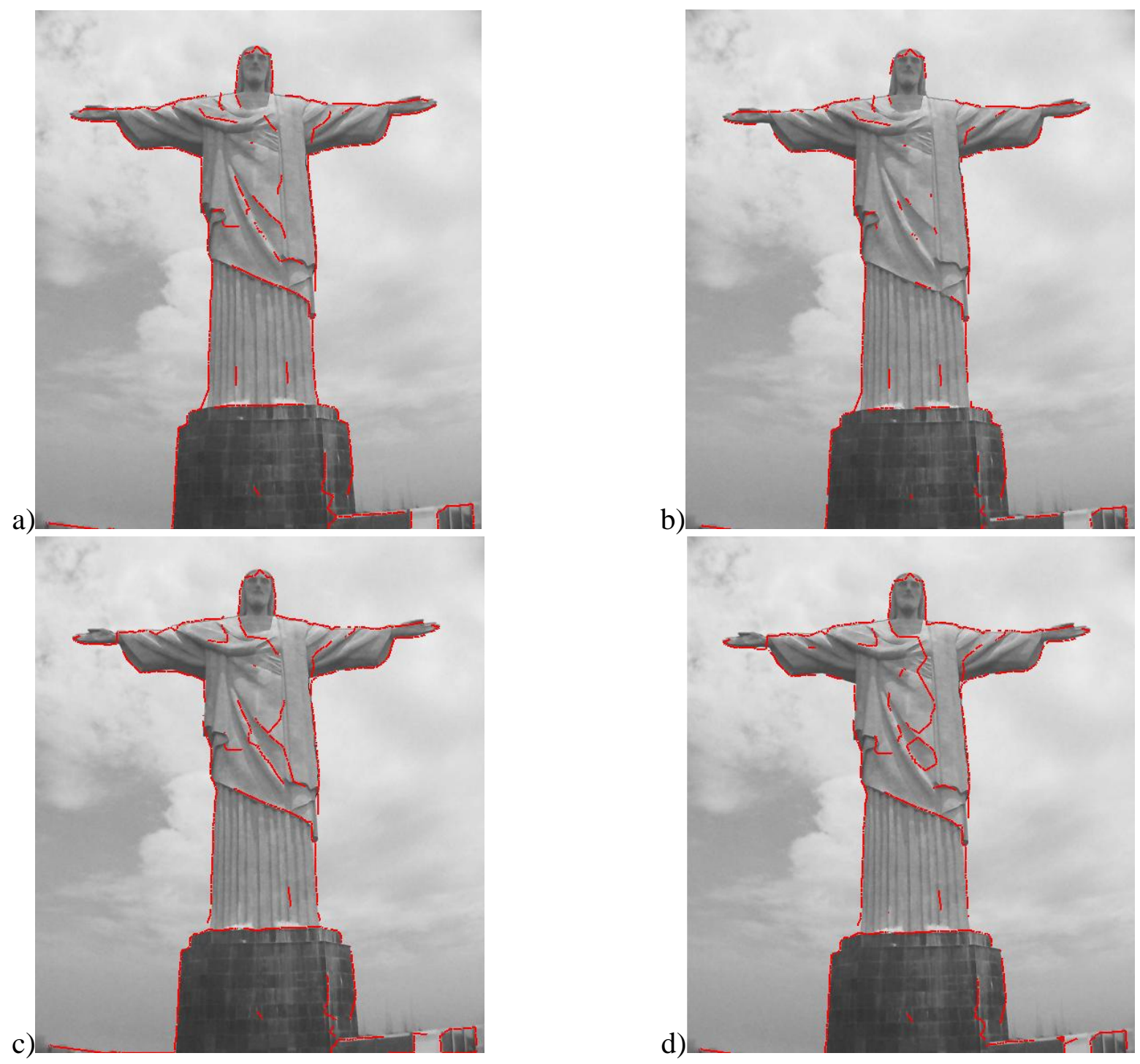

Figura 7.10: Aplicação do método de remoção de ruídos proposto por Amenta (capítulo 5, seção 5.6) aliado aos algoritmos crust e power crust: a) crust sem remoção de ruídos, b) crust com remoção de ruídos, c) power crust, d) power crust com remoção de ruídos. 


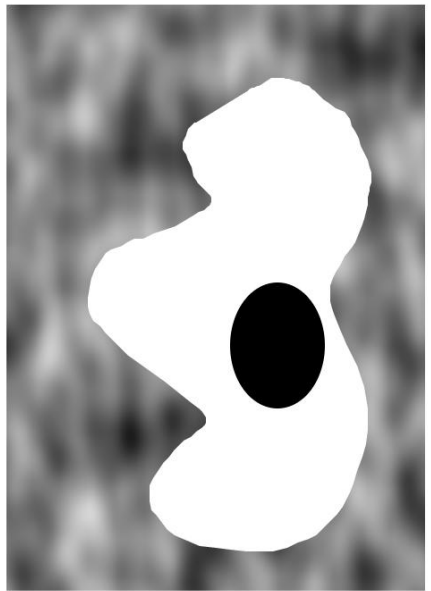

a)
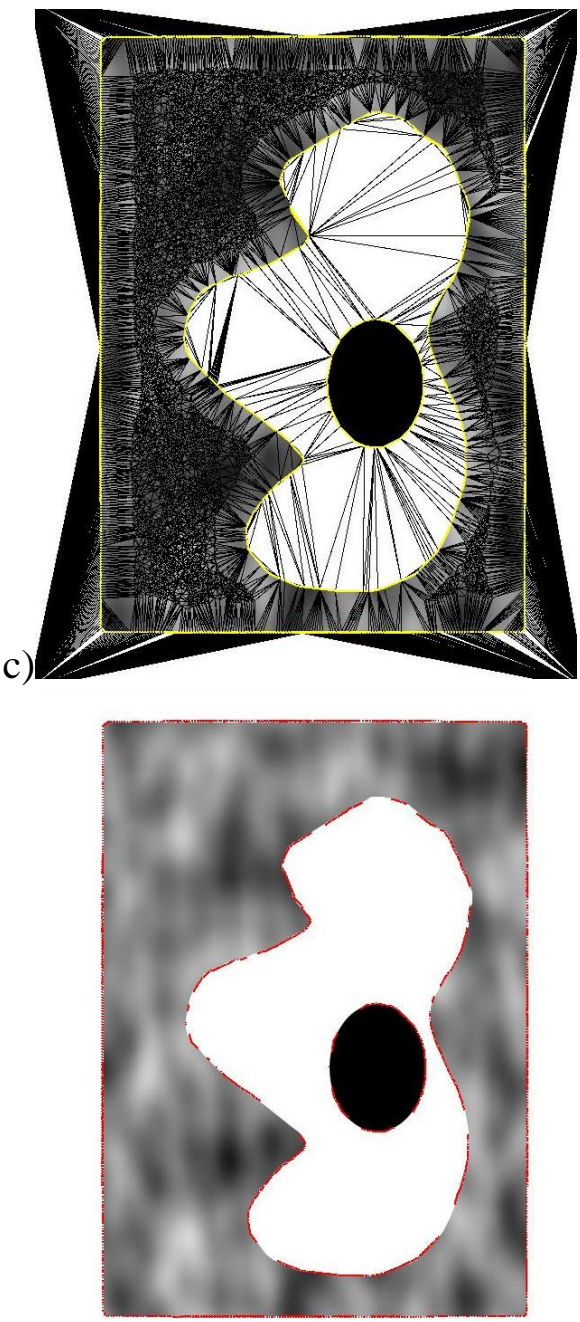

e)

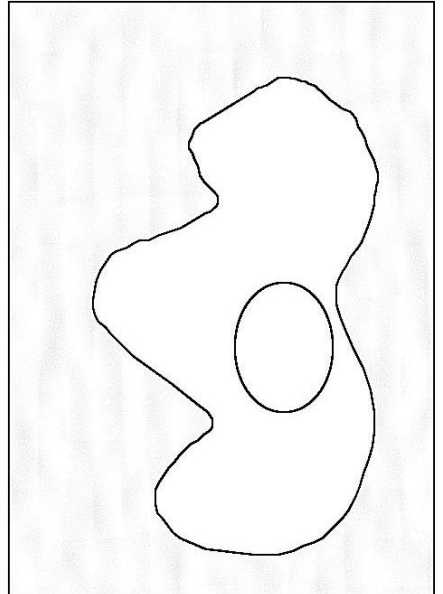

b)
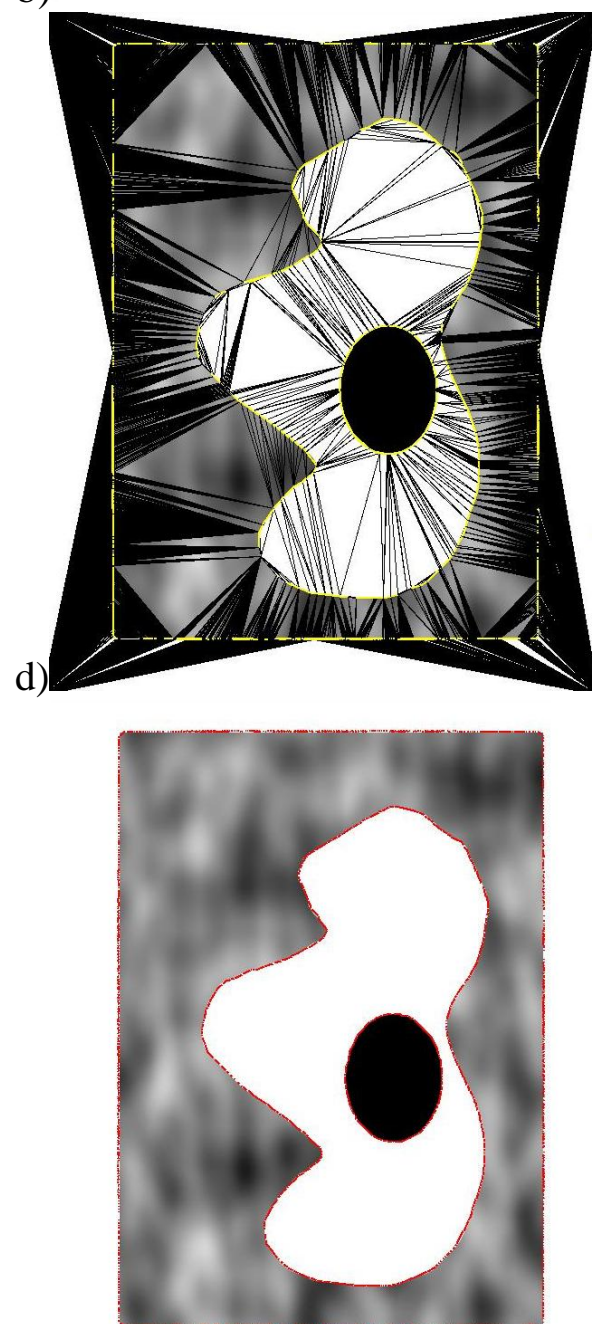

f)

Figura 7.11: Aplicação da técnica de detecção de contornos via triangulação de Delaunay com peso em uma imagem ruidosa: a) imagem original, b) laplaciano da imagem, c) detecção do contorno via triangulação de Delaunay com peso, d) detecção do contorno cuja triangulação não contém pontos cujo peso é menor que $\tau(\tau=1 / 10$ do maior valor de laplaciano da imagem), e) crust, f) power crust. 


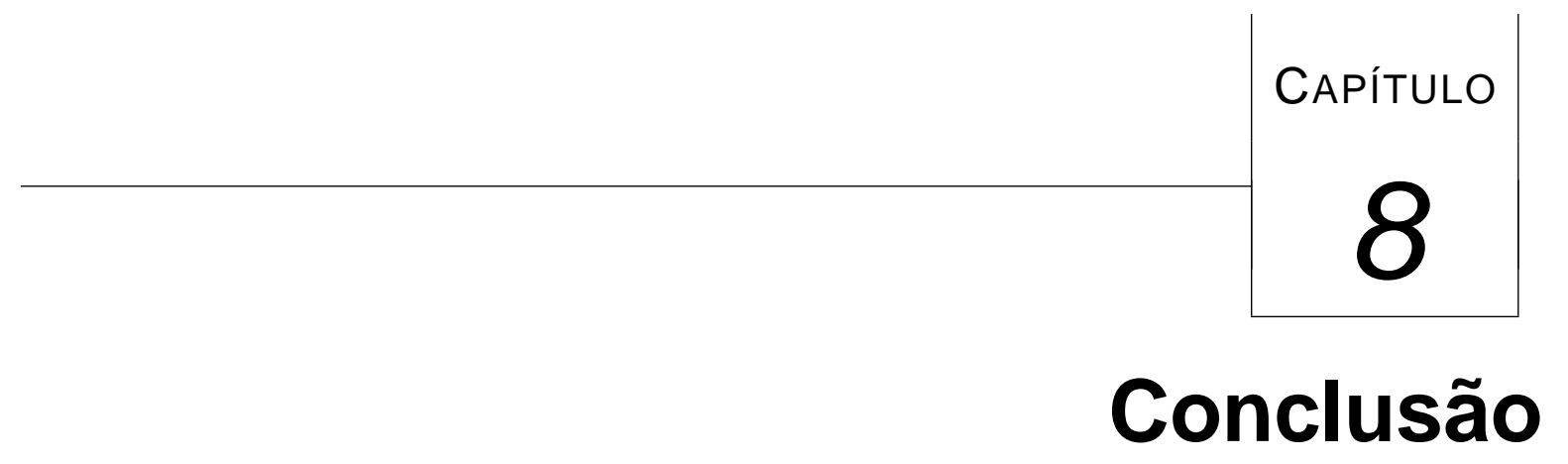

A área de Reconstrução de Superfícies a partir de Nuvens de Pontos está presente em inúmeras áreas do conhecimento (por exemplo Simulação de E.D.P.'s e Imagens Médicas) o que justifica diversos pesquisadores e grupos de pesquisa estarem desenvolvendo métodos para os mais variados objetivos.

Neste trabalho apresentamos um vasto levantamento bibliográfico classificando tais métodos, como esculpimento, iterativos, deformáveis, baseados em funções implícitas e a família Crust. O maior número de trabalhos que apresentamos foram aqueles envolvendo métodos de esculpimento devido ao fato de apresentarem propriedades de Geometria Computacional (por exemplo serem subconjuntos da triangulação de Delaunay ou do power diagrama). Um maior detalhamento foi dado à família Crust, que apresenta resultados teóricos baseados no critério de $r$-amostragem que garantem uma reconstrução homeomorfa e próxima à variedade original.

Após o levantamento bibliográfico selecionamos alguns métodos para realizarmos nossas implementações. Estes algoritmos foram, para o caso bidimensional, $\beta$-skeleton, crust e power crust e, para o caso tridimensional, o raw crust e o power crust. Também propomos e implementamos extensões para o power crust, que julgamos ser uma das técnicas mais eficientes e bem fundamentadas teoricamente.

Após estas etapas, comparamos teórica e experimentalmente os algoritmos que implementamos (bidimensionais: $\beta$-skeleton, crust e power crust e tridimendionais: raw crust e power crust) com outros presentes na literatura que estão disponíveis on-line (tridimen- 
sionais: cocone, tight cocone e $\alpha$-shapes). Como poucas comparações são encontradas na literatura acreditamos ser esta uma importante contribuição deste trabalho.

Finalizamos realizando duas aplicações. A primeira foi referente à simulação de uma Equação Diferencial Parcial (Equação do Calor Tridimensional) em que utilizamos os domínios gerados pela nossa implementação do power crust como entrada para o programa ICEM-CFD que gera malhas tetraedrais volumétricas no interior de domínios e a estrutura de dados Singular Half-Face para resolução numérica pelo método de Volumes Finitos. Na segunda aplicação buscamos utilizar propriedades de Geometria Computacional para detecção de contornos em imagens em que um subconjunto de arestas da triangulação de Delaunay com peso gerada sobre a imagem representa o contorno. O tratamento de ruídos foi semelhante ao que é feito no power crust.

Esta segunda aplicação também é uma das principais contribuições deste trabalho, pois acreditamos na possibilidade de utilizar conceitos de Geometria Computacional e de Reconstrução no processo de detecção de contornos de interesse em imagens, uma vez que na literatura trabalhos nessa linha utilizando estratégias geométricas ainda não estão sendo investigado intensivamente.

Todos estes estudos sugerem direções para trabalho futuros que apresentamos a seguir:

É possível otimizar o power crust realizando etapas de pré e pós-processamento. Na etapa de pré-processamento, é possível aplicar algoritmos de clusterização para reduzir a nuvem de pontos a pontos significativos para a etapa de reconstrução, enquanto que no pós-processamento é possível gerar uma malha triangular e transformar esta malha em Delaunay.

Como extensão deste trabalho existe a necessidade de realizar comparações, principalmente de ordem prática, entre diferentes métodos (implícitos, esculpimento, incremental, deformáveis e a família Crust). Outra comparação não realizada, e um tanto quanto complexa é, quanto a aplicabilidade de cada método em determinada área.

O estudo realizado sobre detecção de contornos via Geometria Computacional deixou algumas questões em aberto: Dada uma triangulação de Delaunay com peso de um conjunto de pontos, qual a complexidade (complexidade em função dos pesos dos pontos) para transformar esta triangulação de Delaunay com peso em uma triangulação de Delaunay tradicional.

Ainda buscamos desenvolver um algoritmo de detecção de contornos com critérios baseado apenas em propriedades de Geometria Computacional. Acreditamos que existe a possibilidade de desenvolver uma teoria, assim como Amenta desenvolveu para remoção de ruídos baseado no formato das células de Voronoi para amostragens de variedades, em que baseado 
no diagrama de Voronoi ou no power diagrama podemos classificar numa imagem, seus contornos de interesse e também detectar os ruídos da imagem.

Outro trabalho futuro é o desenvolvimento de uma interface em que o usuário poderá escolher o método de reconstrução, bem como atribuir os parâmetros pertinentes a cada algoritmo. Esta interface também apresentará como saídas comparações práticas entre os métodos. 


\section{Referências Bibliográficas}

Adamy, U., Giesen, J., e John, M. (2002). Surface reconstruction using umbrella filters. Computational Geometry Theory and Applications, 21:63-86.

Amenta, N. e Bern, M. (1999). Surface reconstruction by voronoi filtering. Discrete and Computational Geometry, 22:481-504.

Amenta, N., Bern, M., e Eppstein, D. (1998a). The crust and the $\beta$-skeleton : Combinatorial curve reconstruction. Graphical Models and Image Processing, 60(2):125-135.

Amenta, N., Bern, M., e Kamvysselis, M. (1998b). A new Voronoi-based surface reconstruction algorithm. Computer Graphics, 32(Annual Conference Series):415-421.

Amenta, N., Choi, S., Dey, T. K., e Leekha, N. (2002). A simple algorithm for homeomorphic surface reconstruction. International Journal of Computational Geometry and Applications, 12(1-2):125-141.

Amenta, N., Choi, S., e Kolluri, R. (2001a). The power crust. Em 6th ACM Symposium on Solid Modeling, 249-260.

Amenta, N., Choi, S., e Kolluri, R. (2001b). The power crust, unions of balls, and the medial axis transform. Computational Geometry: Theory and Applications, 19(2-3):127-153.

Amenta, N. e Kolluri, R. K. (2000). Accurate and efficient unions of balls. Em Symposium on Computational Geometry, pag. 119-128.

Attali, D. (1998). r-regular shape reconstruction from unorganized points. Computational Geometry Theory and Applications, 10:239-249. Elsevier.

Attene, M. e Spagnuolo, M. (2000). Automatic surface reconstruction from point sets in space. Computer Graphics Forum, 19(3):9. 
Aurenhammer, F. e Klein, R. (2000). Voronoi diagrams, pag. 201-290. Handbook of Computational Geometry. Elsevier Science Publishing.

Babuska, I. (1995). Modelling, Mesh Generation, and Adaptative Numerical Methods for Partial Equations, volume 75 of The IMA volumes in Mathematics and its Applications. IMA.

Bajaj, C. L., Bernardini, F., e Xu, G. (1995). Automatic reconstruction of surfaces and scalar fields from 3d scans. Em SeriesComputer Graphics Proceedings, A. C., editor, SIGGRAPH.

Bardinet, E., Cohen, L. D., e Auache, N. (1998). A parametric deformable model to fit unstructured 3d data. Computer Vision and Image Understanding, 71(1):39-54.

Bern, M. e Eppstein, D. (1999). Emerging challenges in computational topology. Workshop on computational topology, NSF, Miami Beach, Florida.

Bernardini, F. e Bajaj, C. L. (1997). Sampling and reconstructing manifolds using alphashapes. Em Proc. 9th Canadian Conf. Computational Geometry, pag. 193-198.

Bernardini, F., Mittleman, J., Rushmeier, H., Silva, C., e Taubin, G. (1999). The ball-pivoting algorithm for surface reconstruction. IEEE Transactions on Visualization and Computer Graphics, 5(4):349-359.

Boissonnat, J. D. (1988). Shape reconstruction from planar cross-sections. Computational Vision Image, 44:1-29.

Boissonnat, J.-D. e Cazals, F. (2002). Smooth surface reconstruction via natural neighbour interpolations of distance functions. Computational Geometry Theory and Applications, 22:185-203.

Boissonnat, J.-D., Devillers, O., Pion, S., Teillaud, M., e Yvinec, M. (2002). Triangulations in cgal. Computational Geometry - Theory and Applications, 22:5-19.

Brandt, J. W. (1994). Convergence and continuity criteria for discrete approximations of the continuous planar skeleton. Em CVGIP: Image Understanding, volume 59, pag. $116-124$.

Bíscaro, H. H. (2001). Singular half-face: uma estrutura de dados volumétrica. Dissertação de Mestrado, Universidade de São Paulo - Instituto de Ciências Matemáticas e Computação. 
CGAL (Acesso em 05/01/2004). Cgal - computational geometry algorithms library. http://www.cgal.org.

Chew, L. P. (1993). Garanteed-quality mesh generation for curved surfaces. Em ACM Symposium on Computational Geometry, pag. 274-280.

Choi, S. e Amenta, N. (2002). Delaunay triangulation programs on surface data. Em The 13th ACM-SIAM Symposium on Discrete Algorithms, pag. 135-136.

Dey, T. K. (2002). Curve and surface reconstruction - http://www.cis.ohiostate.edu/ tamaldey/papers.html (acesso em 08/10/2003).

Dey, T. K., Giesen, J., e Zhao, W. (2001). Robustness issues in surface reconstruction. Lecture Notes in Computer Science, 2073:658-663.

Dey, T. K. e Goswami, S. (2002a). Tight cocone : A water-tight surface reconstruction. Relatório Técnico OSU-CISRC-12/02-TR31, The Ohio State University.

Dey, T. K. e Goswami, S. (2002b). Tight cocone and cgal. Em CGAL workshop, Barcelona, Espanha.

Edelsbrunner, H. (1998). Shape reconstruction with delaunay complex. Em LATIN'98: Theoretical Informatics, C.L. Lucchesi, A. V. M., editores, LNCS 1380.

Edelsbrunner, H. (2001). Geometry and Topology for Mesh Generation. Cambridge Monographs on Applied and Computational Mathematics. Cambridge.

Edelsbrunner, H. (2002). Surface recosntruction by wrapping finite point set in space. Rick Pollack e Eli Goodman Festschrift, ed. A. Aronov, S. Basu, J.Pach e M. Sharir. SpringerVerlag, submetido.

Edelsbrunner, H. e Mücke, E. P. (1994). Three-dimensional alpha shapes. ACM Transactions on Graphics, 13(1):43-72.

Giesen, J. e John, M. (2002). Surface reconstruction based on a dynamical system. Em Eurographics, volume Drettakins, G. e Siedel, H. ditores, 21-30.

Giesen, J. e John, M. (2003). The flow complex: a data structure for geometric modeling. Em Proceedings of the fourteenth annual ACM-SIAM symposium on Discrete algorithms, pag. 285-294. Society for Industrial and Applied Mathematics. 
Gois, J. P., Filho, A. C., e Nonato, L. G. (2003). Reconstrução de superfícies a partir de conjuntos de pontos em $\mathbb{R}^{3}$ utilizando técnicas de esculpimento com triangulações de Delaunay tradicional e com peso. Em Submetido à Revista TEMA - Tendências em Matemática Aplicada e Computacional.

Gopi, M., Krishnan, S., e Silva, C. T. (2000). Surface reconstruction based on lower dimensional localized delaunay triangulation. Em Gross, M. e Hopgood, F. R. A., editores, Computer Graphics Forum (Eurographics 2000), volume 19(3).

Hermes, L. e Buhmann, J. M. (2003). A minimum entropy aproach to adaptative image polygonization. IEEE Transactions on Imagem Processing, 12(10):1243-1258.

Hoppe, H., DeRose, T., Duchamp, T., McDonald, J., e Stuetzle, W. (1992). Surface reconstruction from unorganized points. Computer Graphics, 26(2):71-78.

Huang, J. e Menq, C. H. (2002). Combinatorial manifold reconstruction and optimization from unorganized point cloud with arbitrary topology. Computer-Aided Design, 1(34):149-165.

Isaacson, E. e Keller, H. B. (1966). Analysis of Numerical Methods. John Wiley \& Sons.

Kirkpatric, D. G. e Radke, J. D. (1985). Framework for computational morphology - computational geometry. Computational Methods Applied Mechannical Enginnering, pag. 217-245.

Maliska, C. R. (1995). Tranferência de Calor e Mecânica dos Fluidos Computacional. LTC - Livros Técnicos e Científicos Editora.

Mederos, B., Velho, L., e de Figueiredo, L. H. (2003). Moving least squares multiresolution surface approximation. Em SIBGRAPI 2003, 1:19-26, São Carlos,Brasil.

Mencl, E. e Müller, H. (1998). Graph-based surface reconstruction using structures in scattered point sets. Computer Graphics International, pag. 298-311.

Milnor, J. (1963). Morse theory. Princenton University Press. Annals Mathematics Studies.

Munkres, J. R. (1984). Elements of Algebraic Topology. Addison-Wesley.

Nonato, L. G., Minghim, R., Oliveira, M. C. F., e Tavares, G. (2001). A novel approach for delaunay $3 \mathrm{~d}$ reconstruction with a comparative analysis in the light of applications. Computer Graphics Forum, 20(2):161-174. 
Petitjean, S. e Boyer, E. (2001). Regular and non-regular points sets: Properties and reconstruction. Computational Geometry Theory and Applications, pag. 101-126.

Rodriguez, A., Espadero, J. M., López, D., e Pastor, L. (1994). Delaunay surface reconstruction from scattered points. Em 9th International Conference Discrete Geometry for Computer Imagery, DGCI.

Samet, H. (1990). The Design and Analysis of Spatial Data Structures. Addison-Wesley.

Shewchuk, J. R. (1997). Delaunay Refinement Mesh Generation. Tese de Doutorado, Scholl of Computer Science - Carnegie Mellon University.

Stolfi, P. J. R. J. (1994). Fundamentos de geometria computacional. Recife. IBM/Brasil.

Teichmann, M. e Capps, M. (1998). Surface reconstruction with anisotropic density-scaled alpha shapes. Em Ebert, D., Hagen, H., e Rushmeier, H., editores, IEEE Visualization '98, pag. 67-72.

Teixeira, R. (2001). Introdução aos espaços de escala (edps em processamento de sinais). $23^{\circ}$ Colóquio Brasileiro de Matemática, Rio de Janeiro-RJ. Instituto de Matemática Pura e Aplicada.

Vargas, A. J. Q., Nonato, L. G., de Oliveira, M. C., e Minghin, R. (2002). Beta-connection: An approach to generate families of models from planar sections. Em SIBGRAPI, pag. 187-194, Fortaleza, Brasil.

Veltkamp, R. C. (1992). The $\gamma$-neighborhood graph. Computational Geometry: Theory and Applications, pag. 227-246.

Zhao, H., Merriman, B., Osher, S., e Kang, M. (2000). Implicit nonparametric shape reconstruction from unorganized points using a variational level set method. Computer Vision and Image Understanding, 60:295-313. 


\section{Índice Remissivo}

Símbolos

$\alpha$-shape, 28

$\beta$-skeleton, 47

$\epsilon$-amostragem, 30

$\lambda$-bola, 32

$\lambda$-complexo, 33

$\lambda$-intervalo, 32

$k$-face, 15

$r$-amostrada, 23

$r$-amostragem, 23

$r$-regular shape, 30

A

amostragem, 2, 14

aresta, 16

arvore geradora mínima euclidiana, 20

avanço de fronteira, 39

B

Ball Pivotting, 40

bola polar, 61

bolas polares, 62

bounding box, 59

C

célula, 16

bordo de uma, 17

circuncírculo, 19

circunraio, 19

circunsfera, 19 cocone, 67

complexo celular, 17

complexo de fluxo, 37

complexo de fluxo reduzido, 37

complexo simplicial, 16

dimensão de um, 16

coordenada natural, 38

crust, 54

$3 \mathrm{D}, 59$

curva suave, 14, 47, 114

D

decomposição espacial, 26

diagrama de Voronoi, 18

difeomorfismo, 11

difeomorfos, 11

dimensão de uma célula, 16

disco de Voronoi, 49

disco de Voronoi curvo, 49

domínio anisotrópico, 29

$\mathbf{E}$

eixo medial, 23

escala anisotrópica, 29

esfera $S^{n}, 14$

espaço euclidiano, 10

espaço gerado, 17

estrela, 17

F 
fecho convexo, 10

fluxo, 36

fronteira de avanço, 39

função de Morse, 34

G

genus, 14

grafo, 18

de Gabriel, 20

do vizinho mais próximo, 20

guarda-chuva, 33

condição de, 33

filtro, 32

\section{H}

hipergrafo de Gabriel extendido, 21

homeomorfismo, 10

homeomorfos, 10

$\mathbf{L}$

link, 17, 83

local feature size, 23

\section{M}

métodos

baseado em zero de função, 37

de esculpimento, 27

deformáveis, 43

incrementais, 39

malha híbrida, 91

malha normalizada, 30

mapeamento de densidade, 29

$\mathbf{N}$

nuvem de pontos, 25

O

órbita, 37 ortocentro, 21

$\mathbf{P}$

peso

distância com, 21

ponto com, 21

pólos, 59

ponto crítico, 35

ponto fixo, 36

ponto regular, 13

ponto singular, 13

posição geral, 15

power crust, 61,62

power diagrama, 22

power shape, 62

$\mathbf{R}$

raw crust, 45,58

reconstrução

seções planares, 1

região de Voronoi, 18

regiões proibidas, 46

regular triangulation, 22

$\mathbf{S}$

semi-espaço, 11

simplexo, 15

face de um, 15

fronteira de um, 15

sistema dinâmico, 35, 36

suavização laplaciana, 83

subespaço afim, 14

superfície, 13

superfície suave, 14

T

teoria de Morse, 34 
tetraedro

sliver, 30,59

topologicamente equivalente, 11

transformação do eixo medial, 23

triangulação, 18

triangulação de Delaunay, 19

triangulação de Delaunay com peso, 22

V

vértice, 16

vértice redundante, 22

variedade, 12

com bordo, 12

sem bordo, 12

variedade linear por parte, 17

variedade linear por partes, 14

variedade suave, 14

variedades estáveis, 37

vizinhanças naturais, 38

vizinhos naturais, 38

volume tomado, 38

W

water tight, 69 